\title{
Cellular and molecular aspects of weight regulation: the adipose tissue
}

Citation for published version (APA):

Bouwman, F. G. (2015). Cellular and molecular aspects of weight regulation: the adipose tissue. [Doctoral Thesis, Maastricht University]. Maastricht University. https://doi.org/10.26481/dis.20150619fb

Document status and date:

Published: 01/01/2015

DOI:

$10.26481 /$ dis.20150619fb

Document Version:

Publisher's PDF, also known as Version of record

\section{Please check the document version of this publication:}

- A submitted manuscript is the version of the article upon submission and before peer-review. There can be important differences between the submitted version and the official published version of record.

People interested in the research are advised to contact the author for the final version of the publication, or visit the DOI to the publisher's website.

- The final author version and the galley proof are versions of the publication after peer review.

- The final published version features the final layout of the paper including the volume, issue and page numbers.

Link to publication

\footnotetext{
General rights rights.

- You may freely distribute the URL identifying the publication in the public portal. please follow below link for the End User Agreement:

www.umlib.nl/taverne-license

Take down policy

If you believe that this document breaches copyright please contact us at:

repository@maastrichtuniversity.nl

providing details and we will investigate your claim.
}

Copyright and moral rights for the publications made accessible in the public portal are retained by the authors and/or other copyright owners and it is a condition of accessing publications that users recognise and abide by the legal requirements associated with these

- Users may download and print one copy of any publication from the public portal for the purpose of private study or research.

- You may not further distribute the material or use it for any profit-making activity or commercial gain

If the publication is distributed under the terms of Article $25 \mathrm{fa}$ of the Dutch Copyright Act, indicated by the "Taverne" license above, 


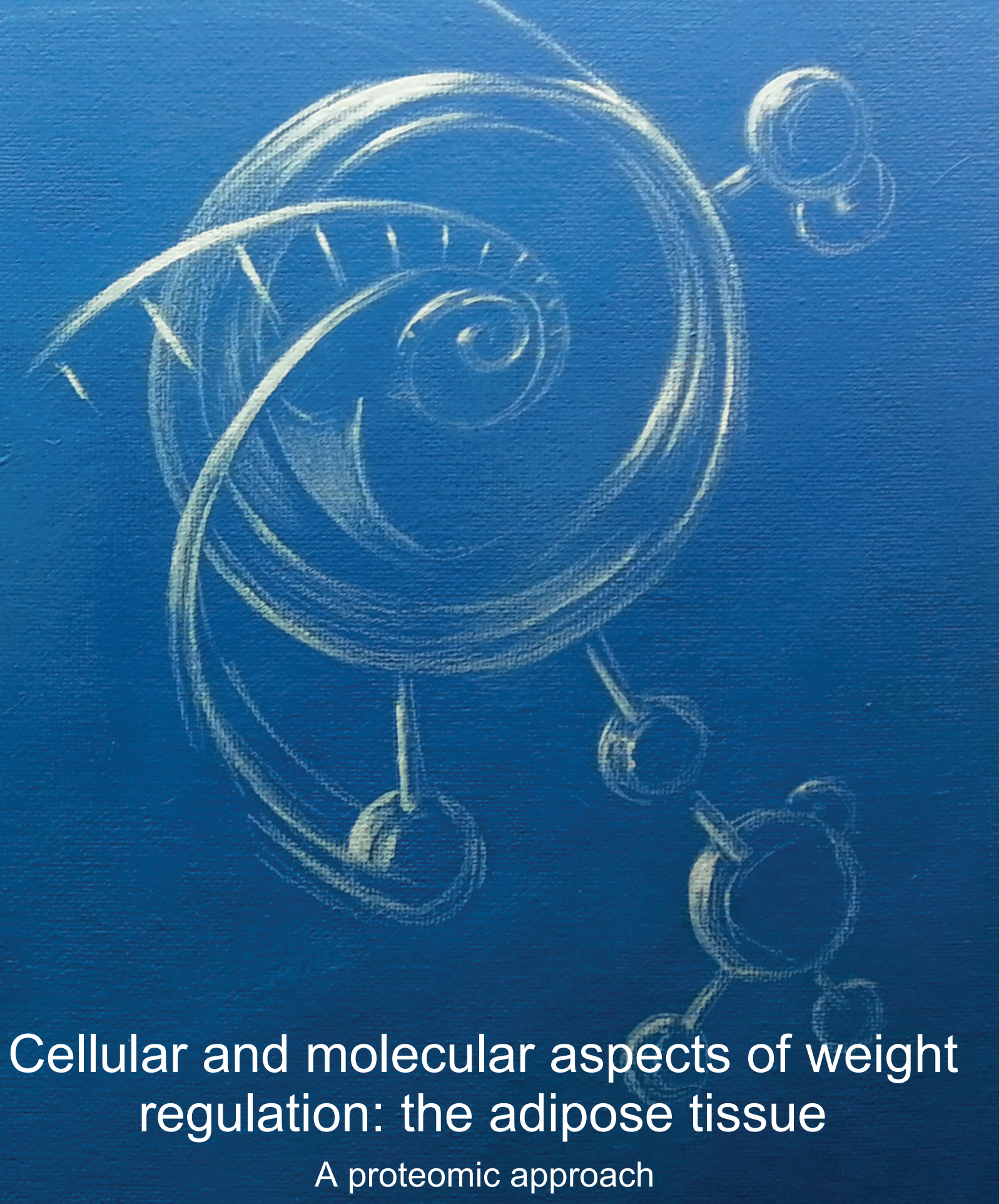

Freek Bouwman 


\title{
Cellular and molecular aspects of weight regulation: the adipose tissue
}

\author{
A proteomic approach
}




\section{NUTRIM}

The studies presented in this thesis were performed within NUTRIM, School of Nutrition and Translational Research in Metabolism.

$\begin{array}{ll}\text { Cover design: } & \text { Nosh, John Mevis } \\ \text { Layout: } & \text { Freek Bouwman } \\ \text { Printed by: } & \text { Ridderprint BV }\end{array}$

ISBN: $\quad$ 978-94-6299-069-2

(c) Copyright Freek Bouwman, Maastricht 2015 


\title{
Cellular and molecular aspects of weight regulation: the adipose tissue
}

\author{
A proteomic approach \\ PROEFSCHRIFT \\ ter verkrijging van de graad van doctor \\ aan de Universiteit Maastricht \\ op gezag van Rector Magnificus, \\ Prof. dr. L.L.G. Soete \\ volgens het besluit van het College van Decanen, \\ in het openbaar te verdedigen \\ op vrijdag 19 juni 2015 om 12.00 uur \\ door \\ Freek Gerwihl Bouwman
}

Geboren te Heerlen op 14 november 1971 


\section{Promotor}

Prof. dr. E.C.M. Mariman

\section{Copromotor}

Dr. P. Wang

\section{Beoordelingscommissie}

Prof. dr. ir. E.E. Blaak (chairman)

Prof. dr. T.M. Hakeng

Prof. dr. ir J. Keijer (Wageningen University)

Prof. dr. ir. R.P. Mensink

Prof. dr. P.D.E.M. Verhaert (TU Delft) 


\section{Content}

$\begin{array}{lll}\text { Chapter } 1 & \text { General introduction } & 7\end{array}$

Chapter 2 2D-electrophoresis and multiplex immunoassay proteomic 23 analysis of different body fluids and cellular components reveal known and novel markers for extended fasting

Chapter 3 The physiologic effects of caloric restriction are reflected in the in vivo adipocyte-enriched proteome of overweight/obese subjects

Chapter 4 Increased $\beta$-oxidation with improved glucose uptake capacity in adipose tissue from obese after weight loss and maintenance

Chapter 5 A combination of protein profiling and isotopomer analysis using matrix-assisted laser desorption/ionization-time of flight mass spectrometry reveals an active metabolism of the extracellular matrix of 3T3-L1 adipocytes

Chapter 6 Common discovered proteins in proteomic analysis - A story of cellular stress response.

Chapter 7 Gender-specific genetic associations of polymorphisms in 123 ACE, AKR1C2, FTO and MMP2 with weight gain over a 10 year period

Chapter 8 General Discussion

Summary

Samenvatting

The impact for society, Valorisation

Abbreviations

Dankwoord

List of publications

Curriculum vitae 

Chapter 1

General introduction 


\section{INTRODUCTION}

\section{Obesity and weight regulation}

Overweight and obesity have developed to worldwide epidemic proportions and have become a threat to human health [1]. In 2008 the World Health Organization estimated that of adults aged 20 and over, $35 \%$ were overweight and $11 \%$ were obese [2]. These numbers are expected to rise to $20 \%$ or more obese in 2015 [3, 4]. Obesity increases the risk for health complications such as cardiovascular diseases and type 2 diabetes mellitus, but also some forms of cancer and reduced fertility in men and women are known complications. In fact, obesity belongs to the top 10 of leading risks of global deaths [5]. Therefore, the major goal in obesity research is to determine why some people become obese and others do not, and use that knowledge for the prevention of obesity. The prevalence of overweight and obesity is assessed by using the body mass index (BMI), defined as the weight in kilograms divided by the square of the height in meters $\left(\mathrm{kg} / \mathrm{m}^{2}\right)$. The relation between the BMI and the weight classification is given in table 1 [6].

Table 1: BMI and weight status

\begin{tabular}{cc}
\hline BMI Weight classification \\
\hline$<19$ & Underweight \\
$19-25$ & Normal \\
$25-30$ & Overweight \\
$30-40$ & Obese \\
$>40$ & Extreme obese \\
\hline
\end{tabular}

In principle, overweight and obesity are the result of a disturbed energy balance. When energy balance is maintained, the energy intake is equal to the total energy expenditure (figure 1). If there is an imbalance between energy intake and energy expenditure this can lead to weight loss, weight gain or even obesity. In the case of overweight and obesity, the energy intake is more than energy expenditure. The most important causes for this imbalance nowadays are an increased calorie intake and a decrease of physical activity [7]. 
Energy intake

Feeding
Energy expenditure

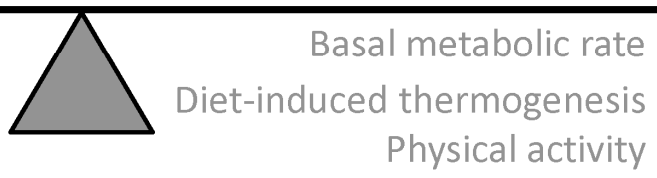

Figure 1: Balance between energy intake and energy expenditure [8]

The recent increase in the prevalence of obesity has been mostly caused by our modern societies in which the demand for physical activity is extremely reduced, and food is broadly available. However, in this 'obesogenic' environment, still many people seem to be protected against obesity [9]. The range of the BMI has broadened compared to hundred years ago. This has been suggested to be due to a change of the consumed food leading to a change in the expression of otherwise silent genetic variation (figure 2). As such, an individual's susceptibility is determined largely by genetics [10], while the observed outcome is determined by environmental factors like diet, physical activity, etc. In addition to a single-gene or multi-gene background [11], there is growing evidence that gene-environment interactions influence the development of obesity [12].

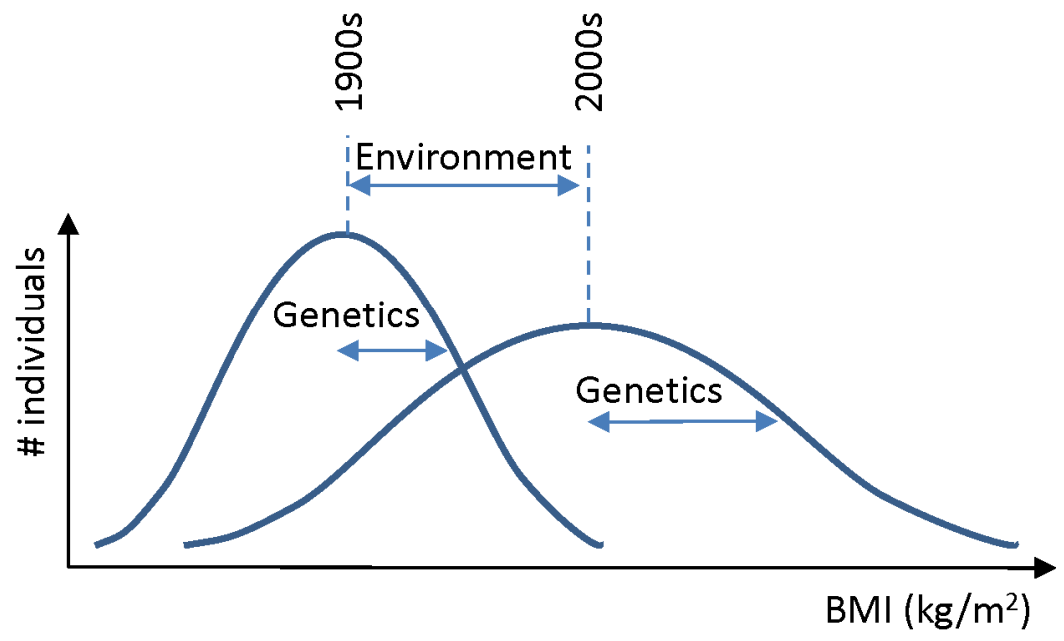

Figure 2: Change in the distribution of BMI over the past century [9].

The etiology of obesity is very complex. For instance, in some cases obesity follows the parent-child relationship. Parents have an important influence on the body weight development of their children. The BMI of the parents is positively correlated to the BMI of the children [13]. This parental association is due to shared genetic background and shared lifestyle. Also age is of influence 
because when people age they tend to gain weight and there is a positive correlation between age and the prevalence of overweight/obesity [4]. Further, studies suggest that a decrease in average sleep duration increases the prevalence of obesity $[14,15]$. Many other influential factors in weight regulation can be named. Figure 3 gives an overview, however this picture is not complete as additional influences are revealed regularly.

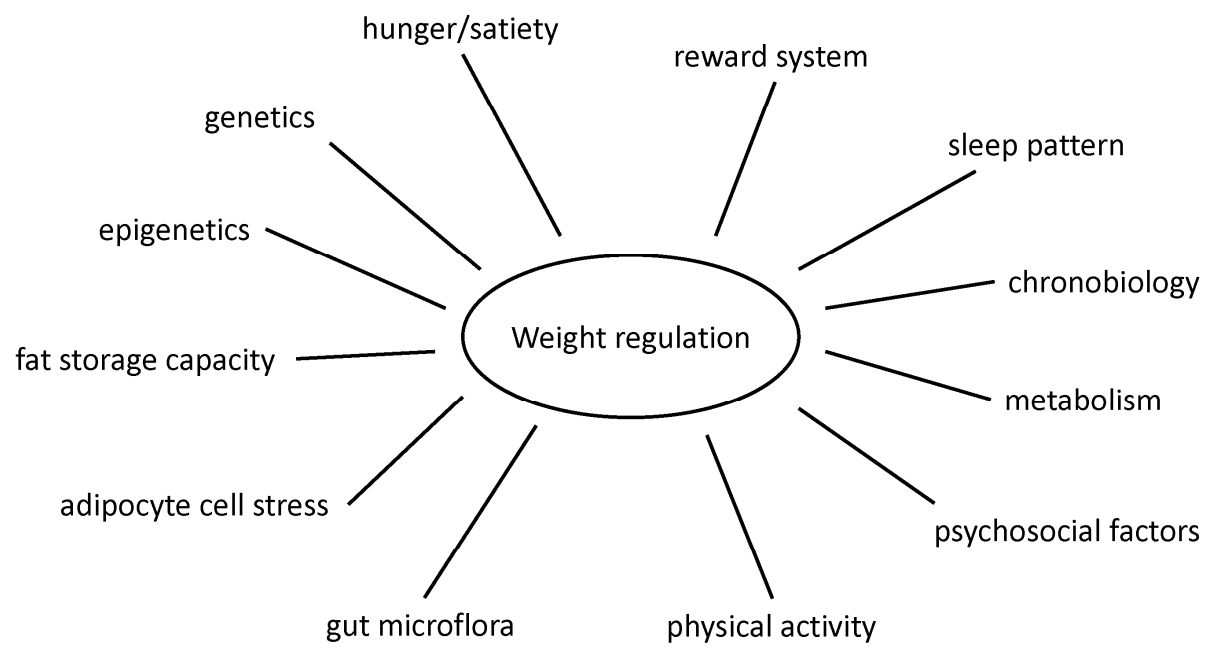

Figure 3: The many aspects of weight regulation.

Overweight and obesity can be reduced or prevented by limiting the energy/food intake, and by increasing the daily physical activity. To achieve this, it demands a lifestyle change that is difficult to maintain often due to a lack of discipline and compliance. When the lifestyle change is not successfully maintained it can result in weight cycling, also known as the yo-yo effect. A more drastic treatment for obesity is bariatric surgery. Weight loss is achieved by reducing the size or the digestive capacity of the stomach. This can be done with a gastric band, by removal of a portion of the stomach or by bypassing the stomach. Although it can be successful in the first period after the operation, a relapse to increased calorie intake is not uncommon in the long term [16].

\section{The role of adipose tissue and adipocytes in obesity}

Different depots of adipose tissue can be defined in humans. Adipose tissue which is located beneath the skin is called 'subcutaneous' adipose tissue, whereas adipose tissue that is located around the internal organs is called 'visceral' or 'abdominal' adipose tissue [17]. According to the morphology and 
function, adipose tissue can be split into two types: white adipose tissue (WAT) and brown adipose tissue (BAT). WAT stores and releases energy, whereas BAT dissipates energy from thermogenesis. White adipocytes contain one big fat droplet, while brown adipocytes are made up of multiple fat droplets and contain more mitochondria than white adipocytes. These mitochondria in the brown adipocytes are responsible for the thermogenic function of this cell type. Activation of white adipose tissue can be regulated by eating and starving, whereas activation of brown adipose tissue can occur by cold exposure. It is debated if an obesogenic diet induces brown-to-white trans-differentiation to meet the need for storing energy [18]. But also a white-to-brown conversion seems possible with an intermediate between WAT and BAT as beige adipocytes [19]. In this thesis we focus on the subcutaneous white adipose tissue and white adipocytes.

One of the main functions of white adipose tissue is synthesis and storage of triglycerides in a period of positive energy balance. It is involved in the mobilization of stored energy during a negative energy balance. Adipose tissue also plays a role as a mechanical shield for organs lying in deeper parts of the body as well as a thermal isolator and as a secretory organ. The life span of adipocytes or adipocyte turnover is about 10 years [20]. Fat mass expansion can be determined by both an increase in adipocyte size (hypertrophy) and adipocyte number (hyperplasia) [20, 21]. It is suggested that the total number of adipocytes is set during adulthood and remains rather stable thereafter. Thus, the most likely fat mass expansion is via the increase in adipocyte size [10]. In addition to adipocytes, adipose tissue contains stromal cells like preadipocytes, fibroblasts, vascular endothelial cells and a variety of immune cells including macrophages. It is unlikely that adipocytes carry out their function independent of those other types of cells in the adipose tissue. Their crosstalk may also play a role in weight regulation [22]. Adipose tissue is a significant component of the endocrine system in humans [23], because it secretes a type of cytokines (cellto-cell signaling proteins) called 'adipokines' or 'adipocytokines', which play a role in obesity-associated complications. Leptin was one of the first discovered adipokines to play a role in adiposity [8,24]. Leptin is supposed to regulate the hunger/satiety feelings. Adiponectin plays a role in the energy metabolism and can regulate glucose homeostasis and insulin sensitivity. Resistin, Acylationstimulating protein (ASP), Visfatin, IL-6 and tumor necrosis factor alpha (TNFa) are inflammatory cytokines expressed in adipose tissue, whereas some of those are also linked to insulin resistance. Those are only a few examples of an estimated 600 proteins and peptides secreted by the adipose tissue [25]. 


\section{Fatty acid handling by white adipose tissue}

\section{Fatty acid uptake}

Adipose tissue is recognized as a highly active metabolic and endocrine organ [26]. The main function of adipocytes is lipid storage and release (figure 4) in communication with other organs and tissues in the body. Human fat tissue is for $87 \%$ made up of lipids. In fact, there is a constant flux of fatty acids (FA) entering and leaving adipose tissue.

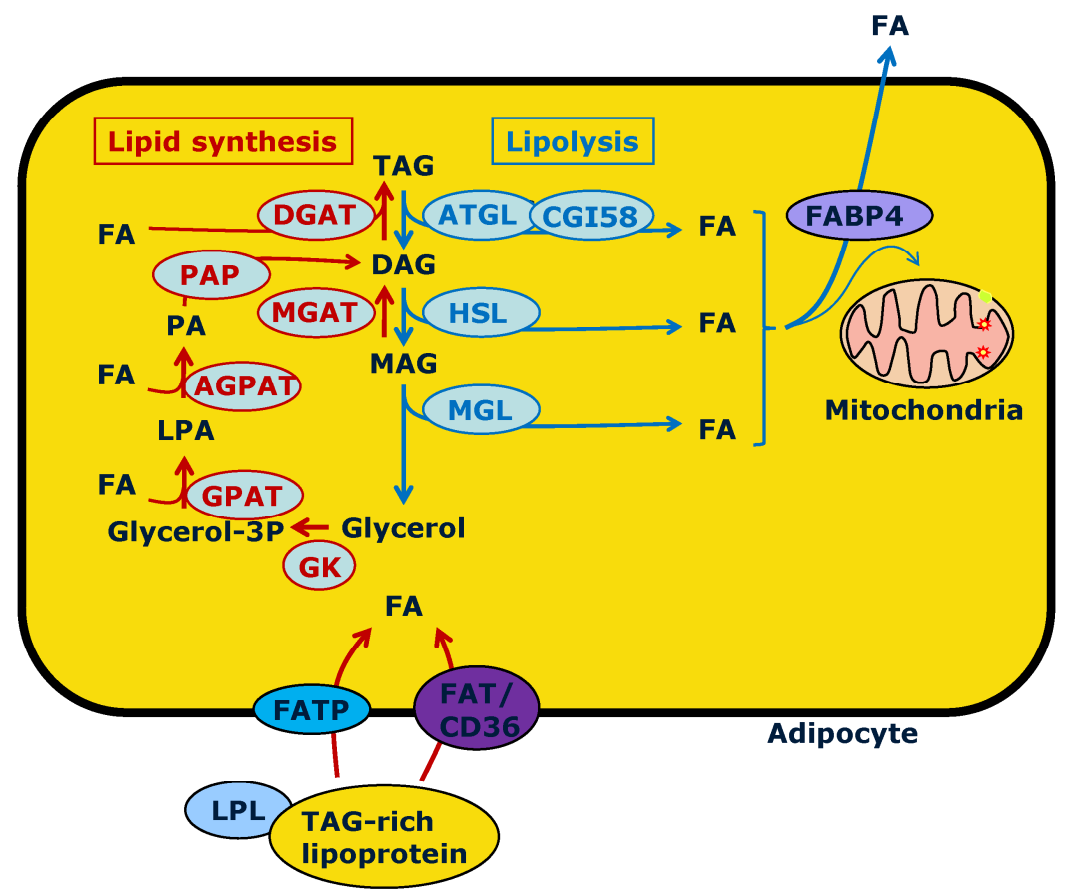

Figure 4: Fatty acid uptake and release pathway in adipocytes. Adipose triglyceride lipase (ATGL), lipoprotein lipase (LPL), fatty acid (FA), diglyceride acyltransferase (DGAT), hormone sensitive lipase (HSL), monoacylglycerol lipase (MGL), triacylglycerol (TAG), diacylglycerol (DAG), monoacylglycerol (MAG), glycerol-3-phosphate acyltransferase (GPAT), acylglycerophosphate acyltransferase (AGPAT), phosphatidic acid phosphohydrolase (PAP), phosphatidic acid (PA), lysophosphatidic acid (LPA), fatty acid transport protein (FATP), fatty acid translocase (FAT/CD36) and fatty acid binding protein 4 (FABP4).

Free fatty acids are liberated from lipoproteins by lipoprotein lipase (LPL) and enter the adipocytes through fatty acid transporters, after which they are reassembled into triglycerides by esterification onto glycerol. The first step in the lipid synthesis is the acylation of glycerol-3-phosphate by glycerol-3phosphate-acyltransferase (GPAT) into lysophosphatidic acid (LPA). The second FA is added by acylglycerol-3-phosphate acyltransferase (AGPAT) forming phosphatidic acid. Phosphatidic acid phosphohydrolase (PAP) converts phosphatidic acid into diacylglycerol (DAG). In the final step diglyceride 
acyltransferase (DGAT) catalyzes the formation of triacylglycerol (TAG) from DAG and FA-CoA.

Fatty acid release

The first step of the release of fatty acid, referred to as 'lipolysis', is where adipose triglyceride lipase (ATGL) hydrolysis TAG into DAG. The next fatty acid is hydrolyzed by hormone sensitive lipase (HSL) converting DAG into monoacylglycerol (MAG). The last fatty acid is hydrolyzed from the glycerol backbone by monoacylglycerol lipase (MGL) releasing also glycerol. The liberated fatty acids can be transported to the mitochondria by Fatty Acid Binding Protein (FABP4) for energy production or be released to the outside of the adipocytes when there is an energy shortage in the periphery. Glycerol is either released from the cells or reused by conversion into glycerol-phosphate by glycerol kinase (GK).

\section{A role for adipocytes in weight regain}

When people engage in a weight loss activity by dieting, adipocytes lose part of their fat content, which is used as a source of energy elsewhere in the body. Fat mass loss from adipocytes during caloric restriction seems limited, which may be the consequence of the stress build up between the shrinking cell volume and the rigid extracellular matrix [27]. Adipocytes under stress are supposed to send off stress signals to the brain to increase food intake. This reverts the process of fat loss into fat storage and leads to a return to the original shape of the adipocytes that coincides with a reduction of cellular stress. It somehow seems that the adipocytes during weight loss 'scream for fat' [28] and as soon as a person stops dieting and returns to energy balance, his/her adipocytes increase their capacity for FA uptake and glucose uptake [29]. This may lead to an increased risk for weight regain after a weight loss program.

\section{Proteomics in adipocytes research}

Proteomics is one of the modern omic-techniques. It can be used to obtain more systems-based knowledge about the proteins/genes involved in the development of adipose tissue during weight gain or weight regain. As such, novel biomarkers for prediction of treatment outcome or as targets for intervention can be identified. The definition of an ideal specific biomarker is that the biomarker has been well characterized and repeatedly shown to correctly predict relevant clinical outcome or another physiological state across a variety of treatments and populations. Due to the complexity and diversity of humans a single biomarker is hard to find and more likely, panels of proteins or protein profiles will be used as biomarker in the future. 
In this thesis proteomics involved separation of protein mixtures by 2dimensional gelelectrophoresis (2DE), quantitative comparison of the 2DEproteome under different conditions and identification of differentially expressed proteins. Occasionally other proteomics techniques, like difference gel electrophoresis (DIGE) or liquid chromatography mass spectrometry (LCMS) have been used [29].

Profiling and proteome comparison of complex protein mixtures by 2-DE The principle of $2 \mathrm{DE}$ is separation of proteins on a gel of a complex sample in two dimensions according to their charge and mass. In the first dimension proteins are separated by isoelectric focusing (IEF), which is based on the isoelectric point of each individual protein. The second dimension separation makes use of molecular weight differences of the proteins on a SDS-PAGE gel (figure 5).

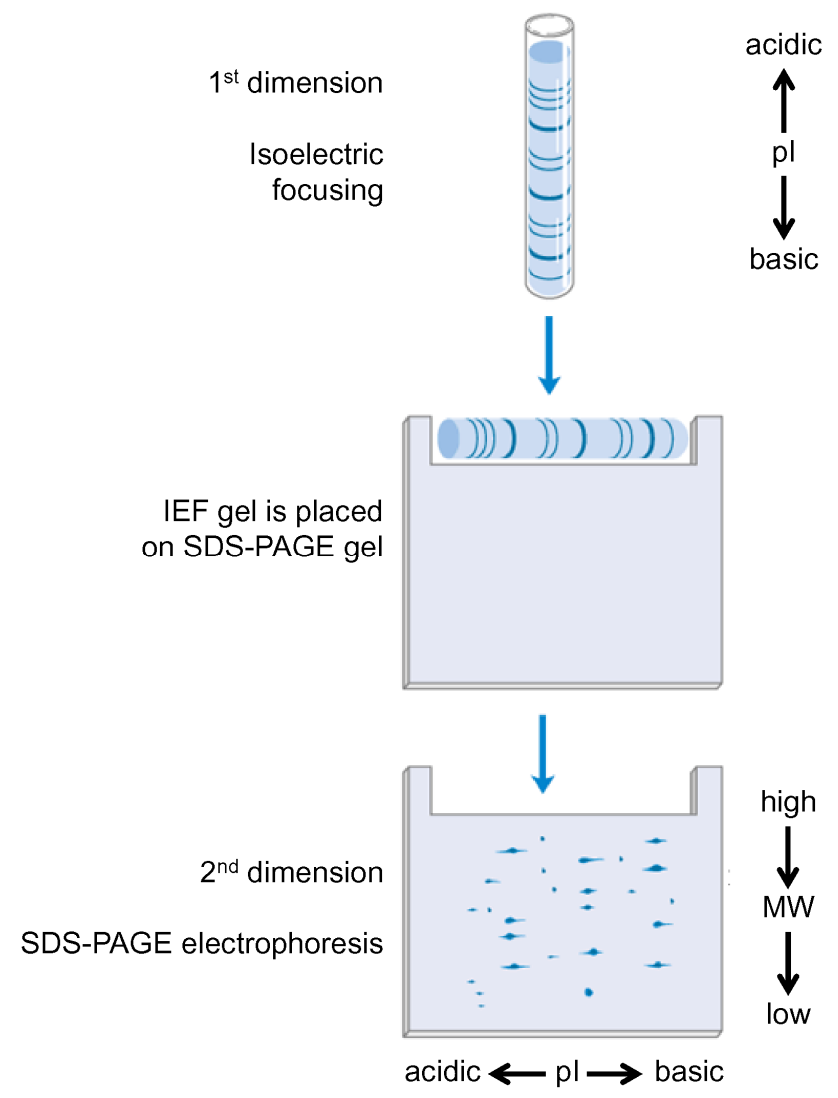

Figure 5: 2D electrophoresis principle 
A third dimension can be added by labeling the proteins with stable isotopes [30]. Complete labeling of cells in vitro (Stable Isotope Labeling by Amino acids in Cell culture, SILAC) has been used in one of the quantitative proteomics approaches [31].

After the electrophoresis the gels need to be treated to visualize the proteins to allow their quantification. Visualization can be done by staining with Coomassie brilliant blue, silver staining, radioactive or fluorescent labeling. After scanning, the gel images are matched and analyzed and compared by using software programs such as PDQuest (BioRad). The proteins differentially expressed between different samples can be excised from the gel. The disulfide bonds between cysteines are broken by dithiothreitol and then blocked with iodoacetamide to prevent the (re-)formation of the disulfide bonds. The protein spots are then in-gel digested with trypsin. Other proteases like lysC or gluC can also be used for digesting proteins. Trypsin cleaves the protein after the basic amino acids arginine and lysine. These tryptic peptides are subsequently eluted from the gel plug and identified by mass spectrometry.

MS

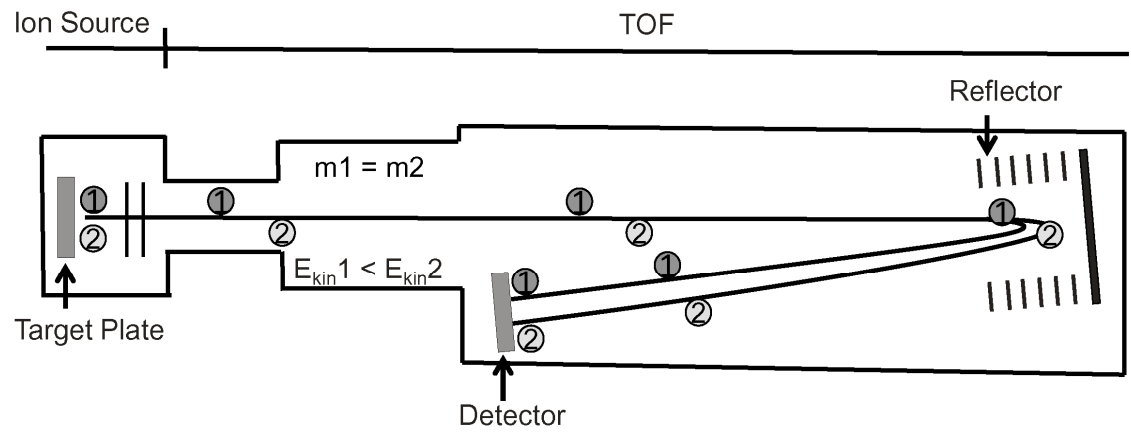

$\mathrm{MS} / \mathrm{MS}$

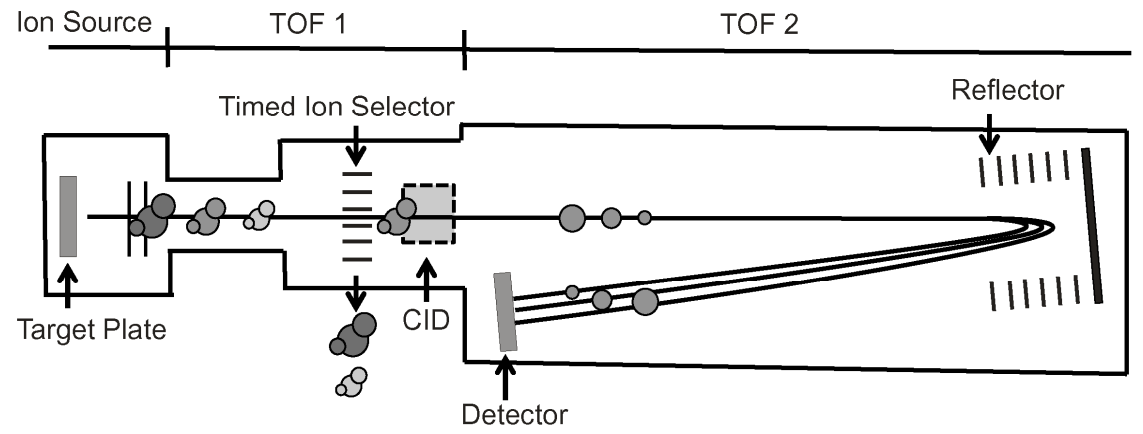

Figure 6: MS and MS/MS separation 


\section{Protein identification by matrix-assisted laser desorption/ionization time-of-flight mass spectrometry (MALDI-TOF MS and MS/MS)}

last decade mass spectrometry has evolved in a tremendous way. Resolution and sensitivity has increased enormously. A mass spectrometer nowadays becomes more standard equipment of research laboratories. MatrixassistedThe formed peptide ions are accelerated in an electric field towards the mass analyzer and are separated in the time of flight tube (TOF). The flight time In the laser desorption/ionization (MALDI) is a popular soft ionization technique for mass spectrometric analysis. The trypsin-digested peptides are mixed with matrix solution and air dried on the target plate. The laser is fired at the matrix crystals in the dried-droplet spot. In this way, the sample molecules are ionized by protonation, and volatilized to enter the mass spectrometer. However, the exact mechanism of MALDI is still debated.through the tube is related to their mass-to-charge ratio $(\mathrm{m} / \mathrm{z})$. The heavier an ion is, the slower it flies. Thus the time the ion takes to fly to the detector is related to its mass (figure 6). A mass spectrum of tryptic peptides gives a peptide mass fingerprint (PMF) of the respective protein. This PMF is compared with PMFs generated in silico from stored proteins in a database, like UniProt. This identification method implies that the sequence of the protein must be present in the database.

Peptide ions of interest, called selected precursor ions, can be further fragmented to product ions, which will be separated in the second TOF (figure $6)$. This fragmentation is induced by collision of the peptide ions with a gas. Breaks most often occur at the amide bonds. This results to a-, b-, c-ions when the charge is placed at the amino-terminal fragment or $x-, y-, z$-ions when the charge is placed on the carboxy-terminal fragment (figure 7). b- and y-ions are the most predominant ions in a MS/MS spectrum because the bond between $\mathrm{C}=\mathrm{O}$ and $\mathrm{N}-\mathrm{H}$ is the weakest in a gas collision setting.

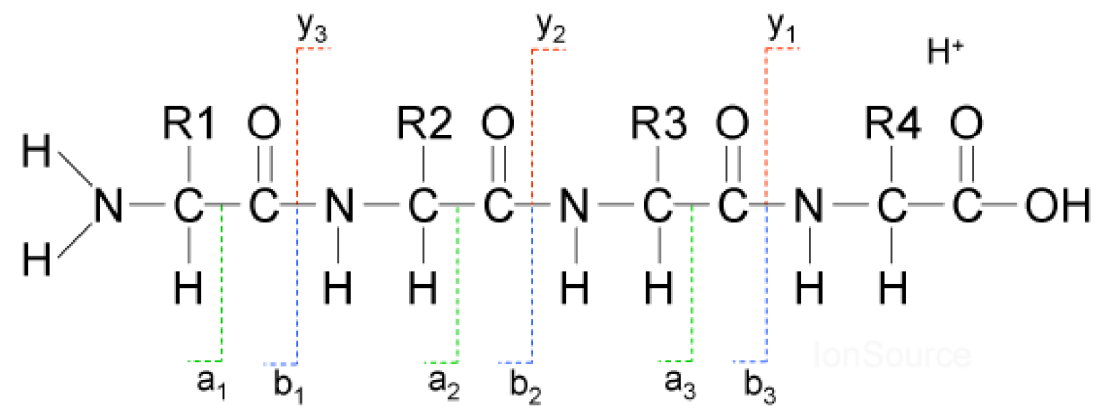

Figure 7: Peptide fragmentation

This MS/MS spectrum can then be used for comparison to data in a protein database or be used for de novo sequencing to get the protein identity [32]. The workflow of protein identification is depicted in figure 8. 

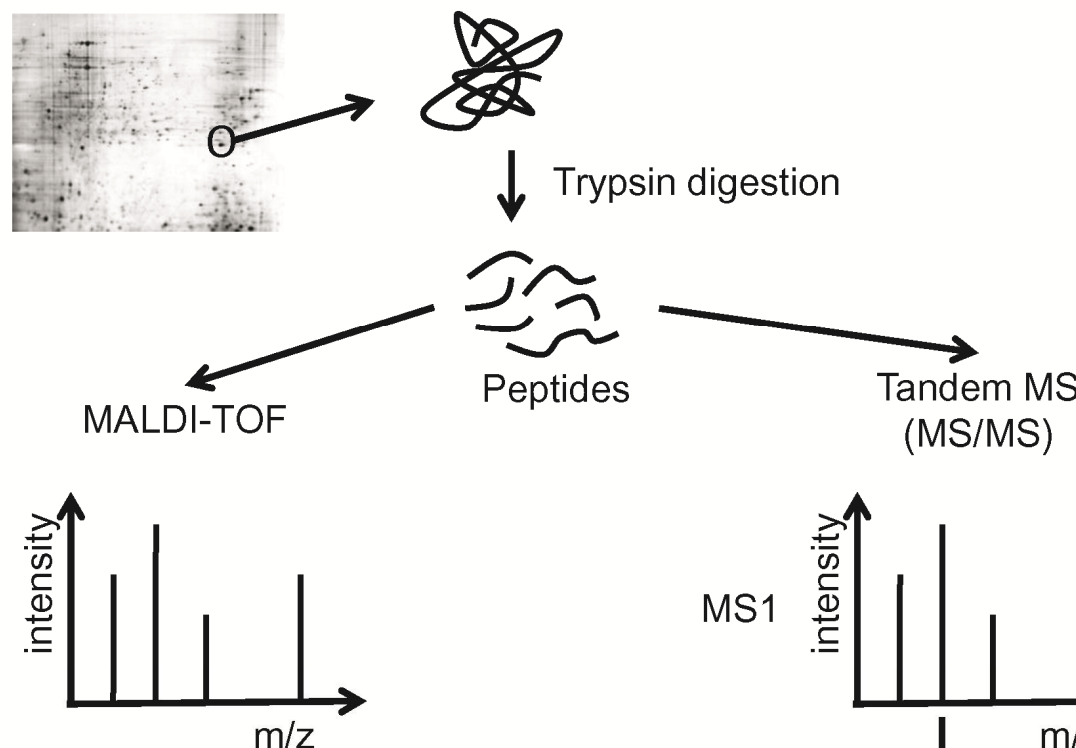

Peptide mass fingerprint
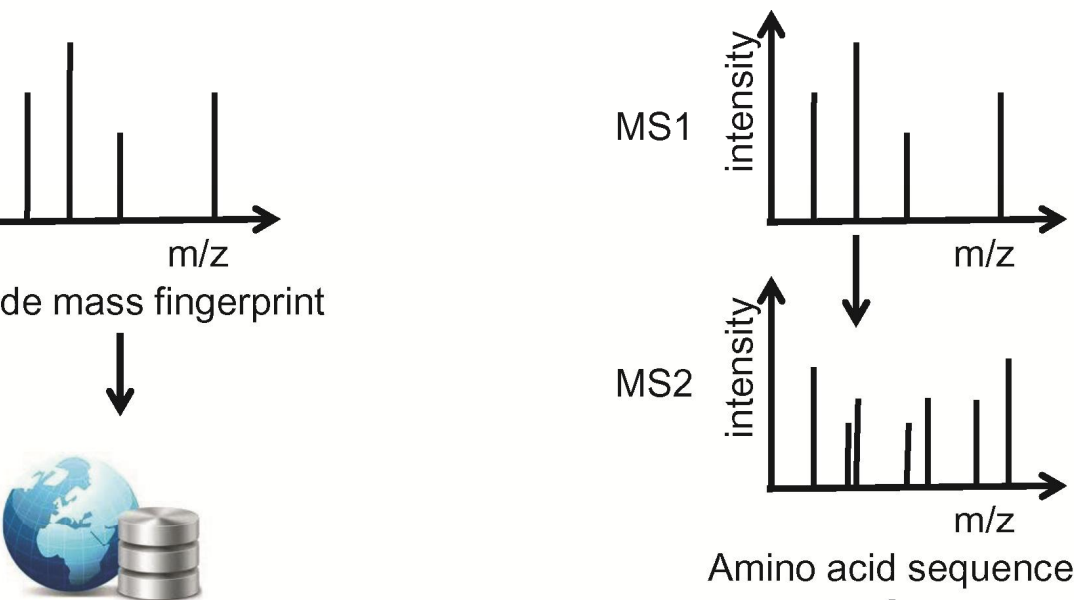

$\mathrm{m} / \mathrm{z}$

Compare against

theoretical fingerprint

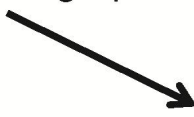

Protein identification

Amino acid sequence

Database search

Figure 8: Workflow of protein identification

\section{Multiplex immunoassay proteomic analysis}

Multiplex immunoassays are targeted proteomics approaches, which are used to detect proteins by using antibodies. The numbers of proteins that can be quantified in one run depend on the availability of good quality antibodies, which are rapidly growing in numbers. An advantage of a multiplex immunoassay is that this method is easy to use and highly reproducible. A disadvantage is that a fixed panel of proteins is addressed and isoforms or post-translational modifications usually cannot be determined. Also, it is a prerequisite that an 
adequate antibody is available. This puts some limitations to this method that the presence of several proteins or the functionality of specific proteins cannot be tested.

\section{Mass spectrometry based targeted proteomics}

To overcome the limited availability of antibodies of sufficient quality, a novel approach in mass spectrometry has emerged. Selected (or multiple) reaction monitoring (SRM or MRM) is a targeted mass spectrometry technique, in which a group of pre-selected proteins is quantified by mass spectrometry. This targeted proteomics method was chosen by Nature Methods as method of the year 2012 [33]. It is a kind of a "mass Western blotting". Also multiplexing is possible with this method.

\section{Proteomics as a source of candidate genes for genetic analysis}

Heritability measurements indicate a large contribution of genetic factors to the risk for a high BMI. However, only $5-10 \%$ of the genetic background has been explained [34]. Part of the missing variation may be due to strong geneenvironment interactions that even may have only a regional impact. In this respect, the underlying genes and genetic variation cannot regularly be identified by genetic experimental approaches. Altogether, there is a need for novel ways to identify candidate genes. Here, proteomics can be of help. Since proteomics experiments often identify proteins that play a crucial role in the processes of weight regulation, the corresponding genes can be regarded as candidates for the genetic background of obesity, which can be tested in genetic studies like association studies. In other words, proteomics is a valuable tool to identify and select candidates involved in the genetic background of obesity.

\section{Outline of the thesis}

This thesis focuses on the cellular and molecular aspects of weight regulation in the adipose tissue. In Chapter 2, a comparison was made between a proteomics analysis using 2D-electrophoresis and an analysis using multiplex immunoassay with respect to their success of identifying biomarkers of extended fasting. In Chapter 3 we used 2D-electrophoresis combined with adipocyte protein enrichment to study the effect of weight loss/maintenance on the adipocyte proteome of overweight/obese subjects. Protein abundances were compared before and after the intervention and crucial proteins and molecular processes were identified. The results of chapter 3 were further 
deepened in Chapter 4 by analyzing additional key proteins of the glucose and lipid handling in adipose tissue. This generated an image of the adipose tissue metabolism after weight loss/maintenance with adipocytes improving their capacity for glucose and lipid uptake but at the same time keeping mitochondrial beta-oxidation at a relatively high level. Some of those metabolic changes in adipose tissue during weight loss may be related to the dynamics of the extracellular matrix. Therefore, in Chapter $\mathbf{5}$ we studied the turnover rate of adipocyte proteins in vitro using proteomics and found that adipocytes do spend a lot of their energy on renewing ECM proteins underscoring the importance of the ECM for the function and survival of adipocytes. Changes in protein abundance as measured by 2D-electrophoresis must be interpreted carefully, because some proteins seem to respond in general to changes in cellular conditions. In this respect, in Chapter 6 we searched for the proteins with a general response to experimental conditions in order to critically assess the specificity of our proteomics results. Since proteomics is in our hands also a method for generating candidate genes for the genetic background, in Chapter 7 we analyzed some of the genes detected in chapters 3 and 4 in a genetic association study looking for genetic factors for long-term weight gain. Finally, Chapter 8 presents a general discussion of the results and interpretations of the described studies and discusses a future perspective on "totalomics" research in the field of weight regulation and obesity.

\section{References}

1. Caballero B (2007) The global epidemic of obesity: an overview. Epidemiol Rev 29:1-5.

2. WHO (2013) Obesity and overweight. (Fact sheet $\mathrm{N}^{\circ} 311$ ).

3. van Vliet-Ostaptchouk JV, et al. (2014) The prevalence of metabolic syndrome and metabolically healthy obesity in Europe: a collaborative analysis of ten large cohort studies. $B M C$ endocrine disorders 14(1):9.

4. von Ruesten A, et al. (2011) Trend in obesity prevalence in European adult cohort populations during follow-up since 1996 and their predictions to 2015. PloS one 6(11):e27455.

5. WHO (2014) The top 10 causes of death. (Fact sheet $\mathrm{N}^{\circ} 310$ ).

6. WHO (2000) Obesity: preventing and managing the global epidemic. Report of a WHO consultation. World Health Organ Tech Rep Ser 894:i-xii, 1-253.

7. Ten Hoor GA, Plasqui G, Schols AM, \& Kok G (2014) Combating adolescent obesity: an integrated physiological and psychological perspective. Current opinion in clinical nutrition and metabolic care.

8. Rosen ED \& Spiegelman BM (2006) Adipocytes as regulators of energy balance and glucose homeostasis. Nature 444(7121):847-853.

9. Galgani J \& Ravussin E (2008) Energy metabolism, fuel selection and body weight regulation. Int J Obes (Lond) 32 Suppl 7:S109-119.

10. Maclean PS, Bergouignan A, Cornier MA, \& Jackman MR (2011) Biology's response to dieting: the impetus for weight regain. Am J Physiol Regul Integr Comp Physiol 301(3):R581-600.

11. Rankinen T, et al. (2006) The human obesity gene map: the 2005 update. Obesity (Silver Spring) 14(4):529-644.

12. Qi L \& Cho YA (2008) Gene-environment interaction and obesity. Nutr Rev 66(12):684-694.

13. Vogels N, et al. (2006) Determinants of overweight in a cohort of Dutch children. Am J Clin Nutr 84(4):717-724. 
14. Marshall NS, Glozier N, \& Grunstein RR (2008) Is sleep duration related to obesity? A critical review of the epidemiological evidence. Sleep medicine reviews 12(4):289-298.

15. Chaput JP, Despres JP, Bouchard C, \& Tremblay A (2008) The association between sleep duration and weight gain in adults: a 6-year prospective study from the Quebec Family Study. Sleep 31(4):517-523.

16. Karmali S, et al. (2013) Weight recidivism post-bariatric surgery: a systematic review. Obesity surgery 23(11):1922-1933.

17. Cinti S (2012) The adipose organ at a glance. Disease models \& mechanisms 5(5):588-594.

18. Cinti S (2011) Between brown and white: novel aspects of adipocyte differentiation. Ann Med 43(2):104-115.

19. Wu J, et al. (2012) Beige adipocytes are a distinct type of thermogenic fat cell in mouse and human. Cell 150(2):366-376.

20. Spalding KL, et al. (2008) Dynamics of fat cell turnover in humans. Nature 453(7196):783-787.

21. Arner $P$ \& Spalding KL (2010) Fat cell turnover in humans. Biochem Biophys Res Commun 396(1):101-104.

22. Schling P \& Loffler G (2002) Cross talk between adipose tissue cells: impact on pathophysiology. News in physiological sciences : an international journal of physiology produced jointly by the International Union of Physiological Sciences and the American Physiological Society 17:99-104.

23. Deng Y \& Scherer PE (2010) Adipokines as novel biomarkers and regulators of the metabolic syndrome. Ann N Y Acad Sci 1212:E1-E19.

24. Zhang $\mathrm{Y}$, et al. (1994) Positional cloning of the mouse obese gene and its human homologue. Nature 372(6505):425-432.

25. Renes J \& Mariman E (2013) Application of proteomics technology in adipocyte biology. Molecular bioSystems 9(6):1076-1091.

26. Wozniak SE, Gee LL, Wachtel MS, \& Frezza EE (2009) Adipose tissue: the new endocrine organ? A review article. Digestive diseases and sciences 54(9):1847-1856.

27. Mariman EC \& Wang P (2010) Adipocyte extracellular matrix composition, dynamics and role in obesity. Cell Mol Life Sci 67(8):1277-1292.

28. Eastman Q (2009) Very low calorie diet makes adipocytes "scream". J Proteome Res 8(12):5408.

29. Bouwman FG, Wang P, van Baak M, Saris WH, \& Mariman EC (2013) Increased betaoxidation with improved glucose uptake capacity in adipose tissue from obese after weight loss and maintenance. Obesity (Silver Spring).

30. Bouwman F, Renes J, \& Mariman E (2004) A combination of protein profiling and isotopomer analysis using matrix-assisted laser desorption/ionization-time of flight mass spectrometry reveals an active metabolism of the extracellular matrix of 3T3-L1 adipocytes. Proteomics 4(12):3855-3863.

31. Mirgorodskaya OA, et al. (2000) Quantitation of peptides and proteins by matrix-assisted laser desorption/ionization mass spectrometry using (18)O-labeled internal standards. Rapid communications in mass spectrometry : RCM 14(14):1226-1232.

32. Steen H \& Mann M (2004) The ABC's (and XYZ's) of peptide sequencing. Nat Rev Mol Cell Biol 5(9):699-711.

33. Anonymous (2013) Method of the Year 2012. Nat Methods 10(1):1.

34. Speliotes EK, et al. (2010) Association analyses of 249,796 individuals reveal 18 new loci associated with body mass index. Nat Genet 42(11):937-948. 


\section{Chapter 2}

\section{D-electrophoresis and multiplex immunoassay proteomic analysis of different body fluids and cellular components reveal known and novel markers for extended fasting}

Freek G. Bouwman1, Baukje de Roos2, Isabel Rubio-Aliaga3, L Katie Crosley2, Susan J Duthie2, Claus Mayer4, Graham Horgan ${ }^{4}$, Abigael C Polley ${ }^{5}$, Carolin Heim ${ }^{3}$, Susan LM Coort ${ }^{6}$, Chris T Evelo $^{6}$, Francis Mulholland ${ }^{5}$, Ian T Johnson ${ }^{5}$, Ruan M Elliott ${ }^{5}$, Hannelore Daniel ${ }^{3}$ \& Edwin CM Mariman $^{1}$

${ }^{1}$ Department of Human Biology, Nutrition and Toxicology Research Institute Maastricht (NUTRIM), Maastricht University, Maastricht, The Netherlands. ${ }^{2}$ Rowett Institute of Nutrition and Health, University of Aberdeen, Aberdeen, UK. ${ }^{3}$ Molecular Nutrition Unit, ZIEL - Research Center for Nutrition and Food Sciences, Technische Universität München, Freising-Weihenstephan, Germany. ${ }^{4}$ Biomathematics and Statistics Scotland, Aberdeen, UK. ${ }^{5}$ Institute of Food Research, Norwich Research Park, Norwich, UK. ${ }^{6}$ Department of Bioinformatics - BiGCaT, NUTRIM, Maastricht University, Maastricht, the Netherlands.

BMC Medical Genomics, 2011, p 4-24 


\section{ABSTRACT}

Background: Proteomic technologies applied for profiling human biofluids and blood cells are considered to reveal new biomarkers of exposure or provide insights into novel mechanisms of adaptation.

Methods: Both a non-targeted (classical 2D-electrophoresis combined with mass spectrometry) as well as a targeted proteomic approach (multiplex immunoassay) were applied to investigate how fasting for $36 \mathrm{~h}$, as compared to $12 \mathrm{~h}$, affects the proteome of platelets, peripheral blood mononuclear cells (PBMC), plasma, urine and saliva collected from ten healthy volunteers. Results: Between-subject variability was highest in the plasma proteome and lowest in the PBMC proteome. Random Forests analysis performed on the entire dataset revealed that changes in the level of the RhoGDI2 protein in PBMC and plasma ApoA4 levels were the two most obvious biomarkers of an extended fasting. Random Forests (RF) analysis of the multiplex immunoassay data revealed leptin and MMP-3 as biomarkers for extended fasting. However, high between-subject variability may have masked the extended fasting effects in the proteome of the biofluids and blood cells.

Conclusions: Identification of significantly changed proteins in biofluids and blood cells using a non-targeted approach, together with the outcome of targeted analysis revealed both known and novel markers for a $36 \mathrm{~h}$ fasting period, including the cellular proteins RhoGDI2 and CLIC1, and plasma proteins ApoA4, leptin and MMP-3. The PBMC proteome exhibited the lowest between-subject variability and therefore these cells appear to represent the best biosamples for biomarker discovery in human nutrigenomics. 


\section{INTRODUCTION}

There is an emerging demand on biomarker discovery especially in the field of nutrition with respect to weight regulation and obesity [1]. Proteomic technologies are increasingly being applied in nutrition research to reveal biomarkers that can help to demonstrate effectiveness of certain diets. Furthermore, these technologies also aid the discovery of mechanisms whereby dietary regimens influence health [2,3]. Caloric restriction or fasting is a popular and efficient way to reduce weight $[4,5]$. In this study we investigated how an extended fasting period from $12 \mathrm{~h}$ to $36 \mathrm{~h}$ is reflected in the proteome of several body fluids and some of their cellular components. After $36 \mathrm{~h}$ fasting all glycogen resources are used [6]. The proteomic applications used were classical 2Delectrophoresis combined with mass spectrometry for protein identification, as a non-targeted approach, and a multiplex-based immunoassay, as a targeted approach. Our aim was to see which type of application best detected responses to a fasting period of $36 \mathrm{~h}$ and which body fluid or blood cells would be most appropriate to reflect such responses.

This human trial was part of the European Nutrigenomics Organization (NuGO) Proof of Principal Study (PPS) in which various omic techniques were applied [7], including transcriptomics, proteomics and metabolomics [8]. This component of the PPS was designed to evaluate experimental and biological variation on the individual level in nutrigenomic experiments as a basis for future personalized nutrition concepts [9].

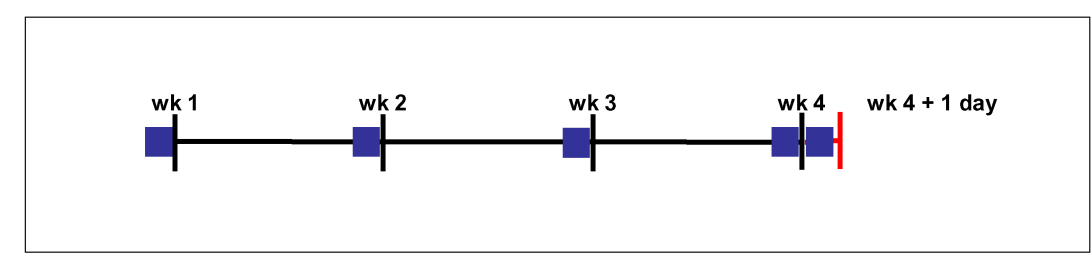

$n=10$ subjects

Fasted (overnight) baseline samples;

Blood (for the isolation of platelets, PBMC and plasma), saliva, and morning urine

Collection of $24 \mathrm{hrs}$ urine

Fasting challenge (36 hrs);

Blood (for the isolation of platelets, PBMC and plasma), saliva, and morning urine

Figure 1: Schematic representation of the study design 


\section{METHODS}

\section{Study design and sample preparation}

The goals and design of the human PPS have been described recently [7]. Ethical permission for the study was obtained from the North of Scotland Research Ethics Services prior to the start of the study, and all volunteers gave informed consent. Ten healthy volunteers ( 3 males and 7 females) were enrolled at the Rowett Institute of Nutrition and Health, University of Aberdeen. The BMI of volunteers ranged from 18.5 to $39.7 \mathrm{~kg} / \mathrm{m} 2$ and the age of the volunteers ranged from 25 to 56 years. The volunteers were asked to come to the Human Nutrition Unit once a week on different days each week during a four week period after an overnight fast to provide a blood sample (for the isolation of plasma, PBMC and platelets) and a saliva and $24 \mathrm{~h}$ urine sample. After the fourth sampling day, volunteers were fasted for an additional $24 \mathrm{~h}$ (total of $36 \mathrm{~h}$ ) followed by sample collection (Figure 1). Blood samples were collected into vacutainers containing potassium EDTA anticoagulant. The isolation of platelets, PBMC, plasma, saliva and urine were performed as described by Crosley et al. [10]. Protein concentrations of platelets, PBMC, saliva and urine were assessed by the RC/DC assay (BioRad) according to the manufacturer's instructions. The protein contents of plasma samples were determined using 2-D Quant kits (GE Healthcare) according to the manufacturer's instructions. The samples were immediately aliquoted, snap frozen in liquid nitrogen, stored at $-80^{\circ} \mathrm{C}$ and shipped to the different laboratories for analysis.

\section{Analysis of plasma proteins by multiplex immunoassay}

The concentrations of 89 proteins were measured by Rules-Based Medicine (RBM) in all plasma samples by a multiplex immunoassay (HumanMAP Version 1.6, Rules-Based Medicine, Inc., Austin TX, USA).

\section{D-electrophoresis}

The platelets and saliva were analyzed in laboratory 1, PBMC and urine in laboratory 2 and depleted plasma in laboratory 3 . Each of the three laboratories ran one gel per sampling time point, the 4 overnight fasting time points were considered as replicates. 2D-electrophoresis was performed as described previously [11]. Briefly, for the blood related samples 200-250 $\mu \mathrm{g}$ protein was loaded onto a $24 \mathrm{~cm} \mathrm{4-7} \mathrm{linear} \mathrm{IPG} \mathrm{strip} \mathrm{for} \mathrm{separation} \mathrm{in} \mathrm{the} \mathrm{first} \mathrm{dimension.}$ 
Prior to IEF the plasma samples were depleted of Albumin and IgG using the Albumin and IgG Removal Kit (GE Healthcare) according to the manufacturer's instructions. The second dimension separation was on a standard $12 \%$ SDSPAGE for platelets and PBMC, the second dimension of the depleted plasma was separated on a $1 \mathrm{~mm}$ thick $10 \%$ Duracryl gel [11]. For the saliva samples, $25 \mu \mathrm{g}$ protein was loaded onto an $11 \mathrm{~cm} \mathrm{4-7} \mathrm{linear} \mathrm{IPG} \mathrm{strip} \mathrm{for} \mathrm{separation} \mathrm{in}$ the first dimension. The second dimension separation was carried out on a $12 \%$ SDS-PAGE. For the urine samples $300 \mu \mathrm{g}$ protein was loaded onto an $18 \mathrm{~cm} \mathrm{pH}$ 4-7 linear IPG strip. The gels with urine proteins were stained with Coomassie. Gels with proteins obtained from other biofluids and blood cells were stained with Flamingo fluorescent stain (Biorad) according to the manufacturer's instructions. Spots were identified and analyzed using the PDQuest v8.0 software (Biorad) for the platelets and saliva; Delta2D v3.6 (Decodon) for the PBMC and urine and Progenesis SameSpots v3.1 (Nonlinear Dynamics) for depleted plasma. Background subtraction and normalization were automatically carried out by the software programs.

\section{Protein identification}

The selected protein spots were excised from the 2D gels and processed for protein identification in the same laboratory where the gels were run. Generation of tryptic digest from the protein by in-gel digestion was performed as described previously $[11,12]$.

\section{MALDI-TOF/TOF mass spectrometry}

For MS/MS analysis of the spots from platelets and saliva (laboratory 1), $1.0 \mu \mathrm{l}$ of the peptide mixture and $1.0 \mu \mathrm{l}$ matrix solution $(2.5 \mathrm{mg} / \mathrm{ml} \mathrm{CHCA}$ in $50 \%$ acetonitrile/0.1\% trifluoroacetic acid; TFA) were spotted on a 384-well MALDI target plate. Data were collected with a MALDI-TOF/TOF mass spectrometer (4800 MALDI-TOF/TOF Proteomics Analyzer, Applied Biosystems). A default calibration was applied using a six-component peptide standard spotted onto 13 different positions of the MALDI target plate for MS, and Glu-Fibrinopeptide B (m/z 1570,68) fragmentation for MS/MS. Typically, 1000 shots were combined for obtaining MS spectra and for MS/MS spectra 2000 shots were combined. The GPS Explorer v3.6 software (Applied Biosystems) was employed to generate peak lists and automated MASCOT searches against the Swiss-Prot protein database (Swiss-Prot release 56.5; 402482 sequences) for protein identification. One miss-cleavage was tolerated; carbamidomethylation was set as a fixed modification and oxidation of methionine as an optional modification. The protein charge was set at 1+. The precursor tolerance was set to $100 \mathrm{ppm}$ and the MS/MS tolerance was set at $0.2 \mathrm{Da}$. No restrictions were made on the 
protein mass. Protein hits with a MASCOT protein score greater than 56 $(p<0.05)$ and a GPS Explorer protein score confidence index $>95 \%$ were validated as confirmed identifications [13].

The identity of the plasma, PBMC and urine spots (laboratory 2 and 3 ) was determined by peptide fingerprinting using an Ultraflex MALDI-TOF/TOF mass spectrometer (Bruker Daltonics Ltd.). A $200 \mathrm{~Hz}$ nitrogen laser was used to desorb/ionize the matrix/analyte material, and ions were detected in positive ion reflectron mode. All spectra were acquired automatically using the Bruker fuzzy logic algorithm (FlexControl 3.0, Bruker) and a Biotools 3.0 search routine. The resulting mass data was interrogated using an offline version of the MASCOT search engine (Matrix Science) using the SPtrEMBL database with the following search criteria: allowance of 0 or 1 missed cleavages; peptide mass tolerance of $50 \mathrm{ppm}$; trypsin as digestion enzyme; carbamidomethyl modification of cysteine; methionine oxidation as partial modification; and charged state as $\mathrm{MH}+[14]$.

\section{Statistical analysis}

Exploratory analysis of the data indicated that a log-transformation was advisable for most data sets. For reasons of consistency all data sets were analyzed on a $\log _{2}$-scale and back transformed to report fold changes. For the extended fasting effect analysis, a linear model including time point (5 levels) and subject (10 levels) as factors was fitted to the 50 data points for each variable. The extended fasting effect was then defined as a contrast that compared time point 5 (36 hours fasting) with the average of the 4 baseline measurements (overnight fasting). The 4 baseline time points were used to determine the between-subject effect, again using a linear model with subject as the only factor. P-values were adjusted for multiple testing within each data set by using the Benjamini-Hochberg method.

Spots were selected for protein identification if their adjusted $p$-value fell below 0.2 allowing a false discovery rate (FDR) of $20 \%$. Linear model analysis and Pvalue adjustment were performed using the $R$ package v2.10.1. In order not to miss any interesting spots we also performed additional analyses on the original scale and also selected proteins with an adjusted $\mathrm{P}$ below 0.2 on this scale. In this way we identified 10 proteins from the $2 \mathrm{D}$-electrophoresis and 39 proteins for the multiplex immunoassay which were significantly changed upon the extended fasting. The data were imported into GeneMaths v2.11 for discriminant principal component analysis and cluster analysis with Pearson correlation. We used the R package v2.10.1 for random forests (RF) analysis, RF package 4.5-34 [15]. RF analysis was applied to normalized data. The number of trees was set to 500 and the number of variables randomly sampled as candidates at each split was set to 9. Ten cycles were calculated and averaged. These average mean decreased Gini results were plotted. The Gini 
importance indicates the importance of the variable in the classification. Cytoscape v2.7 with the MiMl plug-in 3.0.1 was used to create network associations. All proteomic data (2D and RBM) where used for creating the network. The protein-protein interaction network was created using all available databases present in MiMI, among which are IntAct, BIND and KEGG [16].

Table 1: Number of protein spots/proteins that change during fasting challenge. A fasting and a between-subject effect was observed

\begin{tabular}{lccc}
\hline & $\begin{array}{c}\text { Fasting } \\
\text { effect }\end{array}$ & $\begin{array}{c}\text { Subject } \\
\text { effect }\end{array}$ & $\begin{array}{c}\text { Total detected } \\
\text { spots/proteins }\end{array}$ \\
\hline Non-targeted approach & 13 & 703 & 1018 \\
Plasma proteomics & 83 & 4 & 910 \\
PBMC proteomics & 0 & 2 & 604 \\
Platelet proteomics & 1 & 69 & 208 \\
Saliva proteomics & 3 & 58 & 142 \\
Urine proteomics & & & \\
Targeted approach & 39 & 78 & 89 \\
Rules Based Medicine & &
\end{tabular}

\section{RESULTS}

In the proteome of most biofluids and blood cells an effect of an extended fasting period from $12 \mathrm{~h}$ to $36 \mathrm{~h}$ could be observed. However, the number of proteins that changed as a result of the extended fasting was relatively small compared to the large number of proteins that differed significantly between subjects. Of the 2971 detected spots/proteins in all data sets, 153 spots/proteins were changed due to extended fasting (5.1\%), whereas 914 mostly other spots/proteins exhibited significant between-subject differences $(30.8 \%)$. In plasma, for example, extended fasting resulted in a significant alteration of only $1.3 \%$ of the protein spots, whereas $69.1 \%$ of the spots differed significantly between subjects, when using 2D-electrophoresis. Blood cells, on the other hand, showed a remarkably lower number of proteins that exhibited significant between-subject differences $(0.3 \%$ and $0.4 \%$ of the proteins in platelets and PBMC, respectively). Moreover, PBMC showed the highest number of proteins that changed significantly when volunteers extended fasting from $12 \mathrm{~h}$ to $36 \mathrm{~h}(9.1 \%)$. With the targeted approach using RBM, 39 plasma proteins $(43.8 \%)$ changed significantly due to extended fasting, and 78 proteins $(87.6 \%)$ differed significantly between subjects (Table 1 ). 


\section{A}
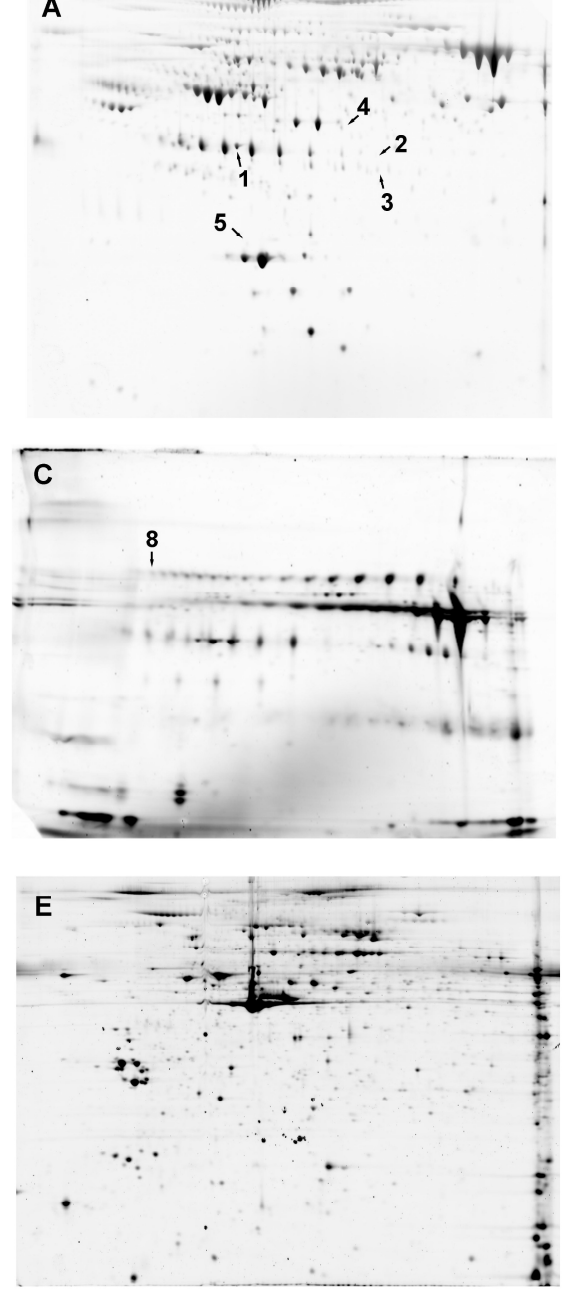

B
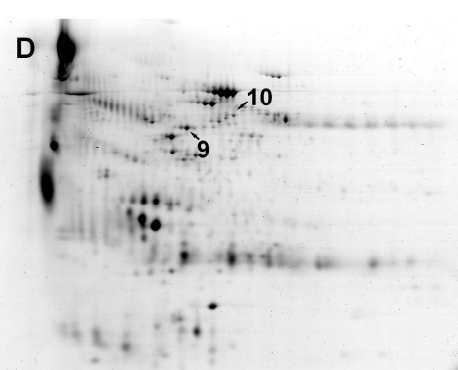

Figure 2: Identified proteins marked on 2D gels representing plasma (A), PBMC (B), saliva (C), urine (D) and platelets $(E)$. The numbers refer to those used in Table 2. 


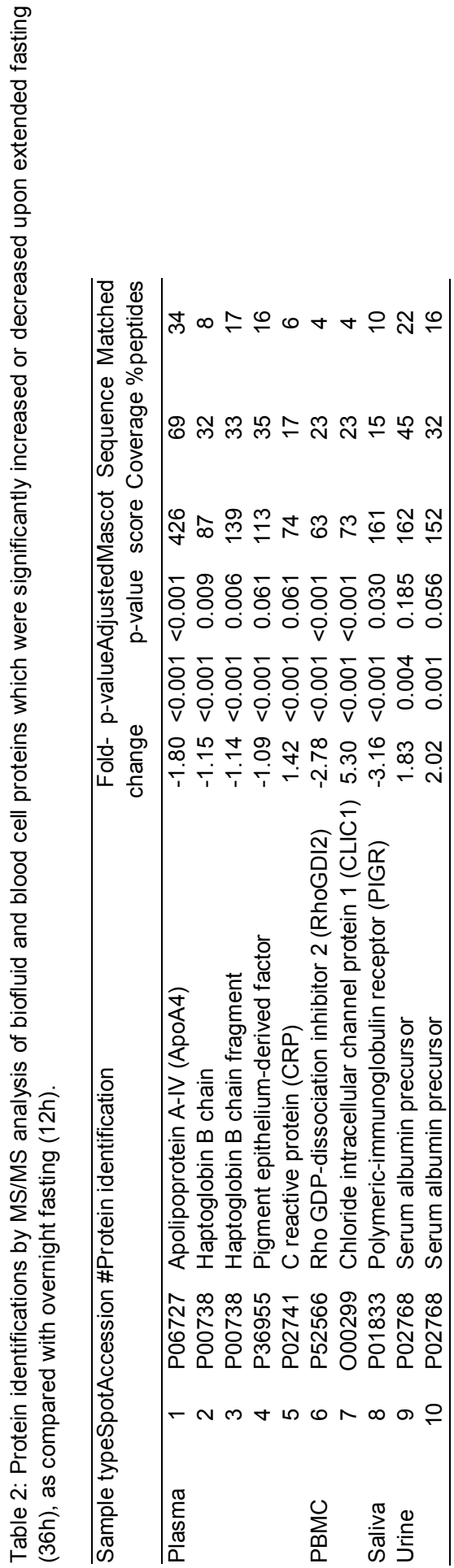


Using the 2D-electrophoresis approach we identified proteins from spots with a relatively highly significant adjusted $p$-value as a result of extended fasting: 5 spots in plasma, 2 spots in PBMC, 1 spot in saliva and 2 spots in urine (see Table 2 and Figure 2). Using the targeted approach, we were able to identify 39 proteins that changed significantly upon $36 \mathrm{~h}$ fasting compared to overnight fasting (Table 3). The chloride intracellular channel protein 1 (CLIC1) in PBMC exhibited a 5.3-fold increase upon the fasting challenge. This was the most pronounced change amongst all proteins (Table 2). C reactive protein (CRP) was detected as increasing in both the plasma 2D proteome and the RBM plasma data set induced by extended fasting (Table 2 and 3 ).

Principal component analysis applied to the multiplex immunoassay (RBM) data set revealed that each of the subjects could be identified based on levels of 89 plasma proteins (Figure 3). It appears that such data can be used to provide a metabolic fingerprint of the individual volunteers participating in this intervention study. However, this demonstrates that the between-subject effects are larger than that of the fasting effect.

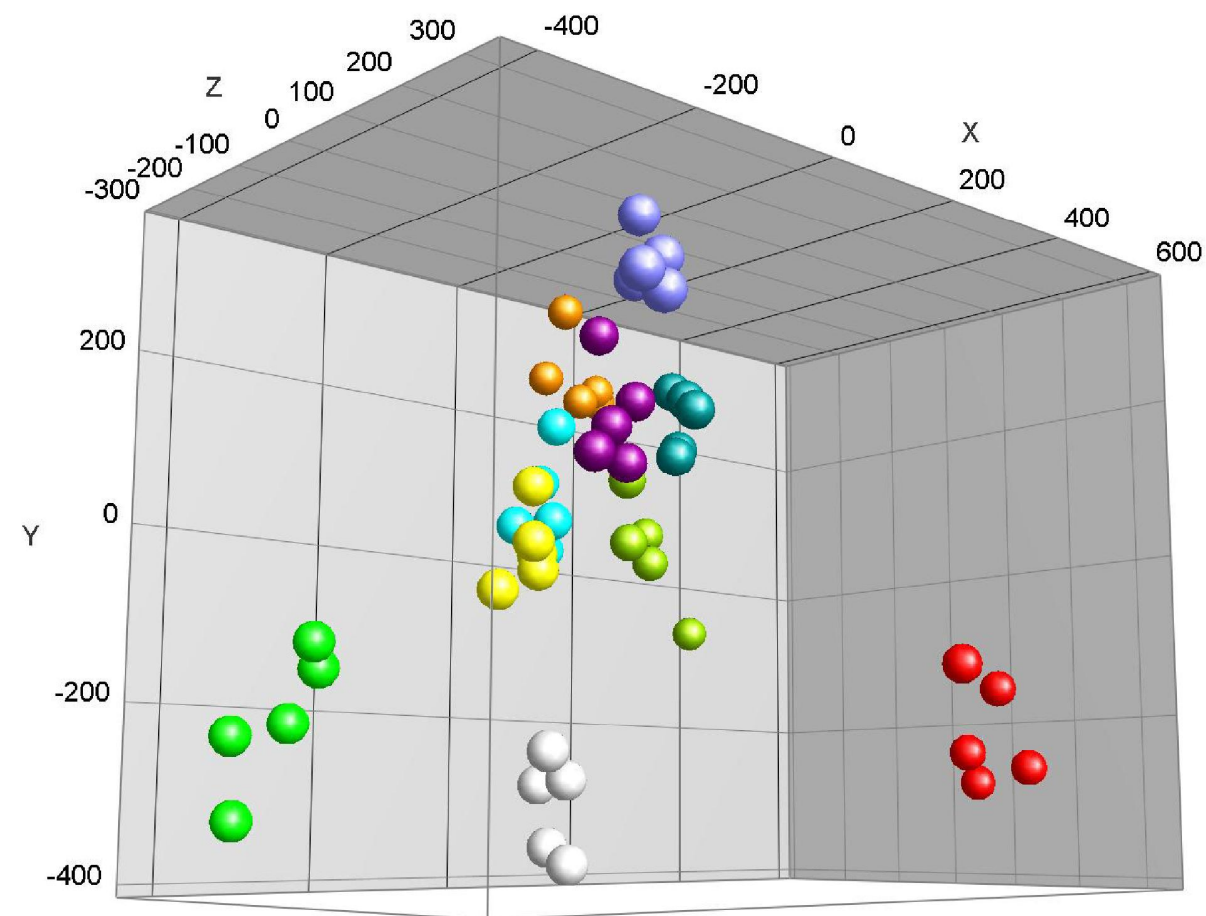

Figure 3: PCA analysis of data obtained from the multiplex immunoassay (RBM). Each color represents a different subject 
Table 3: Plasma proteins of which absolute levels significantly changed due to extended fasting (36h) compared with overnight fasting (12h), as assessed using the multiplex immunoassay (RBM).

\begin{tabular}{|c|c|c|c|c|}
\hline Protein & $\begin{array}{c}\text { Accession } \\
\#\end{array}$ & Fold-change & p-value & $\begin{array}{c}\text { Adjusted } \\
\text { p-value }\end{array}$ \\
\hline IGF-1 & P01343 & -2.72 & $<0.001$ & $<0.001$ \\
\hline Leptin & P41159 & -2.59 & $<0.001$ & $<0.001$ \\
\hline Erythropoietin & P01588 & -1.56 & 0.080 & 0.187 \\
\hline $\lg \mathrm{E}$ & n.a. & -1.54 & 0.002 & 0.013 \\
\hline IL-8 & P10145 & -1.51 & $<0.001$ & 0.001 \\
\hline MMP-3 & P08254 & -1.48 & $<0.001$ & $<0.001$ \\
\hline Thyroid Stimulating Hormone & P01222 & -1.47 & $<0.001$ & $<0.001$ \\
\hline Insulin & P01308 & -1.29 & $<0.001$ & 0.001 \\
\hline Carcinoembryonic Antigen & P06731 & -1.29 & 0.037 & 0.116 \\
\hline IL-1 beta & P01584 & -1.19 & $<0.001$ & $<0.001$ \\
\hline PAI-1 & P05121 & -1.19 & 0.002 & 0.013 \\
\hline Apolipoprotein A-1 (ApoA1) & P02647 & -1.18 & 0.006 & 0.025 \\
\hline MCP-1 & P13500 & -1.17 & $<0.001$ & 0.001 \\
\hline Eotaxin & P51671 & -1.16 & 0.001 & 0.005 \\
\hline VEGF & P15692 & -1.14 & $<0.001$ & $<0.001$ \\
\hline IL-16 & Q14005 & -1.13 & $<0.001$ & 0.002 \\
\hline EGF & $\mathrm{P} 01133$ & -1.12 & 0.085 & 0.190 \\
\hline IL-18 & Q14116 & -1.12 & 0.013 & 0.048 \\
\hline Alpha-Fetoprotein & P02771 & -1.12 & $<0.001$ & $<0.001$ \\
\hline Fatty Acid Binding Protein & P05413 & -1.07 & 0.006 & 0.025 \\
\hline $\lg A$ & n.a. & -1.07 & 0.043 & 0.116 \\
\hline Factor VII (F7) & P08709 & -1.06 & 0.061 & 0.157 \\
\hline Creatine Kinase-MB & P06732 & -1.04 & 0.075 & 0.181 \\
\hline IL-10 & P22301 & -1.04 & 0.041 & 0.116 \\
\hline Glutathione S-Transferase & P09211 & -1.04 & 0.010 & 0.041 \\
\hline Tissue Factor (TF) & P13726 & -1.03 & 0.004 & 0.019 \\
\hline Prostatic Acid Phosphatase & P15309 & -1.03 & 0.018 & 0.067 \\
\hline Alpha-2 Macroglobulin (A2M) & P01023 & 1.02 & 0.021 & 0.072 \\
\hline Complement 3 & P01024 & 1.02 & 0.028 & 0.092 \\
\hline TIMP-1 & P01033 & 1.02 & 0.005 & 0.025 \\
\hline IL-12p70 & P29459 & 1.03 & 0.038 & 0.116 \\
\hline VCAM-1 & P19320 & 1.05 & 0.011 & 0.044 \\
\hline Serum Amyloid P (SAP) & P02743 & 1.07 & 0.072 & 0.179 \\
\hline Lipoprotein (a) & P08519 & 1.09 & 0.041 & 0.116 \\
\hline MIP-1beta & $\mathrm{P} 13236$ & 1.09 & 0.048 & 0.127 \\
\hline TNF-alpha & P01375 & 1.10 & 0.042 & 0.116 \\
\hline EN-RAGE & P80511 & 1.17 & 0.085 & 0.190 \\
\hline Ferritin & P02794 & 1.27 & $<0.001$ & 0.001 \\
\hline C Reactive Protein (CRP) & P02741 & 1.55 & $<0.001$ & 0.002 \\
\hline
\end{tabular}

n.a. $=$ no accession \#

RF analysis applied to the full data set from non-targeted and targeted proteomics applications, revealed that the Rho GDP-dissociation inhibitor 2 (RhoGDI2) in PBMC and the plasma Apolipoprotein A-IV (ApoA4) appeared the most significant biomarkers associated with extended fasting (Figure 4a). RF analysis of the targeted proteomics data set revealed leptin and matrix metalloproteinase-3 (MMP-3) as biomarkers of extended fasting (Figure 4b). 
A

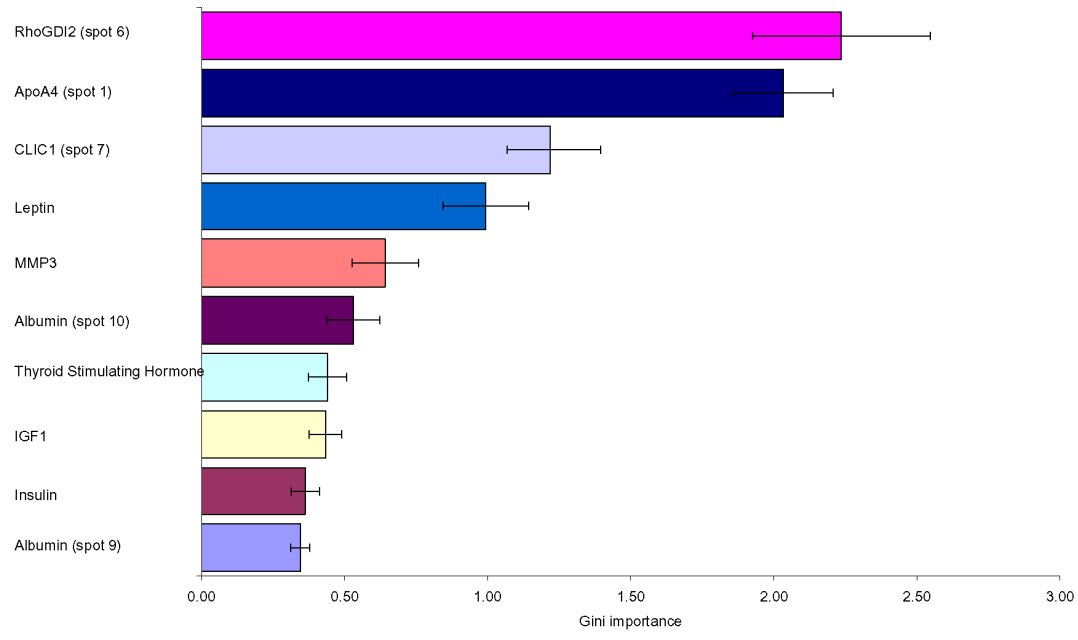

B

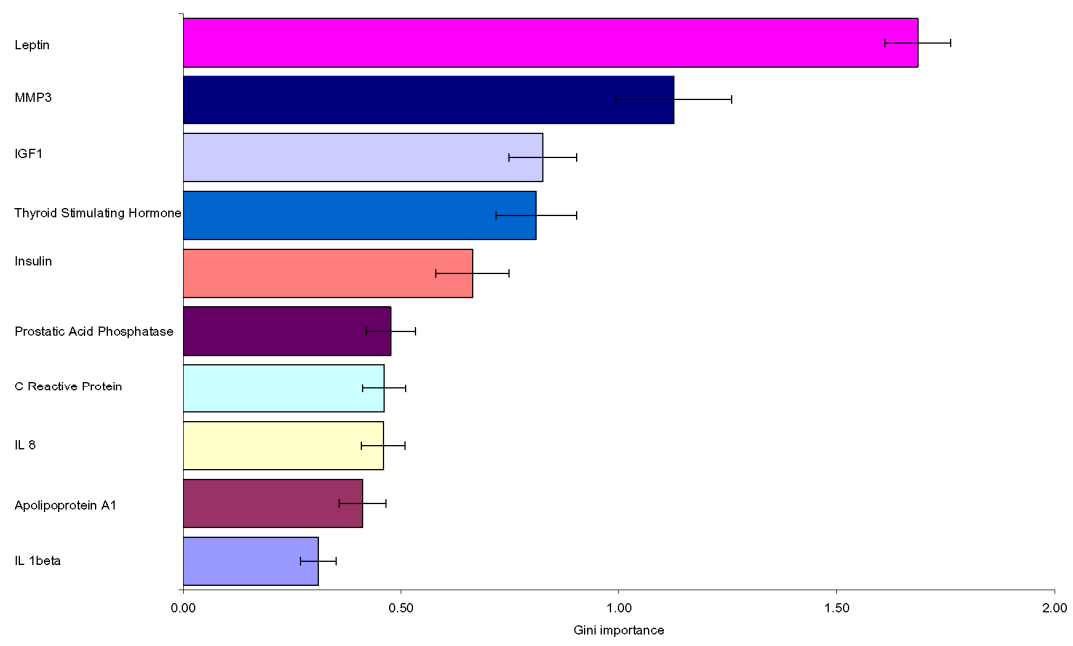

Figure 4: Biomarkers of extended fasting effect calculated by Random Forrest analysis. Panel A: results obtained from analysis of all proteomic data (2D and RBM). Panel B: results obtained from targeted proteomic analysis using multiplex immunoassay (RBM). The spot numbers between brackets refer to those used in Table 2. Proteins without numbers between brackets refer to those used in Table 3. 
Cluster analysis with Pearson correlations between the fold-change in RBM plasma proteins after extended fasting versus overnight fasting is shown in Figure 5. Leptin and Insulin-like growth factor I (IGF-1) are correlated and closely clustered to each other. Both proteins are down-regulated after extended fasting (Table 3). CRP is correlated to changes in alpha-2macroglobulin, serum amyloid $P$ and adiponectin (Figure 5). The close association between CRP, serum amyloid $P$ and alpha-2-macroglobulin is confirmed in the protein-protein interaction network shown in Figure 6. In addition, leptin changes appear directly linked to changes in CRP and alpha-2macroglobulin, whereas MMP-3 appears directly linked to alterations in the tissue inhibitor of metalloproteinase-1 (TIMP-1), monocyte chemotactic protein1 (MCP-1) and plasminogen activator inhibitor-1 (PAl-1).

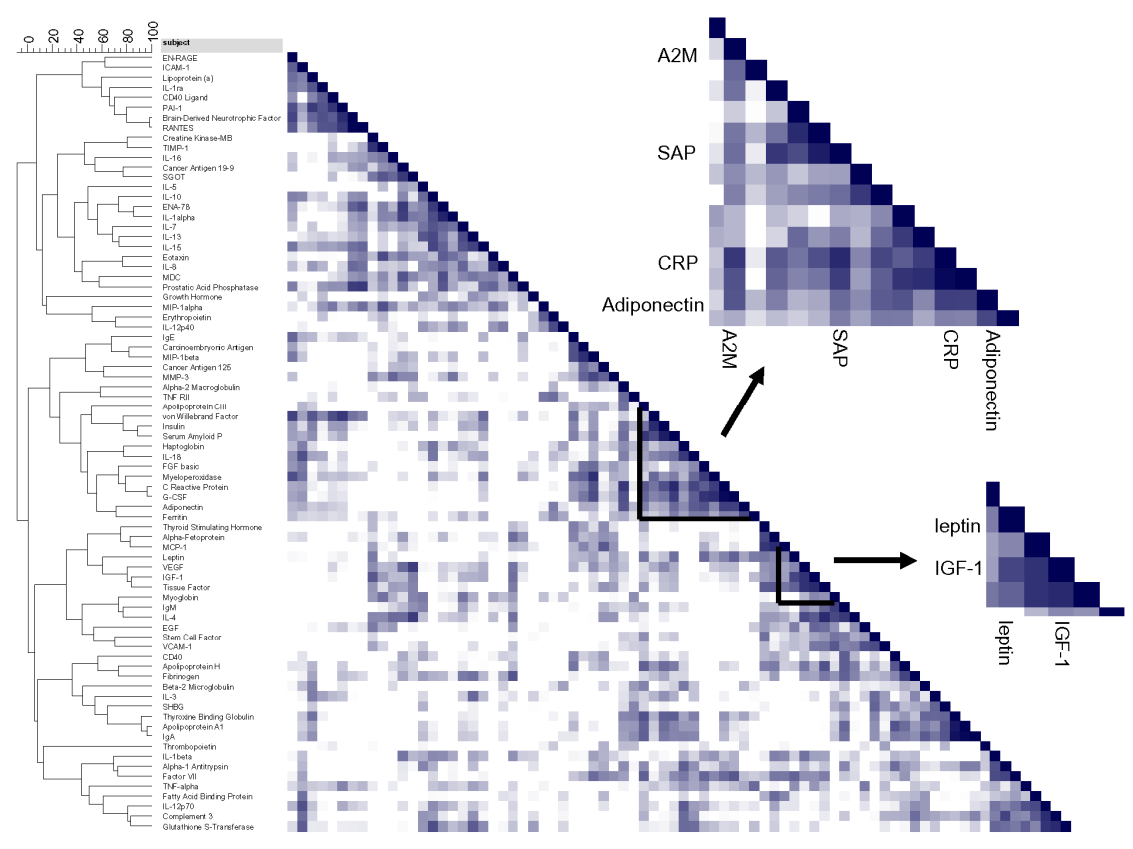

Figure 5: Correlation score on cluster analysis of Heat map of the Pearsons correlations comparing fold-changes in plasma proteins after a $36 \mathrm{~h}$ fasting versus overnight fasting. 


\section{DISCUSSION}

This study, using both non-targeted as well as targeted proteomic approaches applied to biofluids and blood cells to elucidate changes in their proteomes induced by extended fasting, revealed substantial between-subject variability which may mask the true biological effect of fasting on the proteome. This suggests that any nutrigenomic experiment require a sufficient number of replicates and matched samples to identify the usually rather subtle changes that dietary maneuvers may impose. Levels of between-subject variability were higher in all biofluids samples as compared to the cellular proteomes. In this study, PBMC exhibited the largest number of significant changes in protein levels following the extended fast. RF analysis on the entire data set revealed that in PBMC the RhoGDI2 and plasma ApoA4 proteins were the most significant biomarkers for extended fasting. RF analysis of the multiplex immunoassay data set revealed leptin and MMP-3 as potential biomarkers for extended fasting.

It should be noted that the between-subject variation may in part be due to the heterogeneous composition of our study cohort with regard to various parameters, including gender and BMI. Consequently, this type of variability can be reduced by selecting a more homogeneous study population. We observed markedly less inter-individual difference in the PBMC proteome than we observed previously in the PBMC transcriptome of PBMC from human volunteers who were participating in a study with a similar baseline design [17]. In our study $0.4 \%$ of the PBMC proteins detected differed significantly between individuals compared with $39 \%$ of PBMC transcripts [17].

Most interesting biomarkers that are involved in metabolic pathways, as well as those related to inflammation and oxidative stress, are present only in very low concentrations in biosamples. In these cases, their low abundance prevents detection by classical proteomic techniques such as 2D-electrophoresis [18]. Multiplex immunoassays are therefore an interesting alternative because they are more sensitive compared to 2D-electrophoresis [19]. Indeed, a wide range of plasma protein changes caused by extended fasting were detected using the targeted multiplex immunoassay method. However, a big advantage of 2Delectrophoresis is that it can visualize isoforms and possible protein modifications, whereas with an antibody-based approach this depends on the availability of isoform-specific antibodies.

CLIC1 in PBMC was the protein that exhibited the largest fold-change as a result of the extended fasting. In general, chloride channels play important roles in the regulation of cellular excitability, transepithelial transport, cell volume regulation, and acidification of intracellular organelles [20]. CLIC1 is. 

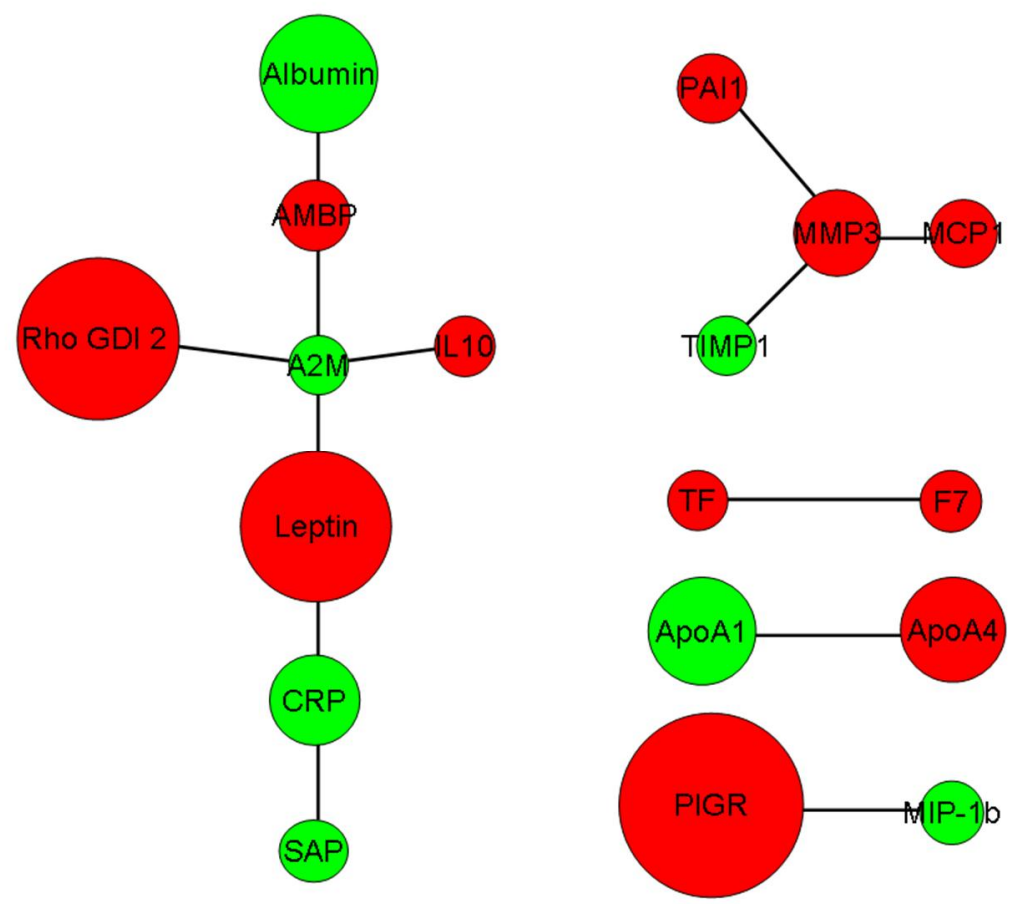

Figure 6: Protein-protein interaction networking based on the outcome of the total dataset. Red represents a decrease and green an increase in protein levels. The size of the circle represents the fold change levels. The short protein names shown in the network refer to Table 2 and 3. Alpha-1microglobulin (AMBP) was down-regulated and ApoA1 was up-regulated in urine, but not significantly (data not shown).

responsible for stabilization of the membrane potential, which could be influenced by the nutrient status in PBMC. Moreover CLIC1 seems to be associated with cellular stress response mechanisms and starvation may be interpreted as a metabolic stress condition [21].

Besides CLIC1, levels of RhoGDI2 and ApoA4 were the best indicators of the extended fasting state based on analysis of all the proteomic data. Insulin has the ability to relocate RhoGDI2 to the membrane [22]. Since plasma glucose and insulin levels are low during fasting, the relative amount of RhoGDI2 in the cytosol of PBMC might be predicted to increase during extended fasting. Since by 2D preferentially cytosolic proteins are detected, RhoGDI2 is expected to rise in spot intensity. However, a decrease was noticed in our experiment indicating that cytosolic RhoGDI2 concentration is influenced by other factors like posttranslational modification or turn-over rate.

ApoA4 is a major component of chylomicrons and is synthesized by the small intestine. It is proposed to represent a circulating satiety signal [23] and after fasting, therefore, may decrease its levels [24]. 
IGF-1, leptin and CRP were the proteins with the biggest negative and positive fold change upon the fasting challenge in the RBM data. Circulating IGF-1 levels are associated with dietary protein intake [25, 26]. This could explain why after an extended fast without protein intake, IGF-1 is decreased [27]. The decrease of leptin is as expected because it is known to be a positive marker for fasting or weight loss [28-30]. Chan et al. [31] have shown that leptin and IGF-1 levels decrease after a $72 \mathrm{~h}$ fasting. Our correlation analysis clustered IGF-1 and leptin suggesting that adipose tissue, as the main source of leptin, and liver, as the origin of circulating IGF-1, undergo metabolic adaptation via a closely linked mechanism. CRP is an acute phase protein and its elevation after this short term fasting might therefore be expected, although after long term fasting or caloric restriction CRP is usually down-regulated [32]. RF analysis applied to the RBM data revealed leptin and MMP-3 as the most obvious biomarkers for a fasting challenge. No direct interaction between leptin and MMP-3 has been reported so far. A possible mechanism could be the inverse correlation between leptin and adiponectin levels $[19,33]$ since the leptin/adiponectin ration changes during extended fasting. Adiponectin by itself has the ability to increase TIMP1, which is able to inhibit the activity of MMPs $[34,35]$. However, adiponectin plasma levels did not change significantly $(p=$ 0.45 ) upon the extended fasting.

Most interestingly, the correlation analysis clustered CRP closely together with adiponectin, serum amyloid $\mathrm{P}$ and alpha-2-macroglobulin. Except for adiponectin, a networking interaction analysis using MiMl, places those proteins together with leptin and RhoGDI2. An interaction between leptin and $\mathrm{CRP}$, which are positively correlated in normal weight, overweight and obese subjects [36], was described by Chen et al [37]. Alpha-2-microglobulin is described as a leptin binding protein [38]. This interaction may be involved in the clearance of leptin by the alpha-2-microglobulin receptor.

Another observation from the networking analysis was an interaction between PAI-1, MMP-3, MCP1 and TIMP1. As mentioned above, TIMP1 inhibits the activity of MMPs [34, 35], whereas both PAI-1 and MCP1 are inactivated through proteolysis mediated by MMP-3 [39, 40]. This interaction between MMP-3 and MCP-1 may be the reason that MMP-3 is ranked relatively high by the RF analysis. An inhibition or decrease of PAI-1 leads to a reduction of fat depots and adipocyte volume [41]. Several studies have shown that PAI-1 is increased in adipose tissue and plasma in obese humans and that plasma PAI1 concentrations decrease after weight loss or fasting [42, 43], which suggests a role for this proteinase inhibitor in the development and maintenance of obesity. Jensen et al. [44] reported that a low glycemic index diet in overweight adults could be beneficial in regulating fasting concentrations of the cardiovascular disease risk factor PAl-1 showing that PAI-1 concentrations are sensitive to the nutritional status. PAI-1, TIMPs and MMPs play a role in 
extracellular matrix remodeling $[41,45,46]$. Interestingly, a correlation has been described between CRP and PAI-1 [47, 48], linking both interaction networks.

\section{CONCLUSIONS}

Both non-targeted and targeted proteomic analysis on a range of human body fluid samples and selected blood cells examining the effect of an extended fasting revealed that there is a considerable between-subject effect with the lowest variability in the PBMC proteome. These cells may therefore be considered as a prime sample source in further nutrigenomic studies when proteomic technologies are applied for biomarker discovery. The antibody based analysis is superior when plasma proteins are analyzed and reveals a distinct metabolic fingerprint that identifies the individuals. The protein panel that characterizes extended fasting by the most significant changes comprises known entities such as leptin, ApoA4 and IGF-1, but also a variety of novel markers including RhoGDI2, CLIC1 and MMP-3. These candidate biomarkers could be of interest in future nutrition studies.

\section{Acknowledgment}

This research was supported by NuGO (The European Nutrigenomics Organization: linking genomics, nutrition and health research; CT-2004505944). The Rowett Institute of Nutrition and Health is funded by the Scottish Government Rural and Environment Research and Analysis Directorate (RERAD). The Institute of Food Research is funded by the Biotechnology and Biological Sciences Research Council (BBSRC). We also thank Barbara Gelhaus for her excellent analysis of the PBMC and urine samples. We thank Ping Wang for the help of the random forests analysis.

\section{References}

1. Kussmann M, Raymond F, \& Affolter M (2006) OMICS-driven biomarker discovery in nutrition and health. Journal of biotechnology 124(4):758-787.

2. de Roos B (2009) Nutrition proteomics and biomarker discovery. Expert review of proteomics 6(4):349-351.

3. de Roos B \& McArdle HJ (2008) Proteomics as a tool for the modelling of biological processes and biomarker development in nutrition research. The British journal of nutrition 99 Suppl 3:S66-71.

4. Johnstone AM (2007) Fasting - the ultimate diet? Obes Rev 8(3):211-222.

5. Bahadori B, McCarty MF, Barroso-Aranda J, Gustin JC, \& Contreras F (2009) A "mini-fast with exercise" protocol for fat loss. Medical hypotheses 73(4):619-622. 
6. Cahill GF, Jr. (2006) Fuel metabolism in starvation. Annual review of nutrition 26:1-22.

7. Baccini M, et al. (2008) The NuGO proof of principle study package: a collaborative research effort of the European Nutrigenomics Organisation. Genes \& nutrition 3(3-4):147-151.

8. Rubio-Aliaga I, et al. (Metabolomics of prolonged fasting in humans: from physiology to individual metabotypes. Metabolomics:accepted.

9. Kussmann M, Rezzi S, \& Daniel H (2008) Profiling techniques in nutrition and health research. Current opinion in biotechnology 19(2):83-99.

10. Crosley LK, et al. (2009) Variation in protein levels obtained from human blood cells and biofluids for platelet, peripheral blood mononuclear cell, plasma, urine and saliva proteomics. Genes \& nutrition 4(2):95-102.

11. de Roos B, et al. (2008) Proteomic methodological recommendations for studies involving human plasma, platelets, and peripheral blood mononuclear cells. Journal of proteome research 7(6):2280-2290.

12. Bouwman F, Suylen D, Renes J, \& Mariman E (2005) Evaluation and improving the success rate of protein identification by peptide mass fingerprinting using matrix-assisted laser desorption/ionization time-of-flight mass spectrometry. Rapid Commun Mass Spectrom 19(17):2465-2468.

13. Cranenburg EC, et al. (2008) The circulating inactive form of matrix Gla Protein (ucMGP) as a biomarker for cardiovascular calcification. Journal of vascular research 45(5):427-436.

14. Fuchs D, Dirscherl B, Schroot JH, Daniel H, \& Wenzel U (2007) Proteome analysis suggests that mitochondrial dysfunction in stressed endothelial cells is reversed by a soy extract and isolated isoflavones. Journal of proteome research 6(6):2132-2142.

15. Breiman L (2001) Random forests. Machine Learning 45(1):5-32.

16. Gao J, et al. (2009) Integrating and annotating the interactome using the MiMl plugin for cytoscape. Bioinformatics (Oxford, England) 25(1):137-138.

17. Eady JJ, et al. (2005) Variation in gene expression profiles of peripheral blood mononuclear cells from healthy volunteers. Physiol Genomics 22(3):402-411.

18. Kenyon GL, et al. (2002) Defining the mandate of proteomics in the post-genomics era: workshop report. Mol Cell Proteomics 1(10):763-780.

19. Schipper HS, et al. (2010) A Multiplex Immunoassay for Human Adipokine Profiling. Clinical chemistry.

20. Nilius B \& Droogmans G (2003) Amazing chloride channels: an overview. Acta physiologica Scandinavica $177(2): 119-147$.

21. Wang P, Bouwman FG, \& Mariman EC (2009) Generally detected proteins in comparative proteomics--a matter of cellular stress response? Proteomics 9(11):2955-2966.

22. Shisheva A, Buxton J, \& Czech MP (1994) Differential intracellular localizations of GDP dissociation inhibitor is oforms. Insulin-dependent redistribution of GDP dissociation inhibitor-2 in 3T3-L1 adipocytes. The Journal of biological chemistry 269(39):23865-23868.

23. Tso P, Chen Q, Fujimoto K, Fukagawa K, \& Sakata T (1995) Apolipoprotein A-IV: a circulating satiety signal produced by the small intestine. Obesity research 3 Suppl 5:689S-695S.

24. Bertile F, Schaeffer C, Le Maho Y, Raclot T, \& Van Dorsselaer A (2009) A proteomic approach to identify differentially expressed plasma proteins between the fed and prolonged fasted states. Proteomics 9(1):148-158.

25. Hoppe C, et al. (2004) Animal protein intake, serum insulin-like growth factor I, and growth in healthy 2.5-y-old Danish children. The American journal of clinical nutrition 80(2):447-452.

26. Hoppe C, et al. (2009) Short-term effects of replacing milk with cola beverages on insulin-like growth factor-I and insulin-glucose metabolism: a $10 \mathrm{~d}$ interventional study in young men. The British journal of nutrition 102(7):1047-1051.

27. Longo VD \& Fontana L (2010) Calorie restriction and cancer prevention: metabolic and molecular mechanisms. Trends in pharmacological sciences 31(2):89-98.

28. Stefan N, Fritsche A, Haring H, \& Stumvoll M (2001) Acute stimulation of leptin concentrations in humans during hyperglycemic hyperinsulinemia. Influence of free fatty acids and fasting. Int $J$ Obes Relat Metab Disord 25(1):138-142.

29. Chan JL, Mietus JE, Raciti PM, Goldberger AL, \& Mantzoros CS (2007) Short-term fastinginduced autonomic activation and changes in catecholamine levels are not mediated by changes in leptin levels in healthy humans. Clinical endocrinology 66(1):49-57.

30. Ahima RS, et al. (1996) Role of leptin in the neuroendocrine response to fasting. Nature 382(6588):250-252. 
31. Chan JL, et al. (2008) Leptin does not mediate short-term fasting-induced changes in growth hormone pulsatility but increases IGF-I in leptin deficiency states. The Journal of clinical endocrinology and metabolism 93(7):2819-2827.

32. Fontana L, Meyer TE, Klein S, \& Holloszy JO (2004) Long-term calorie restriction is highly effective in reducing the risk for atherosclerosis in humans. Proceedings of the National Academy of Sciences of the United States of America 101(17):6659-6663.

33. Matsubara M, Maruoka S, \& Katayose S (2002) Inverse relationship between plasma adiponectin and leptin concentrations in normal-weight and obese women. European journal of endocrinology / European Federation of Endocrine Societies 147(2):173-180.

34. Chen $\mathrm{TH}$, et al. (2006) Evidence for a protective role for adiponectin in osteoarthritis. Biochimica et biophysica acta 1762(8):711-718.

35. Kumada M, et al. (2004) Adiponectin specifically increased tissue inhibitor of metalloproteinase1 through interleukin-10 expression in human macrophages. Circulation 109(17):2046-2049.

36. Shamsuzzaman AS, et al. (2004) Independent association between plasma leptin and Creactive protein in healthy humans. Circulation 109(18):2181-2185.

37. Chen K, et al. (2006) Induction of leptin resistance through direct interaction of C-reactive protein with leptin. Nature medicine 12(4):425-432.

38. Birkenmeier G, Kampfer I, Kratzsch J, \& Schellenberger W (1998) Human leptin forms complexes with alpha 2-macroglobulin which are recognized by the alpha 2-macroglobulin receptor/low density lipoprotein receptor-related protein. European journal of endocrinology / European Federation of Endocrine Societies 139(2):224-230.

39. Lijnen HR, Arza B, Van Hoef B, Collen D, \& Declerck PJ (2000) Inactivation of plasminogen activator inhibitor-1 by specific proteolysis with stromelysin-1 (MMP-3). The Journal of biological chemistry 275(48):37645-37650.

40. McQuibban GA, et al. (2002) Matrix metalloproteinase processing of monocyte chemoattractant proteins generates CC chemokine receptor antagonists with anti-inflammatory properties in vivo. Blood 100(4):1160-1167.

41. Mariman EC \& Wang $P$ (2010) Adipocyte extracellular matrix composition, dynamics and role in obesity. Cell Mol Life Sci 67(8):1277-1292.

42. Mavri A, et al. (2001) Subcutaneous abdominal, but not femoral fat expression of plasminogen activator inhibitor-1 (PAI-1) is related to plasma PAl-1 levels and insulin resistance and decreases after weight loss. Diabetologia 44(11):2025-2031.

43. Murakami T, et al. (2007) Impact of weight reduction on production of platelet-derived microparticles and fibrinolytic parameters in obesity. Thrombosis research 119(1):45-53.

44. Jensen L, et al. (2008) A low-glycemic-index diet reduces plasma plasminogen activator inhibitor-1 activity, but not tissue inhibitor of proteinases-1 or plasminogen activator inhibitor-1 protein, in overweight women. The American journal of clinical nutrition 87(1):97-105.

45. Baker EA \& Leaper DJ (2003) The plasminogen activator and matrix metalloproteinase systems in colorectal cancer: relationship to tumour pathology. Eur J Cancer 39(7):981-988.

46. Chavey C, et al. (2003) Matrix metalloproteinases are differentially expressed in adipose tissue during obesity and modulate adipocyte differentiation. The Journal of biological chemistry 278(14):11888-11896.

47. Kraja AT, et al. (2007) Do inflammation and procoagulation biomarkers contribute to the metabolic syndrome cluster? Nutrition \& metabolism 4:28.

48. Gnacinska M, Malgorzewicz S, Guzek M, Lysiak-Szydlowska W, \& Sworczak K (2010) Adipose tissue activity in relation to overweight or obesity. Endokrynol Pol 61(2):160-168. 


\section{Chapter 3}

\section{The physiologic effects of caloric restriction are reflected in the in vivo adipocyte- enriched proteome of overweight/obese subjects}

Freek G. Bouwman ${ }^{1}$, Mandy Claessens ${ }^{1}$, Marleen A. van Baak ${ }^{1}$, Jean-Paul Noben ${ }^{2}$, Ping Wang ${ }^{1}$, Wim H.M. Saris ${ }^{1}$ \& Edwin C.M. Mariman ${ }^{1}$

${ }^{1}$ Department of Human Biology, Nutrition and Toxicology Research Institute Maastricht (NUTRIM), Maastricht University, Maastricht, The Netherlands and ${ }^{2}$ Hasselt University, Biomedical Research Institute and Transnational University Limburg, School of Life Sciences, Diepenbeek, Belgium

Journal of Proteome Research, 2009, 8 (12) p. 5532-5540 


\section{ABSTRACT}

We have applied our recently designed proteomics apparoach to search for protein changes in the in vivo adipocyte-enriched proteome from 8 overweight/obese subjects who underwent an intervention of 5 weeks of a very low calorie diet followed by 3 weeks of a normal diet. On average, persons lost $9.5 \mathrm{~kg}$ body weight largely contributed by the loss of fat mass $(7.1 \mathrm{~kg})$. Various parameters of adiposity and lipid metabolism changed significantly. Proteomics analysis revealed 6 significantly changed proteins. Analysis indicates that fructose-bisphosphate aldolase $C$ and tubulin beta 5 are potential biomarkers for the present intervention. Further, identified proteins indicate a reduced intracellular scaffolding of GLUT4 (ALDOC, TUBB5, ANXA2), an increased uptake of fatty acids (FABP4), an improved inflammatory profile of the adipose tissue (ApoA1, AOP1) and a change in fat droplet organization (vimentin). Correlation analysis between changes in protein spot intensities and parameters of adiposity or lipid metabolism points to a link between aldoketoreductase 1C2 and parameters of adiposity, between FABP4 and parameters of lipid metabolism, and between proteins for beta-oxidation (HADH, ACADS, ACAT1) and FFA levels. Altogether, our findings underscore the potential value of in vivo proteomics for human intervention studies. 


\section{INTRODUCTION}

The worldwide increasing prevalence of obesity and its consequences for human health request novel ways of prevention and treatment. A better insight in the underlying physiologic and molecular processes is therefore required. Obesity is characterized by the accumulation of excessive fat mass in the body, which is associated with morphological, histological and functional changes of the adipose tissue including fibrosis, infiltration of macrophages and changes in the adipokine profile [1-5]. Some of those changes are believed to increase the risk for obesity-associated diseases like type II diabetes and cardiovascular disorders. Caloric restriction is one way to (partly) ameliorate those adverse conditions [6-8].

The application of proteomics techniques is a welcome new approach to obtain an integrative view of the molecular dynamics of adipose tissue during weight regulation. However, tissue samples like adipose tissue biopsies are collections of various cell types, each with specific functions. As such, the use of tissue samples interferes with the possibility to study cell-type specific processes. Obtaining cell-type specific information from a tissue sample is one of the major challenges of experimental omics-approaches.

Recently, we have designed a proteomics approach that looks more specifically at adipocyte protein regulation in human adipose tissue biopsies by defining the adipocyte-enriched spots in the 2D-tissue proteome using a subtraction protocol[9]. In this protocol protein spots on a 2D-gel of the fat biopsy are regarded adipocyte-derived if the spots are present on a matched 2D-gel of purified adipocyte, but not present on a matched 2D-gel of blood cells. Further, in the present study adipocyte-enriched spots were checked for absence of platelet-derived proteins [10]. In that way differential proteins were identified in adipose tissue that complied with the physiological differences categorizing subjects as high- or low fat-oxidizers [9]. In the present study we have used this protocol to search for diet-induced changes in the in vivo adipocyte-enriched proteome. To this end, abdominal subcutaneous adipose tissue biopsies were taken from overweight/obese persons who were subjected for 5 weeks to a very low calorie diet (VLCD) followed by 3 weeks on a normal diet. Here we report the analysis of the subcutaneous adipocyte-enriched proteome before and after this 8 weeks intervention in relation to the physiological changes. 


\section{EXPERIMENTAL PROCEDURES}

\section{Subjects selection and experimental design}

Four male and four female overweight and obese subjects (BMl $\geq 27 \mathrm{~kg} / \mathrm{m}^{2}$ ), aged 30-60 years, willing to undergo adipose tissue biopsies, were recruited from a study that investigated the role of dietary protein content for long-term weight maintenance after weight loss. An extensive description of the design of this study has been published previously [11]. In short, subjects underwent a brief medical screening examination, including a medical history, routine physical examination and a fasting blood sample was collected. Subjects had to be weight stable over the 2 months before enrollment. Subjects were excluded if fasting glucose (> $6 \mathrm{mmol} / 1)$, triglycerides $(>2.3 \mathrm{mmol} / 1)$ or total cholesterol levels (> $6.5 \mathrm{mmol} / 1)$ were increased, or when diastolic blood pressure exceeded $100 \mathrm{mmHg}$. Furthermore, subjects were excluded during the study when they were unable to lose at least $5 \%$ of their initial body weight (BW) during the weight loss period. Body composition was determined by measuring body weight in air and underwater on a digital balance. Lung volume was measured simultaneously with the helium dilution technique using a spirometer. The body density was used to calculate body fat according to the twocompartment model as described by Siri [12] The Medical Ethics Committee of the Maastricht Academic Hospital and University approved the study and all subjects gave their written informed consent before entering the study.

After baseline measurements of anthropometric and physiologic parameters, collection of fasting blood samples and a biopsy from the abdominal subcutaneous adipose tissue, subjects started a 5-week VLCD period. During this period they consumed a diet providing only 500 kcal per day (Modifast, Nutrition et Sante', France). Subjects were allowed to eat an unrestricted amount of vegetables (all vegetables except pulse crops). During week 6, the VLCD was gradually replaced by normal ad libitum meals and protein or carbohydrate supplements were gradually introduced. All subjects received dietary counseling by a dietician and were advised to limit their fat intake to approximately $30 \%$ of energy intake. Measurements of anthropometric and physiological variables were performed and fasting blood samples were collected in week 6 . In order to make the comparison in an energy balanced situation before and after the weight loss period, the second adipose tissue biopsy was taken three weeks after returning to a normal diet at week 8 in the morning after an overnight fast. 


\section{Fat biopsy}

Abdominal subcutaneous adipose tissue biopsies (approximately $1.5 \mathrm{~g}$ ) were obtained from the para-umbilical region by needle liposuction under local anesthesia (2\% lidocaine with adrenaline 1:80000, AstraZeneca BV, The Netherlands). The tissue was immediately washed in cold saline, frozen in liquid nitrogen and stored at $-80^{\circ} \mathrm{C}$ until protein isolation.

\section{Sample preparation}

Fat tissue biopsy

About $350 \mathrm{mg}$ tissue from the biopsy was washed in PBS to get rid of the major part of blood, frozen again in liquid nitrogen and grinded in a mortar. The powder was dissolved in $200 \mu \mathrm{l} 8 \mathrm{M}$ urea, $2 \%$ w/v CHAPS, $65 \mathrm{mM}$ DTT per 100 $\mathrm{mg}$ biopsy. The homogenate was vortexed for 5 minutes and centrifuged at $20000 \mathrm{~g}$ for 30 minutes at $10^{\circ} \mathrm{C}$. The supernatant containing the adipose tissue proteome was carefully collected and aliquots were stored at $-80^{\circ} \mathrm{C}$.

\section{Purified adipocytes}

From a biopsy of a subject not taking part in the intervention study adipocytes to be used in the subtraction procedure were isolated exactly as described before [9]. These isolated purified adipocytes were resuspended in $8 \mathrm{M}$ urea, $2 \% \mathrm{w} / \mathrm{v}$ CHAPS, $65 \mathrm{mM}$ DTT. Adipocytes were lysed by subjecting them to three cycles of freeze-thawing in liquid nitrogen. The homogenate was vortexed for 1 minute and centrifuged at $20000 \mathrm{~g}$ for 30 minutes at $10^{\circ} \mathrm{C}$. The supernatant was carefully collected and aliquots were stored at $-80^{\circ} \mathrm{C}$.

\section{Blood cells}

From an EDTA containing blood sample of a subject not taking part in the intervention study blood cells were isolated to be used in the subtraction procedure. First, the blood sample was centrifuged at $1000 \mathrm{~g}$ at $4^{\circ} \mathrm{C}$ for $10 \mathrm{~min}$. Afterwards plasma was discarded and erythrocytes were mixed with the buffy coat. This mixture was washed 3 times with $0.9 \% \mathrm{NaCl}$ buffered with PBS. Blood cells were resuspended in $8 \mathrm{M}$ urea, $2 \% \mathrm{w} / \mathrm{v}$ CHAPS and $65 \mathrm{mM}$ DTT and they were lysed by subjecting them to three cycles of quick freezing in liquid nitrogen and subsequent thawing. The homogenate was vortexed for 1 minute and centrifuged at $20000 \mathrm{~g}$ for 30 minutes at $10^{\circ} \mathrm{C}$. The supernatant was carefully collected and aliquots were stored at $-80^{\circ} \mathrm{C}$.

Protein concentration in all samples was determined by a Bradford based protein assay [13]. 


\section{D-electrophoresis}

From all 16 biopsy samples $150 \mu \mathrm{g}$ of total protein was loaded for the first dimension separation. One gel was run with the protein from purified adipocytes and from blood cell proteins. Isoelectric focusing was performed on an IPG PHOR electrophoresis unit (Amersham Biosciences) at $20^{\circ} \mathrm{C}$. Immobiline Dry Strips ( $\mathrm{pH}$ 3-10 Linear, $24 \mathrm{~cm}$ long) were rehydrated overnight in $500 \mu \mathrm{l}$ of $8 \mathrm{M}$ urea, $2 \% \mathrm{w} / \mathrm{v}$ CHAPS, $65 \mathrm{mM}$ DTT, 0.5\% v/v IPG buffer $\mathrm{pH} 3-10$ Linear at $30 \mathrm{~V}$. Isoelectric focusing was performed using the following program: $500 \mathrm{~V}$ for $1 \mathrm{~h}$, $1000 \mathrm{~V}$ for $1 \mathrm{~h}, 1000-8000 \mathrm{~V}$ for $2 \mathrm{~h}$ and a final step of $8000 \mathrm{~V}$ for $6.5 \mathrm{~h}$. After focusing, IPG strips were equilibrated for 15 minutes in $50 \mathrm{mM}$ Tris- $\mathrm{HCl}, \mathrm{pH} 6.8$, $6 \mathrm{M}$ urea, $30 \% \mathrm{v} / \mathrm{v}$ glycerol, $2 \% \mathrm{w} / \mathrm{v}$ SDS, $1 \% \mathrm{w} / \mathrm{v}$ DTT and for 15 minutes in 50 $\mathrm{mM}$ Tris- $\mathrm{HCl}, \mathrm{pH} 6.8,6 \mathrm{M}$ urea, $30 \% \mathrm{v} / \mathrm{v}$ glycerol, $2 \% \mathrm{w} / \mathrm{v}$ SDS, $2.5 \% \mathrm{w} / \mathrm{v}$ iodoacetamide, and were placed onto a slab gel and sealed with a $0.5 \% \mathrm{w} / \mathrm{v}$ agarose solution in Laemmli buffer with a trace of bromophenol blue. The second-dimension run was carried out on $12.5 \%$ SDS-PAGE gels. Electrophoresis was conducted at a constant voltage of $200 \mathrm{~V}$ for $5 \mathrm{~h}$ in a $24 \mathrm{~cm}$ Dodeca Cell (Bio-Rad) [14-16].

These gels were stained with Flamingo fluorescent gel stain according to the manufacturer's protocol. Gel images were obtained with a FX Molecular Imager (Bio-Rad). Spot detection and matching was performed with the PDQuest v7.3 software package (Bio-Rad). Gel images were normalized to the adipocyteenriched spots. Fold changes were obtained by dividing the average spot intensity $(n=8)$ of the after diet group by that of the before diet group. Molecular weight values were estimated using standard MW-markers.

\section{In-gel digestion}

Protein spots were excised from gels using an automated spot cutter (Bio-Rad) and processed on a MassPREP digestion robot (Waters, Manchester UK). A solution of $50 \mathrm{mM}$ ammonium bicarbonate in $50 \% \mathrm{v} / \mathrm{v}$ ACN was used for destaining. Cysteines were reduced with $10 \mathrm{mM}$ DTT in $100 \mathrm{mM}$ ammonium bicarbonate for 30 minutes followed by alkylation with $55 \mathrm{mM}$ iodoacetamide in $100 \mathrm{mM}$ ammonium bicarbonate for 20 minutes. Spots were washed with 100 $\mathrm{mM}$ ammonium bicarbonate to remove excess reagents and were subsequently dehydrated with $100 \%$ acetonitrile. Trypsin $(6 \mathrm{ng} / \mu \mathrm{l})$ in $50 \mathrm{mM}$ ammonium bicarbonate was added to the gel plug and incubation was performed at $37^{\circ} \mathrm{C}$ for $5 \mathrm{~h}$. Peptides were extracted in $30 \mu \mathrm{l}$ of $1 \%(\mathrm{v} / \mathrm{v})$ formic acid / $2 \%(\mathrm{v} / \mathrm{v})$ acetonitrile in water for 30 minutes at room temperature. A second extraction was performed using $24 \mu \mathrm{l}$ of $50 \%(\mathrm{v} / \mathrm{v})$ acetonitrile in water for 20 minutes at room temperature $[16,17]$. 


\section{Mass spectrometry}

For MALDI-TOF mass spectrometry $1.5 \mu \mathrm{l}$ of peptide mixture and $0.5 \mu \mathrm{l}$ matrix solution $(2.5 \mathrm{mg} / \mathrm{ml} \alpha$-cyano-4-hydroxycinnamic acid in $50 \%$ acetonitrile/ $0.1 \%$ TFA) were spotted automatically onto a 96 well-format target plate. Spots were allowed to air dry for homogeneous crystallization. Spectra were obtained using an M@LDI-LR mass spectrometer (Waters). The instrument was operated in positive reflector mode. Acquisition mass range was 800-3500 Da. The instrument was calibrated on 10-12 reference masses from a tryptic digest of alcohol dehydrogenase. In addition, a near point lockmass correction for each sample spot was performed using adrenocorticotropic hormone fragment 18-39 $(\mathrm{MH}+2465.199)$ to achieve maximum mass accuracy. Typically 120 shots were combined and background subtracted. A peptide mass list was generated by Masslynx v4.0 for the subsequent database search [16, 17].

Samples that could not be identified via MALDI-TOF MS were further analysed by nano liquid chromatography tandem mass spectrometry (LC-MSMS) on a LCQ Classic (ThermoFinnigan) [18]. Denovo sequencing of ApoA1 was performed on a MALDI-TOF/TOF mass spectrometer (4800 MALDI TOF/TOF analyzer, Applied Biosystems).

\section{Database search}

The peptide mass list was searched with the Mascot search engine (version 2.2.04; Matrix Science, London, UK) against the Swiss-Prot database (SwissProt release 56.5; 402482 sequences) for protein identification. One miss-cleavage was tolerated, carbamidomethylation was set as a fixed modification and oxidation of methionine as an optional modification. The peptide mass tolerance was set to $100 \mathrm{ppm}$. No restrictions were made on the protein molecular weight and the isoelectric point. A protein was regarded identified when it had a significant Mascot probability score $(p<0.05)$ [17].

\section{Western Blotting}

Samples with equal amount of protein were run on a $12 \%$ SDS polyacrylamide gel (180 V, Criterion Cell; Bio-Rad, Hercules, CA), then were transferred (90 $\mathrm{min}, 100 \mathrm{~V}$, Criterion blotter; Bio-Rad) to $0.45-\mathrm{mm}$ nitrocellulose membranes. After Ponceau $S$ staining and destaining, membranes were blocked in $5 \%$ nonfat dry milk power (NFDM; Bio-Rad) in Tris-buffered saline containing $0.1 \%$ Tween 20 (TBST) for $1 \mathrm{~h}$. Thereafter, the three blots were incubated respectively with the primary antibody's against ApoA1 (1:1000 dilution, Santa Cruz), Fructose-bisphosphate aldolase C (1:250 dilution, Santa Cruz) and 
Tubulin beta (1:500 dilution, Cell signaling) in 5\% NFDM-TBST overnight at $4^{\circ} \mathrm{C}$ on a shaker. Thereafter the blots were washed three times for $10 \mathrm{~min}$ in TBST, then incubated for $1 \mathrm{~h}$ with a 1:10,000 dilution of the horseradish peroxidaseconjugated secondary antibody (DAKO) in 5\% NFDM-TBST. The blots were washed three times for $10 \mathrm{~min}$ in TBST. A CCD camera (XRS-system, Biorad) was used to detect immunoreactive bands using chemiluminescent substrate (SuperSignal CL; Pierce). The quantification was performed with the program Quantity One version 4.6.5 (Bio-Rad). $\beta$-Actin was used to standardize for the amount of protein loaded [19].

Table 1: Physiologic measurements (mean \pm SEM) before and after the diet intervention $(n=8)$.

\begin{tabular}{lccc}
\hline \multicolumn{1}{c}{ variable } & week 0 & week 6 & P value $^{*}$ \\
\hline Body weight $(\mathrm{kg})$ & $99.7 \pm 6.5$ & $90.2 \pm 6.0$ & $<0.001$ \\
Fat mass $(\mathrm{kg})$ & $37.5 \pm 2.8$ & $30.4 \pm 3.0$ & $<0.001$ \\
Fat-free mass $(\mathrm{kg})$ & $62.3 \pm 4.9$ & $59.8 \pm 4.1$ & 0.025 \\
BMI $(\mathrm{kg} / \mathrm{m} 2)$ & $32.6 \pm 1.1$ & $29.5 \pm 1.2$ & $<0.001$ \\
Waist circumference $(\mathrm{cm})$ & $111.6 \pm 4.3$ & $101.9 \pm 4.2$ & $<0.001$ \\
Hip circumference $(\mathrm{cm})$ & $115.9 \pm 3.8$ & $107.5 \pm 4.2$ & 0.011 \\
Systolic blood pressure $(\mathrm{mm} \mathrm{Hg})$ & $138.1 \pm 8.9$ & $132.3 \pm 9.5$ & 0.372 \\
Diastolic blood pressure $(\mathrm{mm} \mathrm{Hg})$ & $91.3 \pm 5.0$ & $86.3 \pm 1.9$ & 0.251 \\
Glucose $(\mathrm{mmol} / \mathrm{L})$ & $5.10 \pm 0.33$ & $4.73 \pm 0.30$ & 0.011 \\
Insulin $(\mu \mathrm{U} / \mathrm{mL})$ & $17.6 \pm 2.5$ & $13.1 \pm 2.0$ & 0.069 \\
Glucagon $(\mathrm{pg} / \mathrm{mL})$ & $73.5 \pm 11.2$ & $53.2 \pm 6.7$ & 0.027 \\
Total cholesterol $(\mathrm{mmol} / \mathrm{L})$ & $4.58 \pm 0.40$ & $3.84 \pm 0.36$ & 0.007 \\
HDL cholesterol $(\mathrm{mmol} / \mathrm{L})$ & $1.01 \pm 0.08$ & $1.02 \pm 0.06$ & 0.887 \\
LDL cholesterol $(\mathrm{mmol} / \mathrm{L})$ & $3.03 \pm 0.39$ & $2.28 \pm 0.31$ & 0.003 \\
Triglycerides $(\mathrm{mmol} / \mathrm{L})$ & $1.68 \pm 0.27$ & $1.16 \pm 0.15$ & 0.116 \\
FFA $(\mathrm{mmol} / \mathrm{L})$ & $0.781 \pm 0.122$ & $0.415 \pm 0.043$ & 0.007 \\
Leptin $(\mathrm{ng} / \mathrm{mL})$ & $47.2 \pm 20.2$ & $22.5 \pm 11.3$ & 0.032 \\
Adiponectin $(\mu \mathrm{g} / \mathrm{mL})$ & $12.8 \pm 3.6$ & $16.1 \pm 4.4$ & 0.304 \\
\hline
\end{tabular}

* Paired-sample t-test week 0 vs week 6

\section{Statistical analysis}

Physiological data are presented as mean \pm SEM. The changes of physiological data and spot intensities between before and after diet intervention groups were analyzed by paired-samples t-tests. Changes in leptin concentrations were logtransformed because of non-normal distribution. All other changes in physiologic measurements were normally distributed. For the associations between the change of protein level and change of physiological parameters, Pearson correlation coefficients were calculated. A P-value $<0.05$ was considered statistically significant. These statistical analyses were done using the SPSS v15.0 statistical software. The FDR of Multiple testing was calculated using the statistical software R v2.8.1 package fdr tool [20]. 


\section{RESULTS}

\section{Subject characteristics}

Adipose tissue biopsies were derived from eight overweight/obese subjects, four males and four females, before and after a dietary intervention that consisted of a VLCD for 5 weeks followed by 3 weeks of adaptation to a weight maintenance diet. Physiological parameters were determined at the start of the intervention and at week 6 , i.e. after one week adaptation to a weight maintenance diet to avoid the influence of a negative energy balance. The physiological results are summarized in Table 1. A significant reduction of BMI was noticed due to an average weight loss of $9.5 \mathrm{~kg}$. Of this, roughly $7 \mathrm{~kg}$ had to be ascribed to loss of fat mass and $2.5 \mathrm{~kg}$ to loss of fat-free mass (Table 1). This was accompanied by a reduction of the leptin level. There was a significant decrease in plasma glucose together with a trend for a lower insulin level. Total plasma cholesterol, LDL-cholesterol and FFA levels were significantly lower after the intervention. No significant difference was noticed for the plasma HDLcholesterol and triglyceride levels. No gender effects were observed. Altogether, this indicates an increase in insulin sensitivity and an improved lipid profile due to the VLCD intervention.

\section{D-gelelectrophoresis}

Proteins were isolated from adipose tissue biopsies and separated by 2Dgelelectrophoresis as described above. On average 516 valid protein spots were detected on the gel. In parallel, proteins isolated from purified human adipocytes and from total blood cells were separated (Figure 1). The latter patterns were then used to select the spots with an increased likelihood to be derived from adipocyte-expressed proteins [9]. In this way 101 adipocytederived spots were selected, which were subsequently used for normalizing the individual gel-patterns. All 101 spots were cut from the gels and subjected to 


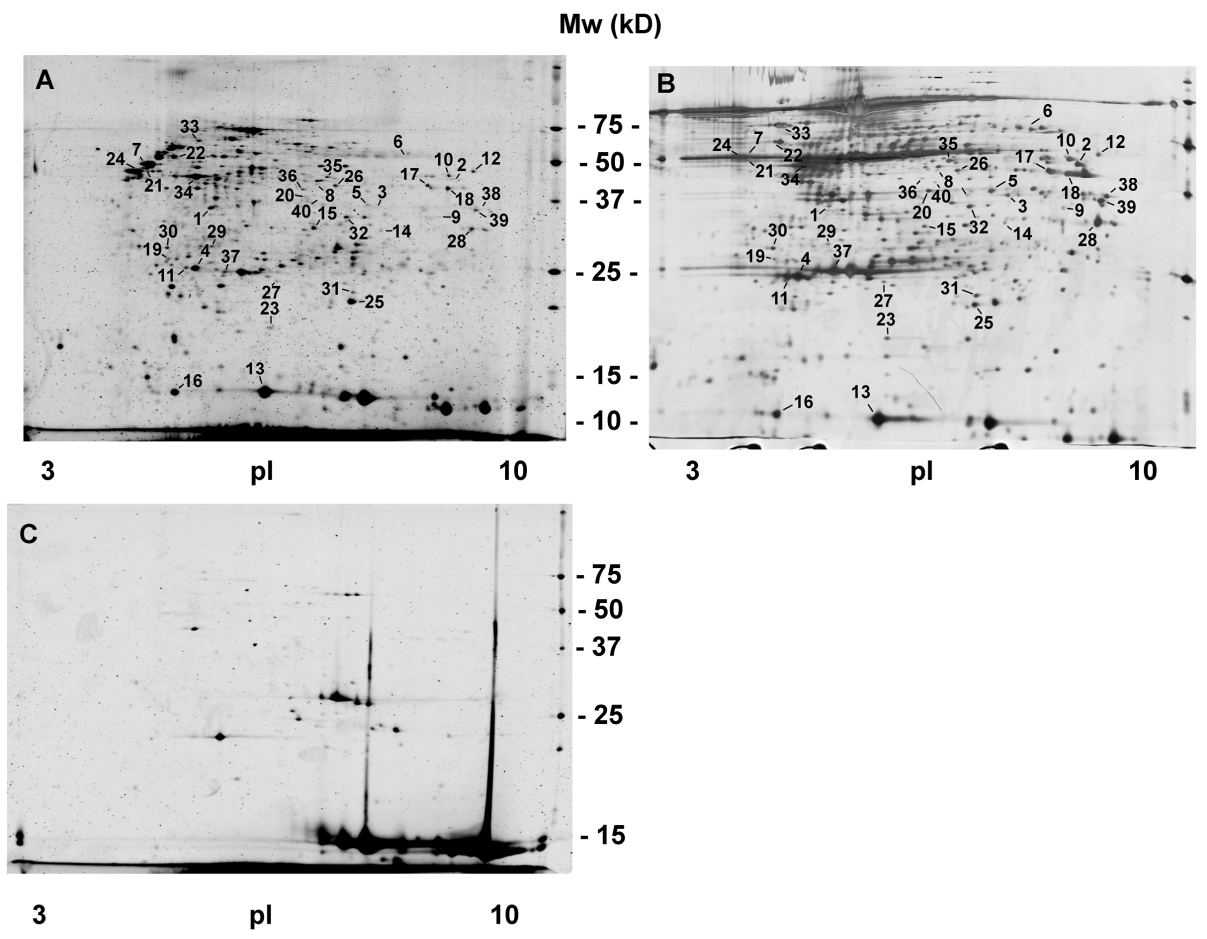

Figure 1. Identified proteins marked on a $2 \mathrm{D}$ gel from a subcutaneous fat tissue biopsy $(A)$, from primary adipocytes purified from a subcutaneous fat tissue biopsy (B) and from isolated blood cells (C). Numbers on the gel images correspond to the spot numbers in Table 2.

tryptic digestion followed by mass spectrometry to identify the protein. From the 101 spots, for 40 the protein could be identified (Table 2) belonging to 34 different proteins. In Table 2 the identified proteins are divided in three groups according to their change in relative abundance. Seven spots showed a significant change $(p<0.05)$ with as identified proteins: tubulin beta 5 (TUBB5), apolipoprotein $A 1$ (ApoA1), fatty acid binding protein 4 (FABP4), thioredoxindependent peroxide reductase (AOP1), annexin A2 (ANXA2, N-term.) and fructose-bisphosphate aldolase C (ALDOC).

Despite the fact that ApoA1 is not produced by adipocytes, two spots of ApoA1 that changed in relative abundance after the intervention were detected in adipose tissue (spot 4 and 12 in Figures $2 \mathrm{~A}$ and 2B). Therefore, we looked in detail for the presence of those spots in total blood cells and isolated adipocytes. As can be seen in Figures $2 \mathrm{C}$ and 2D, the spots are not observed in blood cells, but do appear in the sample of isolated adipocytes. 
A
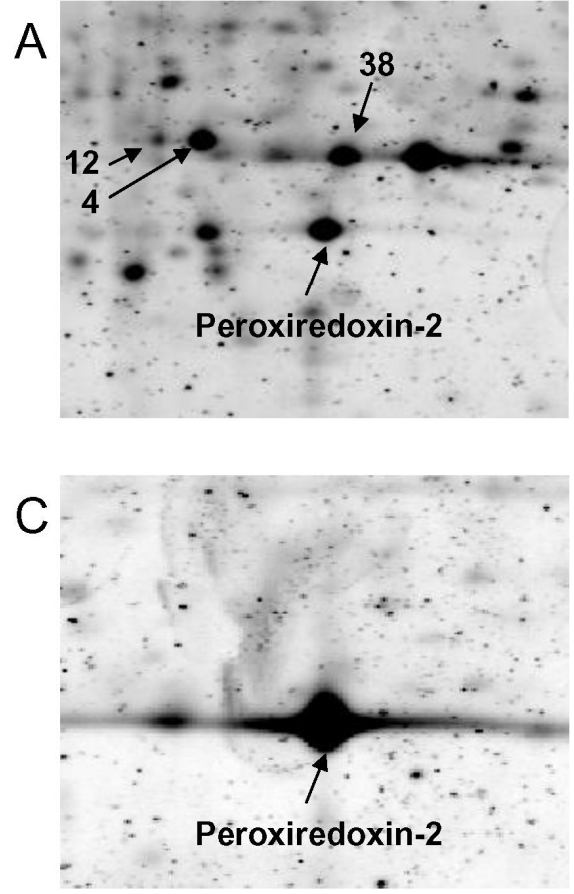
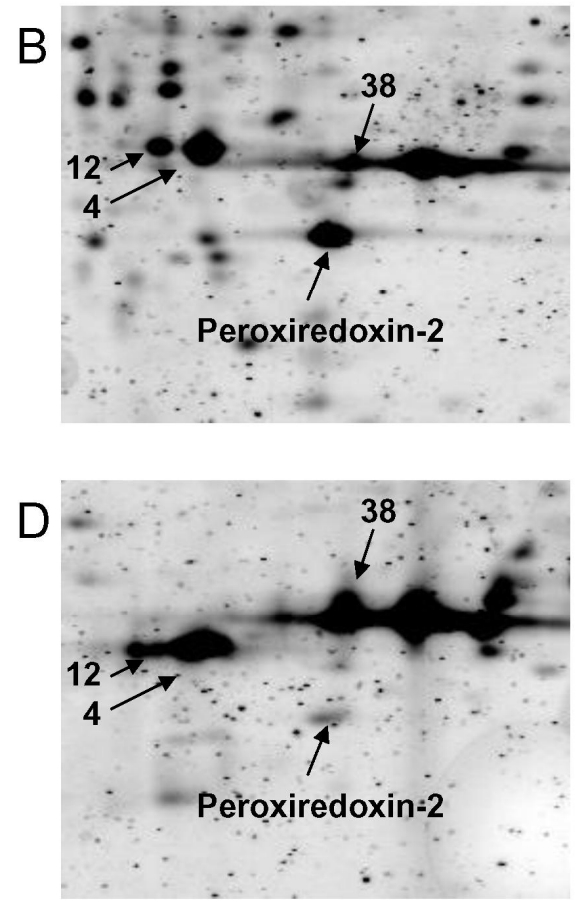

Figure 2: Zoom figure of ApoA1 region: (A) Fat tissue biopsy before diet intervention, (B) Fat tissue biopsy after diet intervention, (C) Isolated blood cells and (D) purified adipocytes from fat tissue biopsy. The spot numbers refer to identifications in Table 2. 


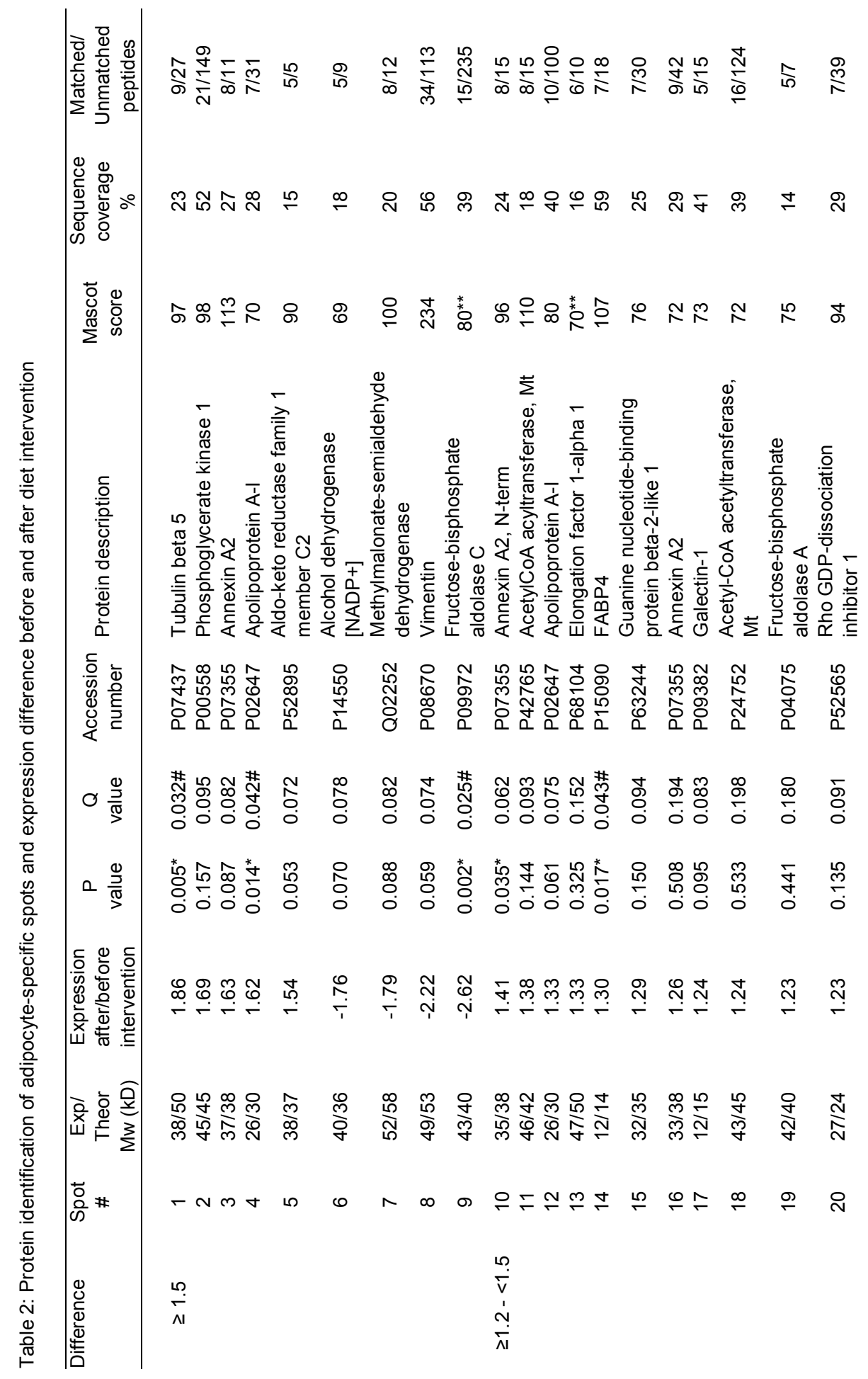




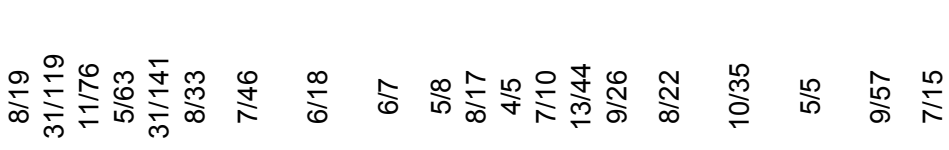

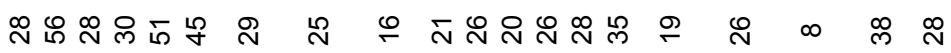
แ

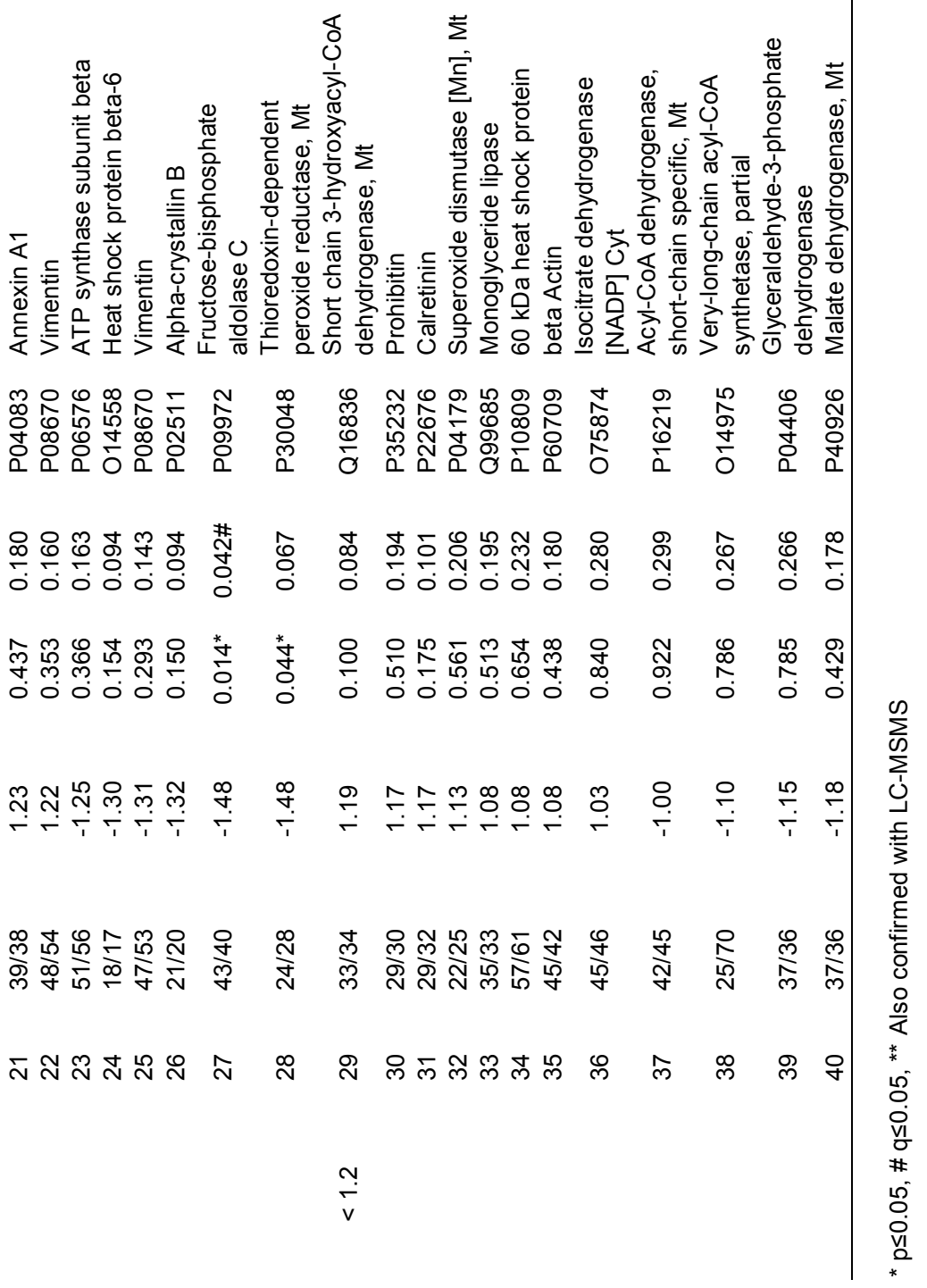




\section{Western blotting}

In order to confirm our findings with 2D-GE, Western blotting was performed for three significantly changed proteins. Individual samples were blotted. The result of the ApoA1 blot (Figure 3A) indeed confirms the results of the 2D analysis. The concentration of ApoA 1 in the adipose tissue is significantly higher after the diet intervention than before $(p=0.017)$. For fructose-bisphosphate aldolase $C$ (Figure 3B) a trend for reduction was observed $(p=0.061)$ in keeping with the 2D analysis. An antibody specific for tubulin beta-5 is not available. Therefore, we used an antibody against tubulin beta in general, but with this antibody the 2D-GE results could not be confirmed (Figure $3 \mathrm{C}$ ).

\section{Detailed analysis of individual data}

For the enzyme fructose-bisphosphate aldolase $C$ two spots were detected by 2D-GE (spots 9 and 27 in Table 2), which may reflect different isoforms. With the pooled 2D-data both spots showed a significant decrease in abundance. More detailed analysis revealed a consistent decrease of all individual 2Dvalues for both spots (Figures 4A and 4B), further corroborating a link with the intervention. A similar analysis of tubulin beta-5 and the $\mathrm{N}$-terminal fragment of annexin A2 learned that also here all the individual 2D-values consistently decreased (data not shown) but in the latter case data from only 5 subjects were available. Although the pooled 2D-data of the other three proteins resulted in a significant change after the intervention, the spot intensity for some individuals increased while for others it decreased. An example can be seen in Figure 4C.

To find out whether changes in physiological parameters, in particular those related to adipose tissue function, were quantitatively linked with changes of the differential proteins, correlation analysis was performed between the changes of those parameters and changes of the 40 spot intensities. Table 3 lists the significant correlations with p-values of less than 0.05 . Since the number of subjects is only 8, after correction for multiple testing (FDR) no significance was reached for any of the calculations. However, we reasoned that when a parameter correlates with more proteins from the same molecular pathway, this may still represent a genuine link. As such, the positive correlations between changes in FFA level and changes in three mitochondrial enzymes of beta-oxidation (short chain specific acyl-CoA dehydrogenase (ACADS), short chain 3-hydroxyacyl-CoA dehydrogenase $(\mathrm{HADH})$ and acetylCoA acetyltransferase (ACAT1)) may be relevant. Similarly suggestive is a situation in which the change of a protein correlates with the change of several physiological parameters. The change in aldo-keto reductase family 1 member C2 (AKR1C2) was found to correlate positively with changes in parameters of 
adiposity, i.e. weight, BMI and waist. The change in fatty acid binding protein (FABP4) was found to inversely correlate with changes in several parameters of lipid metabolism, i.e. plasma total cholesterol, LDL-cholesterol and triglyceride levels. However, it should be kept in mind that those parameters of lipid metabolism or adiposity cannot be regarded as independent.

A.

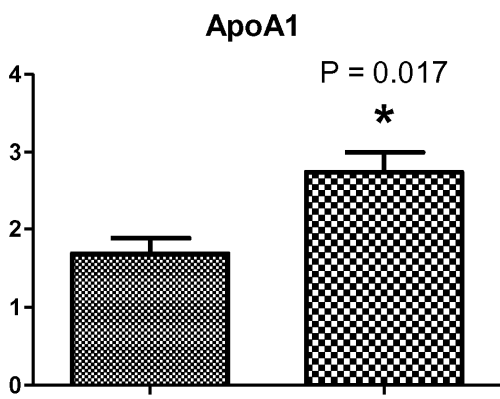

Before diet intervention
After diet intervention
B. Fructose-bisphosphate aldolase $\mathbf{C}$

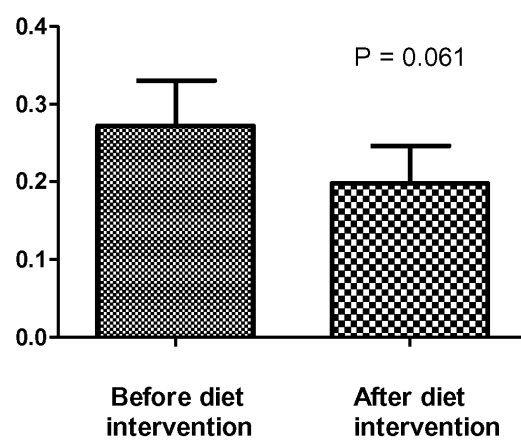

C. Tubulin Beta

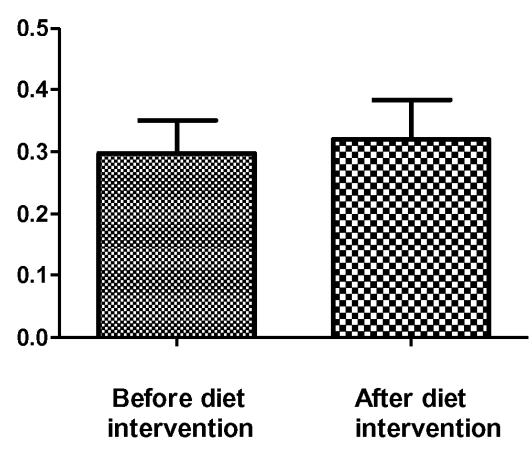

Figure 3: Expression differences of the protein blots before and after diet intervention, (A) ApoA1 blot, (B) Fructose-bisphosphate aldolase C blot and (C) Tubulin beta blot. 
A.

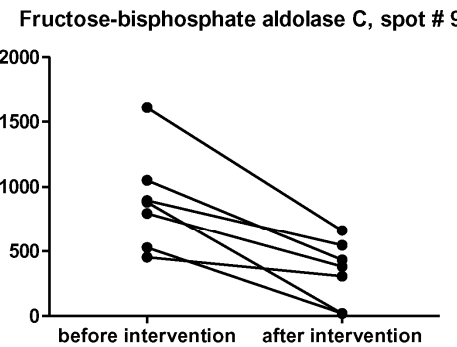

C.

Thioredoxin-dependent peroxide reductase, spot \# 28

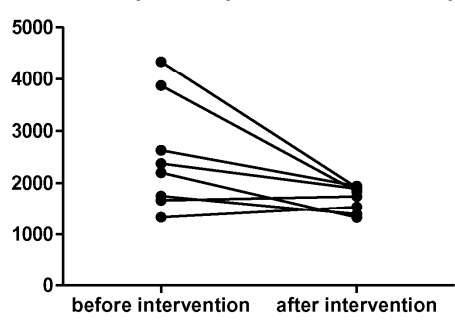

B.

Fructose-bisphosphate aldolase C, spot \# 27

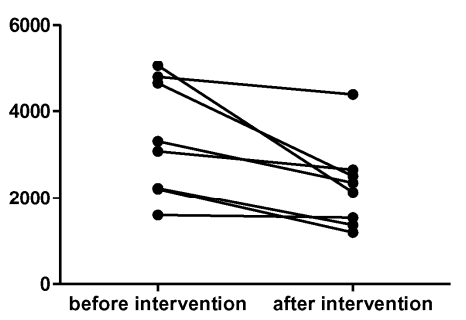

D.

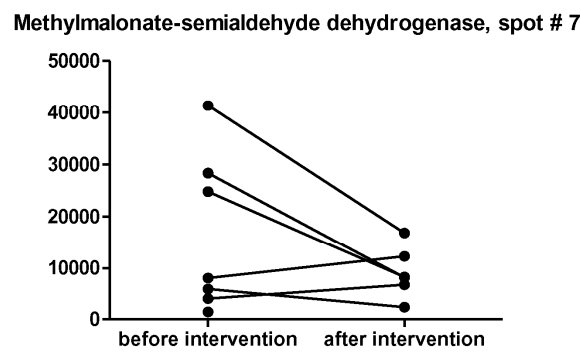

Figure 4: Differences of OD's from the 2D before and after diet intervention of each subject.

\section{DISCUSSION}

In this study we analysed subcutaneous fat biopsies taken from subjects before and after an intervention of 5 weeks on a very low calorie diet followed by 3 weeks of adaptation to a weight-maintaining normal diet in order to prevent influences of a negative energy balance. Using 2D gel separation of biopsy proteins, we searched for differential proteome differences complying with general physiological observations. Indeed, even three weeks after returning to a normal diet, differential proteins were observed, thus reflecting established changes at the level of gene expression due to weight reduction. Six of the identified proteins showed a significant change in abundance $(p<0.05)$. Combining pooled and individual data revealed that fructose-bisphosphate aldolase $C$ (ALDOC) and tubulin beta 5 (TUBB5) are potential markers for the present intervention which includes both the weight loss (5 weeks) and weight maintenance ( 3 weeks) period.

Two spots for ALDOC were detected and both were reduced in abundance after the intervention. ALDOC is an enzyme of the glycolysis. Two other glycolytic enzymes, phosphoglycerate kinase 1 and fructose-bisphosphate aldolase A were found up-regulated and one other glycolytic enzyme, glyceraldehyde-3-phosphate dehydrogenase, was down-regulated, but all not significantly. Therefore, no conclusion can be drawn for a major change in 
glycolysis. Interestingly, ALDOC has been shown to function as a structural component of the actin cytoskeleton. Moreover, it is able to mediate the association of F-actin with the glucose transporter GLUT4 [21]. It was proposed that ALDOC is partly responsible for the intracellular sequestration of GLUT4. Both insulin stimulation as well as the substrates fructose-1,6-bisphosphate and glyceraldehyde-3-phosphate lead to the release of GLUT4 boosting glucose uptake by its translation to the membrane. In this regard, lower ALDOC after the intervention may promote increased levels of GLUT4 in the cell membrane accompanied by increased uptake of glucose necessary for triglyceride synthesis and storage. As such, a decrease of ALDOC might contribute to a decrease in plasma levels of glucose after the intervention (Table 1).

Not much is known about the exact function of the beta- 5 isoform of tubulin. In general, beta-tubulin forms dimers with alpha-tubulin. Interestingly, ALDOC activity can be inhibited by its binding to the C-terminal region of alpha-tubulin [22]. Rearrangement of the tubulin filaments by the significant up-regulation of tubulin beta 5 might thus lead to a functional reduction of the already reduced amount of ALDOC. Similarly, not much is known about the function of annexin A2 in adipocytes. A significant increase of the $\mathrm{N}$-terminal part indicates increased production of the mature protein. In 3T3-L1 cells annexin A2 has been shown to support GLUT4 translocation [23]. Altogether, our findings with the three consistently up- or down-regulated proteins suggest changes in glucose uptake in adipocytes by the intervention. Similarly, the uptake of fatty acids seems improved because on average there is a $40 \%$ increase in the abundance of FABP4 after the intervention. Taken together this provides evidence that weight reduction, in particular loss of fat mass, stimulates the basal function of triglyceride storage by adipocytes. However, since we were not able to directly measure glucose and fatty acid uptake, this remains speculative. Since tubulin beta 5 and annexin A2 are on the list of 44 generally detected differential proteins [24], part of this stimulation may come from a change in cellular stress in the adipocytes due to metabolic effects of decreased energy supply.

ApoA1 is believed to be produced by liver and intestine, but not by adipocytes. Yet, ApoA1 was detected in the proteome of purified adipocytes. One explanation could be that during adipocyte purification some macrophages remain attached to the adipocytes. Macrophages have a high affinity for ApoA1 leading to co-purification of this protein with the adipocytes. On the other hand, the increase in ApoA1 may reflect a genuine biological function as it has been reported that adipocytes can process HDL particles [25, 26]. ApoA1 has been recognized as an anti-inflammatory factor [27-29]. Thus, the increased concentration of ApoA1 after the intervention indicates an improved inflammatory profile of the adipose tissue. Interestingly, ApoA1 in adipocytes was seen as two differentially expressed spots (4 and 12 in Figure 2). It has 
C H A P E R 3

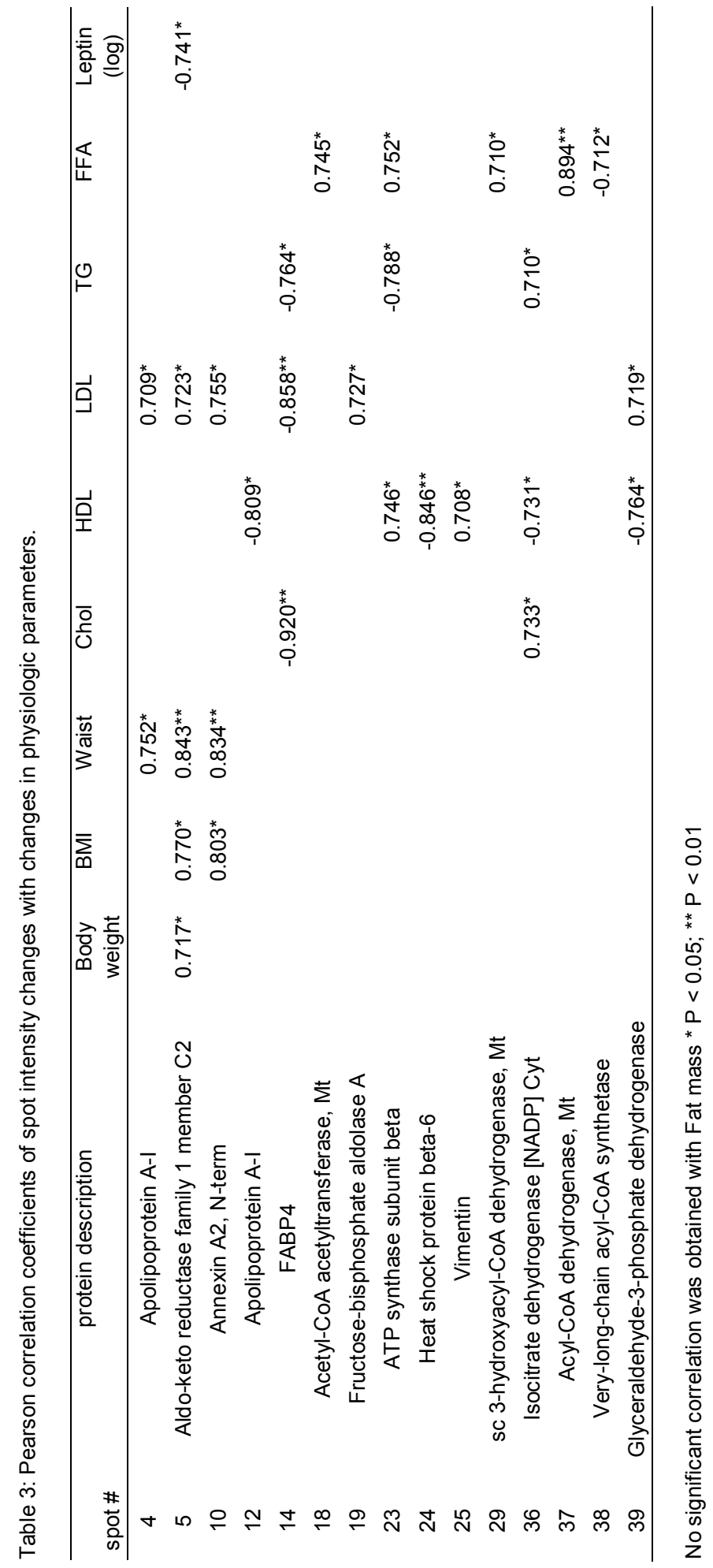


been reported that ApoA1 can become palmitoylated [30]. This posttranslational modification of serine and cysteine residues allows proteins to attach to the cell membrane [31]. It is tempting to assume that one of the spots represents this membrane binding form. Alternatively, ApoA1 is known to be processed from a precursor by the removal of a 6-amino acid $\mathrm{N}$-terminal propeptide [32, 33]. Therefore, the two spots could represent the processed and non-processed form. Maldi-TOF/TOF de novo sequencing did not allow us to decide on this matter. The presence of ApoA1 in the adipocytes-enriched proteome needs further investigation.

Another spot with significant differential expression is that of mitochondrial thioredoxin-dependent peroxide reductase (fold change -1.48), also known as peroxiredoxin-3 or antioxidant protein 1 (AOP1). Analysis of the individual samples shows a reduction of high individual values (Figure $4 \mathrm{C}$ ). The window of spot values before the intervention (1300-4400 units) is reduced by more than $4 x$ after the intervention (1300-2000 units) as if weight loss induces normalization of this protein to a basal level. It has been reported that this protein can bind to leucine zipper-bearing kinase (LZK) and this interaction was shown to enhance the LZK-induced activation of NF-kappaB, a well-known mediator of inflammatory pathways [34]. Therefore, the reduction of this protein may indicate a reduced level of oxidative stress inside the adipocytes after weight loss, but may also reflect the inflammatory status of the adipose tissue.

Although not reaching significance, three spots belonging to vimentin displayed a fold changes of $-2.22(p=0.06),+1.22(p=0.35)$ and $-1.31(p=0.29)$, respectively, suggesting that the vimentin filaments undergo rearrangement during the intervention. This seems plausible, because vimentin filaments have been shown to be linked to the fat droplets [35]. A change in vimentin thus might be in line with a change in fat droplet organization in the adipocytes [36]. In a previous study we have compared the adipocyte-enriched proteome of human adipose tissue between physiologically distinguished low and high fatoxidizing obese subjects [9]. There we found a 2.4-fold higher abundance of ALDH6A1 in low fat-oxidizers, which was suggested to promote the input of carbon atoms into the TCA-cycle via succinyl-CoA as a compensation for decreased oxaloacetate formation. Present analysis of the individual samples shows that the overall effect is due to the extreme reduction of the enzyme level in half of the individuals (Figure 4D). It is tempting to speculate that those subjects would be physiologically classified as low-fat oxidizers. In this respect, the 2-fold down-regulation of ALDH6A1 after the present intervention might indicate sufficient formation of oxaloacetate from pyruvate in line with improved uptake of glucose.

Loss of fat mass is generally associated with decreased fatty acid oxidation $[37,38]$. There may even be a mechanistic link, because fatty acid oxidation is correlated with lipolysis resulting in decreased extrusion of FA into the plasma [39]. Correlation analysis between changes in spot intensities and physiological 
parameters showed that three enzymes of the fatty acid oxidation pathway (HADH, ACADS, ACAT1) are positively correlated with the decrease in the plasma FFA level. Although suggestive of a functional link, the outcome of this analysis does not allow conclusions about the regulation of fatty acid oxidation. No correlation was found between the FFA level and another enzyme of fatty acid oxidation: acetyl-CoA acyltransferase. Remarkably, this enzyme is involved in the breakdown of FA from the n16-stage on, whereas the other three only catalyze the catabolic steps down from the n6-stage.

Other interesting correlations were those of AKR1C2 and FABP4 with parameters of adiposity or lipid metabolism, respectively. It has already been reported that the level of the mRNA AKR1C2 expression in adipose tissue of females positively correlates with adiposity [40]. FABP4 inversely correlates with total plasma and LDL-cholesterol levels, and at lower significance with the plasma triglyceride level. It has been indicated that the cholesterol level in adipocytes is linked to their metabolic activity, such as fatty acid uptake. Therefore a significantly decreased cholesterol supply from the blood stream, especially of LDL-cholesterol, may require adaptive up-regulation of FABP4 to maintain a normal fatty acid uptake function of adipocytes [41, 42].

In short, after 5 weeks of a very low calorie diet followed by 3 weeks of a normal diet, changes in the adipocyte-enriched proteome can be detected. Those changes suggest a reduced intracellular scaffolding of GLUT4 (ALDOC, TUBB5, ANXA2), an improved inflammatory status (ApoA1, AOP1), a higher uptake of fatty acids (FABP4), a change in fat droplet organization (vimentin), and a correlation between plasma FFA-level and fatty acid oxidation (HADH, ACADS, ACAT1). Additional studies can now be initiated to confirm and deepen the role of specific proteins and their molecular pathways indicated by the present results. Overall, our results underscore the potential of in vivo proteomics to provide insight in physiologic effects of human intervention studies. In the present study we successfully analyzed subcutaneous adipose tissue. The same analyses can now be applied to visceral adipose tissue, which is less accessible but not less relevant in the context of weight regulation.

\section{Acknowledgements}

This research was supported by the Maastricht Proteomics Center of the Maastricht University and by Kerry Bio-Science, Almere, The Netherlands. We also thank Antoine Zorenc and Yvonne Essers for their excellent assistance of the protein blots and Janneke de Wilde for the helping in constructing the figures. 


\section{References}

1. Bogaert YE \& Linas S (2009) The role of obesity in the pathogenesis of hypertension. Nature clinical practice 5(2):101-111.

2. Wellen KE \& Hotamisligil GS (2003) Obesity-induced inflammatory changes in adipose tissue. The Journal of clinical investigation 112(12):1785-1788.

3. Berg AH \& Scherer PE (2005) Adipose tissue, inflammation, and cardiovascular disease. Circulation research 96(9):939-949.

4. Mojiminiyi OA, Al Mulla F, \& Abdella NA (2009) Which obesity index best explains the link between adipokines, coronary heart disease risk and metabolic abnormalities in type 2 diabetes mellitus? Med Princ Pract 18(2):123-129.

5. Zou C \& Shao J (2008) Role of adipocytokines in obesity-associated insulin resistance. The Journal of nutritional biochemistry 19(5):277-286.

6. Goldstein DJ (1992) Beneficial health effects of modest weight loss. Int J Obes Relat Metab Disord 16(6):397-415.

7. Jazet IM, de Craen AJ, van Schie EM, \& Meinders AE (2007) Sustained beneficial metabolic effects 18 months after a 30-day very low calorie diet in severely obese, insulin-treated patients with type 2 diabetes. Diabetes research and clinical practice 77(1):70-76.

8. Fontana $L$ (2008) Calorie restriction and cardiometabolic health. Eur J Cardiovasc Prev Rehabil 15(1):3-9.

9. Claessens M, et al. (2007) Differential valine metabolism in adipose tissue of low and high fatoxidizing obese subjects. Proteomics Clin. Appl 1(10):1306-1315.

10. de Roos B, et al. (2008) Proteomic methodological recommendations for studies involving human plasma, platelets, and peripheral blood mononuclear cells. Journal of proteome research 7(6):2280-2290.

11. Claessens M, van Baak MA, Monsheimer S, \& Saris WH (2009) The effect of a low-fat, highprotein or high-carbohydrate ad libitum diet on weight loss maintenance and metabolic risk factors. International journal of obesity (2005) 33(3):296-304

12. Siri WE (1993) Body composition from fluid spaces and density: analysis of methods. 1961. Nutrition (Burbank, Los Angeles County, Calif 9(5):480-491; discussion 480, 492.

13. Bradford MM (1976) A rapid and sensitive method for the quantitation of microgram quantities of protein utilizing the principle of protein-dye binding. Analytical biochemistry 72:248-254.

14. Rabilloud T, Adessi C, Giraudel A, \& Lunardi J (1997) Improvement of the solubilization of proteins in two-dimensional electrophoresis with immobilized $\mathrm{pH}$ gradients. Electrophoresis 18(3-4):307-316.

15. Gorg A, et al. (2000) The current state of two-dimensional electrophoresis with immobilized pH gradients. Electrophoresis 21(6):1037-1053.

16. Bouwman F, Renes J, \& Mariman E (2004) A combination of protein profiling and isotopomer analysis using matrix-assisted laser desorption/ionization-time of flight mass spectrometry reveals an active metabolism of the extracellular matrix of 3T3-L1 adipocytes. Proteomics 4(12):3855-3863.

17. Bouwman F, Suylen D, Renes J, \& Mariman E (2005) Evaluation and improving the success rate of protein identification by peptide mass fingerprinting using matrix-assisted laser desorption/ionization time-of-flight mass spectrometry. Rapid Commun Mass Spectrom 19(17):2465-2468.

18. Dumont D, Noben JP, Raus J, Stinissen P, \& Robben J (2004) Proteomic analysis of cerebrospinal fluid from multiple sclerosis patients. Proteomics 4(7):2117-2124.

19. Koopman R, Zorenc AH, Gransier RJ, Cameron-Smith D, \& van Loon LJ (2006) Increase in S6K1 phosphorylation in human skeletal muscle following resistance exercise occurs mainly in type II muscle fibers. American journal of physiology 290(6):E1245-1252.

20. Strimmer K (2008) A unified approach to false discovery rate estimation. BMC bioinformatics 9:303.

21. Kao AW, Noda Y, Johnson JH, Pessin JE, \& Saltiel AR (1999) Aldolase mediates the association of F-actin with the insulin-responsive glucose transporter GLUT4. The Journal of biological chemistry 274(25):17742-17747.

22. Volker KW \& Knull H (1997) A glycolytic enzyme binding domain on tubulin. Archives of biochemistry and biophysics 338(2):237-243. 
23. Huang J, Hsia SH, Imamura T, Usui I, \& Olefsky JM (2004) Annexin II is a thiazolidinedioneresponsive gene involved in insulin-induced glucose transporter isoform 4 translocation in 3T3L1 adipocytes. Endocrinology 145(4):1579-1586.

24. Wang P, Bouwman FG, \& Mariman EC (2009) Generally detected proteins in comparative proteomics--a matter of cellular stress response? Proteomics 9(11):2955-2966.

25. Fong BS, et al. (1985) Characterization of high density lipoprotein binding to human adipocyte plasma membranes. The Journal of clinical investigation 75(6):1804-1812.

26. Despres JP, Fong BS, Julien P, Jimenez J, \& Angel A (1987) Regional variation in HDL metabolism in human fat cells: effect of cell size. The American journal of physiology 252(5 Pt 1):E654-659.

27. Van Lenten BJ, et al. (2008) Anti-inflammatory apoA-I-mimetic peptides bind oxidized lipids with much higher affinity than human apoA-I. Journal of lipid research 49(11):2302-2311.

28. Navab M, Anantharamaiah GM, \& Fogelman AM (2005) The role of high-density lipoprotein in inflammation. Trends in cardiovascular medicine 15(4):158-161.

29. Tabet F \& Rye KA (2009) High-density lipoproteins, inflammation and oxidative stress. Clin Sci (Lond) 116(2):87-98.

30. Hoeg JM, Meng MS, Ronan R, Fairwell T, \& Brewer HB, Jr. (1986) Human apolipoprotein A-I. Post-translational modification by fatty acid acylation. The Journal of biological chemistry 261(9):3911-3914.

31. Nadolski MJ \& Linder ME (2007) Protein lipidation. The FEBS journal 274(20):5202-5210.

32. Brewer HB, Jr., et al. (1983) Human plasma proapoA-I: isolation and amino-terminal sequence. Biochemical and biophysical research communications 113(2):626-632.

33. Pyle LE, Sviridov D, \& Fidge NH (2001) Characterization of the maturation of human proapolipoprotein A-I in an in vitro model. Biochemistry 40(10):3101-3108.

34. Masaki M, Ikeda A, Shiraki E, Oka S, \& Kawasaki T (2003) Mixed lineage kinase LZK and antioxidant protein-1 activate NF-kappaB synergistically. European journal of biochemistry / FEBS 270(1):76-83.

35. Funatsumaru S (1995) Cellular structure and function of rat fat cells in the primary culture. Cell structure and function 20(1):23-32.

36. Lieber JG \& Evans RM (1996) Disruption of the vimentin intermediate filament system during adipose conversion of 3T3-L1 cells inhibits lipid droplet accumulation. Journal of cell science 109 ( Pt 13):3047-3058.

37. Jackman MR, et al. (2008) Weight regain after sustained weight reduction is accompanied by suppressed oxidation of dietary fat and adipocyte hyperplasia. Am J Physiol Regul Integr Comp Physiol 294(4):R1117-1129.

38. van Aggel-Leijssen DP, Saris WH, Hul GB, \& van Baak MA (2001) Short-term effects of weight loss with or without low-intensity exercise training on fat metabolism in obese men. The American journal of clinical nutrition 73(3):523-531.

39. Nicklas BJ, Rogus EM, \& Goldberg AP (1997) Exercise blunts declines in lipolysis and fat oxidation after dietary-induced weight loss in obese older women. The American journal of physiology 273(1 Pt 1):E149-155.

40. Blouin K, et al. (2005) Expression and activity of steroid aldoketoreductases 1C in omental adipose tissue are positive correlates of adiposity in women. American journal of physiology 288(2):E398-404.

41. Pohl J, et al. (2004) Long-chain fatty acid uptake into adipocytes depends on lipid raft function. Biochemistry 43(14):4179-4187.

42. Chui PC, Guan HP, Lehrke M, \& Lazar MA (2005) PPARgamma regulates adipocyte cholesterol metabolism via oxidized LDL receptor 1 . The Journal of clinical investigation 115(8):2244-2256. 


\section{Chapter 4}

\section{Increased $\beta$-oxidation with improved glucose uptake capacity in adipose tissue from obese after weight loss and maintenance}

Freek G. Bouwman, Ping Wang, Marleen van Baak, Wim H.M. Saris \& Edwin C.M. Mariman

Department of Human Biology, Nutrition and Toxicology Research Institute Maastricht (NUTRIM), Maastricht University, Maastricht, The Netherlands

Obesity 2014 22(3) p.819-27 


\section{ABSTRACT}

Objective: We investigated protein markers for pathways of the fatty acids and glucose metabolism in human adipose tissue after a weight loss program by calorie restriction.

Design and Methods: Overweight/obese subjects underwent an intervention of 5 weeks of a very low calorie diet followed by a 3 weeks weight maintenance diet. Abdominal subcutaneous adipose tissue biopsies were sampled before and after the intervention. 17 target proteins as markers of metabolic pathways for the uptake and handling of fatty acids and glucose, were quantified by Western blotting and 11 were retrieved from previous proteomics work. Correlation coefficients were calculated among changes of these proteins.

Results: 3-hydroxyacyl-CoA dehydrogenase (HADH), catalase, fatty acid translocase, fatty acid transporter protein 3 , adipose triglyceride lipase, fatty acid binding protein 4 , aldolase- $C$, tubulin- $\beta-5$, and annexin A2 changed significantly, and lipoprotein lipase, perilipin 1 and hormone-sensitive lipase tended to change. On average increased GLUT4-translocation was observed, supported by a consistent increase of tyr-24 phosphorylated annexin A2.

Conclusions: Our findings suggest that after weight loss by calorie restriction and a short-period of maintenance, adipose tissue has an increased capacity for glucose uptake, and lipid mobilization and oxidation. Such metabolic profile may relate to the health benefit of weight loss. 


\section{INTRODUCTION}

Weight loss in overweight/obese subjects reduces the risk for the development of chronic diseases like diabetes, cancer and cardiovascular disorders [1]. Weight loss obviously improves metabolic function, but the underlying molecular mechanisms are still under investigation [2]. Adipose tissue is an important metabolic organ that can store and release energy in response to variations in the demand. In the energy-balanced state, glucose is the primary energy source of white adipose tissue for regulatory and biosynthetic purposes [3]. However, during calorie restriction, when there is a low availability of glucose, fatty acid (FA) oxidation is increased in adipocytes [4]. This metabolic shift from carbohydrate to FA oxidation has been proposed as an explanation for the beneficial health effects of calorie restriction, since it may increase mitochondrial biogenesis and reduce the production of reactive oxygen species (ROS) [5]. Using fatty acids as energy source reduces the FA load of the body and may have a positive effect on insulin sensitivity of peripheral tissues [6]. However, it is unknown if such metabolic shift maintains after switching to balanced energy intake during a weight loss program.

Numerous studies have been published on the effects of weight loss by calorie restriction in the adipose tissue and adipocytes [1, 7, 8]. However, information is lacking at the protein level concerning the regulation of enzymes involved in the uptake and handling of fatty acids and glucose. Considering that enzymes/proteins are the real working horses in the cell, and that there are large differences between the expression of mRNAs and proteins [9], we investigated the molecular changes of the metabolism of fatty acids and glucose at the protein level in human adipose tissue after a weight loss program by calorie restriction

Previously, we have investigated the proteome of adipocytes from subjects who underwent weight loss by calorie restriction followed by a short period of weight maintenance by using 2-dimentional gel electrophoresis (2DE) [10]. We observed changes in protein abundance pointing to improved glucose uptake and fatty acid handling. Here, we have extended those results by using a targeted proteomics approach to cover the related pathways involved in glucose and fatty acid metabolism. Our findings show that in the adipose tissue of overweight/obese subjects, the weight loss/maintenance intervention indeed leads to increased capacities on glucose uptake and fatty acid oxidation. 


\section{METHODS AND PROCEDURES}

\section{Subjects and experimental design}

Eight overweight or obese subjects (BMI $\geq 27 \mathrm{~kg} / \mathrm{m} 2$, aged 30-60 years, 4 men and 4 women) were selected from a weight loss-maintenance intervention study that we reported previously $[10,11]$. In brief, the weight loss period consisted of a 5-week very-low-calorie diet (VLCD) and one week normalizing. In the first 5 weeks, subjects consumed a liquid VLCD diet providing $500 \mathrm{kcal}$ per day (Modifast, Nutrition et Santé, France). During week 6, the VLCD was gradually replaced by normal ad libitum meals with protein or carbohydrate supplements. Afterwards there was a weight maintenance period of low-fat ad libitum diet with dietary consulting. For the present study, the maintenance period was set for 2-week. Anthropometrical and physiological parameters were measured, and fasting blood samples were taken for biochemical analysis at baseline and week 6 . Two abdominal subcutaneous adipose tissue biopsies were taken at baseline and week 8 in the morning after an overnight fast. The Medical Ethics Committee of the Maastricht Academic Hospital and University approved the study and all subjects gave their written informed consent before entering the study.

\section{Sample preparation}

About $350 \mathrm{mg}$ tissue from the biopsy was washed in PBS to get rid of the major part of blood, frozen in liquid nitrogen and grinded in a mortar. The powder was dissolved in $200 \mu \mathrm{l} 8 \mathrm{M}$ urea, $2 \% \mathrm{w} / \mathrm{v}$ CHAPS, $65 \mathrm{mM}$ DTT per $100 \mathrm{mg}$ biopsy. The homogenate was vortexed for 5 minutes and centrifuged at $20,000 \mathrm{~g}$ for 30 minutes at $10^{\circ} \mathrm{C}$. The supernatant containing the adipose tissue proteome was carefully collected and aliquots were stored at $-80^{\circ} \mathrm{C}$.

\section{Western Blotting}

Samples with an equal amount of protein were run on a $12 \%$ SDS polyacrylamide gel (180 V, Criterion Cell; Bio-Rad, Hercules, CA), after electrophoresis proteins were transferred $(90 \mathrm{~min}, 100 \mathrm{~V}$, Criterion blotter; BioRad) to $0.45 \mu \mathrm{m}$ nitrocellulose membranes. SDS-PAGE electrophoresis was performed as described before [10]. After Ponceau $S$ staining and destaining, membranes were blocked for $1 \mathrm{~h}$ in $5 \%$ nonfat dry milk power (NFDM; Bio-Rad) in Tris-buffered saline containing $0.1 \%$ Tween 20 (TBST) or 5\% BSA-TBST depending on the primary antibody. Thereafter, the blots were incubated respectively with the primary antibodies against ALDOC (1:250 dilution, Santa Cruz sc-12066), catalase (1:500 dilution, Santa Cruz sc69762), HADH (1:500 
dilution, Santa Cruz, sc-74650), GLUT4 (1:5,000 dilution, Santa Cruz; sc-1608), HSL (1:1,000 dilution, donated by C. Holm), pHSL-Ser565 (1:1,000 dilution, Cell Signaling 4137), ATGL (1:1,000 dilution, Cell Signaling 2138), LPL (1:1,000 dilution, Santa Cruz sc-58780), FABP4 (1:1,000 dilution, Cayman 10004944), annexinA2 (1:1,000 Santa Cruz sc-47696) and PLIN1 A/B (1:5,000 Dilution, ProGen GP33) in $5 \%$ NFDM-TBST overnight at $4^{\circ} \mathrm{C}$ on a shaker. For antibodies against FAT/CD36 (1:100,000 dilution, MO25 monoclonal antibody donated by J. Glatz, Maastricht University, The Netherlands), ACOX1 (1:500 dilution, Santa Cruz sc-130678), FAS (1:1,000 dilution, Abcam ab22756), CPT1a (1:500 dilution, Abgent AP2524b) and FATP3 (1:1,000 dilution, Atlas HPA006935) blots were incubated with the primary antibody in 5\%BSA-TBST overnight at $4^{\circ} \mathrm{C}$ on a shaker. For phospho-annexinA2 (Santa Cruz sc-135753) the blot was incubated with the primary antibodies in $1 \%$ BSA-TBST overnight at $4^{\circ} \mathrm{C}$ on a shaker. Thereafter the blots were washed three times for $10 \mathrm{~min}$ in TBST, and then incubated for $1 \mathrm{~h}$ with a 1:10,000 dilution of the horseradish peroxidaseconjugated secondary antibody (DAKO) in 5\% NFDM-TBST or 5\% BSA-TBST. The blots were washed three times for $10 \mathrm{~min}$ in TBST and once in TBS. A CCD camera (XRS-system, Biorad) was used to detect immunoreactive bands using chemiluminescent substrate (SuperSignal CL; Pierce). The quantification was performed with the program Quantity One version 4.6.5 (Bio-Rad). $\beta$-Actin was used to standardize for the amount of protein loaded [12].

\section{GLUT4 translocation}

The plasma membrane fractionation was performed according to a validated method [13]. Briefly, $100 \mathrm{mg}$ tissue from the biopsy was grinded under liquid nitrogen in a mortar. The powder was dissolved in $200 \mu \mathrm{l} 20 \mathrm{mM}$ Tris-HCL $\mathrm{pH} 7.4,10 \mathrm{mM}$ EDTA and 2mM EGTA. The homogenate was vortexed for 5 minutes and centrifuged at $160,000 \mathrm{~g}$ for 20 minutes at $4^{\circ} \mathrm{C}$. The supernatant containing the cytosol fraction was collected and stored at $-80^{\circ} \mathrm{C}$. The pellet was resuspended in $200 \mu \mathrm{l} 20 \mathrm{mM}$ Tris-HCL pH7.4, $10 \mathrm{mM}$ EDTA, 2mM EGTA and $0.2 \%$ Triton $\mathrm{X}-100$. Sonicated for 5 seconds, vortexed and incubated one hour on ice. The homogenate was centrifuged at $160,000 \mathrm{~g}$ for 20 minutes at $4^{\circ} \mathrm{C}$. The supernatant containing the membrane fraction was collected and stored at $80^{\circ} \mathrm{C}$. The cytosolic and membrane fraction were Western blotted and the amount of GLUT4 was quantified. The degree of translocation is expressed by dividing the amount of GLUT4 in the membrane fraction by the amount of GLUT4 in the cytosolic fraction. For the purity of the fractionation, Caveolin-1 was used as a control for the membrane fraction and GAPDH used for the cytosolic fraction. 


\section{Statistical Analysis}

Statistical analyses were done using SPSS v15.0 statistical software. The changes of protein intensities on the blots before and after the intervention were analyzed by paired-samples T-tests. To determine relationships between the changes in protein levels, Spearman correlation coefficients were calculated. In this analysis, also protein changes from a previous $2 \mathrm{DE}$ experiment on the same samples were used [10]. A P-value $<0.05$ was considered statistically significant. A connectivity map was created, a protein was added to this connectivity map if there was a Spearman corrected correlation of $P<0.01$ with one or more of the other proteins, or at least two correlations of $P<0.02$ with other proteins. In that case, also the proteins, with which the correlations were found, were added to the map.

Table 1: Physiologic measurements (mean \pm SEM) before and after the diet intervention $(n=8)$.

\begin{tabular}{llll}
\hline Variable & week 0 & week 6 & $\mathrm{P} \mathrm{value}^{*}$ \\
\hline BMI $(\mathrm{kg} / \mathrm{m} 2)$ & $32.6 \pm 1.1$ & $29.5 \pm 1.2$ & $<\mathbf{0 . 0 0 1}$ \\
Body weight $(\mathrm{kg})$ & $99.7 \pm 6.5$ & $90.2 \pm 6.0$ & $<\mathbf{0 . 0 0 1}$ \\
Fat mass $(\mathrm{kg})$ & $37.5 \pm 2.8$ & $30.4 \pm 3.0$ & $<\mathbf{0 . 0 0 1}$ \\
Fat-free mass $(\mathrm{kg})$ & $62.3 \pm 4.9$ & $59.8 \pm 4.1$ & $\mathbf{0 . 0 2 5}$ \\
Waist circumference $(\mathrm{cm})$ & $111.6 \pm 4.3$ & $101.9 \pm 4.2$ & $<\mathbf{0 . 0 0 1}$ \\
Hip circumference $(\mathrm{cm})$ & $115 \pm 3.8$ & $107.5 \pm 4.2$ & $\mathbf{0 . 0 1 1}$ \\
Glucose $(\mathrm{mmol} / \mathrm{L})$ & $5.10 \pm 0.33$ & $4.73 \pm 0.30$ & $\mathbf{0 . 0 1 1}$ \\
Insulin $(\mu \mathrm{H} / \mathrm{mL})$ & $17.6 \pm 2.5$ & $13.1 \pm 2.0$ & 0.069 \\
FFA $(\mathrm{mmol} / \mathrm{L})$ & $0.781 \pm 0.122$ & $0.415 \pm 0.043$ & $\mathbf{0 . 0 0 7}$ \\
Triglycerides $(\mathrm{mmol} / \mathrm{L})$ & $1.68 \pm 0.27$ & $1.16 \pm 0.15$ & 0.116 \\
Total cholesterol $(\mathrm{mmol} / \mathrm{L})$ & $4.58 \pm 0.40$ & $3.84 \pm 0.36$ & $\mathbf{0 . 0 0 7}$ \\
HDL cholesterol $(\mathrm{mmol} / \mathrm{L})$ & $1.01 \pm 0.08$ & $1.02 \pm 0.06$ & 0.887 \\
LDL cholesterol $(\mathrm{mmol} / \mathrm{L})$ & $3.03 \pm 0.39$ & $2.28 \pm 0.31$ & $\mathbf{0 . 0 0 3}$ \\
Leptin $(\mathrm{ng} / \mathrm{mL})$ & $47.2 \pm 20.2$ & $22.5 \pm 11.3$ & $\mathbf{0 . 0 3 2}$ \\
\hline
\end{tabular}

* Paired-sample t-test week 0 vs week 6

\section{RESULTS}

\section{Subject characteristics}

The characteristics of the subjects participating in the intervention are shown in Table 1. On average the subjects had lost $9.5 \mathrm{~kg}$ of total body weight after the weight loss program. About $7 \mathrm{~kg}$ was attributed to fat mass and $2.5 \mathrm{~kg}$ to fatfree mass. Other anthropometric parameters (BMI, waist circumference, hip circumference) as well as plasma leptin concentration all decreased significantly. Fasting plasma glucose and free fatty acid levels were significantly lower than that of baseline $(P=0.011$ and $P=0.007$, respectively). Together with trends of a decreased insulin concentration $(P=0.069)$ and a decreased 
HOMA index $(P=0.059)$, it showed an improved insulin sensitivity at the whole body level was induced by weight loss.

\section{Proteins involved in the fatty acid handling}

The fatty acid handling pathways in adipose tissue during the intervention till week 8 were investigated more closely by Western blotting of pre-selected marker proteins in addition to proteins previously detected by 2DE [10]. Those proteins were chosen to represent various processes of fatty acid metabolism: fatty acid uptake and transport: LPL, FAT/CD36, FATP3, FABP4; fat droplet turnover. PLINA, PLINB, ATGL, HSL, pHSL, in addition to spots 8 and 25 of vimentin (VIM); fatty acid synthesis: FAS; peroxisomal beta-oxidation: ACOX1, CAT, in addition to VLACS (spot 38); mitochondrial beta-oxidation: CPT1a, HADH, in addition to ACAT1 (spot 18), ACAA2 (spot 11), ACADS (spot 37), and ATPS (spot 23) [10].

The results of all Western blotting quantifications together with the results of the previous 2DE analysis are shown in Table 2. Based on Western blotting, a significant increase $(p<0.05)$ by the intervention was observed for ATGL and HADH (Figure 1A), Particularly, HADH increased consistently in all participants (Figure 1B). PLINB had the highest up-regulation with a fold change of 9.56 and PLINA was more than 3-fold up-regulated, but both did not reach significance $(P=0.058$ and $P=0.189$, respectively). A significant decrease was detected for FAT/CD36, FATP3, and CAT (Figure 1A), whereas a trend for decrease was found for LPL.

\section{Proteins involved in the insulin-regulated glucose uptake machinery}

When we previously compared the proteome of adipocytes between the fat biopsies from week 0 and week 8 , we found significant changes in the relative abundance of TUBB5 (spot 1), ALDOC (spot 9), ANXA2 (spot 10) (Table 2, [10]). Based on information from the literature, we proposed that this indicated an increased translocation of GLUT4 to the cell membrane [10]. To look into this more deeply, we decided to analyze ANXA2 and GLUT4 further.

Out of the three spots for ANXA2 previously detected by 2DE, only spot 10 increased consistently and significantly by the intervention (fold change 1.41, $P=0.035$ ). Here we examined the nature of this isoform. Total protein was separated by $2 \mathrm{DE}$ and probed with an antibody against ANXA2. This resulted in the detection of 5 different spots (Figure 2), three of which matched to the previous spots 3, 10 and 16 (Table 3). When an antibody against phosphorylation of tyrosine-24 was used, only one spot lighted up (number 5 in Figure 2) that matches with the previously reported spot 10 . Although 
phosphorylated, it is the most basic of the ANXA2 isoforms and has a slightly lower MW $(\sim 3 \mathrm{kD})$ than 3 of the other spots. It may miss the C-terminus ending with two aspartic acid residues that stick out of the protein, but MS/MS peptide sequencing did not provide further insight.

Western blotting showed that on average total GLUT4 increased, but not significantly (fold change $1.49, \mathrm{P}=0.165$ ). We then decided to determine the degree of translocation of GLUT4 to the membrane. On average, the fraction of GLUT4 translocated to the cell membrane increased during the intervention, but also not significantly (fold change 1.26, $\mathrm{P}=0.170$ ). Four subjects showed a clear increase and in 3 subjects the level of GLUT4

Table 2: The different biological processes and the fold-change of the involved protein by Western blotting and 2D electrophoresis.

\begin{tabular}{|c|c|c|c|c|c|}
\hline \multirow{3}{*}{ Process } & \multirow{3}{*}{ Protein } & \multicolumn{4}{|l|}{ Technique } \\
\hline & & \multirow{2}{*}{\multicolumn{2}{|c|}{ Western blot }} & \multicolumn{2}{|c|}{ 2D electrophoresis } \\
\hline & & & & FC & P-value \\
\hline \multirow{4}{*}{$\begin{array}{l}\text { FA uptake and } \\
\text { handling }\end{array}$} & FAT/CD36 & -1.44 & $0.042^{*}$ & & \\
\hline & FATP3 & -1.41 & $0.029^{*}$ & & \\
\hline & LPL & -1.20 & 0.095 & & \\
\hline & FABP $4_{14}$ & 1.46 & 0.067 & 1.30 & $0.017^{*}$ \\
\hline \multirow{7}{*}{$\begin{array}{l}\text { Fat storage and } \\
\text { release }\end{array}$} & PLINA & 3.01 & 0.189 & & \\
\hline & PLINB & 9.56 & 0.058 & & \\
\hline & vimentin $_{8}$ & & & -2.22 & 0.059 \\
\hline & vimentin $_{25}$ & & & -1.31 & 0.293 \\
\hline & HSL & 1.97 & 0.187 & & \\
\hline & pHSL & 1.66 & 0.072 & & \\
\hline & ATGL & 3.05 & $0.014^{*}$ & & \\
\hline FA synthesis & FAS & 1.66 & 0.190 & & \\
\hline \multirow{6}{*}{ Glucose uptake } & GLUT4 & 1.49 & 0.165 & & \\
\hline & $\begin{array}{l}\text { GLUT4 } \\
\text { translocation }\end{array}$ & 1.26 & 0.170 & & \\
\hline & $\mathrm{ALDOA}_{19}$ & & & 1.23 & 0.441 \\
\hline & $\mathrm{ALDOC}_{9}$ & -1.38 & 0.060 & -2.62 & $0.002^{*}$ \\
\hline & TUBB5 $_{1}$ & & & 1.86 & $0.005^{\star}$ \\
\hline & ANXA2 10 & & & 1.41 & $0.035^{*}$ \\
\hline \multirow[t]{3}{*}{ Peroxisomal $\beta$-ox } & catalase & -1.56 & $0.011^{*}$ & & \\
\hline & ACOX1 & 1.24 & 0.308 & & \\
\hline & $\mathrm{VLACS}_{38}$ & & & -1.10 & 0.786 \\
\hline \multirow[t]{6}{*}{ Mitochondrial $\beta$-ox } & $\mathrm{HADH}$ & 1.96 & $0.001^{*}$ & 1.19 & 0.100 \\
\hline & 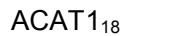 & & & 1.24 & 0.533 \\
\hline & ACAA2 11 & & & 1.38 & 0.144 \\
\hline & ACADS $_{37}$ & & & -1.00 & 0.922 \\
\hline & ATPS $_{23}$ & & & -1.25 & 0.366 \\
\hline & CPT1a & -1.25 & 0.439 & & \\
\hline
\end{tabular}

$F C=$ fold-change and ${ }^{*} P<0.05$. The subscript refers to the protein spot numbers in Bouwman et al. [10].

translocation remained the same, but in one subject there was a clear decrease (red line, Figure 3A).At baseline this subject had a more than $5 x$ higher amount of total GLUT4 in the adipocytes together with the highest baseline membranebound GLUT4 content. Since this subject had also the highest baseline glucose 
level and lowest BMI, it suggests that he/she may have an extraordinary phenotype of GLUT4. Omitting this subject from the analysis results in a significant increase of translocated GLUT4 from week 0 to 8 (Figure 3B, $\mathrm{P}=$ $0.030)$. The two subjects with the lowest baseline translocation who contribute to the average increase, did not show extraordinary values for total GLUT4 or baseline glucose.
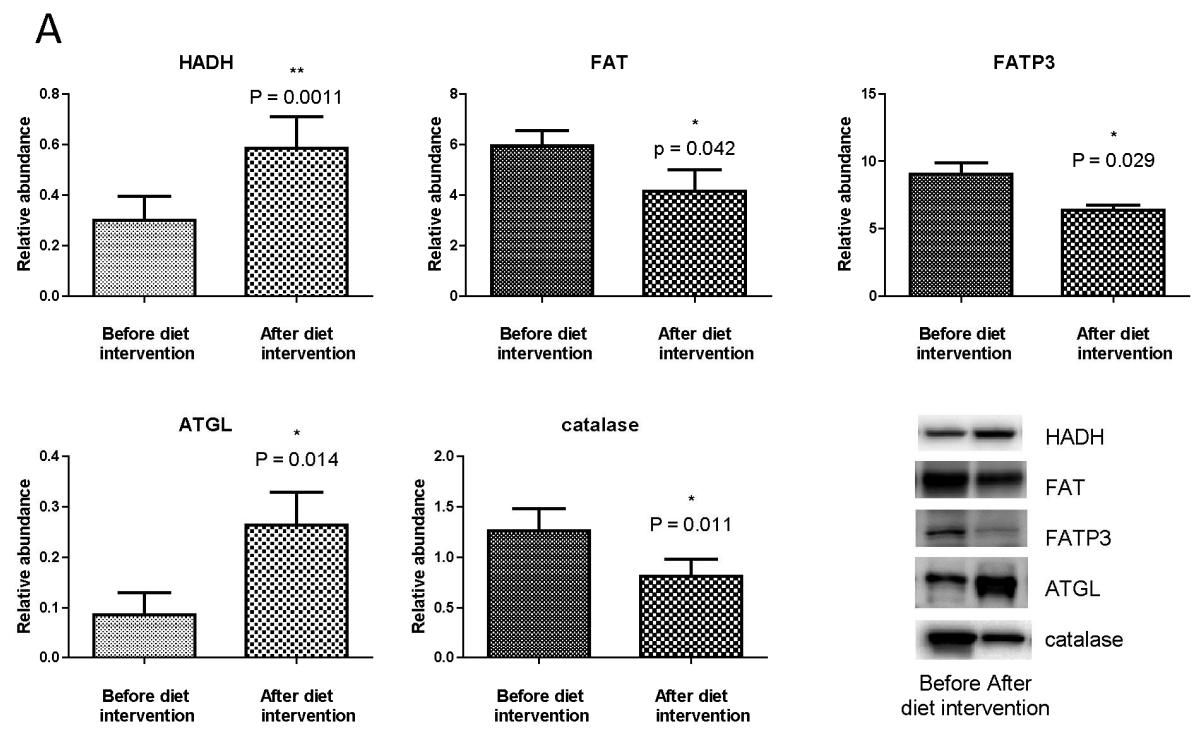

B

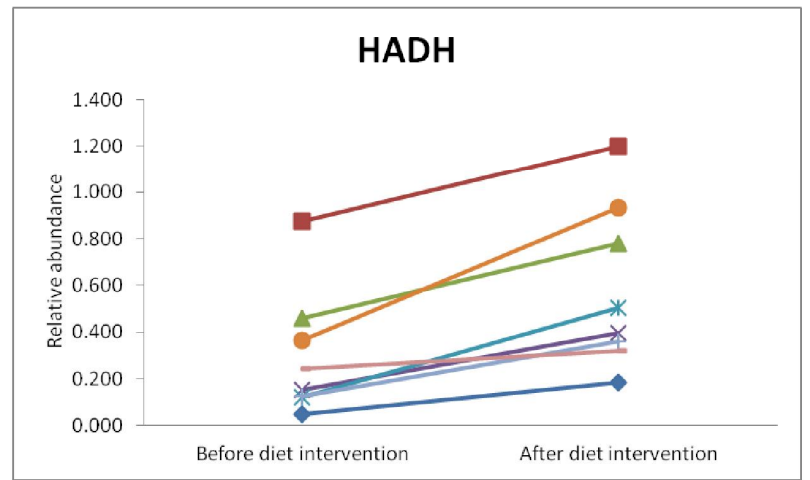

Figure 1: (A) Expression differences of the proteins HADH, FAT, FATP3, ATGL and catalase before and after the diet intervention as revealed by Western blotting. (B) HADH expression differences of the individual subject. 


\section{Before diet intervention}

\section{After diet intervention}
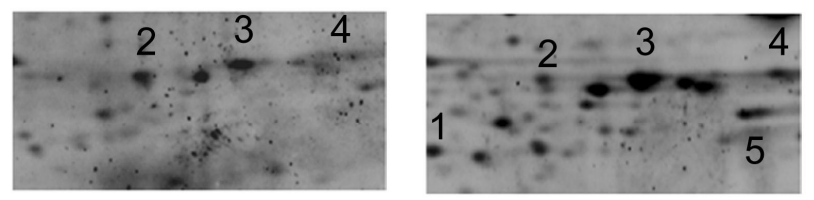

Sypro Ruby

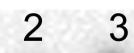

4
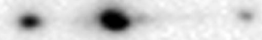

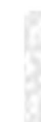
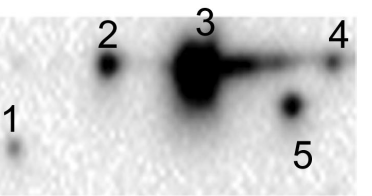

WB Annexin A2

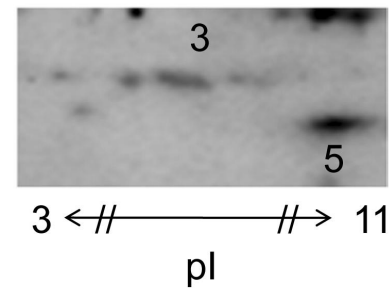

WB pTyr24 Annexin A2
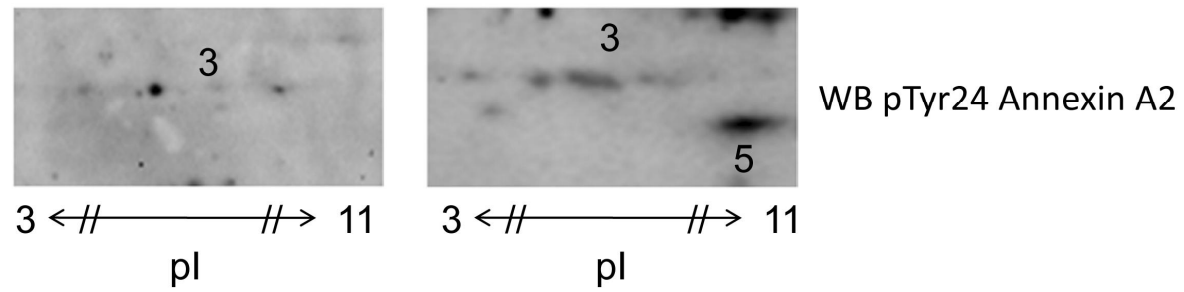

Figure 2: Phosphorylation of annexin A2 at Tyr24 after the diet intervention. The total 2D electrophoresis proteome was stained with Sypro-Ruby (upper panels) and subjected to Western blotting using antibodies against total annexin A2 (middle panels) and phospho-annexin A2 (lower panels).

Table 3: Identification of the indicated annexinA2 protein spots in figure 2 before and after the diet intervention.

\begin{tabular}{ccrrrrc}
\hline Spot & $\begin{array}{l}\text { Matched to } \\
\text { spot }\end{array}$ & $\begin{array}{l}\text { Accession } \\
\text { number }\end{array}$ & $\begin{array}{l}\text { Protein } \\
\text { description }\end{array}$ & $\begin{array}{l}\text { Mascot } \\
\text { score }\end{array}$ & $\begin{array}{l}\text { Sequence } \\
\text { coverage } \%\end{array}$ & $\begin{array}{l}\text { Matched } \\
\text { peptides }\end{array}$ \\
\hline 1 & ANXA2 16 & P07355 & ANXA2 & 63 & 11 & 4 \\
2 & & P07355 & ANXA2 & 42 & 8 & 3 \\
3 & ANXA $_{23}$ & P07355 & ANXA2 & 81 & 22 & 6 \\
4 & & P07355 & ANXA2 & 38 & 8 & 3 \\
5 & ANXA2 10 & P07355 & ANXA2 & 95 & 25 & 7 \\
\hline
\end{tabular}

The subscript refers to the protein spot numbers in Bouwman et al. [10]

\section{Connectivity network}

The individual protein changes during the intervention were used to determine Spearman correlations between all the proteins examined here and before [10]. A connectivity network was created (see Materials and Methods) of all the significant correlations (Figure 4). This reveals important relationships between glucose and fatty acid handling in adipocytes. Strong connectivity was observed between glucose uptake and fat storage/release either directly or via fatty acid synthesis, Another link exists between glucose uptake and mitochondrial $\beta$ oxidation. Via VLACS, peroxisomal beta-oxidation seems to participate in this connection. Based on the analyzed proteins, glucose and fatty acid uptake 
appeared to have no direct connection. Fat uptake seemed to link to fat storage/release and peroxisomal beta-oxidation. Key nodes in the connectivity map are: phospho-ANXA2, TUBB5, ALDOA, HSL, PLINA, PLINB, FAS, HADH, ACAT1 and VLACS.

A

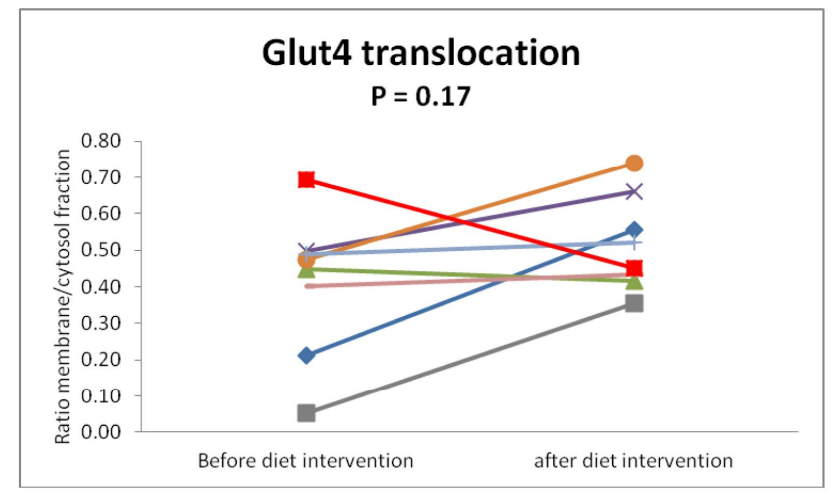

C

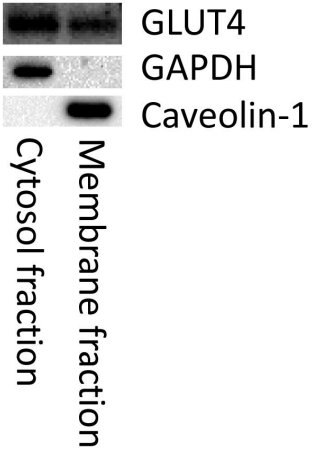

B

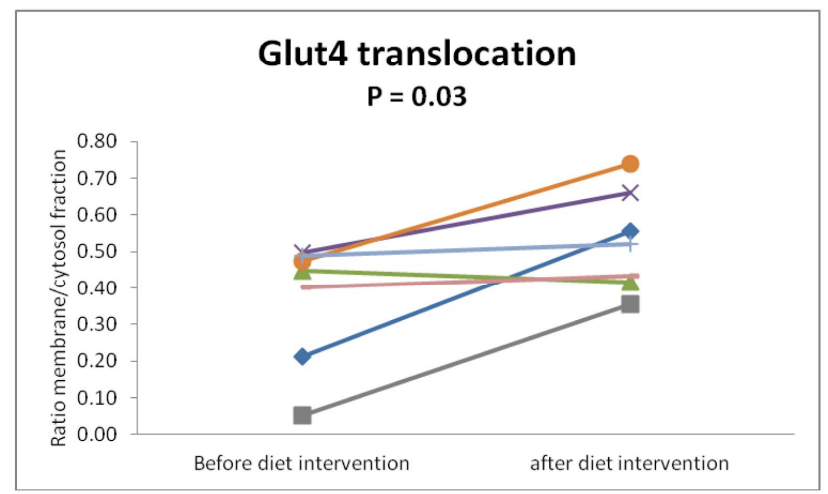

Figure 3: GLUT4 translocation with $(A)$ and without $(B)$ the subject indicated in red. As controls for the fractionation into the cytosolic and membrane fractions, antibodies against caveoline-1 and GAPDH were used for Westen blotting (C).

\section{DISCUSSION}

In the present study, anthropometric and physiological measurements were done at week 6 to examine the effect of weight loss on the whole body. In order to avoid effects of negative energy balance, adipose tissue was sampled with a delay of two weeks in the maintenance period. The gap between those time points was a weakness of this study design and did not allow linking protein expression with anthropometric and physiological measurements. Other 
limitations may be the small sample size and the fact that no metabolites could be analyzed. Although no functional measurements were performed directly, the strength of the present study is that by targeted proteomics of a broad list of proteins we thoroughly characterized potential metabolic adaptations of the adipose tissue occurring during the weight loss intervention.

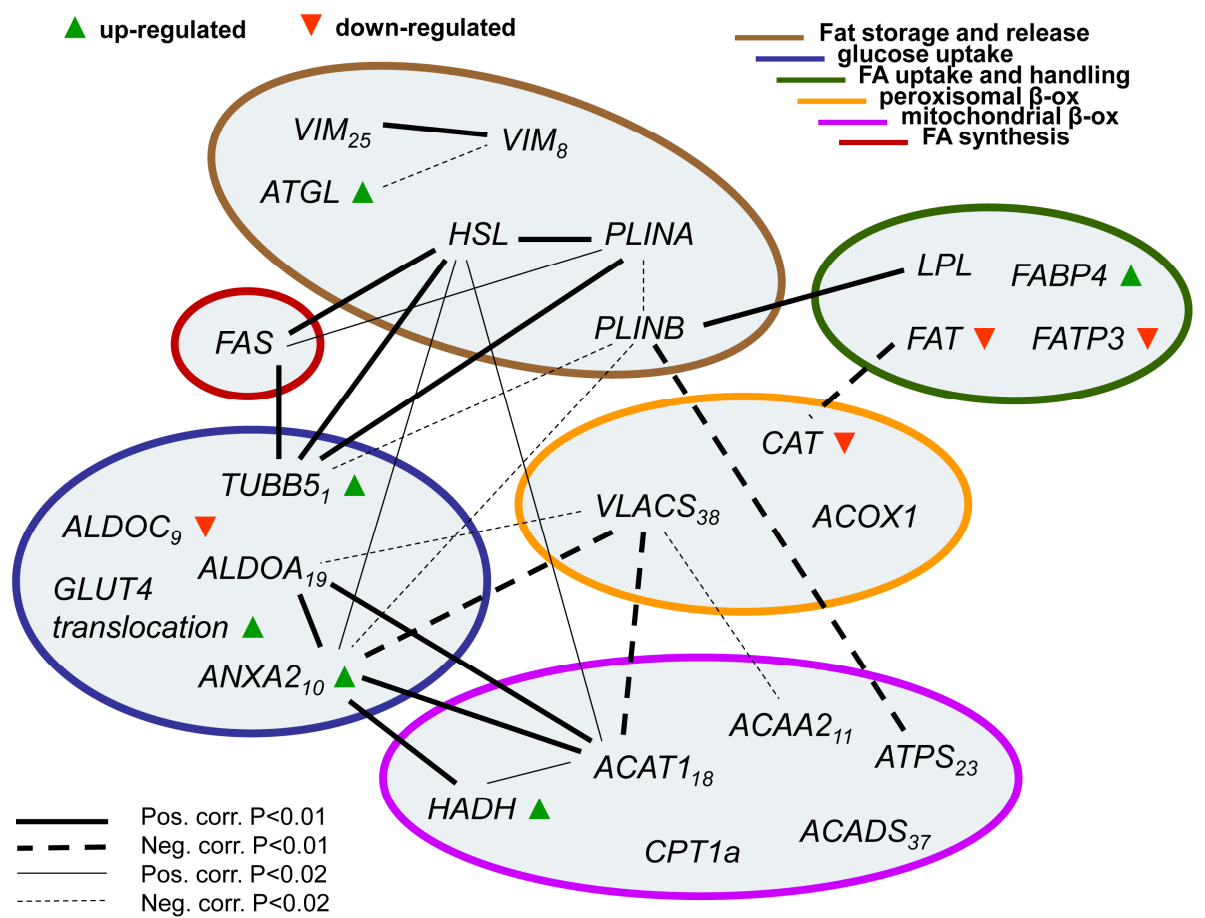

Figure 4: Connections between the various proteins and their metabolic processes. Drawn lines reflect a positive correlation and dotted lines a negative correlation. The thicker the line the more significant the correlation.

\section{Enhanced glucose uptake capacity without activated glycolysis}

As expected the intervention led to lower fasting plasma glucose and insulin levels, indicating improved insulin sensitivity in the body. In line with this we found on average an increase of GLUT4 translocation to the cell membrane in the subjects. In support of improved GLUT4 translocation we showed consistent up-regulation of an ANXA2 isoform that is phosphorylated at tyr-24, which enhances membrane phospholipid binding as shown in endothelial cells [14, 15]. Previously it was mentioned that aldolase favors the positioning of GLUT4vesicles to the actin filaments of the cytoskeleton in preparation of translocation to the membrane [10, 16]. Two isoforms of aldolase are present in adipose tissue. Only the concentration of ALDOA correlated with that of pANXA2 supporting a role for the A-isoform in GLUT4-translocation. ALDOC was 
decreased significantly after the intervention. Although aldolase is not a rate limiting enzyme, it suggests that the total glycolytic capacity, despite improved glucose uptake capacity, is reduced. The product of its reaction, glycerol-3phospate, is used as backbone in esterification of exogenous or de novo synthesized fatty acids to synthesize triglycerides. On the other hand, we found no significant change of FAS [17], which suggests a basal level of de novo fatty acid and triglyceride synthesis from glucose throughout the intervention. Altogether, the metabolic fate of increased intracellular glucose via the improved GLUT4 system therefore is unclear. Perhaps, glycogen synthesis is increased. Normally only $5 \%$ of glucose will enter this pathway, but under a refeeding state, it might be more significant [18].

\section{Enhanced mitochondrial beta-oxidation}

Adipocytes prefer to use glucose as the source of energy [3], but under conditions of calorie restriction, they turn to oxidation of fatty acids [2]. We wondered whether there would be a return to glucose as energy source in line with improved glucose uptake capacity, once moving into the maintenance phase. As expected, the peroxisomal enzymes involved in beta-oxidation were not different from baseline. Also, no difference from baseline was observed in the relative abundance of CPT1a, which facilitates the entering of long chain fatty acids into mitochondria.

However, HADH, the rate-limiting enzyme of mitochondrial beta-oxidation [19], increased almost 2 -fold as compared to the baseline. This suggests that after the intervention mitochondrial beta-oxidation of long-chain fatty acids in the adipose tissue is increased rather than has returned to basal levels.

\section{Elevated intracellular lipolysis}

Two major lipases are involved in the lipid droplet degradation, ATGL and HSL. The latter is activated by phosphorylation [20]. The significant up-regulation of ATGL and the same tendency of pHSL suggest an enhanced lipolysis after the intervention. The increased FABP4 might be used for binding newly released fatty acids. Since there is no indication for increased free fatty acid release into the circulation, the increased intracellular fatty acids might be used for the mitochondrial beta-oxidation.

\section{Reduced uptake but enhanced handling of lipid droplets}

We found that both fatty acid transporters FAT/CD36 and FATP3 were decreased in abundance by $30 \%$ after the intervention. In line with this, is the 
$20 \%$ lower level of LPL, the enzyme that releases fatty acids from lipoprotein particles at the outer membrane. This suggests an overall decrease of fatty acid uptake, which might be related to the low-fat diet during the maintenance period. The fat content in the diet was about $35 \%$ of the total energy intake at baseline, and reduced to less than $30 \%$ in the maintenance diet [11]. The significant reduction of catalase suggests also a reduced uptake and processing of very long chain fatty acids in the peroxisomes.

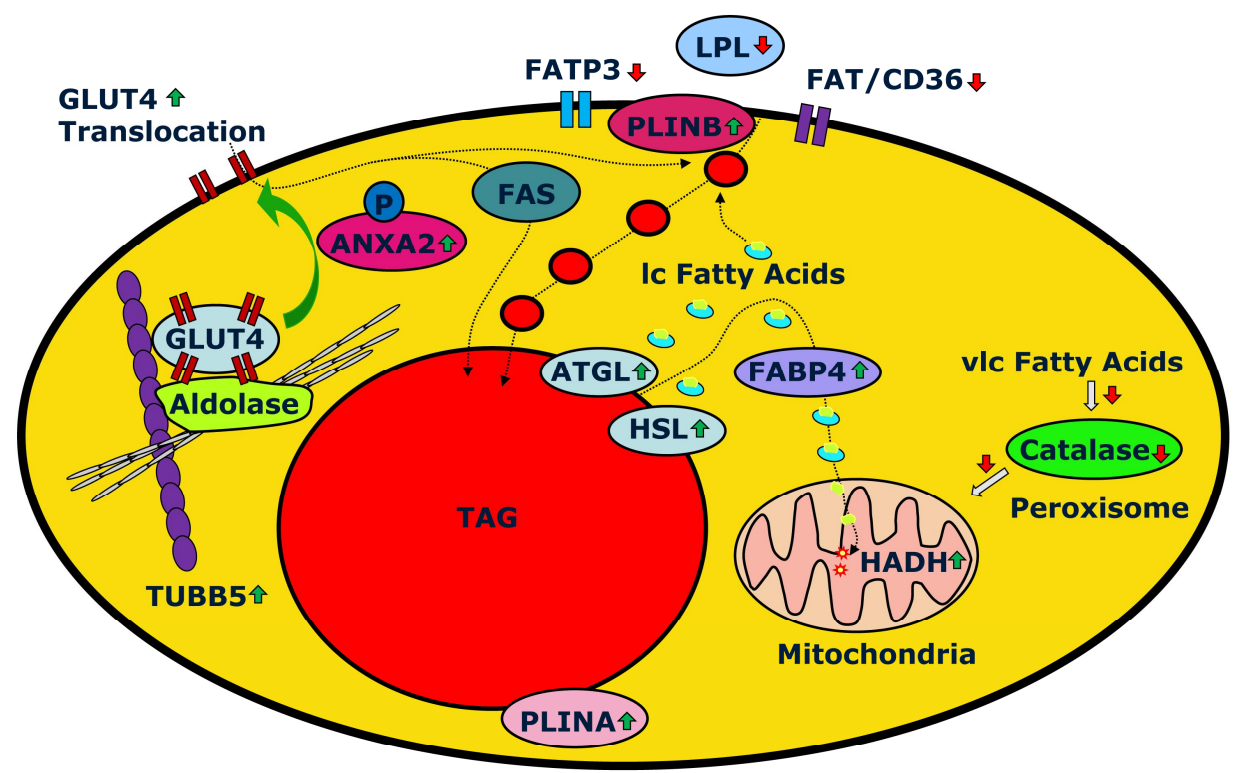

Figure 5: Proposed model for improved glucose uptake capacity with persistent beta-oxidation (IC: long-chain, vlc: very long-chain).

Two lipid droplet-associated proteins were examined. PLINA is the major coating protein of the central lipid droplet [21]. It increased 3-fold on average but not significantly. Nevertheless, this suggests that the overall lipid-storage capacity of the adipocytes did not decrease despite the considerable loss of fat mass. One possibility is that a significant proportion of PLINA has been phosphorylated and exists in the unbound state [22], which is in line with activated lipolysis [23]. Alternatively, fat droplets may have been dispersed to more and smaller droplets, which have a higher total surface area and require more PLINA.

PLINB is an alternative splicing form of PLINA. In primary human adipocytes it has been shown that insulin stimulates the accumulation of PLINB at the plasma membrane to protect the triglycerides freshly synthesized from reesterification of exogenous fatty acids [21, 24, 25]. Triglyceride synthesis 
probably happens at specific membrane caveolae forming lipid bulbs [25, 26] and from there triglycerides can be transported towards the central droplet either directly or via the endoplasmic reticulum [27]. Thus, PLINB is associated with the newly synthesized small and micro size lipid droplets. Our observations of a highly up-regulated PLINB would be in line with more and small lipid droplets. Small adipocyte size with small lipid droplets is generally considered as a metabolically more active, insulin sensitive and healthier state [28]. The change of PLINA and of PLINB seems to comply with such a health benefit of weight loss. Interestingly, PLINB showed a strong positive correlation with LPL, while the later one decreased over the same period. We speculate that after an initial decrease during the VLCD, both proteins are on rising at the maintenance period. PLINB increased more dramatically than LPL, leading to the final abundance higher than at baseline.

In summary, our observations indicates that after three weeks post-VLCD on a low-fat weight maintenance diet, adipocytes have not returned to glucose as their major source of energy despite improvement of the glucose uptake machinery. Rather, adipocytes still continue to favor energy from mitochondrial beta-oxidation of fatty acids released from the central lipid droplet. Since the central lipid droplet seems not to be replenished by uptake of fatty acids from the cell environment and by enhanced de novo lipid synthesis, the lipid droplet may tend to be dispersed and get smaller (Figure 5), the correlation analysis showed that there is a strong connection between mitochondrial beta-oxidation and PANXA2 as the regulator of GLUT4 translocation. It suggests that glucose uptake is sustaining or even required for enhanced beta-oxidation. Our results confirm the interdependence of glucose and lipid metabolism in adipocytes [18]. However, such a model is based on the assumption that all these protein changes occur in matured adipocytes experiencing calorie restriction and refeeding. The reality for the adipose tissue can be far more complex [29]. The increase of glucose uptake, mitochondrial beta-oxidation, lipid droplet-coating proteins and lipases is also a profile of adipogenesis [30]. De novo adipogenesis after weight loss and refeeding was suggested for the rat [31]. The observed profile would also fit to that of brown adipocytes on the RNA level $[32,33]$. Although there is no evidence yet that weight loss and maintenance stimulate adipocyte differentiation or white-to-brown transdifferentiation, it might be interesting to explore those possibilities in future studies.

Whatever the exact explanation may be, this protein profile of the white adipose tissue suggests that after weight loss by calorie restriction and a short period of maintenance, adipose tissue has an increased capacity for glucose uptake, lipid mobilization and oxidation. Such a metabolic profile may relate to the health benefit of weight loss. 


\section{Acknowledgements}

This research was supported by the Maastricht Proteomics Center of Maastricht University. We thank Gert Schaart for the donation of the pHSL-Ser565 antibody and help with cytosol and membrane isolation and Johan Jocken for the donation of the ATGL antibody. We also thank Mandy Claessens for executing the human study and collecting the samples.

\section{References}

1. Speakman JR \& Mitchell SE (2011) Caloric restriction. Mol Aspects Med 32(3):159-221.

2. Franck $\mathrm{N}$, et al. (2011) Identification of adipocyte genes regulated by caloric intake. J Clin Endocrinol Metab 96(2):E413-418.

3. Frayn KN, Humphreys SM, \& Coppack SW (1995) Fuel selection in white adipose tissue. The Proceedings of the Nutrition Society 54(1):177-189.

4. Magnusson B, et al. (2008) Cell death-inducing DFF45-like effector C is reduced by caloric restriction and regulates adipocyte lipid metabolism. Metabolism 57(9):1307-1313.

5. Guarente L (2008) Mitochondria--a nexus for aging, calorie restriction, and sirtuins? Cell 132(2):171-176.

6. Maassen JA, Romijn JA, \& Heine RJ (2007) Fatty acid-induced mitochondrial uncoupling in adipocytes as a key protective factor against insulin resistance and beta cell dysfunction: a new concept in the pathogenesis of obesity-associated type 2 diabetes mellitus. Diabetologia 50(10):2036-2041.

7. Johansson LE, et al. (2012) Differential gene expression in adipose tissue from obese human subjects during weight loss and weight maintenance. The American journal of clinical nutrition 96(1):196-207.

8. Viguerie $\mathrm{N}$, et al. (2005) Transcriptomics applied to obesity and caloric restriction. Biochimie 87(1):117-123.

9. Vogel C \& Marcotte EM (2012) Insights into the regulation of protein abundance from proteomic and transcriptomic analyses. Nature reviews. Genetics 13(4):227-232.

10. Bouwman FG, et al. (2009) The physiologic effects of caloric restriction are reflected in the in vivo adipocyte-enriched proteome of overweight/obese subjects. J Proteome Res 8(12):55325540.

11. Claessens M, van Baak MA, Monsheimer S, \& Saris WH (2009) The effect of a low-fat, highprotein or high-carbohydrate ad libitum diet on weight loss maintenance and metabolic risk factors. Int J Obes (Lond) 33(3):296-304.

12. Koopman R, Zorenc AH, Gransier RJ, Cameron-Smith D, \& van Loon LJ (2006) Increase in S6K1 phosphorylation in human skeletal muscle following resistance exercise occurs mainly in type II muscle fibers. American journal of physiology 290(6):E1245-1252.

13. Borghouts LB, Schaart G, Hesselink MK, \& Keizer HA (2000) GLUT-4 expression is not consistently higher in type-1 than in type-2 fibres of rat and human vastus lateralis muscles; an immunohistochemical study. Pflugers Arch 441(2-3):351-358.

14. Deora AB, Kreitzer G, Jacovina AT, \& Hajjar KA (2004) An annexin 2 phosphorylation switch mediates p11-dependent translocation of annexin 2 to the cell surface. The Journal of biological chemistry 279(42):43411-43418.

15. Johnsson N, Marriott G, \& Weber K (1988) p36, the major cytoplasmic substrate of src tyrosine protein kinase, binds to its $\mathrm{p} 11$ regulatory subunit via a short amino-terminal amphiphatic helix. EMBO J 7(8):2435-2442.

16. Kao AW, Noda Y, Johnson JH, Pessin JE, \& Saltiel AR (1999) Aldolase mediates the association of F-actin with the insulin-responsive glucose transporter GLUT4. The Journal of biological chemistry 274(25):17742-17747.

17. Kuerschner L, Moessinger C, \& Thiele C (2008) Imaging of lipid biosynthesis: how a neutral lipid enters lipid droplets. Traffic 9(3):338-352. 
18. Markan KR, Jurczak MJ, \& Brady MJ (2010) Stranger in a strange land: roles of glycogen turnover in adipose tissue metabolism. Mol Cell Endocrinol 318(1-2):54-60.

19. Sato M, Tsuneyoshi Y, Sato K, \& Furuse M (2009) Comparison of 3-Hydroxyacyl CoA Dehydrogenase Activity Between Broiler and Layer Chickens During Embryonic Development. Research Journal of Biological Sciences 4(5):585-587.

20. Langin D \& Arner P (2006) Importance of TNFalpha and neutral lipases in human adipose tissue lipolysis. Trends Endocrinol Metab 17(8):314-320.

21. Aboulaich N, Vener AV, \& Stralfors $P$ (2006) Hormonal control of reversible translocation of perilipin B to the plasma membrane in primary human adipocytes. The Journal of biological chemistry 281(17):11446-11449.

22. Brasaemle DL (2007) Thematic review series: adipocyte biology. The perilipin family of structural lipid droplet proteins: stabilization of lipid droplets and control of lipolysis. Journal of lipid research 48(12):2547-2559.

23. Granneman JG, et al. (2007) Analysis of lipolytic protein trafficking and interactions in adipocytes. The Journal of biological chemistry 282(8):5726-5735.

24. Large V, Peroni O, Letexier D, Ray H, \& Beylot M (2004) Metabolism of lipids in human white adipocyte. Diabetes Metab 30(4):294-309.

25. Ost A, Ortegren U, Gustavsson J, Nystrom FH, \& Stralfors P (2005) Triacylglycerol is synthesized in a specific subclass of caveolae in primary adipocytes. The Journal of biological chemistry 280(1):5-8.

26. Cohen AW, et al. (2004) Role of caveolin-1 in the modulation of lipolysis and lipid droplet formation. Diabetes 53(5):1261-1270.

27. Garg A \& Agarwal AK (2008) Caveolin-1: a new locus for human lipodystrophy. J Clin Endocrinol Metab 93(4):1183-1185.

28. Varlamov O, et al. (2010) Single-cell analysis of insulin-regulated fatty acid uptake in adipocytes. American journal of physiology 299(3):E486-496.

29. Cinti S (2012) The adipose organ at a glance. Dis Model Mech 5(5):588-594.

30. Ross SE, et al. (2002) Microarray analyses during adipogenesis: understanding the effects of Wnt signaling on adipogenesis and the roles of liver $\mathrm{X}$ receptor alpha in adipocyte metabolism. Mol Cell Biol 22(16):5989-5999.

31. Maclean PS, Bergouignan A, Cornier MA, \& Jackman MR (2011) Biology's response to dieting: the impetus for weight regain. Am J Physiol Regul Integr Comp Physiol 301(3):R581-600.

32. Wu HT, et al. (2009) Insulin resistance without obesity induced by cotton pellet granuloma in mice. Lab Invest 89(3):362-369.

33. Ahfeldt T, et al. (2012) Programming human pluripotent stem cells into white and brown adipocytes. Nat Cell Biol 14(2):209-219. 


\section{Chapter 5}

\section{A combination of protein profiling and isotopomer analysis using matrix-assisted laser desorption/ionization-time of flight mass spectrometry reveals an active metabolism of the extracellular matrix of 3T3-L1 adipocytes}

Freek Bouwman, Johan Renes \& Edwin Mariman

Department of Human Biology, Nutrition and Toxicology Research Institute Maastricht (NUTRIM), Maastricht University, Maastricht, The Netherlands

Proteomics, 2004, Dec, 4 (12), p. 3855-3863 


\section{ABSTRACT}

Differential gel electrophoresis followed by MALDI-TOF mass spectrometry is a commonly used protein profiling method. However, observed changes can be explained in multiple ways, one is by protein turnover rate. In order to easily and rapidly obtain information on both identity and turnover of individual proteins, we applied the combination of protein labeling with L-(ring-2,3,4,5,6 2H5) phenylalanine and MALDI-TOF mass spectrometry. While the spectrum reveals the identity of a protein, mass isotopomer analysis provides information about the rate of protein labeling as a measure for synthesis or turnover. Using this approach on mature 3T3-L1 adipocytes, we were able to discriminate between rapidly and slowly metabolising proteins. In our isolate, proteins of the cytoskeleton appeared to be slowly metabolising, whereas components of the extracellular matrix, in particular collagen type I alpha 1 (COL1A1) and collagen type I alpha 2 (COL1A2) show a rapid accumulation of newly synthesized proteins. Both proteins appeared to be metabolised in the same ratio as they are present in collagen fibers, i.e. 2:1 (COL1A1:COL1A2). In addition, functionally related proteins were also readily labeled. Taken together, we have shown that a combination of stable isotope labeling and protein profiling by gel electrophoresis and MALDI-TOF analysis can simultaneously provide information on the identity and on the relative metabolic rate of proteins in eukaryotic cells in a simple, non-hazardous and rapid-throughput way. 


\section{INTRODUCTION}

Differential gel electrophoresis is commonly accepted as a powerful technique to study changes in gene expression at the level of the proteins. Traditionally, the composition of various protein isolates is compared after separation on 1-Dor 2-D-polyacrylamide gels as band- or spot-patterns, respectively. Quantitative differences observed in this way are the reflection of differences in the expression of individual genes, which can be identified using mass spectrometric analysis of the respective proteins. Differences in protein concentration as seen on gels can in principle be ascribed to alternative mechanisms of regulation including changes in protein turnover, posttranslational modification and transition to or from an organelle or a cellular substructure which is not represented in the protein isolate [1, 2]. To be able to discriminate between those alternatives, protein profiling needs to be followed by other analytical assays [3].

Protein turnover is a result of synthesis and breakdown and, in general, labeling experiments are performed to quantify these processes [4]. Rate of incorporation of label can be taken as a measure of protein turnover, which usually involves incubation of cells or tissues with one or more radioactive amino acids [5]. This approach has the practical limitation that analyses have to be executed under conditions of containment and that different samples have to be used for protein profiling on one hand and for quantification of label incorporation on the other. Here we report on a method in which protein profiling and measurement of label incorporation are performed with the same sample from mature 3T3-L1 adipocytes using an amino acid labeled with a stable isotope. MALDI-TOF analysis of individual proteins separated by 1-D- or 2-Dgelelectrophoresis enables the identification of the proteins whereas the analysis of isotopomer peaks from the spectrum provides additional information on the metabolism of each protein. This combined method can be used in a high-throughput set-up.

\section{MATERIALS AND METHODS}

\section{Materials}

DMEM/F12 was from Invitrogen (Carlsbad, CA, USA). Fetal calf serum was from Bodinco (Alkmaar, The Netherlands). L-(ring-2,3,4,5,6 2H5) phenylalanine was obtained from Cambridge Isotope Laboratories (Andover, MA, USA). Insulin, 3-isobutyl-1-methyl-xanthine, dexamethasone, CHAPS, DTT, iodoacetamide, $\alpha$-cyano-4-hydroxycinnamic acid, alcohol dehydrogenase and 
adrenocorticotropic hormone fragment 18-39 were from Sigma (St. Louis, MO, USA). Prostaglandin 12 was from Biomol (Plymouth Meeting, PA, USA). Urea was from Bio-Rad (Hercules, CA, USA). Immobiline Dry Strips pH 3-10 Non Linear $18 \mathrm{~cm}$ long and ${ }^{14} \mathrm{C}$-phenylalanine were from Amersham Biosciences (Little Chalfont, England). Sequencing grade modified trypsin was obtained from Promega (Madison, WI, USA).

\section{Cell culture}

Mouse 3T3-L1 preadipocytes were obtained from the American Type Culture Collection and cultured in DMEM/F12 containing 10\% fetal calf serum. Two days after reaching confluence, preadipocytes were induced to differentiate into adipocytes by culturing in DMEM/F12 containing $10 \%$ fetal calf serum plus 0.5 $\mathrm{mM}$ 3-isobutyl-1-methyl-xanthine, $1 \mu \mathrm{M}$ Dexamethasone and $10 \mu \mathrm{M}$ prostaglandin 12 for one day [6], followed by 12 days in DMEM/F12 containing $10 \%$ fetal calf serum plus $1 \mu \mathrm{M}$ insulin. Differentiation was monitored by the visual appearance of fat droplets in the cells [7]. At day 12 adipocytes were incubated for 0,6 and 24 hours, respectively, in culture medium to which 35.48 $\mathrm{mg} / \mathrm{l}$ stable isotope $\mathrm{L}-($ ring-2,3,4,5,6 $2 \mathrm{H} 5$ ) phenylalanine was added. The final concentration of phenylalanine was thereby doubled with a 1:1 ratio of labeled vs. unlabeled. For comparison with standard labeling methods 3T3-L1 adipocytes were labeled with $20 \mu \mathrm{Ci}(450 \mu \mathrm{Ci} / \mu \mathrm{mol}){ }^{14} \mathrm{C}$-phenylalanine for 6 hours. Phenylalanine was chosen for these experiments, because this amino acid is known to have a rapid exchange with the unlabeled phenylalanine-pool. In addition, it is known to be poorly metabolised in most tissues, except for liver.

\section{Sample preparation}

Cells were washed twice with ice-cold serum free medium, scraped off in PBS and collected in a tube. After centrifugation at $350 \times \mathrm{g}$ for 5 minutes at $4^{\circ} \mathrm{C}$ the cells were resuspended in $200 \mu \mathrm{l} 8 \mathrm{M}$ urea, $2 \%$ w/v CHAPS, $65 \mathrm{mM}$ DTT. Cells were lysed by subjecting them to three cycles of quick freezing in liquid nitrogen and subsequent thawing. The homogenate was vortexed for 1 minute and centrifuged at $20000 \mathrm{x} \mathrm{g}$ for 30 minutes at $10^{\circ} \mathrm{C}$. The supernatant was carefully collected and aliquots were stored at $-50^{\circ} \mathrm{C}$. The protein concentration was determined by a Bradford based protein assay [8].

\section{SDS-PAGE}

$25 \mu \mathrm{g}$ of total protein was loaded on 12.5\% SDS-PAGE gels and electrophoresis was conducted at a constant current of $35 \mathrm{~mA}$ for 4 hours. The 
gels were stained with $\mathrm{CBB}$ according the following protocol. The gels were rinsed with deionized water, stained overnight with $0.1 \% \mathrm{w} / \mathrm{v}$ CBB in $40 \% \mathrm{v} / \mathrm{v}$ ethanol and $10 \% \mathrm{v} / \mathrm{v}$ acetic acid and destained in $30 \% \mathrm{v} / \mathrm{v}$ methanol and $10 \%$ $\mathrm{v} / \mathrm{v}$ acetic acid for 8 hours. Gel images were obtained with a GS-800 calibrated densitometer (Bio-Rad). Molecular weight values were estimated using standard MW-markers.

\section{2-D-electrophoresis}

$100 \mu \mathrm{g}$ of total protein was loaded for the first dimension. Isoelectric focusing was performed on a IPG PHOR electrophoresis unit (Amersham Biosciences) at $20^{\circ} \mathrm{C}$. Immobiline Dry Strips $(\mathrm{pH} \mathrm{3-10} \mathrm{Non} \mathrm{Linear,} 18 \mathrm{~cm}$ long) were rehydrated overnight in $350 \mu \mathrm{l}$ of $8 \mathrm{M}$ urea, $2 \% \mathrm{w} / \mathrm{v}$ CHAPS, $65 \mathrm{mM}$ DTT, $0.5 \%$ $\mathrm{V} / \mathrm{V}$ IPG buffer $\mathrm{pH}$ 3-10 Non Linear at $30 \mathrm{~V}$. Isoelectric focusing was performed using the following program: $500 \mathrm{~V}$ for 1 hour, $1000 \mathrm{~V}$ for 1 hour, $1000-8000 \mathrm{~V}$ for 2 hours and a final step of $8000 \mathrm{~V}$ for $56250 \mathrm{Vh}$. After focusing, IPG strips were equilibrated for 15 minutes in $50 \mathrm{mM}$ Tris- $\mathrm{HCl}, \mathrm{pH} 6.8,6 \mathrm{M}$ urea, $30 \% \mathrm{v} / \mathrm{v}$ glycerol, $2 \% \mathrm{w} / \mathrm{v}$ SDS, $1 \% \mathrm{w} / \mathrm{v}$ DTT and for 15 minutes in $50 \mathrm{mM}$ Tris- $\mathrm{HCl}, \mathrm{pH}$ $6.8,6 \mathrm{M}$ urea, $30 \% \mathrm{v} / \mathrm{v}$ glycerol, $2 \% \mathrm{w} / \mathrm{v}$ SDS, $2.5 \% \mathrm{w} / \mathrm{v}$ iodoacetamide, and were placed onto a slab gel and sealed with a $0.5 \% \mathrm{w} / \mathrm{v}$ agarose solution in Laemmli buffer with a trace of bromophenol blue. The second-dimension run was carried out on $12.5 \%$ SDS-PAGE gels. Electrophoresis was conducted at a constant voltage of $200 \mathrm{~V}$ for 5 hours in a $24 \mathrm{~cm}$ Dodeca Cell (Bio-Rad) [9, 10]. In-gel proteins were stained with CBB as described above. Gel images were obtained with a GS-800 calibrated densitometer (Bio-Rad).

\section{In-gel digestion}

Protein spots were manually excised on a glass plate from the gel and processed on a MassPREP digestion robot (Waters, Manchester UK). A solution of $50 \mathrm{mM}$ ammonium bicarbonate in $50 \%(\mathrm{v} / \mathrm{v})$ acetonitrile was used for destaining. Cysteines were reduced with $10 \mathrm{mM}$ DTT in $100 \mathrm{mM}$ ammonium bicarbonate for 30 minutes followed by alkylation with $55 \mathrm{mM}$ iodoacetamide in $100 \mathrm{mM}$ ammonium bicarbonate for 20 minutes. Spots were washed with 100 $\mathrm{mM}$ ammonium bicarbonate to remove excess reagents and were subsequently dehydrated with $100 \%$ acetonitrile. Trypsin $(6 \mathrm{ng} / \mathrm{\mu l})$ in $50 \mathrm{mM}$ ammonium bicarbonate was added to the gel plug and incubation was performed at $37{ }^{\circ} \mathrm{C}$ for 5 hours. The peptides were extracted with $1 \%(\mathrm{v} / \mathrm{v})$ formic acid / $2 \%(\mathrm{v} / \mathrm{v})$ acetonitrile [11]. 


\section{Mass spectrometry}

For MALDI-TOF mass spectrometry $1.5 \mu \mathrm{l}$ of each peptide mixture and $0.5 \mu \mathrm{l}$ matrix solution $(10 \mathrm{mg} / \mathrm{ml} \alpha$-cyano-4-hydroxycinnamic acid in $50 \%$ acetonitrile/ $0.1 \%$ TFA) was spotted automatically onto a 96 well-format target plate. The spots were allowed to air dry for homogeneous crystallization. Spectra were obtained using a M@LDI-LR mass spectrometer (Waters). The instrument was operated in positive reflector mode. Acquisition mass range was 900-3000 Da. The instrument was calibrated on 6-8 reference masses from a tryptic digest of alcohol dehydrogenase. In addition, a near point lockmass correction for each sample spot was performed using adrenocorticotropic hormone fragment 18-39 $(\mathrm{MH}+2465.199)$ to achieve maximum mass accuracy. Typically 100 shots were combined and background subtracted. A peptide mass list was generated for the subsequent database search. For semi-quantitative labeling measurements, the area of the $M+5$ peak was divided by that of the $M$ peak $\times 100 \%$. A standard deviation was obtained for this isotopomer mass peak ratio by repeating the experiment three times. Significance of differences between ratios was determined by ANOVA.

\section{Database search}

The peptide mass list was searched with ProteinLynx Global Server (Waters) or Mascot search engine (http://www.matrixscience.com) against the Swiss-Prot database (http://expasy.ch/sprot) for protein identification. One miss-cleavage was tolerated, carbamidomethylation was set as a fixed modification and oxidation of methionine as an optional modification. The peptide mass tolerance was set to $100 \mathrm{ppm}$. No restrictions were made on the protein molecular weight and the isoelectric point. A protein was regarded identified with a significant ProteinLynx or Mascot probability score $(p<0.05)$ and at least five peptide mass hits or sequence coverage of at least $30 \%$ of the complete protein sequence.

\section{RESULTS}

\section{Detection of label-accumulating proteins by 1-D-profiling}

In order to analyse the accumulation of label in proteins as an indication of protein turnover, 12-day differentiated mouse 3T3-L1 adipocytes were incubated with L-(ring-2,3,4,5,6 2H5) phenylalanine for 0,6 and 24 hours, respectively. Total protein was isolated and separated by SDS-PAGE. After staining the gels with $\mathrm{CBB}$, no differences were observed in the protein banding 
patterns (Figure $1 \mathrm{~A}$ ) indicating that our labeling procedure did not interfere with protein metabolism in these cells. Labeling of individual proteins was assessed by random selection of 27 of the most prominent bands. Those bands were excised from the gel and subjected to MALDI-TOF mass spectrometry for identification. As an example, the spectrum of a protein of approximately 170 $\mathrm{kDa}$ (band 1 in Figure $1 \mathrm{~A}$ ) is shown in Figure 2. Using the spectrometric data to search the Swiss-Prot database revealed the identity of the protein as the precursor of COL1A1. In Figure 3 the primary sequence of the protein is given and the tryptic peptides that were matched with peaks of the spectrum, are underlined. The coverage was $33 \%$. The two peptides that contain the amino acid phenylalanine and correspond to prominent peaks in the spectrum are boxed. Analysis of the corresponding peaks, m/z 1411 and 2647, at a high resolution revealed that already after 6 hours of labeling a considerable isotopomer peak was present (Figure 4), which increased in relative height up to 24 hours of labeling.

Table 1. List of identified proteins from the SDS PAGE gel.

\begin{tabular}{|c|c|c|c|c|c|c|}
\hline \multirow[t]{2}{*}{ Band } & \multirow{2}{*}{$\begin{array}{l}\text { Accession } \\
\text { number }\end{array}$} & \multirow{2}{*}{ Protein name } & \multicolumn{3}{|c|}{ Peak ratio (x 100\%) } & \multirow{2}{*}{$\begin{array}{l}\# \text { of } F \text { in } \\
\text { spectrum } \\
\text { peaks }\end{array}$} \\
\hline & & & $\mathrm{Oh}$ & $6 \mathrm{~h}$ & $24 \mathrm{~h}$ & \\
\hline 1 & P11087 & $\begin{array}{l}\text { Collagen type I alpha 1, } \\
\text { precursor }\end{array}$ & $11.2 \pm 6.5$ & $48.1 \pm 12.5^{*}$ & $75.3 \pm 6.6^{*}$ & 3 \\
\hline 2 & Q01149 & $\begin{array}{l}\text { Collagen type I alpha } 2 \text {, } \\
\text { precursor }\end{array}$ & $11.3 \pm 2.4$ & $36.8 \pm 8.7^{*}$ & $66.4 \pm 5.1^{*}$ & 1 \\
\hline 3 & P57780 & Alpha-actinin 4 & $26.7 \pm 7.5$ & $23.4 \pm 0.29$ & $35.4 \pm 5.8$ & 2 \\
\hline 4 & P20029 & $\begin{array}{l}78 \mathrm{kDa} \text { glucose-regulated } \\
\text { protein }\end{array}$ & $6.9 \pm 2.7$ & $12.4 \pm 3.9$ & $21.0 \pm 2.3^{*}$ & 7 \\
\hline 5 & P20029 & $\begin{array}{l}78 \mathrm{kDa} \text { glucose-regulated } \\
\text { protein }\end{array}$ & $5.5 \pm 1.6$ & $12.2 \pm 3.7$ & $21.4 \pm 2.7^{*}$ & 7 \\
\hline 6 & P38647 & $\begin{array}{l}\text { Mitochondrial stress-70 } \\
\text { protein }\end{array}$ & $10.5 \pm 1.2$ & $13.6 \pm 8.0$ & $22.6 \pm 2.8$ & 4 \\
\hline 7 & P14211 & Calreticulin & $6.1 \pm 2.1$ & $8.5 \pm 2.2$ & $16.2 \pm 0.64^{*}$ & 4 \\
\hline 8 & P09103 & Protein disulfide isomerase & $11.3 \pm 4.3$ & $11.2 \pm 3.1$ & $23.1 \pm 2.5^{\star}$ & 5 \\
\hline 9 & P11516 & Lamins $\mathrm{C}$ and $\mathrm{C} 2$ & $17.1 \pm 10.9$ & $7.9 \pm 1.3$ & $15.8 \pm 5.2$ & 1 \\
\hline 10 & P56480 & Mt ATP synthase beta chain & $6.8 \pm 2.5$ & $6.8 \pm 0.94$ & $13.1 \pm 0.77^{*}$ & 5 \\
\hline 11 & P20152 & Vimentin & $12.7 \pm 3.4$ & $9.7+1.8$ & $18.6 \pm 6.1$ & 3 \\
\hline 12 & P20152 & Vimentin & $4.4 \pm 2.1$ & $5.5 \pm 3.6$ & $10.2 \pm 2.9$ & 3 \\
\hline 13 & P99022 & Gamma-actin & $5.6 \pm 2.8$ & $4.8 \pm 0.22$ & $10.9 \pm 0.54^{*}$ & 4 \\
\hline 14 & P07356 & Annexin A2 & $6.5 \pm 3.3$ & $5.6 \pm 2.6$ & $8.6 \pm 1.0$ & 2 \\
\hline 15 & O88569 & hnRNP A2/B1 & $5.8 \pm 3.2$ & $9.9 \pm 1.8$ & $24.5 \pm 3.0^{*}$ & 8 \\
\hline 16 & P17742 & $\begin{array}{l}\text { Peptidyl-prolyl cis-trans } \\
\text { isomerase A }\end{array}$ & $7.0 \pm 1.8$ & $8.9 \pm 1.6$ & $17.0 \pm 1.0^{*}$ & 8 \\
\hline 17 & P16045 & Galectin-1 & $8.1 \pm 2.9$ & $10.3 \pm 2.9$ & $16.4 \pm 5.5^{*}$ & 3 \\
\hline
\end{tabular}

Peak ratio values are expressed as mean $\pm \mathrm{SD}, \mathrm{n}=3,{ }^{*} \mathrm{P}<0.05$ by ANOVA 
A

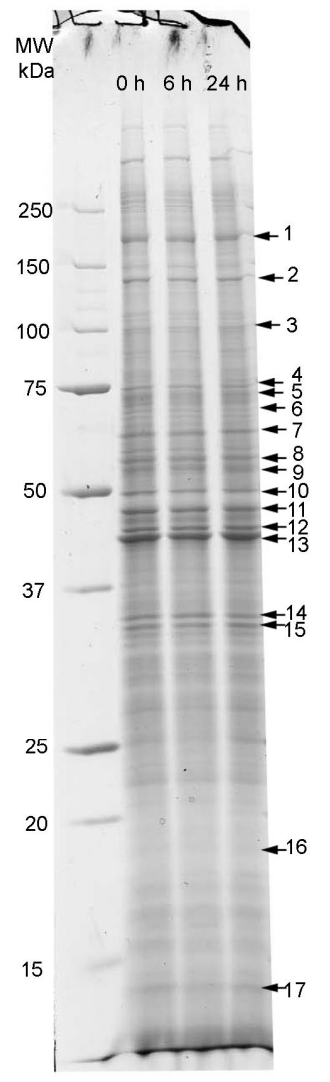

B $6 \mathrm{~h}$

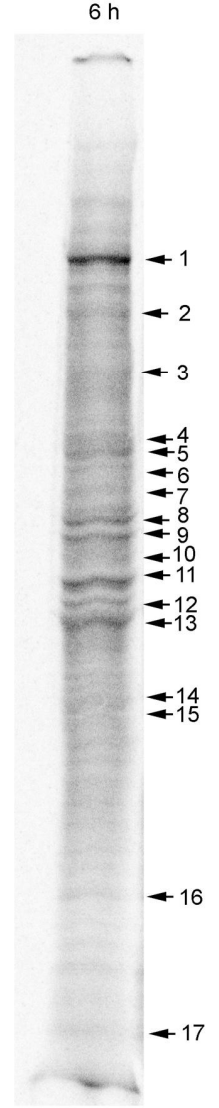

Figure 1. (A) CBB stained band pattern of proteins isolated from mouse 3T3-L1 adipocytes and separated by SDS-PAGE after 0,6 and 24 hours incubation with the stable isotope labeled L-(ring$2,3,4,5,62 \mathrm{H} 5$ ) phenylalanine. 17 bands are indicated of which the protein identity was revealed (see table 1). These proteins had at least one phenylalanine containing peptide in the MALDI-TOF spectrum. (B) Autoradiogram of proteins isolated from mouse 3T3-L1 adipocytes and separated by SDS-PAGE after 6 hours incubation with 14C-phenylalanine. The band numbers refer to table 1 and figure $1 \mathrm{~A}$.

From the excised 27 proteins, 17 could be identified which had at least one phenylalanine-containing peptide in the spectrum (Figure 1A, Table 1). A semiquantitative value with respect to labeling efficiency was assigned to the proteins by determining the isotopomer peak area ratio at each time point (Table 1). Of those 17 proteins, 2 showed already labeling after $6 \mathrm{~h}$, an additional 9 proteins showed labeling after $24 \mathrm{~h}$, whereas no significant labeling could be observed for the other proteins. This shows that in our protein sample there is indeed a considerable difference in labeling rate between individual proteins. For instance, for COL1A1 a peak area ratio of 0.48 (labeled/unlabeled) 
was observed at 6 hours labeling. According to the formula $2 x$ (area of labeled peak)/(area of labeled peak + area of unlabeled peak) and taking its value at 0 hours as background, $45 \%$ of that protein in our sample had been replaced by newly produced molecules after 6 hours. In contrast, only $17 \%$ of calreticulin had been renewed within 24 hours.

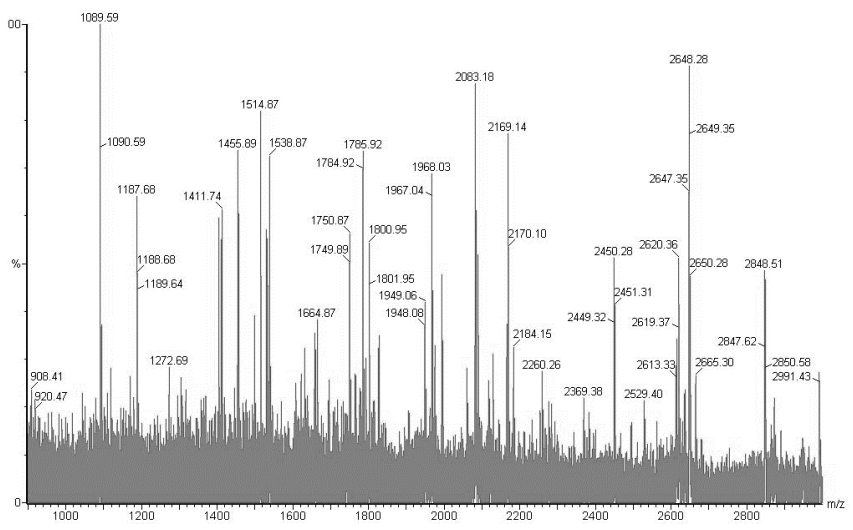

Figure 2. Tryptic MALDI-TOF spectrum of the collagen type I alpha 1 precursor protein.

In order to compare our labeling procedure with an established labeling method, 3T3-L1 adipocytes were incubated with 14C-phenylalanine for 6 hours. As can be seen in Figure 1B, after 1-D-gel separation COL1A1 appeared as a prominently labeled band confirming our findings with non-radioactive labeling. COL1A2 presented a weaker band which can be explained by its lower abundance in our protein sample and by the fact that it has a lower labeling rate according to our measurements. Some other bands appeared after radioactive labeling, which correspond to the analysed prominent bands on the CBBstained gel. Analysing these bands by the MALDI-TOF approach did not reveal significant labeling (Table 1). Very likely these bands are constituted by multiple proteins making the radioactive labeling of bands different from that of single proteins as determined by our MALD-TOF approach.

\section{Detection of label-accumulating proteins by 2-D-profiling}

Since protein profiling traditionally involves 2-D-separation, we decided to combine protein identification and detection of label by MALDI-TOF mass spectrometry also after subjecting our protein samples $(0,6$ and 24 hours incubation) to 2-D-gel electrophoresis (Figure 5). Labeling of individual proteins 
MFSFVDLRLLLLLGATALLTHGQEDIPEVSCIHNGLRVPNGETWKPEVCLICICHNGTAVCDDVQCN EELDCPNPQRREGGCCAFCPEEYVSPNSEDVGVEGPKGGPGPQGPRGPVGPPGRDGIPGQPGL PGPPGPPGPPGPPGLGGNFASQMSYGYDEKSAGVSVPGPMGPSGPRGLPGPPGAPGPQGFQG PPGEPGEPGGSGPMGPRGPPGPPGKNGDDGEAGKPGRPGERGPPGPQGARGLPGTAGLPGMK GHRGFSGLDGAKGDAGPAGPKGEPGSPGENGAPGQMGPRGLPGERGRPGPPGTAGARGNDGA VGAAGPPGPTGPTGPPGFPGAVGAKGEAGPQGARGSEGPQGVRGEPGPPGPAGAAGPAGNPG ADGQPGAKGANGAPGIAGAPGFPGARGPSGPQGPSGPPGPKGNSGEPGAPGNKGDTGAKGEP GATGVQGPPGPAGEEGKRGARGEPGPSGLPGPPGERGGPGSRGFPGADGVAGPKGPSGERGA PGPAGPKGSPGEAGRPGEAGLPGAKGLTGSPGSPGPDGKTGPPGPAGQDGRPGPAGPPGARG QAGVMGFPGPKGTAGEPGKAGERGLPGPPGAVGPAGKDGEAGAQGAPGPAGPAGERGEQGPA GSPGFQGLPGPAGPPGEAGKPGEQGVPGDLGAPGPSGARGERGFPGERGVQGPPGPAGPRGN NGAPGNDGAKGDTGAPGAPGSQGAPGLQGMPGERGAAGLPGPKGDRGDAGPKGADGSPGKD GARGLTGPIGPPGPAGAPGDKGEAGPSGPPGPTGARGAPGDRGEAGPPGPAGFAGPPGADGQP GAKGEPGDTGVKGDAGPPGPAGPAGPPGPIGNVGAPGPKGPRGAAGPPGATGFPGAAGRVGP PGPSGNAGPPGPPGPVGKEGGKGPRGETGPAGRPGEVGPPGPPGPAGEKGSPGADGPAGSPG TPGPQGIAGQRGVVGLPGQRGERGFPGLPGPSGEPGKQGPSGSSGERGPPGPMGPPGLAGPP GESGREGSPGAEGSPGRDGAPGAKGDRGETGPAGPPGAPGAPGAPGPVGPAGKNGDRGETGP AGPAGPIGPAGARGPAGPQGPRGDKGETGEQGDRGIKGHRGFSGLQGPPGSPGSPGEQGPSGA SGPAGPRGPPGSAGSPGKDGLNGLPGPIGPPGPRGRTGDSGPAGPPGPPGPPGPPGPPSGGYD FSFLPQPPQEKSQDGDRYYRADDANVVRDRDLAVDATLKSLSQQIENIRSPEGSRKNPARTCRDL KMCHSDWKSGEYWIDPNQGCNLDAIKVYCNMETGQTCVFPTQPSVPQKNWYISPNPKEKKHVWF GESMTDGFPFEYGSEGSDPTDVAIQLTFLRLMSTEASQNITYHCKNSVAYMDQQTGNLKKALLLQG SNEIELRGEGNSRFTYSRVVDGCTSHTGTWGKTVIEYKTTKTSRLPIIDVAPLDIGAPDQEFGLDIGP ACFV

Figure 3. Collagen I alpha 1 coverage map. Underlined are tryptic peptides represented as peaks in the mass spectrum. Boxed are two peptides corresponding to prominent peaks of the mass spectrum and containing phenylalanine. The first peptide has an $\mathrm{m} / \mathrm{z}$ value of 1411 and the second of 2647

was assessed by random selection of 28 spots, which were cut from the gel and subjected to MALDI-TOF analysis for identification. In this way, 16 proteins could be identified (Table 2), of which 15 had at least one phenylalaninecontaining peptide in the spectrum. Of those 15 proteins 7 were the same as in the 1-D experiment, which can be explained by the fact that the most prominent bands/spots were selected. Of the 8 additional proteins, 4 were found to have acquired label after 24 hours as detected by isotopomer analysis. Two proteins, vimentin and gamma-actin, were detected more than once. This may be ascribed to the fact that these proteins undergo processing and/or modification, or to mild proteolytic activity during sample preparation. When labeling data of the same proteins obtained from different experiments are compared (Tables 1 and 2), some spreading is observed in the peak area ratio. As expected, the spreading is larger for proteins of which the compared isotopomer peaks are less pronounced with respect to the background. 

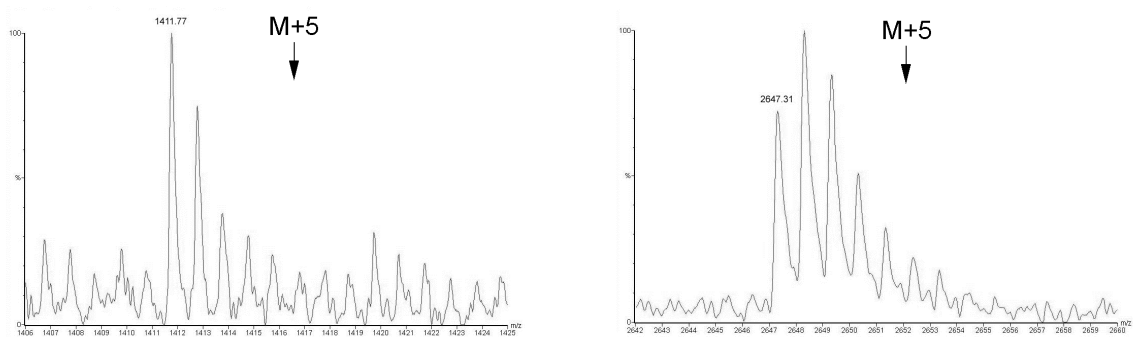

$\mathrm{Oh}$
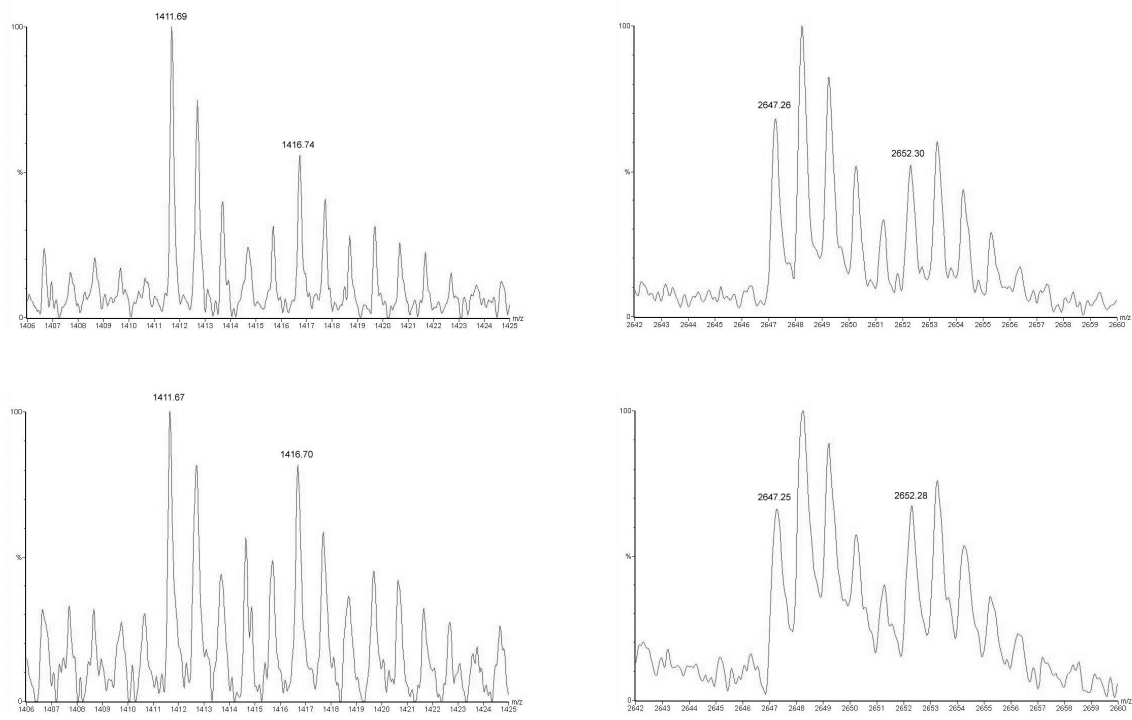

$24 \mathrm{~h}$

Figure 4. High resolution of the peaks from the spectrum of collagen I alpha 1 corresponding to $\mathrm{m} / \mathrm{z}$ values of 1411 (left panels) and 2647 (right panels). The figures illustrate the increasing abundance of the $\mathrm{M}+5$ ion due to $\mathrm{L}$-(ring-2,3,4,5,6 2H5) phenylalanine incorporation after 6 and 24 hours of labeling.

\section{DISCUSSION}

In the present study we have used MALDI-TOF mass spectrometry in combination with 1-D- and 2-D-gel electrophoresis after stable isotope labeling of proteins to retrieve additional information from this popular protein profiling approach. For an individual protein an indication about its labeling rate in comparison to that of other proteins is easily obtained in addition to its identity. As such, this method may help to discriminate between alternative explanations for differential protein expression. A limitation of the procedure is that this information can only be obtained for proteins containing the labeled amino acid. 
Using phenylalanine, 24 (96\%) of 25 randomly selected and identified proteins did contain this amino acid. One should also be aware that information about the relative labeling rate only applies to the isolated protein fraction and is a priori not a measure for the cellular turnover rate of proteins. For extracellular proteins like COL1A1 and COL1A2, accumulation of label reflects their rate of synthesis rather than their turnover. Advantages of this method are that it is simple, non-hazardous and can easily be combined with rapid- to highthroughput standard protein profiling.

Mature non-dividing 3T3-L1 adipocytes were used to demonstrate the feasibility of our approach. With the present experimental design we were able to distinguish three categories of proteins in the isolated protein fraction according to the time that significant labeling was detected. The fastest labeling was found for the precursor proteins of COL1A1 and COL1A2, two components of the extracellular matrix. Indeed, a high metabolic activity of the extracellular matrix has been reported for adipocytes [12-15] substantiating the discriminative

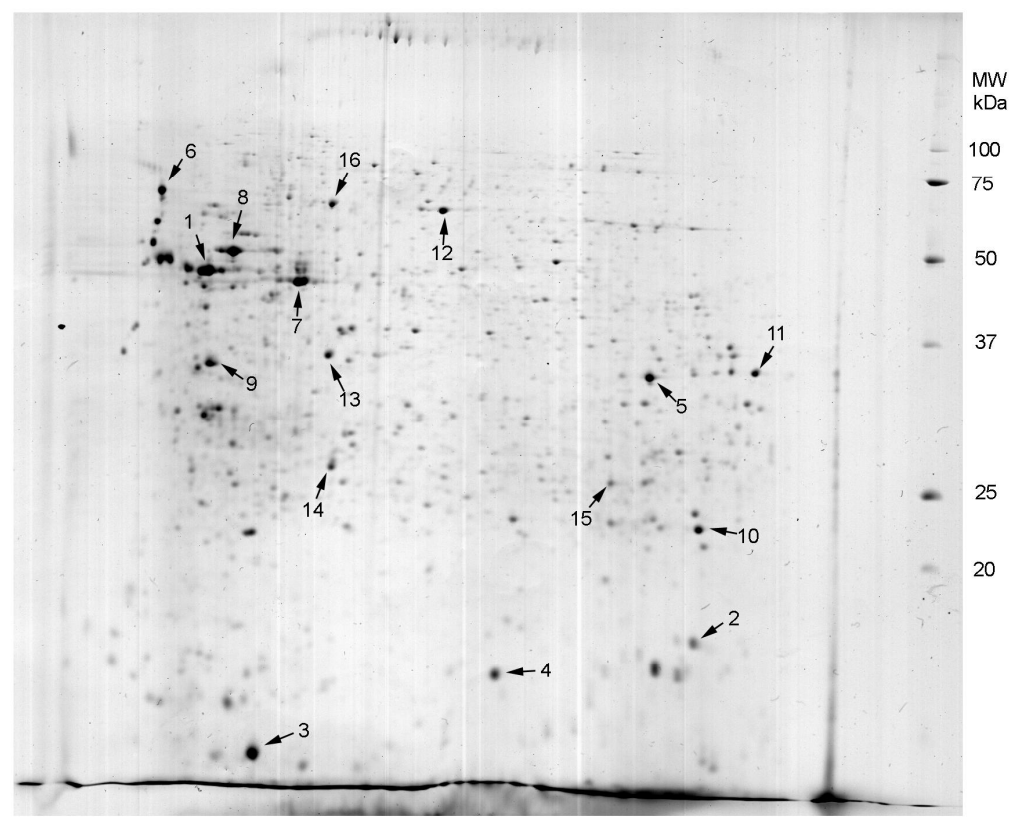

Figure 5. CBB stained spot pattern of proteins isolated from mouse 3T3-L1 adipocytes and separated by 2-D-gel electrophoresis. Only the 24 hours incubation with the stable isotope labeled $\mathrm{L}$-(ring-2,3,4,5,6 2H5) phenylalanine is shown. 16 spots are indicated of which the protein identity was revealed (see table 2). 15 proteins had at least one phenylalanine containing peptide in the MALDI-TOF spectrum. 
Table 2. List of identified proteins from the 2-D-gel electrophoresis.

\begin{tabular}{|c|c|c|c|c|c|c|}
\hline Banc & Accession & Protein name & $\mathrm{Pe}$ & ratio $(x 1$ & & $\#$ of $F$ in \\
\hline & & & $0 \mathrm{~h}$ & $6 \mathrm{~h}$ & $24 \mathrm{~h}$ & peaks \\
\hline 1 & P20152 & Vimentin & $4.2 \pm 2.0$ & $10.4 \pm 5.5$ & $11.2 \pm 1.2$ & 3 \\
\hline 2 & P18760 & Cofilin, non-muscle isoform & $14.0 \pm 2.1$ & $12.7 \pm 5.5$ & $17.6 \pm 3.4$ & 1 \\
\hline 3 & P16045 & Galectin-1 & $3.5 \pm 0.3$ & $4.5 \pm 0.7$ & $14.3 \pm 2.8^{*}$ & 3 \\
\hline 4 & P08228 & Superoxide dismutase [Cu-Zn] & $6.2 \pm 1.8$ & $12.7 \pm 4.1$ & $23.9 \pm 2.6^{*}$ & 1 \\
\hline 5 & P16858 & $\begin{array}{l}\text { Glyceraldehyde 3-phosphate } \\
\text { dehydrogenase }\end{array}$ & $4.6 \pm 1.7$ & $9.1 \pm 2.3$ & $14.9 \pm 0.7^{*}$ & 1 \\
\hline 6 & P14211 & Calreticulin & $6.3 \pm 1.3$ & $10.7 \pm 4.2$ & $20.2 \pm 3.6^{*}$ & 4 \\
\hline 7 & P99022 & Gamma-actin & $6.3 \pm 2.0$ & $6.8 \pm 1.3$ & $12.9 \pm 1.0^{*}$ & 4 \\
\hline 8 & P20152 & Vimentin & $3.7 \pm 1.2$ & $7.9 \pm 3.9$ & $7.1 \pm 3.4$ & 3 \\
\hline 9 & P58771 & Tropomyosin 1 alpha chain & - & - & - & 0 \\
\hline 10 & P35700 & Peroxiredoxin 1 & $5.1 \pm 2.0$ & $6.1 \pm 2.0$ & $22.9 \pm 2.8^{*}$ & 3 \\
\hline 11 & O88569 & hnRNP A2/B1 & $1.8 \pm 0.1$ & $6.1 \pm 0.8$ & $24.1 \pm 2.7^{*}$ & 8 \\
\hline 12 & P27773 & Protein disulfide isomerase $\mathrm{A} 3$ & $2.8 \pm 0.3$ & $8.1 \pm 3.1$ & $23.4 \pm 3.5^{\star}$ & 1 \\
\hline 13 & Q9ERD7 & Tubulin beta 3 & $4.12 \pm 1.8$ & $4.2 \pm 1.6$ & $7.5 \pm 2.9$ & 5 \\
\hline 14 & P99022 & Gamma-actin & $3.0 \pm 1.2$ & $8.6 \pm 4.3$ & $10.9 \pm 1.9^{*}$ & 4 \\
\hline 15 & P17751 & Triosephosphate isomerase & $11.2 \pm 1.7$ & $11.4 \pm 1.5$ & $10.5 \pm 0.3$ & 4 \\
\hline 16 & P19226 & $\begin{array}{l}\text { Mitochondrial } 60 \mathrm{kDa} \text { heat } \\
\text { shock protein }\end{array}$ & $19.1 \pm 18.0$ & $18.3 \pm 3.4$ & $25.3 \pm 10.3$ & 1 \\
\hline
\end{tabular}

Peak ratio values are expressed as mean $\pm S D, n=3,{ }^{*} P<0.05$ by ANOVA

power of our approach. Both proteins are components of collagen type I and occur in this fiber in a 2:1 ratio (COL1A1:COL1A2). After 6h of labeling, approximately $45 \%$ of the COL1A1 in our sample had been replaced by newly synthesized protein while $34 \%$ of the COL1A2 had been replaced. In order to try and get an indication about the relative production rate of both proteins, these numbers were corrected for relative amount of protein as determined by densitometry and for molecular weight. This resulted in a replacement ratio of 2.1:1 (COL1A1:COL1A2) which closely resembles their relative presence in the collagen fiber, i.e. $2: 1$. It suggests that production of the two subunits occurs in de mature adipocyte in a coordinated manner. In contrast to both collagen proteins, several members of the cytoskeleton like vimentin, tubulin and alphaactinin showed no significant labeling, confirming that our cells were indeed in a mature "resting" state [16]. It stresses that the extracellular matrix remodelling is a functional characteristic of mature adipocytes, at least in vitro. At the same time, it shows that our procedure of combined profiling and labeling is able to demonstrate biologically relevant processes in cells. Interesting in this respect is the fact that some of the other randomly selected proteins that were found to become labeled can functionally be linked to the extracellular matrix and in particular to collagen type I. A common posttranslational modification of collagen is the hydroxylation of the -X-Pro-Gly- triplets [17]. It is achieved by the enzyme collagen prolyl 4-hydroxylase which catalyses the formation of 4hydroxyproline. This enzyme is a tetramer of two different subunits, one of 
which is protein disulfide isomerase (band 8 , Table 1; spot 12, Table 2). Since its activity probably depends on thioredoxin domains, peroxiredoxin-1 (spot 10, Table 2) might be involved in this process as well. The $78 \mathrm{kDa}$ glucoseregulated protein (bands 4 and 5 , Table 1 ) was reported as a molecular chaperone of procollagen I [18]. Although calreticulin (band 7, Table 1; spot 6, Table 2) is known as a protein of the endoplasmic reticulum, it has been detected on the cell surface of platelets, where antibodies against this protein inhibit the binding of platelets to collagen type I [19]. Apparently, calreticulin can function as a factor influencing cell adhesion via collagen type I. The same has been demonstrated for galectin-1 (band 17, Table 1; spot 3, Table 2), which is a lactose binding protein. Lactose has been shown to inhibit the adhesion of PC3 human prostate cancer cells to collagen type I by $86 \%$ [20] suggesting that galectin-1, which is secreted by these cells, is involved in regulating cell adhesion via collagen type I.

We proved that with our method relevant biological can be obtained in an in vitro cell system. The use of MALDI-TOF mass spectrometry to measure isotopomer peaks after protein labeling has been explored with yeast and Escherichia coli for various applications including peptide identification [21, 22], for confirmation of peptide sequencing and calibration of mass spectrometry [23], and for improving identification of protein modifications [24]. Complete labeling of cells in vitro (SILAC) has been described as a quantitative proteomics approach [25]. Also, labeling during analysis has been employed for protein quantification with MALDI-TOF [26]. Here we have shown that nonradioactive labeling can be combined with 1-D- and 2-D-gel electrophoresis and, although it is in essence not to be regarded as a solid quantitative approach, it can provide discriminative information on relative rate of protein synthesis or turnover in eukaryotic cells in a simple and rapid-throughput way. In this respect, it may add a valuable dimension to differential protein expression measurements and provide essential biologic information.

\section{Acknowledgements}

We thank Dr. N. Deutz for providing the stable isotope L-(ring-2,3,4,5,6 2H5) phenylalanine. This research was supported by the Maastricht Proteomics Center, the Brede Ondezoek Strategie and the research institute NUTRIM of the Maastricht University.

\section{References}

1. Resing KA (2002) Analysis of signaling pathways using functional proteomics. Annals of the New York Academy of Sciences 971:608-614.

2. van Eijk HM \& Deutz NE (2003) Plasma protein synthesis measurements using a proteomics strategy. The Journal of nutrition 133(6 Suppl 1):2084S-2089S.

3. Ping P (2003) Identification of novel signaling complexes by functional proteomics. Circulation research 93(7):595-603. 
4. Wolfe RR (1992) Radioactive and Stable Isotope Tracers in Biomedicine. Wiley-Liss Inc., New York:377-416.

5. Papageorgopoulos C, Caldwell K, Shackleton C, Schweingrubber H, \& Hellerstein MK (1999) Measuring protein synthesis by mass isotopomer distribution analysis (MIDA). Analytical biochemistry 267(1):1-16.

6. Brun RP, et al. (1996) Differential activation of adipogenesis by multiple PPAR isoforms. Genes \& development 10(8):974-984.

7. Engelman JA, Lisanti MP, \& Scherer PE (1998) Specific inhibitors of p38 mitogen-activated protein kinase block 3T3-L1 adipogenesis. The Journal of biological chemistry 273(48):3211132120.

8. Bradford MM (1976) A rapid and sensitive method for the quantitation of microgram quantities of protein utilizing the principle of protein-dye binding. Analytical biochemistry 72:248-254.

9. Rabilloud T, Adessi C, Giraudel A, \& Lunardi J (1997) Improvement of the solubilization of proteins in two-dimensional electrophoresis with immobilized $\mathrm{pH}$ gradients. Electrophoresis 18(3-4):307-316.

10. Gorg A, et al. (2000) The current state of two-dimensional electrophoresis with immobilized pH gradients. Electrophoresis 21(6):1037-1053.

11. Shevchenko A, Wilm M, Vorm O, \& Mann M (1996) Mass spectrometric sequencing of proteins silver-stained polyacrylamide gels. Analytical chemistry 68(5):850-858.

12. Kubo Y, Kaidzu S, Nakajima I, Takenouchi K, \& Nakamura F (2000) Organization of extracellular matrix components during differentiation of adipocytes in long-term culture. In vitro cellular \& developmental biology. Animal 36(1):38-44.

13. Weiner FR, Shah A, Smith PJ, Rubin CS, \& Zern MA (1989) Regulation of collagen gene expression in 3T3-L1 cells. Effects of adipocyte differentiation and tumor necrosis factor alpha. Biochemistry 28(9):4094-4099.

14. Yi T, Choi HM, Park RW, Sohn KY, \& Kim IS (2001) Transcriptional repression of type I procollagen genes during adipocyte differentiation. Experimental \& molecular medicine 33(4):269-275.

15. Tsuruga $H$, Kumagai $H$, Kojima $T$, \& Kitamura $T$ (2000) Identification of novel membrane and secreted proteins upregulated during adipocyte differentiation. Biochemical and biophysical research communications 272(1):293-297.

16. Spiegelman BM \& Farmer SR (1982) Decreases in tubulin and actin gene expression prior to morphological differentiation of 3T3 adipocytes. Cell 29(1):53-60.

17. Kukkola L, Hieta R, Kivirikko KI, \& Myllyharju J (2003) Identification and characterization of a third human, rat, and mouse collagen prolyl 4-hydroxylase isoenzyme. The Journal of biological chemistry 278(48):47685-47693.

18. Ko MK \& Kay EP (2002) Differential interaction of molecular chaperones with procollagen I and type IV collagen in corneal endothelial cells. Molecular vision 8:1-9.

19. Elton CM, Smethurst PA, Eggleton P, \& Farndale RW (2002) Physical and functional interaction between cell-surface calreticulin and the collagen receptors integrin alpha2beta1 and glycoprotein VI in human platelets. Thrombosis and haemostasis 88(4):648-654.

20. Andersen H, Jensen ON, Moiseeva EP, \& Eriksen EF (2003) A proteome study of secreted prostatic factors affecting osteoblastic activity: galectin-1 is involved in differentiation of human bone marrow stromal cells. Journal of bone and mineral research : the official journal of the American Society for Bone and Mineral Research 18(2):195-203.

21. Chen X, Smith LM, \& Bradbury EM (2000) Site-specific mass tagging with stable isotopes in proteins for accurate and efficient protein identification. Analytical chemistry 72(6):1134-1143.

22. Zhu H, Pan S, Gu S, Bradbury EM, \& Chen X (2002) Amino acid residue specific stable isotope labeling for quantitative proteomics. Rapid communications in mass spectrometry : RCM 16(22):2115-2123.

23. Hunter TC, et al. (2001) Peptide mass mapping constrained with stable isotope-tagged peptides for identification of protein mixtures. Analytical chemistry 73(20):4891-4902.

24. Zhu H, et al. (2002) Residue-specific mass signatures for the efficient detection of protein modifications by mass spectrometry. Analytical chemistry 74(7):1687-1694.

25. Mirgorodskaya OA, et al. (2000) Quantitation of peptides and proteins by matrix-assisted laser desorption/ionization mass spectrometry using (18)O-labeled internal standards. Rapid communications in mass spectrometry : RCM 14(14):1226-1232.

26. Ong SE, et al. (2002) Stable isotope labeling by amino acids in cell culture, SILAC, as a simple and accurate approach to expression proteomics. Molecular \& cellular proteomics : MCP 1(5):376-386. 


\section{Chapter 6}

\section{Common discovered proteins in proteomic analysis - A story of cellular stress response.}

Ping Wang, Freek G. Bouwman \& Edwin Mariman

Department of Human Biology, Nutrition and Toxicology Research Institute Maastricht (NUTRIM), Maastricht University, Maastricht, The Netherlands

Proteomics, 2009, 9, p. 2955-2966 


\section{ABSTRACT}

The specificity of proteins identified by proteomics as biomarkers for defined conditions or as components of biological processes and pathways is crucial. We critically reviewed differentially expressed proteins from comparative proteomic studies identified by two-dimensional gel electrophoresis followed by mass spectrometry, especially with MALDI technique. Based on 66 of those studies, a list of 44 proteins is presented as generally detected proteins regardless of species, in vivo or in vitro conditions, tissues and organs, and of experimental objective. Similarly, a list of 28 generally detected protein families is presented. The enriched functions linked to these generally detected proteins reveal that there are some common biological features beyond the technical limitations. Cellular stress response can be the universal reason that these proteins are generally expressed differentially. Using those proteins as biomarkers for cellular processes other than stress response should be done with caution. In future proteomic studies more profound approaches should be applied to look beyond these proteins to find specific biomarkers. Our results are discussed in relation to a recent viewpoint publication by Petrak et al. in Proteomics 2008. 


\section{INTRODUCTION}

Two-dimensional gel electrophoresis (2DE) in combination with mass spectrometry (MS) is a widely used proteomic technology platform in comparative protein profiling studies, for the identification of biomarkers of specific conditions (e.g. diseases, nutritional status and drug treatment) or components of biological processes and pathways (e.g. development, apoptosis and signal transduction). Obviously, the specificity of such biomarker(s) or component(s) for applied study condition is crucial.

We have worked with this platform, mainly using a matrix assisted laser desorption/ionization - time of flight (MALDI-TOF) MS, for years and observed that some proteins were often detected in different studies, no matter what kind of study condition was applied. This phenomenon that some proteins are generally detected greatly challenges the specificity of the outcome of each individual experiment.

Recently, a meta-analysis of proteins reported as 'differentially expressed' in 186 individual 2DE studies, showed that some proteins (as well as some protein families) were recurrent [1]. Therefore, they were non-specific for each individual condition studied. Here we reported independently the outcome of analysis on this phenomenon with focus on MALDI technique and covering mainly different studies and more species. Furthermore we applied bioinformatics to analyse the function of these proteins.

\section{MATERIALS AND METHODS}

\section{Collection of data on differentially expressed proteins identified by 2DE and MS in comparative proteomic studies}

The data were extracted from 66 published proteomic studies from 2000 till 2007 that used the 2DE/MS method, especially including MALDI, and were performed in 5 species. The detailed selection criteria of studies are listed in Figure 1. These original research studies were mainly selected from papers in the following proteomics journals, but also from other journals via PUBMED (latest access on 19 September 2007): Proteomics (http://www3.interscience .wiley.com/journal/76510741/home, latest access on 20 September 2007) Journal of Proteome Research

(http://pubs.acs.org/journals/jprobs/index.html, latest access on 8 October 2007) BBA-proteins and proteomics (http://www.elsevier.com/locate/bbapap, latest access on 9 October 2007) Proteomics Science (http://www.proteomesci.com/, 
latest access on 9 October 2007) Electrophoresis http://www3.interscience .wiley.com/journal/10008330/home, latest access on 9 October 2007) Molecular \& Cellular Proteomics (http://www.mcponline.org/, latest access on 18 October 2007)

From each paper, we extracted the differentially expressed proteins into our database manually. When the same protein appeared more than once in the paper due to either different isoforms or detection under different conditions, we only extracted it once. Ten of sixty-six studies reported differentially expressed proteins without clear statistical evaluation. Since those papers represent the initial observation and do not influence the results significantly, they were taken along in the data set.

\section{Translation of proteins from different species to human orthology}

\section{Worm proteins}

The original protein identification numbers or symbols (IDs) of different databases were first converted to WormBase gene ID by WormBase the Batch Information Retrieval tool [2] (http://www.wormbase.org, release WS170, 09 February 2007). The IDs that could not be mapped were checked in NCBI Entrez Gene (http://www.ncbi.nlm.nih.gov/sites/entrez) to get an updated ID number. Then, the human ortholog Ensembl ID was obtained from WormBase by "best BLASTP matches to the longest protein product". The characteristics of human orthology on the gene name, description, HUGO Gene Nomenclature Committee (HGNC) ID, Swiss-Prot ID were retrieved by the Ensembl BioMart search tool [3] (http://www.ensembl.org/biomart/martview/) using Ensembl 48 database [4] (released in December 2007).

\section{Fruit fly proteins}

The original IDs that were lacking an accession number were first converted to FlyBase gene IDs [5] (http://flybase.bio.indiana.edu/) by searching the protein/gene name in NCBI Entrez Gene. The FlyBase gene IDs were used to find human orthology information in Ensembl BioMart or by blasting in NCBI using BLASTP.

\section{Mouse proteins}

Original IDs stated as NCBI GI numbers in the articles were first checked in NCBI to get updated ones, then were transferred to Mouse Genome Informatics accession number [6] (MGI, http://www.informatics.jax.org/) by Protein Information Resource [7] (PIR, http://pir.georgetown.edu/pirwww/search/ batch.shtml). Original IDs that were lacking an accession number were first searched in NCBI Entrez Gene to get their MGI accession number. These MGI IDs and original IDs of UniProt/Swiss-Prot or IPI were used to find human 
orthology in Ensembl Biomart, or searched in (1) MGI Gene Detail Mammalian Orthology, (2) NCBI HomoloGene, and (3) NCBI using BLASTP.

\section{Rat proteins}

Similar to mouse proteins, the rat proteins were transferred to human orthology. The Rat Genome Database [8] (RGD, http://rgd.mcw.edu/wg/) was used instead of MGI.

\section{Human proteins}

The original IDs of different databases were first updated in NCBI and the UniProt Knowledgebase [9] (UniProtKB, http://www.uniprot.org/uniprot/), respectively, then Ensembl BioMart was used to obtain the gene/protein characteristics as done for the other species.

After comparing the databases for redundancy and completion, HGNC was chosen to be used in further statistical analyses. The original IDs from different species were translated into their human orthology with HGNC IDs, then gene family information was retrieved. It turned out that less than $20 \%$ of the protein entries could be assigned to a gene family. Therefore we turned to UniProtKB to retrieve protein families and this time $87 \%$ of the protein entries were assigned to a protein family. Regarding protein family as synonymous with gene family, with both structural and functional aspects taken into account, we reassigned the protein family based on both HGNC and UniProtKB family annotation, and $92 \%$ of the protein entries were assigned to protein families. 


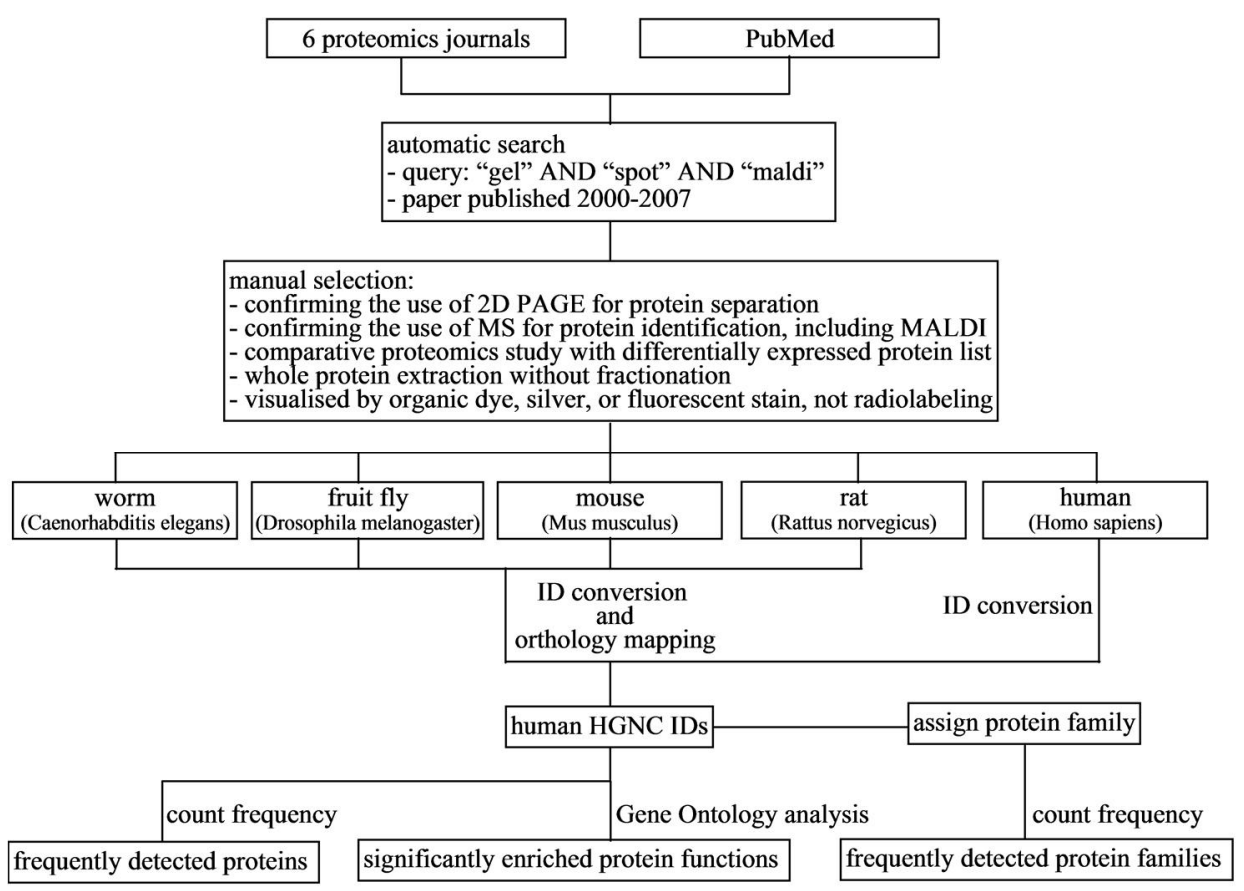

Figure 1. Flow diagram of data collection and identification of frequently detected proteins (families).

\section{Identification of frequently detected proteins and protein families}

All the protein entries with their experimental conditions (species, in vivo/in vitro, experimental objective, organ and tissues), HGNC IDs and protein family IDs were used to construct our database in Excel. The data were analyzed in SPSS 12.0.1 for Windows (SPSS Inc. Chicago, Illinois, USA). The frequency tables were exported. We defined the "detection frequency" as the chance that a particular protein can be detected in one experiment, which is equal to the protein counts divided by the number of source papers under the particular condition. Then we defined 3-fold of the average detection frequency as the threshold for "the frequently detected protein". This threshold was equals to 95 percentiles in general. For a type of experimental condition under which there were only a few source papers, if the detection frequency was more than 0.60 , this protein was also defined as frequently detected. By this definition, we picked out the list of frequently discovered proteins in general and per type of experimental condition. Similar to this, we defined "the frequently discovered protein family" by using the counts per protein family per paper and the 3-fold threshold. Also the exception for the condition with a few source papers was applied. The correlation between the protein IDs and the conditions of the study 
were analyzed by the nonparametric Kendall tau rank correlation coefficient, with the correlation to protein family as a reference.

\section{Characterisation of frequently detected proteins}

The properties of sequence, length, and subcellular locations of frequently detected proteins and the rest of proteins were retrieved from UniProtKB. ProtParam tool (http://www.expasy.ch/tools/protparam.html) was used to calculate the amino acids composition.

The gene expression levels by the average number of transcripts per million in the body were calculated from UniGene database EST profile (http://www.ncbi.nlm.nih.gov/UniGene). We picked 8 top and 5 bottom proteins/genes of the list and retried data manually. The first 800 gene in Unigene database (Hs.data.gz on ftp.ncbi.nih.gov/repository/UniGene/ Homo_sapiens/) were selected to compose a reference average value.

\section{Identification of significantly enriched functions among the detected proteins}

The functional interpretation by statistical analysis was based on Gene Ontology (GO). Gene score resampling, an unbiased method based on overrepresentation analysis was used to pick out significantly enriched function sets among detected proteins. For this, all the unique proteins presented in our database were annotated with GO terms and the total counts over all 66 source papers were used as expression value in ErmineJ software version 2.1.15 [10]. The annotation of our protein database was based on Affymetrix array HGU133_Plus_2 annotated by ErmineJ on 6 March 2007. If a gene was not present singly on the array, it was annotated by retrieving data from Entrez Gene gene2go file of 19 January 2008. Full resampling was run and 1205 GO terms were tested. Only sets with minimum 10 and maximum 65 proteins were taken into account, because very large or very small sets are less informative. We analyzed all three GO aspects: biological process, molecular function and cellular component. The significance of a protein set is evaluated by both score and $p$-value. The score is the mean of the counts for the proteins in that protein set, and it is the bigger, the better. ErmineJ uses multiple test BenjaminiHochberg correction of $p$-values with a particular false discovery rate (FDR). Protein sets that satisfied the criterion of FDR $<0.001$ were considered to be significantly enriched, and the rank is according to the set score. 


\section{RESULTS}

\section{Frequently detected differential proteins}

To test the hypothesis that some proteins are generally detected in comparative proteomic studies using 2DE and MS (using MALDI at least), regardless of experimental conditions, we did an unbiased selection of 66 studies, executed in 5 species, in vivo, in vitro or ex vivo, on 20 different tissues and organs, and for 18 different experimental objectives (Table 1). We limited our selection to worm, fruit fly, mouse, rat and human, because for these species there is a high quality gene/protein database. These studies contributed 1931 protein entries in total. Among these entries, 38 could not be processed further because the original ID number did not exist, or was from another species than the one under study, which we regarded as miss-identification or contamination. Two exceptions to this were that a mouse ID or a human ID was regarded as acceptable in the studies on rat, and that rat IDs were acceptable in mouse studies. As we later used human protein orthology for total data analysis, 11 entries for which no human protein orthology could be found, had to be left out. Another 10 entries were left out because no information was present in the HGNC database. Finally, we ended up with 1872 (96.9\%) valid entries in our database of differentially expressed proteins identified by 2DE and MS in comparative proteomic studies.

Among these 1872 protein entries, there are 892 unique protein IDs. The average detection frequency of one particular protein to be found in one study is 0.032 . However, some proteins are much more often detected in general, with a maximum detection frequency of 0.333 . We used 3 -fold of the average as the cut-off $(P<0.05)$ and found that 44 proteins were frequently detected over all studies (Table 2). These proteins account for $23.2 \%$ of the database entries, although they represent only $4.9 \%$ of all unique proteins.

Different experimental conditions generated different lists of frequently detected protein. The frequently detected proteins per condition are presented in Supplement material 2. A link between frequently detected proteins and the type of organ and tissue, or the experimental objective, seems to exist. However, a definite conclusion could not be drawn because of the limited number of source studies. When only a few studies could be recruited for a certain condition, a list could hardly be generated or depended heavily on the source studies. On the other side, there is clear overlap. Proteins like enolase and heat shock proteins were often detected regardless of conditions. With respect to different species, it is remarkable that despite relatively large evolutionary distance between worm and mammals, the frequently detected protein of worm, NME2, can still be found in the list of humans. The lists of mouse and rat also show overlap with the list of human. ENO1 and HSPA5 appear in the list of all three mammals. In vivo and in vitro studies show 
Table 1. Overview of the source papers and entries in the analysis.

\begin{tabular}{|c|c|c|c|c|c|}
\hline \multirow[b]{2}{*}{ Species } & \multirow[b]{2}{*}{ worm } & \multicolumn{2}{|c|}{ number percentage } & \multicolumn{2}{|c|}{ extracted valid entries } \\
\hline & & 3 & $4.5 \%$ & 26 & $1.4 \%$ \\
\hline & fly & 2 & $3.0 \%$ & 42 & $2.2 \%$ \\
\hline & human & 33 & $50.0 \%$ & 1054 & $56.3 \%$ \\
\hline & mouse & 16 & $24.2 \%$ & 505 & $27.0 \%$ \\
\hline & rat & 12 & $18.2 \%$ & 245 & $13.1 \%$ \\
\hline \multirow[t]{3}{*}{ in vivo / in vitro } & in vitro & 33 & $50.0 \%$ & 947 & $50.6 \%$ \\
\hline & in vivo & 30 & $45.5 \%$ & 858 & $45.8 \%$ \\
\hline & ex vivo & 3 & $4.5 \%$ & 67 & $3.6 \%$ \\
\hline \multirow[t]{20}{*}{ Tissues and organ } & adipocytes & 1 & $1.5 \%$ & 14 & $0.7 \%$ \\
\hline & amnion & 1 & $1.5 \%$ & 64 & $3.4 \%$ \\
\hline & blood cells & 4 & $6.1 \%$ & 59 & $3.2 \%$ \\
\hline & bone and bone marrow & 2 & $3.0 \%$ & 144 & $7.7 \%$ \\
\hline & breast & 2 & $3.0 \%$ & 42 & $2.2 \%$ \\
\hline & cervical & 1 & $1.5 \%$ & 62 & $3.3 \%$ \\
\hline & embryo & 3 & $4.5 \%$ & 67 & $3.6 \%$ \\
\hline & immuno system & 3 & $4.5 \%$ & 60 & $3.2 \%$ \\
\hline & intestine & 10 & $15.2 \%$ & 239 & $12.8 \%$ \\
\hline & kidney & 2 & $3.0 \%$ & 141 & $7.5 \%$ \\
\hline & liver & 7 & $10.6 \%$ & 241 & $12.9 \%$ \\
\hline & lung & 2 & $3.0 \%$ & 59 & $3.2 \%$ \\
\hline & muscle & 3 & $4.5 \%$ & 99 & $5.3 \%$ \\
\hline & nerve system & 9 & $13.6 \%$ & 211 & $11.3 \%$ \\
\hline & ovary & 2 & $3.0 \%$ & 14 & $0.7 \%$ \\
\hline & pancreas & 2 & $3.0 \%$ & 62 & $3.3 \%$ \\
\hline & retina & 2 & $3.0 \%$ & 70 & $3.7 \%$ \\
\hline & skin & 6 & $9.1 \%$ & 158 & $8.4 \%$ \\
\hline & vascular & 1 & $1.5 \%$ & 40 & $2.1 \%$ \\
\hline & whole body & 3 & $4.5 \%$ & 26 & $1.4 \%$ \\
\hline \multirow{18}{*}{$\begin{array}{l}\text { Experimental } \\
\text { objective }\end{array}$} & aging & 3 & $4.5 \%$ & 58 & $3.1 \%$ \\
\hline & apoptosis & 2 & $3.0 \%$ & 53 & $2.8 \%$ \\
\hline & disease, cancer & 12 & $18.2 \%$ & 431 & $23.0 \%$ \\
\hline & disease, endocrine system & 5 & $7.6 \%$ & 229 & $12.2 \%$ \\
\hline & disease, inflammatory & 2 & $3.0 \%$ & 61 & $3.3 \%$ \\
\hline & disease, neurotic disordor & 2 & $3.0 \%$ & 28 & $1.5 \%$ \\
\hline & drug treatment & 8 & $12.1 \%$ & 388 & $20.7 \%$ \\
\hline & growth and development & 4 & $6.1 \%$ & 105 & $5.6 \%$ \\
\hline & immunostimulation & 2 & $3.0 \%$ & 43 & $2.3 \%$ \\
\hline & individual variation & 3 & $4.5 \%$ & 42 & $2.2 \%$ \\
\hline & nutrition & 9 & $13.6 \%$ & 228 & $12.2 \%$ \\
\hline & periodicity & 1 & $1.5 \%$ & 12 & $0.6 \%$ \\
\hline & radiation & 1 & $1.5 \%$ & 11 & $0.6 \%$ \\
\hline & signal transduction & 3 & $4.5 \%$ & 42 & $2.2 \%$ \\
\hline & stress, hyperosmotic & 1 & $1.5 \%$ & 7 & $0.4 \%$ \\
\hline & stress, oxidative & 4 & $6.1 \%$ & 73 & $3.9 \%$ \\
\hline & temperature & 1 & $1.5 \%$ & 4 & $0.2 \%$ \\
\hline & toxins & 3 & $4.5 \%$ & 57 & $3.0 \%$ \\
\hline Total & & 66 & & 1872 & \\
\hline
\end{tabular}


Table 2. Frequently detected proteins in general.

\begin{tabular}{|c|c|c|c|}
\hline $\begin{array}{l}\text { HGNC } \\
\text { ID }\end{array}$ & $\begin{array}{l}\text { HGNC } \\
\text { Symbol }\end{array}$ & Name & $\begin{array}{l}\text { Detection } \\
\text { frequency }\end{array}$ \\
\hline 5238 & HSPA5 & $\begin{array}{l}\text { heat shock } 70 \mathrm{kDa} \text { protein } 5 \text { (glucose-regulated protein, } \\
78 \mathrm{kDa} \text { ) }\end{array}$ & 0.333 \\
\hline 3350 & ENO1 & enolase 1, (alpha) & 0.318 \\
\hline 830 & ATP5B & $\begin{array}{l}\text { ATP synthase, } \mathrm{H}+\text { transporting, mitochondrial F1 complex, } \\
\text { beta polypeptide }\end{array}$ & 0.227 \\
\hline 132 & АСТВ & actin, beta & 0.197 \\
\hline 4606 & PDIA3 & protein disulfide isomerase family $\mathrm{A}$, member 3 & 0.197 \\
\hline 12009 & TPI1 & triosephosphate isomerase 1 & 0.197 \\
\hline 144 & ACTG1 & actin, gamma 1 & 0.182 \\
\hline 4141 & GAPDH & glyceraldehyde-3-phosphate dehydrogenase & 0.182 \\
\hline 5246 & HSPB1 & heat shock $27 \mathrm{kDa}$ protein 1 & 0.182 \\
\hline 5261 & HSPD1 & heat shock $60 \mathrm{kDa}$ protein 1 (chaperonin) & 0.182 \\
\hline 6636 & LMNA & $\operatorname{lamin} A / C$ & 0.182 \\
\hline 12022 & TPT1 & tumor protein, translationally-controlled 1 & 0.182 \\
\hline 12692 & VIM & vimentin & 0.182 \\
\hline 1455 & CALR & calreticulin & 0.152 \\
\hline 5241 & HSPA8 & heat shock $70 \mathrm{kDa}$ protein 8 & 0.152 \\
\hline 7850 & NME2 & non-metastatic cells 2, protein (NM23B) expressed in & 0.152 \\
\hline 8548 & $\mathrm{P} 4 \mathrm{HB}$ & $\begin{array}{l}\text { procollagen-proline, 2-oxoglutarate 4-dioxygenase (proline 4- } \\
\text { hydroxylase), beta polypeptide }\end{array}$ & 0.152 \\
\hline 11179 & SOD1 & superoxide dismutase 1 , soluble & 0.152 \\
\hline 16753 & PRDX6 & peroxiredoxin 6 & 0.152 \\
\hline 399 & ALB & albumin & 0.136 \\
\hline 404 & ALDH2 & aldehyde dehydrogenase 2 family (mitochondrial) & 0.136 \\
\hline 414 & ALDOA & aldolase A, fructose-bisphosphate & 0.136 \\
\hline 543 & ANXA5 & annexin A5 & 0.136 \\
\hline 9021 & PKM2 & pyruvate kinase, muscle & 0.136 \\
\hline 9253 & PPIA & peptidylprolyl isomerase A (cyclophilin A) & 0.136 \\
\hline 537 & ANXA2 & $\operatorname{annexin~A2~}$ & 0.121 \\
\hline 678 & ARHGDIA & Rho GDP dissociation inhibitor (GDI) alpha & 0.121 \\
\hline 1874 & CFL1 & cofilin 1 (non-muscle) & 0.121 \\
\hline 2529 & CTSD & cathepsin D & 0.121 \\
\hline 11655 & TCP1 & t-complex 1 & 0.121 \\
\hline 20778 & TUBB & tubulin, beta & 0.121 \\
\hline 2062 & CLIC1 & chloride intracellular channel 1 & 0.106 \\
\hline 4638 & GSTP1 & glutathione S-transferase pi & 0.106 \\
\hline 6510 & STMN1 & stathmin 1/oncoprotein 18 & 0.106 \\
\hline 8888 & PGAM1 & phosphoglycerate mutase 1 (brain) & 0.106 \\
\hline 8896 & PGK1 & phosphoglycerate kinase 1 & 0.106 \\
\hline 9568 & PSME1 & $\begin{array}{l}\text { proteasome (prosome, macropain) activator subunit } 1 \text { (PA28 } \\
\text { alpha) }\end{array}$ & 0.106 \\
\hline 12012 & TPM3 & tropomyosin 3 & 0.106 \\
\hline 3214 & $\mathrm{EEF} 2^{\mathrm{a}}$ & eukaryotic translation elongation factor 2 & 0.106 \\
\hline 3300 & EIF5A ${ }^{a}$ & eukaryotic translation initiation factor $5 \mathrm{~A}$ & 0.106 \\
\hline 6446 & KRT8_a & keratin 8 & 0.106 \\
\hline 8912 & $\mathrm{PHB}^{\mathrm{a}}$ & prohibitin & 0.106 \\
\hline 9352 & $P R D X 1^{a}$ & peroxiredoxin 1 & 0.106 \\
\hline 12855 & YWHAZ & $\begin{array}{l}\text { tyrosine } 3 \text {-monooxygenase/tryptophan } \\
\text { activation protein, zeta polypeptide }\end{array}$ & 0.106 \\
\hline
\end{tabular}

${ }^{a}$ These proteins appear influenced by the studies without clear statistical evaluation 
differences in their list, but still $50 \%$ of proteins from in vivo studies are also frequently detected in in vitro studies. To give this observation a more scientific basis, we picked the 434 entries with the 44 frequently detected proteins, and analyzed the relations between the protein and the experimental condition by nonparametric correlation analysis with the Kendall tau rank correlation coefficient. Compared to the real correlation between the protein and the protein family $(r=0.651, P<0.001)$, there is no relationship between detected proteins and in vivolin vitro $(r=-0.089, P=0.02)$, species, organ and tissues, or experimental objective $(r=-0.061,0.004,0.000$ respectively, $P>0.05$ for all). Since these 44 proteins were detected irrespective of experimental conditions, they can be referred to as "generally detected proteins".

\section{Frequently detected protein family}

Some proteins by themselves were not on the list of frequently detected proteins, but together with their family members constituted an important part of the database. Therefore we assigned the proteins to protein families according to both HGNC and UniProtKB family annotation, and with respect to both structure and function. As a result, 1730 entries were assigned to one of 381 protein families. As the same as for proteins, we used 3-fold over the average to define the frequently detected protein family and in this way 28 families were selected (Table 3). Although these families are just $7.3 \%$ of the total number of protein families, they cover $37.6 \%$ of the database entries. For most of the families on the top, such as heat shock protein 70 family and actin family, we had already found their single members on the top of the protein list (Table 2). However, other families, such as the family of heterogeneous nuclear ribonucleoproteins and the proteasome subunit family, score high due to both their large family size and the significant contribution from the members.

\section{Characteristics of the generally detected proteins}

The length of 44 proteins ranges from 16 to $94 \mathrm{kDa}$, with the average of $41 \mathrm{kDa}$, which is not statistically different from the average of $50 \mathrm{kDa}$ of the rest of the proteins. Out of 44 proteins, 32 are annotated with "cytoplasm" or "cytosol". This occurs much more often than the rest of the proteins with $38 \%$ frequency. We did not found significant difference except higher lysine $(P<0.05)$ in the frequently detected proteins with regard to the amino acids composition (Table 4).The gene expression profile (NCBI UniGene EST profile) indicates that proteins at the top of the list (ENO1, HSAP5, ATP5B, ACTB, ACTG1, PDIA3, TPI1 and GAPDH) are encoded by genes highly represented in many libraries. The bottom proteins of the list, PHB, PRDX1, PSME1, TPM3 and YWHAZ are encoded by genes highly represented in several libraries. Their number of 
Table 3. Frequently detected protein families.

\begin{tabular}{|c|c|c|c|}
\hline & Family name & $\begin{array}{l}\text { Detection } \\
\text { frequency }\end{array}$ & Family member HGNC symbol \\
\hline 1 & Heat shock protein 70 family & 0.833 & $\begin{array}{l}\text { HSPA1A, HSPA1B, HSPA2, HSPA4, } \\
\text { HSPA5, HSPA6, HSPA8, HSPA9, } \\
\text { HYOU1, HSPH1, HSPA4L }\end{array}$ \\
\hline 2 & Intermediate filament family & 0.591 & $\begin{array}{l}\text { DES, GFAP, INA, LMNA, LMNB1, } \\
\text { LMNB2, VIM }\end{array}$ \\
\hline 3 & heterogeneous nuclear ribonucleoproteins & 0.561 & $\begin{array}{lcc}\text { HNRNPA1, } & \text { HNRNPA2B1, } & \text { HNRPAB, } \\
\text { HNRNPC, } & \text { HNRPDL, } & \text { HNRPF, } \\
\text { HNRPH1, } & \text { HNRPH2, } & \text { HNRPH3, } \\
\text { HNRPK, HNRPM, HNRNPR, HNRPA3 }\end{array}$ \\
\hline 4 & Annexin family & 0.545 & $\begin{array}{l}\text { ANXA1, ANXA2, ANXA3, ANXA4, } \\
\text { ANXA5, ANXA6, ANXA7, ANXA8 }\end{array}$ \\
\hline 5 & Actin family & 0.530 & $\begin{array}{l}\text { ACTA1, ACTA2, ACTB, ACTC1, } \\
\text { ACTG1, ACTG2, ACTR1A, ACTR1B, } \\
\text { ACTR2, ACTL6A }\end{array}$ \\
\hline 6 & ATP synthase & 0.515 & $\begin{array}{l}\text { ATP5A1, ATP5B, ATP5F1, ATP5H, } \\
\text { ATP5O, ATP6V1A, ATP6V1B1, } \\
\text { ATP6V1B2, ATP6V1E1, ATP6V1F }\end{array}$ \\
\hline 7 & proteasome subunit family & 0.470 & $\begin{array}{l}\text { PSMA1, PSMA3, PSMA5, PSMA6, } \\
\text { PSMB3, PSMB4, PSMB5, PSMB6, } \\
\text { PSMC1, PSMC2, PSMD11, PSMD13, } \\
\text { PSME1, PSME2 }\end{array}$ \\
\hline 8 & Peroxiredoxin & 0.455 & $\begin{array}{l}\text { PRDX1, PRDX2, PRDX3, PRDX5, } \\
\text { PRDX6, PRDX4 }\end{array}$ \\
\hline 9 & Protein disulfide isomerase family & 0.439 & $\begin{array}{l}\text { PDIA3, P4HB, TXNDC5, PDIA4, } \\
\text { PDIA6 }\end{array}$ \\
\hline 10 & Enolase family & 0.424 & ENO1, ENO2, ENO3 \\
\hline 11 & Tubulin family & 0.409 & 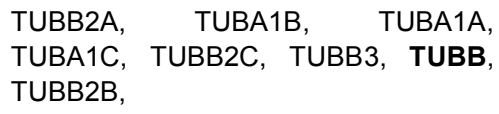 \\
\hline 12 & Aldehyde dehydrogenase family & 0.394 & $\begin{array}{lcc}\text { ALDH1A1, } & \text { ALDH2, } & \text { ALDH3A1, } \\
\text { ALDH4A1, } & \text { ALDH1B1, } & \text { ALDH9A1, } \\
\text { ALDH7A1, } & \text { ALDH1L1, } & \text { ALDH6A1, } \\
\text { ALDH8A1, ALDH16A1 } & \end{array}$ \\
\hline 13 & TCP-1 chaperonin family & 0.394 & $\begin{array}{l}\text { ССТ2, ССТ3, ССТ4, ССТ5, ССТ6А, } \\
\text { ССТ7, ССТ8, ТСР1 }\end{array}$ \\
\hline 14 & 14-3-3 family & 0.379 & $\begin{array}{l}\text { SFN, YWHAB, YWHAE, YWHAG, } \\
\text { YWHAH, YWHAQ, YWHAZ }\end{array}$ \\
\hline 15 & Intermediate filament family, Keratins & 0.379 & $\begin{array}{lll}\text { KRT1, KRT10, KRT16, } & \text { KRT18, } \\
\text { KRT19, KRT2, KRT7, KRT8, } & \text { KRT9, } \\
\text { KRT20 } & \end{array}$ \\
\hline 16 & Elongation factors & 0.364 & $\begin{array}{l}\text { EEF1A1, EEF1AL3, EEF1B2, EEF1D, } \\
\text { EEF1G, EEF2, TUFM, GFM1, TCEAL3 }\end{array}$ \\
\hline 17 & Tropomyosin family & 0.333 & TPM1, TPM2, TPM3, TPM4 \\
\hline 18 & Actin-binding proteins ADF family & 0.288 & CFL1, CFL2, GMFB, DSTN, COTL1 \\
\hline
\end{tabular}


19 Small heat shock protein (HSP20)/alpha crystallin family

20 Acyl-CoA dehydrogenase family

21 Eukaryotic translation initiation factors

22 Fatty-acid binding protein (FABP) family

23 Aldo/keto reductase family

24 Cathepsins (CTS)

25 Protein kinase superfamily, Ser/Thr protein kinase family

26 Serpin family

27 superoxide dismutase family

28 Villin/gelsolin family
0.273

0.258

0.258

0.258

0.227

0.227

0.227

0.212

0.212

0.212 CAPG, GSN, VIL1, EZR HSPB8 ACADVL, GCDH, IVD EIF4E, EIF5A, EIF4A3 FABP7, RBP1, RBP2 AKR7A2, GCLM GRK7 SERPINB13, SERPINB3

SOD1, SOD2
CRYAB, HSPB1, HSPB6,HSPB7,

ACADL, ACADM, ACADS, ACADSB,

EIF2S1, EIF3A, EIF3I, EIF3F, EIF4A1,

CRABP1, CRABP2, FABP1, FABP2, FABP3, FABP4, FABP5, FABP6,

AKR1A1, AKR1B1, AKR1B10, AKR1C1, AKR1C2, AKR1C3,

CTSB, CTSD, CTSK, CTSL1

AKT2, BMPR2, BRAF, CASK, CHUK, DMPK, IRAK2, LIMK1, MAP2K6, MAP3K7, MAPK1, PRKX, RPS6KA3,

SERPINA3, SERPINH1, SERPINB1, SERPINE1, SERPINB2, SERPINA1,

The family member with highest counts is indicated in bold letter

transcripts per million over all body parts are in the range of 133 to 4500 , which is far higher than the average of about 40 for 800 randomly selected genes from the UniGene database.

\section{Functions of the generally detected proteins}

Based on literature information, mainly from $\mathrm{NCBI}$, we divided the generally detected proteins into functional classes (Figure 2). Each protein was assigned to one major function. Energy metabolism (including lipid and carbohydrate catabolism), cytoskeleton organization, cellular growth, cycle and death, and molecular chaperones are the main functional classes of these proteins. In addition, to evaluate in an unbiased manner which functions are linked to the generally detected proteins in proteomic studies, we chose to perform Gene Ontology (GO) over-representation analysis. With the particular "gene score resampling" method, we used all GO annotated proteins (877 out of 892) as background. In this way not only our defined generally detected proteins, but also others contribute to the score of the functional classes. The probability distribution of all the proteins was used to compute p-values. The program takes the overlap-problem of GO annotations into account and applies multiple testing to get corrected $p$-values (false discovery rate, FDR). Setting the FDR 
$<0.001$, the significantly enriched GO classes on biological process, molecular function and cellular component are shown in Table 5. As biological processes, glycolysis, anti-apoptosis, response to oxidative and unfolded protein stress, and cytoskeleton related movement are significantly enriched, which is in line with the enriched molecular function of electron carrier activity, antioxidant activity, unfolded protein binding, peptidase activity, and cytoskeleton binding. The enriched biological processes are also in accordance with the enriched cellular components of the cytosolic part, endoplasmic reticulum, mitochondria and cytoskeleton. In addition, ribonucleoprotein complex as cellular component is significantly enriched in line with RNA binding as molecular function.

Table 4. Comparison of average amino acid composition (\%)

\begin{tabular}{lll}
\hline Amino acid & $\begin{array}{l}\text { Forty four frequently } \\
\text { detected proteins }\end{array}$ & The rest of the proteins \\
\hline Ala & 8.5 & 7.6 \\
Cys & 1.4 & 1.8 \\
Asp & 6.3 & 5.6 \\
Glu & 8.5 & 7.6 \\
Phe & 3.6 & 3.7 \\
Gly & 7.2 & 7.6 \\
His & 1.7 & 2.3 \\
Ile & 5.5 & 4.8 \\
Lys & 7.7 & 6.3 \\
Leu & 8.8 & 9.1 \\
Met & 2.4 & 2.4 \\
Asn & 3.7 & 3.8 \\
Pro & 4.2 & 5.4 \\
Gin & 3.8 & 4.3 \\
Arg & 4.9 & 5.3 \\
Ser & 6.1 & 6.8 \\
Thr & 5.3 & 5.1 \\
Val & 7.0 & 6.5 \\
Trp & 0.7 & 1.1 \\
Tyr & 2.7 & 2.9 \\
\hline
\end{tabular}

\section{DISCUSSION}

We examined the proteins detected by comparative proteomics using 2DE in combination with protein identification by MS, particularly with MALDI. In accordance to our own observations and to the outcome of a recent metaanalysis [1] we have found that indeed some proteins and protein families are much more frequently detected than others. Although a broad range of studies contributes to the list of frequently detected proteins presented here, there seems no relation of these proteins with specific study condition, including species, in vivo or in vitro, organs and tissues, and experimental objective. 
Therefore these 44 proteins constitute a list of generally detected proteins. Interestingly these proteins belong to a limited number of functional classes. Due to the criteria with focus on MALDI, the studies that we selected for analysis have only a small overlap (13/66) with the study set of Petrak et al. [1].

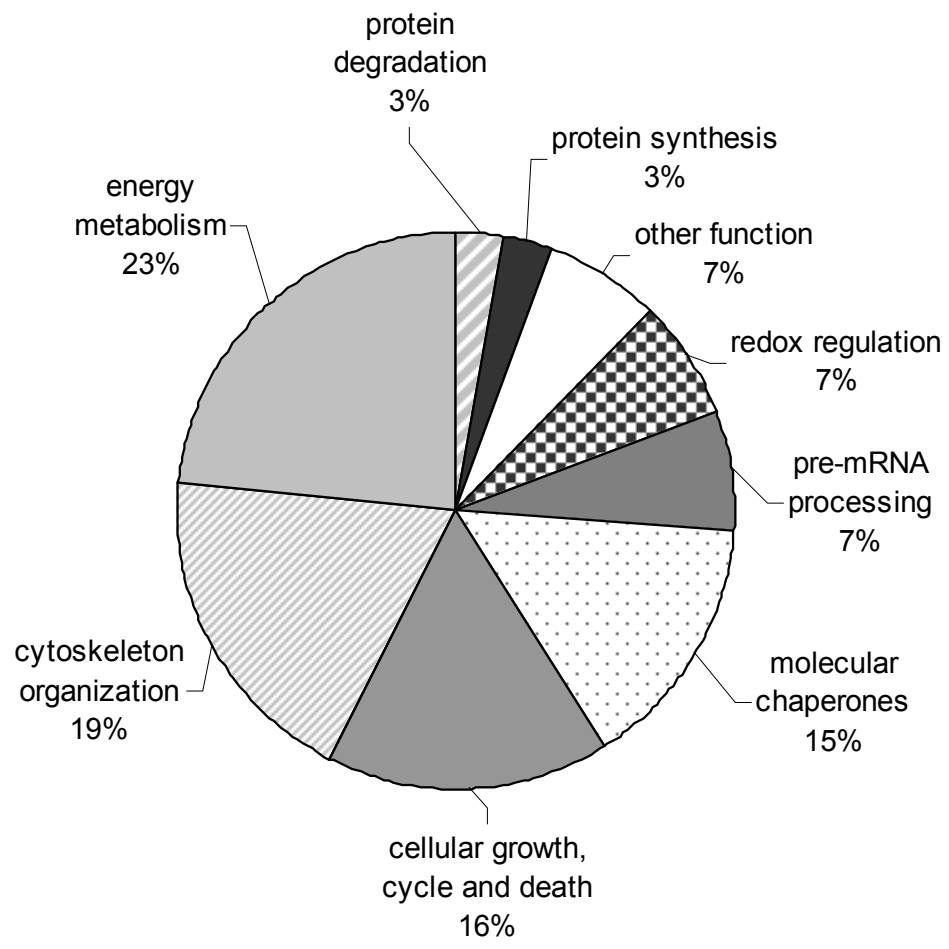

Figure 2. Functional classification of 44 generally detected proteins. Each protein was assigned to one function. The percentage of the numbers of protein in each function is listed.

Despite the largely different study sample, our outcome show considerable overlap with the results of Petrak et al. They reported 23 proteins as often identified either in humans or rodents. Of those, 17 can be found in our list of frequently detected proteins, of which 7 are among the top 10 proteins. In their work, mouse and rat data were combined, but there may be a species dependency for some proteins like for GAPDH that mainly appeared in experiments with mouse, whereas HSPD1 (HSP60) was found with rat. However, we were not able to provide statistical significance for species dependency. Of the 22 protein families reported by Petrak et al. 14 were also ranked in our list of frequently detected protein family and 7 of those were 
among the top 10. On the top of our list is the heat shock protein 70 family, which was not prioritized by Petrak et al. This may be due to the fact that they did not process different gene IDs for the same protein in different studies, whereas we converted them all to the same human IDs. Using for Grp78, HSC71 and Grp75 the corresponding human IDs HSPA5, HSPA8 and HSPA9, respectively, should have lead to the detection of the heat shock protein 70 family in their data. This may also explain why the following families showed up only in our list: heterogeneous nuclear ribonucleoproteins, proteasome subunit family, elongation factors. Apparently Petrak et al. noticed their importance and mentioned them separately as 'pseudo-groups'. It indicates that the systematic approach with application of bioinformatics presented here may be a better method for analysis of such data. On the other hand, the considerable overlap of the results of both studies indicates that we are looking at a genuine phenomenon.

The chance of a protein to be detected in a proteomics study is influenced by the employed techniques. It is already known that using 2DE to generate a proteome pattern has some limitations. The relatively low and high molecular weight proteins are not visible on the gel. Hydrophobic, extreme acidic or alkaline proteins are often underrepresented. Besides this, the technique has low dynamic range and sensitivity. Except radiolabeling, the most sensitive silver stain can detect 1-2 ng (about 10-20 fmol) of protein [11], which is still 100-times less sensitive than immunoblotting. In addition, the sensitivity of MS requires about 50-500 fmol of protein [12]. Therefore the low abundant proteins are not detectable. These technical limitations allow us to predict that the detected proteins will be enriched as hydrophilic, middle sized (10 -100 kDa), and abundant proteins. Since we choose to only analyze studies on whole proteome, the detected proteins are more possible to be cytosolic proteins than to be membrane proteins or secreted proteins.

We do observe that 44 generally detected proteins possess most of these predicted features. Although the gene expression level is not necessarily correlated to the protein level [13], there is a large chance that highly expressed genes produce abundant proteins. Therefore, we feel safe to say that the list of the generally discovered proteins represents abundant proteins. Also, these features confirm that the technical limitations influence the characteristics of the generally detected proteins.

Bedsides the factors from $2 \mathrm{DE}$, it is known that some physiochemical characters of peptides governing the ion yield in MALDI, such Argininecontaining peptides fly more easily in MALDI [14] and hydrophobic peptides may be poorly ionized [15]. We analysed the amino acid frequency of frequently detected 44 proteins compared to the rest of the proteins and did not found difference except higher lysine, which implies more shorter peptides. However, MALDI was found to tend to identify larger peptides [16]. The amino acid that are reported to enhance the ion yield in MALDI-MS, Arg, Phe and Tyr [17], were 
all with lower frequency but not significantly. These indicate that MALDI-MS does not favour identification of these 44 proteins than the others. The considerable overlap with the outcome of Petrak et al.[1] also indicated that MALDI did not play specific role on these protein detection frequency in general.

Table 5. Gene Ontology classes over-represented in detected proteins.

\begin{tabular}{|c|c|c|c|c|c|}
\hline & ID & GO Name & $\begin{array}{l}\text { Number } \\
\text { of protein }\end{array}$ & Score & $\begin{array}{l}\text { Corrected } \\
\text { p-value }\end{array}$ \\
\hline I & \multicolumn{5}{|c|}{ Biological process } \\
\hline 1 & GO:0006096 & glycolysis & 24 & 5.2 & 7.43E-12 \\
\hline 2 & GO:0006916 & anti-apoptosis & 27 & 4.9 & 3.47E-11 \\
\hline 3 & $\begin{array}{l}\text { GO:0051093, } \\
\text { GO:0043066, } \\
\text { GO:0043069 }\end{array}$ & $\begin{array}{l}\text { negative regulation of developmental } \\
\text { process, negative regulation of apoptosis, } \\
\text { negative regulation of programmed cell } \\
\text { death }\end{array}$ & 33 & 4.8 & $5.94 \mathrm{E}-12$ \\
\hline 4 & $\begin{array}{l}\text { GO:0006007, } \\
\text { GO:0019320 }\end{array}$ & $\begin{array}{l}\text { glucose catabolic process, hexose } \\
\text { catabolic process }\end{array}$ & 28 & 4.7 & $5.33 \mathrm{E}-12$ \\
\hline 5 & GO:0046365 & monosaccharide catabolic process & 29 & 4.6 & 1.49E-11 \\
\hline 6 & GO:0046164 & alcohol catabolic process & 30 & 4.5 & $5.20 \mathrm{E}-11$ \\
\hline 7 & $\begin{array}{l}\text { GO:0044275, } \\
\text { GO:0016052 }\end{array}$ & $\begin{array}{l}\text { cellular carbohydrate catabolic process, } \\
\text { carbohydrate catabolic process }\end{array}$ & 30 & 4.5 & $1.22 \mathrm{E}-11$ \\
\hline 8 & GO:0006979 & response to oxidative stress & 11 & 4.3 & $7.70 \mathrm{E}-12$ \\
\hline 9 & $\begin{array}{l}\text { GO:0043067, } \\
\text { GO:0042981 }\end{array}$ & $\begin{array}{l}\text { regulation of programmed cell death, } \\
\text { regulation of apoptosis }\end{array}$ & 56 & 4.2 & $6.93 \mathrm{E}-12$ \\
\hline 10 & GO:0006006 & glucose metabolic process & 36 & 4.1 & 5.07E-12 \\
\hline 11 & $\begin{array}{l}\text { GO:0055082, } \\
\text { GO:000687 }\end{array}$ & $\begin{array}{l}\text { cellular chemical homeostasis, cellular } \\
\text { ion homeostasis }\end{array}$ & 11 & 4.1 & $6.50 \mathrm{E}-12$ \\
\hline 12 & GO:0055080 & cation homeostasis & 11 & 4.1 & 4.95E-12 \\
\hline 13 & GO:0019318 & hexose metabolic process & 38 & 4.0 & $1.30 \mathrm{E}-11$ \\
\hline 14 & GO:0005996 & monosaccharide metabolic process & 39 & 4.0 & $1.04 \mathrm{E}-10$ \\
\hline 15 & GO:0050793 & regulation of developmental process & 63 & 4.0 & $9.04 \mathrm{E}-12$ \\
\hline 16 & $\begin{array}{l}\text { GO:0051789, } \\
\text { GO:0006986 }\end{array}$ & $\begin{array}{l}\text { response to protein stimulus, response to } \\
\text { unfolded protein }\end{array}$ & 21 & 3.9 & 4.16E-11 \\
\hline 17 & GO:0009607 & response to biotic stimulus & 24 & 3.9 & 7.17E-12 \\
\hline 18 & GO:0048878 & chemical homeostasis & 15 & 3.9 & 4.84E-04 \\
\hline 19 & GO:0044262 & cellular carbohydrate metabolic process & 43 & 3.7 & $6.93 \mathrm{E}-11$ \\
\hline 20 & $\begin{array}{l}\text { GO:0051674, } \\
\text { GO:0006928 }\end{array}$ & localization of cell, cell motility & 23 & 3.7 & $2.60 \mathrm{E}-11$ \\
\hline 21 & GO:0006091 & $\begin{array}{l}\text { generation of precursor metabolites and } \\
\text { energy }\end{array}$ & 57 & 3.6 & $2.97 \mathrm{E}-11$ \\
\hline II & \multicolumn{5}{|c|}{ Molecular function } \\
\hline 1 & GO:0016209 & antioxidant activity & 12 & 4.7 & $4.90 \mathrm{E}-04$ \\
\hline 2 & GO:0051082 & unfolded protein binding & 34 & 3.8 & $5.81 \mathrm{E}-12$ \\
\hline 3 & GO:0004857 & enzyme inhibitor activity & 25 & 3.5 & 8.46E-12 \\
\hline 4 & GO:0009055 & electron carrier activity & 22 & 3.2 & $5.17 \mathrm{E}-04$ \\
\hline 5 & GO:0016853 & isomerase activity & 28 & 3.2 & $3.10 \mathrm{E}-11$ \\
\hline 6 & GO:0005200 & structural constituent of cytoskeleton & 26 & 3.2 & $1.03 \mathrm{E}-11$ \\
\hline 7 & GO:0030234 & enzyme regulator activity & 52 & 2.8 & $1.86 \mathrm{E}-11$ \\
\hline
\end{tabular}




\begin{tabular}{|c|c|c|c|c|c|}
\hline 8 & GO:0016829 & lyase activity & 31 & 2.7 & 4.65E-04 \\
\hline 9 & GO:0008092 & cytoskeletal protein binding & 47 & 2.6 & $9.30 \mathrm{E}-11$ \\
\hline 10 & GO:0003779 & actin binding & 41 & 2.5 & $9.30 \mathrm{E}-12$ \\
\hline 11 & GO:0008289 & lipid binding & 44 & 2.4 & $1.16 \mathrm{E}-11$ \\
\hline 12 & GO:0048037 & cofactor binding & 35 & 2.4 & 4.43E-04 \\
\hline 13 & GO:0004175 & endopeptidase activity & 41 & 2.4 & $7.75 \mathrm{E}-12$ \\
\hline 14 & GO:0003677 & DNA binding & 53 & 2.3 & 7.15E-12 \\
\hline 15 & GO:0022892 & substrate-specific transporter activity & 43 & 2.2 & $6.64 \mathrm{E}-12$ \\
\hline 16 & GO:0016818 & $\begin{array}{l}\text { hydrolase activity, acting on acid } \\
\text { anhydrides, in phosphorus-containing } \\
\text { anhydrides }\end{array}$ & 62 & 2.2 & $5.47 \mathrm{E}-12$ \\
\hline 17 & GO:0016301 & kinase activity & 40 & 2.2 & $1.55 \mathrm{E}-11$ \\
\hline 18 & GO:0008233 & peptidase activity & 52 & 2.2 & $4.65 \mathrm{E}-11$ \\
\hline 19 & GO:0017111 & nucleoside-triphosphatase activity & 58 & 2.1 & $1.33 \mathrm{E}-11$ \\
\hline 20 & GO:0005215 & transporter activity & 56 & 2.1 & $6.20 \mathrm{E}-12$ \\
\hline 21 & GO:0003723 & RNA binding & 52 & 2.0 & $2.33 \mathrm{E}-11$ \\
\hline III & \multicolumn{5}{|c|}{ Cellular Component } \\
\hline 1 & GO:0044445 & cytosolic part & 19 & 4.2 & $5.33 \mathrm{E}-12$ \\
\hline 2 & $\begin{array}{l}\text { GO:0005882, } \\
\text { GO:0045111 }\end{array}$ & $\begin{array}{l}\text { intermediate filament, intermediate } \\
\text { filament cytoskeleton }\end{array}$ & 17 & 3.8 & 8.00E-12 \\
\hline 3 & GO:0015630 & microtubule cytoskeleton & 18 & 3.5 & 4.00E-04 \\
\hline 4 & GO:0044430 & cytoskeletal part & 62 & 3.1 & $2.40 \mathrm{E}-11$ \\
\hline 5 & GO:0005783 & endoplasmic reticulum & 40 & 3.1 & 4.36E-12 \\
\hline 6 & GO:0031090 & organelle membrane & 32 & 3.0 & $6.86 \mathrm{E}-12$ \\
\hline 7 & $\begin{array}{l}\text { GO:0031974, } \\
\text { GO:0043233 }\end{array}$ & $\begin{array}{l}\text { membrane-enclosed lumen, organelle } \\
\text { lumen }\end{array}$ & 51 & 2.6 & $1.20 \mathrm{E}-11$ \\
\hline 8 & GO:0044429 & mitochondrial part & 39 & 2.3 & $4.80 \mathrm{E}-12$ \\
\hline 9 & GO:0044428 & nuclear part & 55 & 2.3 & $6.00 \mathrm{E}-12$ \\
\hline 10 & GO:0030529 & ribonucleoprotein complex & 37 & 2.3 & $1.60 \mathrm{E}-11$ \\
\hline 11 & GO:0015629 & actin cytoskeleton & 44 & 2.2 & $4.80 \mathrm{E}-11$ \\
\hline
\end{tabular}

However, the 2DE technical limitations cannot be the only factor influencing the outcome of our analysis, because the proteins were selected from comparative proteomics studies. It is not likely that the chance of a protein to be differentially expressed depends on its abundance or size. It will more depend on its function in relation to the experimental conditions. In fact, the limited functional classes regardless of experimental conditions imply that these generally detected proteins are involved in some common response(s) to all the changes, and that such response(s) is preserved in different species and different body parts.

A transcriptomic study has shown that in yeast a set of genes can be induced by almost all environmental changes, which is called the environmental stress response [18]. In general, cellular stress response is defined as a reaction to the threat of macromolecular damage by environmental changes. Not only in yeast but evolutionarily conserved in all cellular organisms, cellular stress response is a universal mechanism and not stressor specific [19]. Because stress response is highly conserved, the concept of a minimal cellular stress 
proteome has been proposed [19, 20]. This proteome of about 300 proteins was composed of evolutionarily highly conserved proteins in three super-kingdoms (bacteria, fruit fly and human), based on protein structure analysis. Functional analysis of this minimal stress proteome reveals that the key aspects of the cellular stress response include DNA damage sensing/repair, redox regulation, cell cycle control, molecular chaperone function, protein degradation, fatty acids/lipid metabolism, and energy metabolism. Interestingly, the frequently detected proteins in comparative proteomics have alike functions. And many of our listed proteins have been mentioned in the minimal cellular stress proteome, such as ALDH2, PRDX6, SOD1, P4HB, GAPDH, ENO1, HSPA5 (HSP70), HSPD1 (HSP60), PPIA, etc. This strongly suggests that these proteins were differentially expressed in the diverse experiments due to the intrinsic cellular stress response. It implies that one should be cautious to call the proteins from this list (Table 2) biomarkers for processes other than cellular stress. This also implies that if only these proteins are detected, the used proteomic method is not suitable to identify proteins that specifically respond to the experimental conditions. In that case, other more sensitive or more specific methods should be applied.

Our analysis also pointed out that among all aspects of cellular stress response, protein stabilization and homeostasis control is particularly easy to be detected by classical proteomics. This is concluded from the large number of Endoplasmic Reticulum (ER)-resident chaperones, including heat shock proteins, and proteasome proteins. These two classes of proteins are known to be largely responsible for the integrity of soluble cytosolic proteins [21]. ER stress, characterized by the up-regulation of ER residents, especially molecular chaperones, has been linked to diseases. Often these molecular chaperones are used as biomarkers [22, 23]. Our results indicate that classical proteomics is useful to study ER stress linked diseases and situations. However, the response of molecular chaperones to diverse stimuli is universal. Therefore, finding a particular member of the protein family, which is specific for a disease or a certain situation, is needed to generate useful diagnostic information.

Among the top proteins in our generally detected protein list is an enzyme, ENO1, that is involved in glycolysis. Because glucose is the major energy fuel for the species studied here [24], it is not surprising that the glycolysis is sensitive to environmental change. The flexibility of this pathway can assure that the cellular energy demand is satisfied under different conditions. On the other side, ENO1, unlike other glycolysis enzymes, has a shorter form as a structural component of lens (tau-crystallin), and also has been reported as transcription factor (c-myc promoter-binding protein 1) with a role in the regulation of cell growth $[25,26]$. The broad function of ENO1 possibly explains why it is one of the most often detected proteins in comparative proteomics.

Although many studies reported that cytoskeleton reorganization is influenced by stress stimuli $[27,28]$, cytoskeleton (re)organization has not been recognized 
as a main aspect of stress response. The intermediate filament family and actin family are essential for maintaining cell morphology and for intracellular transport [29]. The components of the cytoskeleton, such as actin, are also evolutionarily highly conserved, showing their importance for the cell survival. It suggests that this class of proteins should be included in the common stress response, but this requires further investigation.

The heterogeneous nuclear ribonucleoproteins are a family that is frequently detected as differential proteins under various conditions. This family with about 20 members is highly conserved and forms large RNA-binding complexes. They play central roles in regulating gene expression and protein production. The best known is their role in posttranscriptional events including pre-mRNA splicing, pre-mRNA polyadenylation, 3'-end processing and stability, and mRNA nuclear export [30]. A change at the level of the heterogeneous nuclear ribonucleoproteins itself may introduce a rapid and flexible manner to regulate the amount and function of other proteins, under stress conditions.

By analysing reported differentially expressed proteins and applying bioinformatics we have composed a list of 44 proteins and of 28 protein families frequently detected in comparative proteomic studies using 2DE/MS. Our findings largely confirm and broaden those of a previous survey [1]. Cellular stress response can be the universal reason that these proteins are generally expressed differentially. In future proteomic studies more profound approaches should be applied to look beyond these proteins and find specific biomarkers.

\section{Acknowledgements}

We thank Prof P. Verhaert from Delft University for useful discussion. The authors declare no conflict of interest. This research was supported by the Maastricht Proteomics Center and the research institute NUTRIM of the Maastricht University. P. Wang is also supported by the DIOGENES project (Contract no. FOOD-CT-2005-513946) from the European Community. Prof. E. Mariman is a member of the Dutch NutriGenomics Consortium (NGC-TIFN).

\section{References}

1. Petrak J, et al. (2008) Deja vu in proteomics. A hit parade of repeatedly identified differentially expressed proteins. Proteomics 8(9):1744-1749.

2. Bieri T, et al. (2007) WormBase: new content and better access. Nucleic Acids Res 35(Database issue):D506-510.

3. Kasprzyk A, et al. (2004) EnsMart: a generic system for fast and flexible access to biological data. Genome Res 14(1):160-169. 
4. Hubbard TJ, et al. (2007) Ensembl 2007. Nucleic Acids Res 35(Database issue):D610-617.

5. Wilson RJ, Goodman JL, \& Strelets VB (2008) FlyBase: integration and improvements to query tools. Nucleic Acids Res 36(Database issue):D588-593.

6. Bult CJ, Eppig JT, Kadin JA, Richardson JE, \& Blake JA (2008) The Mouse Genome Database (MGD): mouse biology and model systems. Nucleic Acids Res 36(Database issue):D724-728.

7. Wu C \& Nebert DW (2004) Update on genome completion and annotations: Protein Information Resource. Hum Genomics 1(3):229-233.

8. Twigger SN, Shimoyama M, Bromberg S, Kwitek AE, \& Jacob HJ (2007) The Rat Genome Database, update 2007--easing the path from disease to data and back again. Nucleic Acids Res 35(Database issue):D658-662.

9. Consortium U (2007) The Universal Protein Resource (UniProt). Nucleic Acids Res 35(Database issue):D193-197.

10. Lee HK, Braynen W, Keshav K, \& Pavlidis P (2005) ErmineJ: tool for functional analysis of gene expression data sets. BMC Bioinformatics 6:269.

11. Baharvand $H$, Fathi $A$, van Hoof D, \& Salekdeh GH (2007) Concise review: trends in stem cell proteomics. Stem Cells 25(8):1888-1903.

12. Wittmann-Liebold B, Graack HR, \& Pohl T (2006) Two-dimensional gel electrophoresis as tool for proteomics studies in combination with protein identification by mass spectrometry. Proteomics 6(17):4688-4703.

13. Hegde PS, White IR, \& Debouck C (2003) Interplay of transcriptomics and proteomics. Curr Opin Biotechnol 14(6):647-651.

14. Krause E, Wenschuh $H$, \& Jungblut PR (1999) The dominance of arginine-containing peptides in MALDI-derived tryptic mass fingerprints of proteins. Anal Chem 71(19):4160-4165.

15. Lubec G \& Afjehi-Sadat L (2007) Limitations and pitfalls in protein identification by mass spectrometry. Chem Rev 107(8):3568-3584.

16. Hansen KC, et al. (2003) Mass spectrometric analysis of protein mixtures at low levels using cleavable 13C-isotope-coded affinity tag and multidimensional chromatography. Mol Cell Proteomics 2(5):299-314.

17. Nishikaze T \& Takayama M (2006) Cooperative effect of factors governing molecular ion yields in desorption/ionization mass spectrometry. Rapid Commun Mass Spectrom 20(3):376-382.

18. Gasch AP, et al. (2000) Genomic expression programs in the response of yeast cells to environmental changes. Mol Biol Cell 11(12):4241-4257.

19. Kultz D (2005) Molecular and evolutionary basis of the cellular stress response. Annu Rev Physiol 67:225-257.

20. Kultz D (2003) Evolution of the cellular stress proteome: from monophyletic origin to ubiquitous function. J Exp Biol 206(Pt 18):3119-3124.

21. Leidhold C \& Voos W (2007) Chaperones and proteases--guardians of protein integrity in eukaryotic organelles. Ann N Y Acad Sci 1113:72-86.

22. Xu C, Bailly-Maitre B, \& Reed JC (2005) Endoplasmic reticulum stress: cell life and death decisions. J Clin Invest 115(10):2656-2664.

23. Banhegyi G, et al. (2007) Endoplasmic reticulum stress. Ann N Y Acad Sci 1113:58-71.

24. Wang $P$ \& Mariman EC (2008) Insulin resistance in an energy-centered perspective. Physiol Behav 94(2):198-205.

25. Ghosh AK, Steele R, \& Ray RB (2005) c-myc Promoter-binding protein 1 (MBP-1) regulates prostate cancer cell growth by inhibiting MAPK pathway. J Biol Chem 280(14):14325-14330.

26. Ito S, et al. (2007) Differential expression of the human alpha-enolase gene in oral epithelium and squamous cell carcinoma. Cancer Sci 98(4):499-505.

27. Yahara I, et al. (1996) A role of cofilin/destrin in reorganization of actin cytoskeleton in response to stresses and cell stimuli. Cell Struct Funct 21(5):421-424.

28. McCue S, Noria S, \& Langille BL (2004) Shear-induced reorganization of endothelial cell cytoskeleton and adhesion complexes. Trends Cardiovasc Med 14(4):143-151.

29. DePina AS \& Langford GM (1999) Vesicle transport: the role of actin filaments and myosin motors. Microsc Res Tech 47(2):93-106.

30. Carpenter B, et al. (2006) The roles of heterogeneous nuclear ribonucleoproteins in tumour development and progression. Biochim Biophys Acta 1765(2):85-100. 


\section{Chapter 7}

\section{Gender-specific genetic associations of polymorphisms in ACE, AKR1C2, FTO and MMP2 with weight gain over a 10 year period}

Freek Bouwman ${ }^{1}$, Jolanda M.A. Boer ${ }^{2}$, Sandra Imholz ${ }^{2}$, Ping Wang ${ }^{1}$, Monique Verschuren ${ }^{2}$, Martijn E.T. Dollé ${ }^{2}$ \& Edwin C.M. Mariman ${ }^{1}$

${ }^{1}$ Department of Human Biology, Nutrition and Toxicology Research Institute Maastricht (NUTRIM), Maastricht University, Maastricht, The Netherlands and ${ }^{2}$ National Institute for Public Health and the Environment (RIVM), Bilthoven, The Netherlands

Genes \& Nutrition 2014, 9 (6), 434 


\section{ABSTRACT}

Background: Weight gain, when it leads to overweight or obesity, is nowadays one of the major health problems. ACE, FTO, AKR1C2, TIMP4 and MMP2 genes have been implicated in previous studies on weight regulation. This study investigated the contribution of polymorphisms in these five candidate genes to the risk of weight gain over a 10 year time period.

Methods: Two groups were selected from participants of the Doetinchem cohort study who were followed over a 10 year period: a stable weight group $( \pm 2$ $\mathrm{kg} / 10 \mathrm{y} ; \mathrm{n}=259$ ) and a weight gainers group who increased their body weight by roughly $10 \%$ (>8 kg/10y; $\mathrm{n}=237$ ). Starting $\mathrm{BMI}$ was between $20-35 \mathrm{~kg} / \mathrm{m}^{2}$ and baseline age between 20-45 years. Selected SNPs and insert/deletion in candidate genes were measured in each group.

Results: In men the allelic distribution of FTO rs9939609 (X2 P=0.005), ACE rs4340 (X2 P=0.006) and AKR1C2 rs12249281 (X2 P=0.019) differed between the weight stable and weight gainers group. Interaction between FTO rs9939609 and ACE rs4340 was observed. In women the allelic distribution of MMP2 rs1132896 differed between the weight stable and weight gainers group ( $\mathrm{X} 2 \mathrm{P}=0.00001$ ). The A allele of FTO was associated with a 1.99x higher risk of gaining weight in men (OR 1.99, $p=0.020$ ), while in women the $C$ allele of MMP2 was associated with a 2.50x higher risk of weight gain (OR 2.50, $\mathrm{p}=0.001$ ) over the 10 year period.

Conclusion: We found that FTO in men and MMP2 in women are associated with weight gain over a 10 year follow-up period. 


\section{INTRODUCTION}

Weight gain, when it leads to overweight or obesity, is nowadays one of the major health problems [1]. Unfortunately, the etiology of weight gain is complex and has remained largely unclear. Studies have indicated that lifestyle factors like for instance physical activity, eating behavior and the way to spend leisure time are of influence [2]. Moreover, body weight seems also to be determined by genetic background, which may be important as an offset of the energy balance as MacLean reported [3].

Several genetic variants have been associated with body weight or weight gain. Polymorphisms in the angiotensin converting enzyme (ACE) gene have been found to be associated with body weight, body mass index (BMI), overweight and obesity [4]. Recent data suggest that the renin-angiotensin system might be involved in the pathophysiology of obesity and associated hypertension [5]. ACE gene polymorphisms influence the levels of plasma ACE, and thereby the level of Angiotensin II which is known to play a role in adipocyte growth and the differentiation of preadipocytes to mature adipocytes [6]. The best studied ACE gene polymorphism in this respect is the insertion/deletion (I/D) located in intron 16. Additionally, rs9939609 in the gene coding for fat mass and obesityassociated protein (FTO) is a well-known predictor for increased body weight and BMI $[7,8]$. In adults, individuals with the AA genotype of rs9939609 weigh on average $3 \mathrm{~kg}$ more than those with the TT genotype and each A allele increases the BMI with approximately $0.4 \mathrm{~kg} / \mathrm{m}^{2}$ [7]. How FTO influences the development of obesity remains unclear, but recent studies suggest that FTO may influence adiposity by affecting appetite [9]. Another suggested mechanism is that obesity-associated SNPs in the intron region of the FTO gene act on body weight via regulation of the expression of IRX3, a homeobox gene playing a role in early neuron development $[10,11]$. Another candidate gene is the gene for aldo-keto reductase 1C2 (AKR1C2). We have observed correlations between AKR1C2 protein level in adipose tissue and parameters of adiposity [12]. It has also been reported that the level of AKR1C2 mRNA expression in adipose tissue of women positively correlates with adiposity [13]. Similarly, Wake et al. showed that central fat distribution, measured by waist/hip ratio, was associated with mRNA expression for AKR1C2 in white adipose tissue [14]. An association has also been found between obesity and genetic variation in the gene for matrix metalloproteinase-2 (MMP2) [15], of which the activity is controlled by tissue inhibitor of metalloproteinase 4 (TIMP4). MMP2 and TIMP4 are proteins involved in the remodeling of the extracellular matrix (ECM) of adipocytes, which is essential for the development of adipocytes [16]. An imbalance between MMP2 and TIMP4 could have an effect on ECM remodeling and as such on fat mass development [17]. 
The aim of the present study was to investigate if preselected genetic polymorphisms in these candidate genes influence weight gain over a 10 year period of time

\section{MATERIALS AND METHODS}

\section{Study population}

The present study selected subjects from the ongoing Doetinchem cohort [18, 19]. The design of the Doetinchem study and detailed methods have been reported earlier [20]. Participants were eligible for the present study if he/she has participated in three consecutive rounds of examinations covering a 10 year period, were stable in smoking habits and not pregnant, starting Body Mass Index (BMI) between 20-35 kg/m², and baseline age between 20-45 years (Figure 1).

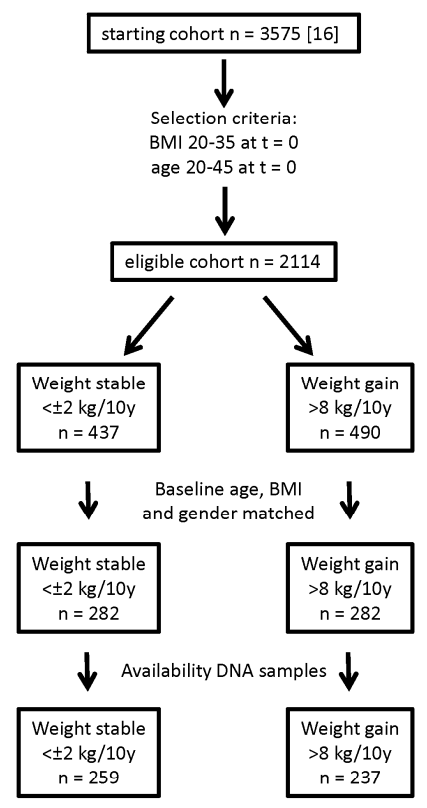

Figure 1: Flow chart of the different selection steps and the number of participants

Based on a relative risk of 2, a power calculation indicated that 208 subjects in each group are required for a power of 0.8 . We selected a stable weight group $(< \pm 2 \mathrm{~kg} / 10 \mathrm{y})$ and a weight gainers group ( $>8 \mathrm{~kg} / 10 \mathrm{y})$ from these eligible 
subjects. The two groups were group-matched for baseline age, BMI and gender, resulting in 282 participants per group.

In the stable weight group, 259 DNA samples of the participants were available and in the weight gainers group, 237 DNA samples of the participants (Figure 1 ). The $8 \mathrm{~kg}$ weight gain is roughly $10 \%$ of the initial body weight. The study was approved by the external Medical Ethics Committee (MEC) of the Netherlands Organization of Applied Scientific Research according to the guidelines of the Declaration of Helsinki. A written informed consent, approved by the MEC, was obtained from all participants. At the start of the study a blood sample was drawn, fractionated to obtain buffy coats for isolation of DNA and subsequently stored at $-30^{\circ} \mathrm{C}$.

\section{DNA isolation, SNP selection and genotyping}

Genomic DNA was isolated from stored buffy coats using a salting out method as described before [19]. To ensure a considerable fraction of carriers of the minor allele, only SNPs with a minor allele frequency in Europeans of at least $25 \%$, as indicated in the SNP public database (dbSNP; http://www.ncbi.nlm.nih.gov/SNP), were considered as candidates. Preferably, SNPs were considered that had earlier been shown to be associated with relevant phenotypes, such as BMI or body composition. Polymorphisms in angiotensin converting enzyme (ACE), fat mass and obesity-associated protein (FTO), aldo-keto reductase 1C2 (AKR1C2), tissue inhibitor of metalloproteinase 4 (TIMP4) and matrix metalloproteinase-2 (MMP2) were chosen as candidate genes for weight gain, also based on previous research [4, 12]. Genotyping was performed using commercially available TaqMan SNP genotyping assays from Applied Biosystems (Foster City, CA, USA). The procedure was performed according to the manufacturer's protocol and measured on an Applied Biosystems $7900 \mathrm{HT}$ fast real-time PCR system. Allelic calls were determined semi-automatically using the SDS 2.3 software. The ACE deletion/insertion (rs4340) was determined with the following primers: Forward primer 5'CCTTTCTCCCATTTCTCTAGACCTG-3' DEL-Reverse Primer 5'GCTCAGAGAATTTCAGAGCTGGA-3' INS-Reverse Primer 5'GATCCCGCCACTGCACTC-3' DEL-Probe 5'-VICTGCCTATACAGTCACTTTTATGTGGTTTCGC-TAMRA-3' and INS-Probe 5'FAM-CTCGCTCTGTCGCCCAGGCT-TAMRA-3'. The PCR reaction was performed using the following PCR program: denaturation 10 minutes at $95^{\circ} \mathrm{C}$ followed by 40 cycles of denaturation at $95^{\circ} \mathrm{C}$ for 15 seconds and annealing/extension at $62^{\circ} \mathrm{C}$ for 1 minute [21]. The allelic calls were determined semi-automatically using the SDS 2.3 software. 


\section{Statistical analysis}

Hardy-Weinberg equilibrium (HWE) for the different polymorphisms was calculated using the chi-square test. Linkage disequilibrium (LD) was calculated using SNAP which is a web-based tool for identification and annotation of SNPs in LD using HapMap 3 (release 2) [22]. SNAP is publicly available at http://www.broad.mit.edu/mpg/snap. We used Pearson's $x^{2}$ to examine differences in the frequencies of the genotypes between the weight stable and weight gainers group. The inheritance model with the most significant $p$-value was chosen using the SNPStats program [23]. SNPStats is publicly available at http://bioinfo.iconcologia.net/snpstats. All statistical analyses were performed for men and women separately and adjusted for matching criteria, i.e. baseline age and baseline BMI. Logistic regression was performed using the Logit function in Generalized Linear Model to examine the effect of the polymorphisms on weight gain, using baseline age and BMI as covariates. Pearson's $x^{2}$ and logistic regression analyses were done using the SPSS v20.0 statistical software. To identify epistatic interactions, the multi-factor dimensionality reduction (MDR) method was used [24]. The MDR software is publicly available at http://www.epistasis.org. A P-value $<0.05$ was considered statistically significant. To evaluate the gene-dietary interaction, the cohort was stratified to low, medium and high intake level for each dietary factor in each sex group. Logistic regression was used to examine the effect of the interaction between allelic type and dietary intake level for weight gain on each dietary factor and each SNP. To correct for multiple testing Bonferroni correction was applied, a significance threshold of $\mathrm{P}$-value $=0.007$ was used in the $\mathrm{X}^{2}$ test for examining the relation between 7 SNPs and weight gain.

Table 1: Characteristics of the study population

\begin{tabular}{lllll}
\hline & Men & \multicolumn{3}{l}{ Women } \\
\cline { 2 - 5 } & Weight stable & Weight gainers & Weight stable & Weight gainers \\
\hline Number of subjects & 132 & 120 & 127 & 117 \\
Baseline & & & & \\
Age (years) & $35.2 \pm 6.1$ & $36.0 \pm 5.6$ & $35.4 \pm 5.6$ & $36.0 \pm 5.6$ \\
Weight $(\mathrm{kg})$ & $79.0 \pm 8.6$ & $80.5 \pm 8.7$ & $67.3 \pm 8.0$ & $68.5 \pm 8.0$ \\
BMl $\left(\mathrm{kg} / \mathrm{m}^{2}\right)$ & $24.1 \pm 2.2$ & $24.4 \pm 2.5$ & $23.8 \pm 2.7$ & $24.1 \pm 2.6$ \\
& & & & \\
Follow-up & & & & \\
Follow-up time (years) & $10.9 \pm 0.2$ & $10.9 \pm 0.2$ & $10.9 \pm 0.2$ & $10.9 \pm 0.2$ \\
Weight $(\mathrm{kg})$ & $79.7 \pm 8.6$ & $92.4 \pm 9.3$ & $67.6 \pm 7.8$ & $81.7 \pm 9.2$ \\
Weight gain (kg/10 years) & $0.7 \pm 1.1$ & $11.8 \pm 2.8$ & $0.3 \pm 1.2$ & $13.2 \pm 4.2$ \\
BMl $\left(\mathrm{kg} / \mathrm{m}^{2}\right)$ & $24.3 \pm 2.2$ & $27.9 \pm 2.8$ & $23.9 \pm 2.7$ & $28.8 \pm 3.2$ \\
\hline
\end{tabular}

Results are presented as mean \pm SD. 


\section{Results}

\section{Subject characteristics}

On average weight gainers increased their body weight with $11.8 \mathrm{~kg}$ in men and $13.2 \mathrm{~kg}$ in women. This was roughly $10 \%$ or more of their baseline weight and resulted in a 3.6 and $4.9 \mathrm{~kg} / \mathrm{m}^{2}$ increase in BMl, respectively (Table 1). Information on dietary intake is given in Table 2. In women, carbohydrate and protein intake differed between the weight stable and weight gainers group. No differences were observed in men.

Table 2: Average dietary intake in men and women over the ten-year follow-up period

\begin{tabular}{lrllll}
\hline & & Men & & Women \\
\cline { 3 - 6 } & & $\begin{array}{l}\text { Weight stable } \\
\mathrm{n}=132\end{array}$ & $\begin{array}{l}\text { Weight gainers } \\
\mathrm{n}=120\end{array}$ & $\begin{array}{l}\text { Weight stable } \\
\mathrm{n}=127\end{array}$ & $\begin{array}{l}\text { Weight gainers } \\
\mathrm{n}=117\end{array}$ \\
\hline $\begin{array}{l}\text { Energy } \\
\text { intake }\end{array}$ & (MJ/day) & $11.1 \pm 2.5$ & $10.6 \pm 2.1$ & $8.0 \pm 1.6$ & $8.4 \pm 1.7$ \\
$\begin{array}{l}\text { Fat } \\
\text { Carbohydrate(g/day) }\end{array}$ & $107 \pm 27$ & $101 \pm 24$ & & \\
Protein & $297 \pm 72$ & $282 \pm 65$ & $215 \pm 50^{*}$ & $81 \pm 22$ \\
\hline
\end{tabular}

Values are presented as mean $\pm S D,{ }^{*} p<0.05$ between weight groups

\section{Genetic analysis}

The genotypic and allelic distributions of the determined polymorphisms are shown in Table 3. All SNPs were in Hardy-Weinberg equilibrium. None of the SNPs were in linkage disequilibrium (LD), indicating that all SNPs provided independent information and thus can be used separately for further statistics.

ACE deletion/insertion rs 4340. The distribution of the genotypes between the weight stable and weight gainers group was significantly different $(p=0.006)$ in men, but not in women ( $p=0.84$, Table 4). Although borderline statistically significant when using a recessive model, that fitted best, the $1 / 1$ genotype increased the risk of weight gain over the 10 years in men (OR 1.91, 95\% Cl: (0.93-3.93), Table 5).

FTO rs9939609. The A-allele of this SNP was associated with weight gain in men, but not in women. The A-allele frequency was significantly higher in the weight gainers than in the weight stable group ( 0.45 vs $0.35, p=0.001$, Table 4). Also the genotype distribution differed between the weight gainers and weight stable group $\left(x^{2} p=0.005\right)$. Logistic regression analysis shows that the combined A/A and A/T genotypes of FTO in men were associated with weight gain (Table 5). Being a male A-allele carrier increased the risk of gaining weight over the 10 year period by 1.99 -fold ( $95 \%$ Cl: $1.16-3.39$, Table 5$)$. 
Table 3: Genotype and allele frequencies per polymorphism in the whole study population.

\begin{tabular}{|c|c|c|c|c|c|c|c|}
\hline Gene & Polymorphism & Genotypes & $\mathrm{n}$ & $F(\%)$ & Allele & $F(\%)$ & $\mathrm{HWE}^{\mathrm{a}}$ \\
\hline \multirow[t]{3}{*}{$\overline{\mathrm{ACE}}$} & rs4340 & Del/Del & 141 & 28.4 & Del & 55.1 & 0.10 \\
\hline & & Del/Ins & 263 & 53.0 & Ins & 44.9 & \\
\hline & & Ins/Ins & 91 & 18.3 & & & \\
\hline \multirow[t]{3}{*}{ FTO } & rs9939609 & $\mathrm{A} / \mathrm{A}$ & 78 & 15.7 & A & 38.0 & 0.14 \\
\hline & & $A / T$ & 214 & 43.1 & T & 62.0 & \\
\hline & & $T / T$ & 195 & 39.3 & & & \\
\hline \multirow[t]{3}{*}{ AKR1C2 } & rs2854482 & $\mathrm{A} / \mathrm{A}$ & 457 & 92.1 & A & 96.1 & 0.36 \\
\hline & F46Y & $\mathrm{A} / \mathrm{T}$ & 39 & 7.9 & $\mathrm{~T}$ & 3.9 & \\
\hline & & $T / T$ & 0 & 0 & & & \\
\hline AKR1C2 & rs4143631 & $\mathrm{C} / \mathrm{C}$ & 258 & 52.0 & C & 71.2 & 0.20 \\
\hline \multirow[t]{2}{*}{ Promoter } & & $\mathrm{C} / \mathrm{T}$ & 191 & 38.5 & T & 28.8 & \\
\hline & & $T / T$ & 47 & 9.5 & & & \\
\hline AKR1C2 & rs12249281 & $\mathrm{A} / \mathrm{A}$ & 129 & 26.0 & A & 48.9 & 0.07 \\
\hline \multirow[t]{2}{*}{ Promoter } & & $A / G$ & 227 & 45.8 & G & 51.1 & \\
\hline & & $\mathrm{G} / \mathrm{G}$ & 140 & 28.2 & & & \\
\hline \multirow[t]{3}{*}{ TIMP4 } & rs3755724 & $\mathrm{C} / \mathrm{C}$ & 219 & 44.2 & C & 66.4 & 0.84 \\
\hline & & $\mathrm{C} / \mathrm{T}$ & 219 & 44.2 & T & 33.6 & \\
\hline & & $T / T$ & 57 & 11.5 & & & \\
\hline \multirow[t]{3}{*}{ MMP2 } & rs1132896 & $\mathrm{C} / \mathrm{C}$ & 60 & 12.1 & C & 35.6 & 0.63 \\
\hline & & $\mathrm{C} / \mathrm{G}$ & 231 & 46.6 & G & 64.4 & \\
\hline & & $\mathrm{G} / \mathrm{G}$ & 202 & 40.7 & & & \\
\hline
\end{tabular}

${ }^{\mathrm{a}} \mathrm{P}$-values obtained from the $\mathrm{X}^{2}$ of Hardy-Weinberg equilibrium (HWE). n, number of subjects; $F$, relative frequency $(\%)$

AKR1C2 rs2854482, rs4143631 and rs12249281. rs2854482 is until now the only known functional SNP in the NCBI database of AKR1C2. This amino acid variation has an effect on the enzyme activity and on cofactor binding [25]. The A allele exchanges the amino acid $F$ into $Y$, which decreases the enzyme activity. rs4143631 is in the promoter inside the CNV region, while rs12249281 is in the promoter but outside the CNV region. Figure 2 shows a schematic overview of the relative position of the AKR1C2 gene, the CNV and the investigated SNPs. The T/T homozygote of rs2854482 was not present in our study population (Table 4). For this SNP as well as for rs4143631 no significant differences in the genotype and allele frequencies between the weight stable and weight gainer groups were observed. In contrast, in men, the A/A genotype of rs12249281 was more frequent and the $A / G$ genotype less frequent among weight gainers than among the weight stable group $\left(x^{2} p=\right.$ 0.019 Table 4). However, linear regression based on a recessive model did not show significant results (Table 5). In women no association with any of the AKR1C2 genotypes was observed. 


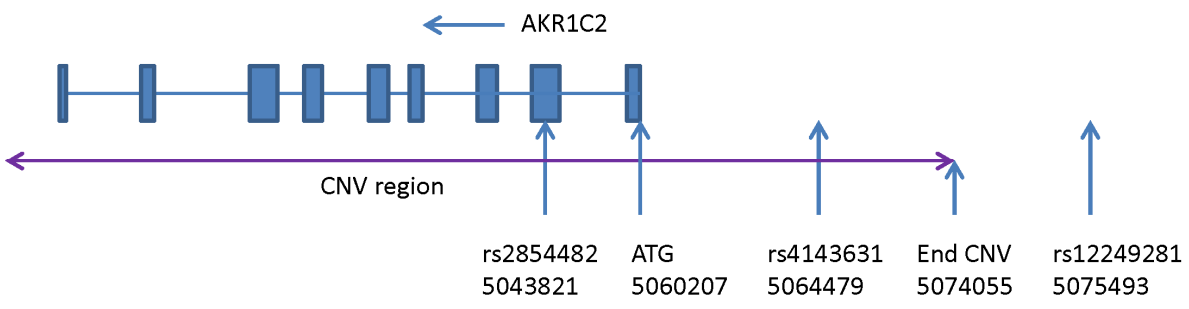

Figure 2: Schematic overview of the position of the AKR1C2 gene, the CNV-region (Copy Number Variation) and the investigated SNPs.

TIMP4 rs3755724. In both men and women, no significant differences were found in the genotype or allele frequencies between the weight stable and weight gainers group (Table 4).

MMP2 rs1132896. Significantly different allele frequencies were observed between the female weight stable and weight gainers group with the C-allele being more frequent among the weight gainers ( $43 \%$ vs $34 \%, p=0.005$, Table 4). Also the genotype distribution between the weight stable and gainers differed $\left(x^{2} p=0.00001\right)$. The frequency of the $C / G$ genotype was higher in the weight gainers $(65 \%)$ than in the weight stable group (43\%). The G/G genotype was lower ( $25 \%$ vs $45 \%$, Table 4$)$. Logistic regression analysis showed being a carrier of the C allele of MMP2 in women conferred a 2.50 -fold (95\% Cl: $1.44-$ 4.35) higher risk for weight gain over a 10 year period than being carrier of the $\mathrm{G} / \mathrm{G}$ genotype (Table 5). No significant differences between weight gainers and the weight stable group were observed for men.

\section{SNP-SNP interactions}

MDR analysis revealed a significant SNP-SNP interaction for weight gain between FTO and ACE in men (Figure 3). Logistic regression shows that men with the $T / T$ genotype for FTO in combination with the $D$ allele for ACE were protected against weight gain (OR $0.47,95 \% \mathrm{Cl}$ : $0.27-0.85, \mathrm{p}=0.011$ ). In contrast, the TT genotype for FTO in combination with the II genotypes for ACE seemed to increase the risk of weight gain, though not statistically significant. No SNP-SNP interactions were found in women.

\section{Gene-dietary interaction}

We tested the possible contribution to the weight gain from the interactions of gene-dietary intake. However, we could not detect any significant contribution. The energy intake in women was $1.06 x$ higher $(p=0.032)$ in the MMP2 C/C$\mathrm{C} / \mathrm{G}$ vs $\mathrm{G} / \mathrm{G}$ carriers. This suggests that the MMP2 SNP works synergistically with energy intake on weight regulation. 


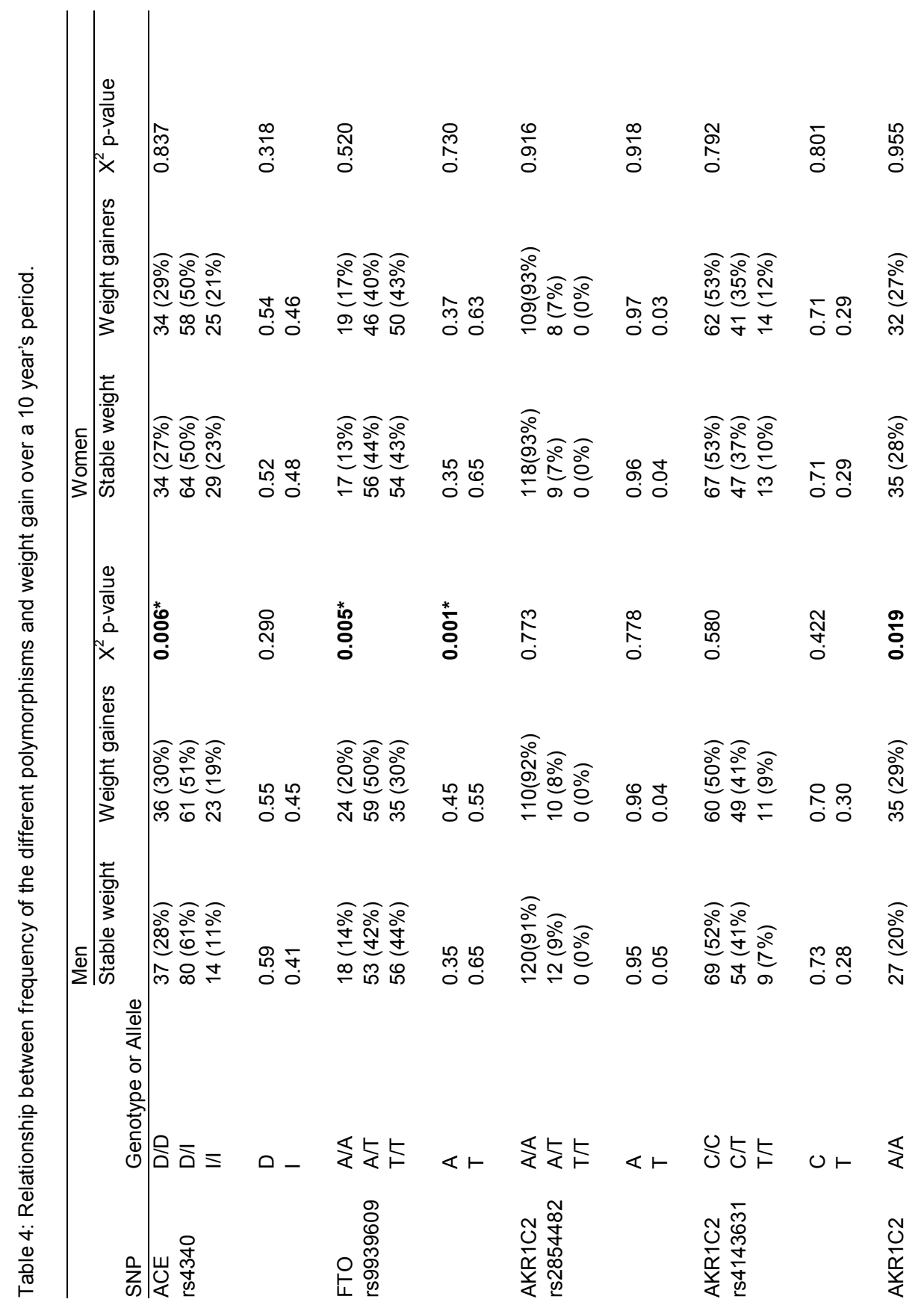




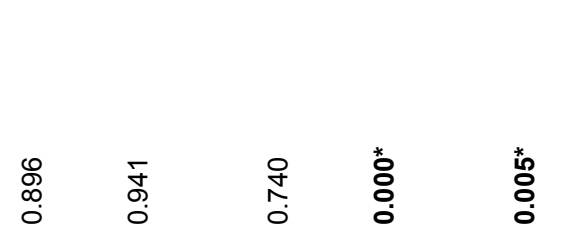

ஓे

政

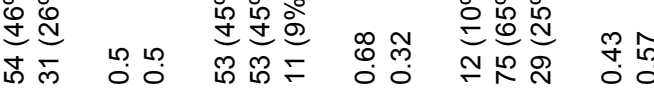

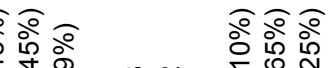

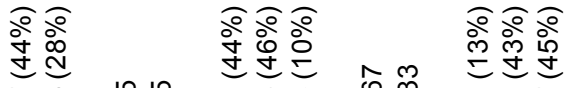

占

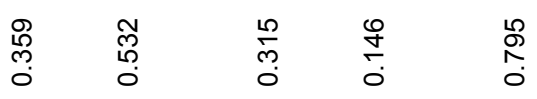

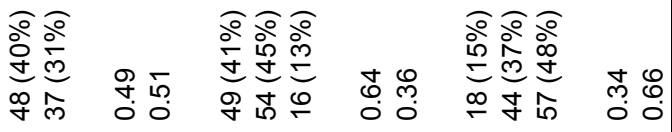

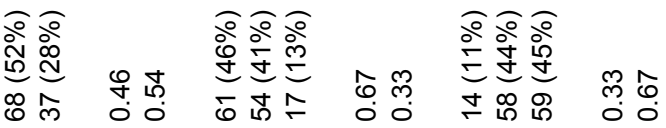

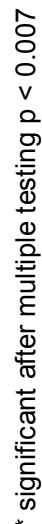




\section{DISCUSSION}

Here we present a study of several gene polymorphisms in relation to weight gain over a long time period. It should be noted that our study-population is rather defined as being composed of a group that remain at normal weight over ten years and a group that develops overweight during that period. We defined a weight gain of more than $8 \mathrm{~kg}$ over 10 years, as an obvious cutoff for weight gain. Because gender differences are regularly seen in matters of weight and weight regulation [26-28], we decided to study men and women separately. Indeed we found sex-specific genetic associations. AKR1C2, ACE and FTO were associated with long-term weight gain in men, while MMP2 was associated with long-term weight gain in women over a 10 year period. It should be noted that about $30 \%$ of the women passed the age of 50 during the 10 year period and therefore menopause might have affected weight gain. However, as we matched for age, the proportion was the same for the weight stable (39/127) and the weight gainers group (40/117) suggesting a minimal effect on our results.

AKR1C2 plays a role in the crosstalk between glucocorticoids and androgens as part of the regulation of adipogenesis and lipid accumulation [29]. The androgen dihydrotestosterone (DHT) inhibits adipocyte differentiation in humans [30]. Studies show that an increased expression or activation of AKR1C2 induces adipocyte differentiation by inactivating DHT [29, 31]. Previously, we found that AKR1C2 protein expression after weight loss/maintenance was increased and that the increase correlated with changes in parameters of adiposity including weight, BMI, waist and plasma LDL [12]. Takahashi reported that the F46Y polymorphism (rs2854482) has a lowering effect on the enzyme activity [32]. However, we did not find a genetic effect on weight gain, which might be explained by the low frequency of the T allele in our population. In fact, only rs 12249281 showed an association with long-term weight gain in men. This variation may have an influence via promoter activity of the AKR1C2 gene, but this requires confirmation in another cohort in addition to functional studies.

The Alu insertion/deletion (I/D) polymorphism in intron 16 of the ACE gene has been shown to be associated with body weight, BMI, overweight and obesity in various ethnic groups [33]. However, weight gain over a longer period has rarely been studied. Strazzullo et al. [34] found that the DD genotype was associated with more spontaneous body weight gain and adiposity over 20 years in middleaged men. Although in our study also an association between the ACE I/D polymorphism and weight gain was observed in men, it was the II-genotype that seems associated with long-term weight gain in men. Associations between ACE I/D and obesity parameters show the same controversy regarding the risk 


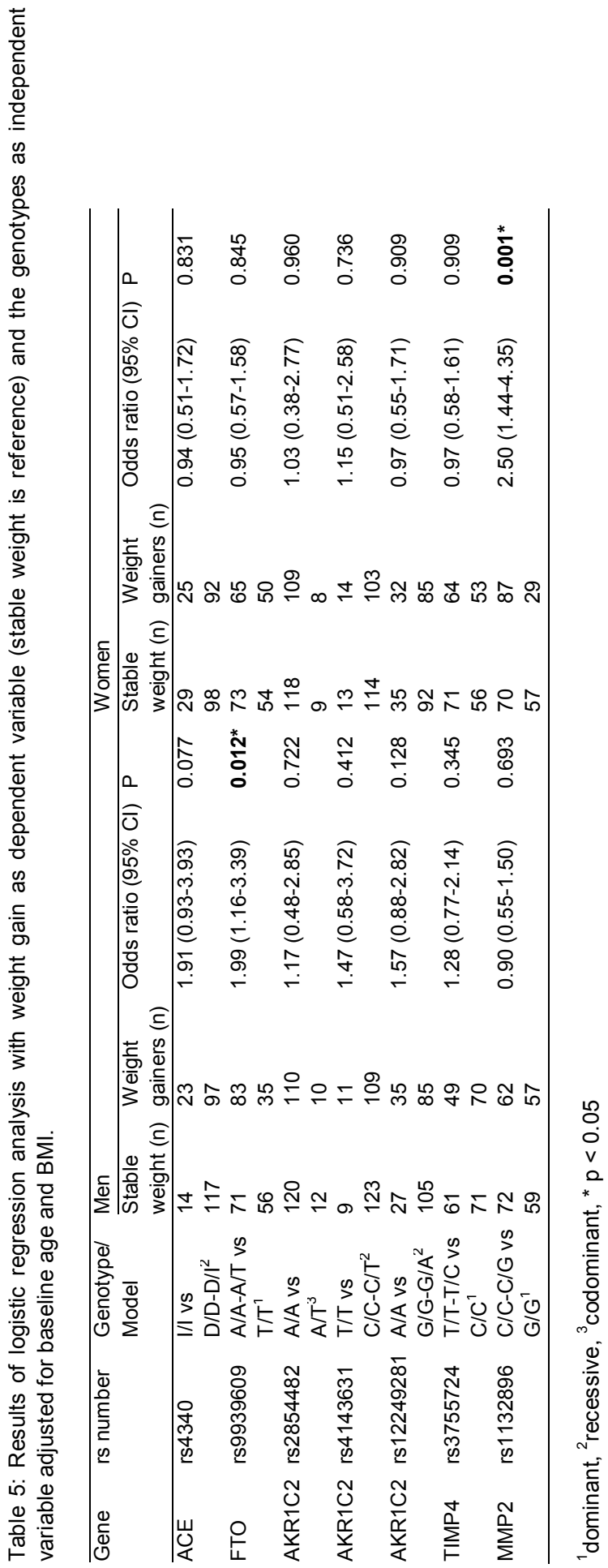


allele. For instance, in the study of Bienertova-Vasku et al. [35] the II-genotype was found associated with the prevalence of obesity, whereas Settin et al. reported a significantly higher BMI in D-allele carriers [36].

It has also been shown that subjects with the D/D genotype lose less body fat with similar amounts of weight loss than I-allele carriers [37]. It must be noted that rs4340 and rs 1799752 are located in the same 288 bp insertion/deletion. In fact, rs 1799752 is a 2 bp indel and compassing the 3'nucleotides of the $288 \mathrm{bp}$ indel of rs4340. It is also known that the ACE I/D polymorphism influences plasma ACE concentration and activity. D-allele carriers have a higher mean plasma ACE concentration than I-allele carriers [38]. Interestingly, a change in ACE plasma concentration during weight loss might predict the risk for weight regain [4]. It is tempting to speculate that D-allele carriers can more easily reduce their plasma ACE levels during weight loss, which is favorable for weight maintenance and would be in line with our results. However, no evidence has shown whether such concentration change and eventually the risk for weight regain is associated with ACE genetic variation.

The FTO gene has been repeatedly reported for being associated with parameters of adiposity [39, 40]. Here we found that the A-allele conferred increased risk of weight gain over 10 years, but only in men. At the moment, we do not have a clear explanation for this sex difference. Interestingly, it has been shown that physical inactivity was associated with a BMI increase $(1.95 \pm 0.3$ $\mathrm{kg} / \mathrm{m}^{2}$ ) in homozygous A-allele carriers compared with homozygous T-allele carriers [41]. The FTO genotype has also been shown to interact with weight loss [42] and the A-allele seems to complicate weight maintenance in severe obese patients [43]. Studies also show that the A-allele is associated with increased energy intake [44], but this could not be confirmed in the present study. Alternatively, the FTO gene may be involved in the control of appetite as FTO expression is decreased in the hypothalamus of fasted mice when compared to fed mice [45]. Also, in humans associations with appetite have been found [46]. It suggests that genetic influence of FTO on long-term weight gain in men is not only a matter of physical activity or energy intake per se, but could follow another mechanism involving the brain.

In men genetic interaction was observed between FTO and ACE (Figure 3 ). This may point to fat storage/turnover capacity as the major process for long/term weight gain in men. In genetically obese diabetic mice, it was shown that ACE-inhibition blocks PAI-1 activity indicating that ACE is necessary for the formation of active PAI-1 [47]. ACE converts angiotensin I into angiotensin II and in humans angiotensin II increases the expression of PAI-1, whereas inhibition of ACE decreases PAI-1 in plasma and tissues [48, 49]. In the mouse inhibition of PAI-1 has been associated with reduced weight of fat depots and adipocyte size [50]. Influence of ACE on tissue plasminogen activator (tPA) has also been reported, but remains controversial [48]. Overall, the adipose-specific renin-angiotensin system appears involved in positive 
regulation of adiposity [51]. Mechanistically, ACE may influence adipocyte ECM dynamics which is an important cellular parameter of weight loss and weight regain. In this respect, we have proposed that the ECM has a lower metabolic plasticity than the cell, leading during weight loss to the accumulation of stress between the shrinking cell and the rigid ECM, which forms a driving force for weight regain because re-storage of fat may alleviate this stress [52, 53]. The genetic interaction between FTO and ACE opens the possibility that also FTO may exert its effect somehow through the ECM dynamics.

Matrix metalloproteinases (MMPs) are essential for proper ECM remodeling $[16,17]$. MMP2 is an endopeptidase that degrades the basement membrane surrounding adipocytes and thus may facilitate hypertrophic development of adipocytes and formation of adipocyte clusters [54]. An induction of the MMP2 transcription in adipose tissue of obese mice and during human adipocyte differentiation has been reported $[17,55]$. In this study we found that the C-allele of MMP2 in women is associated with weight gain over a 10 year period, which is in line with a study of Han et al. who showed that the Callele is associated with obesity [15]. The polymorphism is located in a codon for glycine but is not accompanied by a change of this amino acid. Therefore, the biology behind the observed association remains unknown. Interestingly, a role for estrogens in the expression and activity of MMP2 has been proposed $[56,57]$, which may explain the fact that the association was found only in women. Maybe a different plasticity of the adipose tissue through MMP2 under increased energy intake can explain the difference in risk of long-term weight gain in women.

The interaction between genes and environmental factors, including nutrition and life style, can be a contribution to the long term weight gain. Therefore in the present study we have also investigated the interaction of SNPs and macronutrient intake levels, but we have not detected any significant contribution for these SNPs. Our interaction results are in agreement with several reports for FTO and energy intake, fat, carbohydrate and protein [58, 59], but in contrast to other reports [60, 61]. An overview of interactions between FTO and environmental factors are given in supplementary table 1. No known interactions of environmental factors with the genes for AKR1C2, MMP2 and TIMP4 have been reported. However, it cannot be excluded that other nutrients may play a role in the interaction with these SNPs in the long term weight gain. 


\section{FTO}

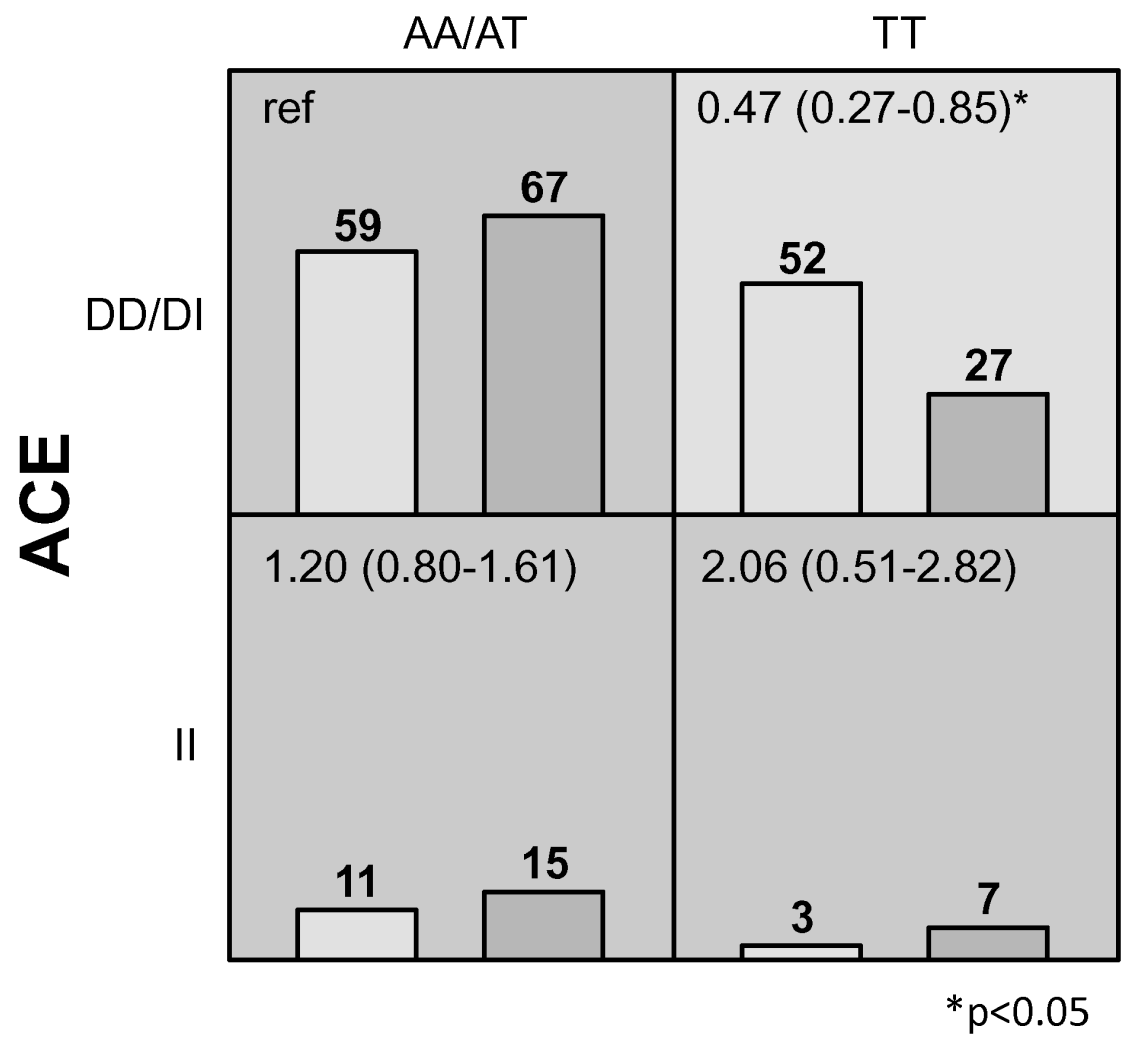

Figure 3: Numbers of weight stable and weight gainers group in men for the different multi-locus genotypes of the best model obtained by Multifactor Dimensionality Reduction (MDR) $(p=0.05)$. Dark grey cells indicate increased risk of weight gain. Light gray cells indicate decreased risk of weight gain, In each segment, the left bar indicates the number of weight stable subjects and the bar on the right the number of weight gainers. The odds ratio is shown in the left upper corner. ${ }^{*} p<0.05$

In a former study with a different cohort, we have investigated other genetic influences on weight gain over a period of almost 7 years [28]. CNTF was found associated with weight gain in men, whereas in women IL6 appeared influencing long-term weight gain. Obviously, together with the present findings this corroborates the concept that long-term weight regulation is influenced by genetic factors in a sex-specific manner. As a mechanism the activity of the sympathetic nervous system was proposed, which has a strong effect on the balance between fat storage in and release from adipocytes. Our present results suggest ECM dynamics as a possible mechanistic factor working through this same balance of storage and release of fat in adipocytes. 
All taken together, genetic association was found between SNPs in ACE, FTO and AKR1C2 and weight gain over 10 years in men, and between an SNP in MMP2 and weight gain over the same period in women. Our results indicate that the investigated SNPs in FTO and MMP2 contribute to the risk of long-term weight gain in men and women, respectively. Epistasis was observed for the SNPs in FTO and ACE in men. Further research can now be conducted to validate our findings concerning gender-specific genetic influences on long-term weight gain during adulthood.

\section{Acknowledgements}

This research was supported by the Maastricht Proteomics Center of the Maastricht University. The authors thank the epidemiologists and fieldworkers of the Municipal Health Service in Doetinchem for their contribution to the data collection for this study. Logistic management was provided by J Steenbrink and $\mathrm{P}$ Vissink, and administrative support by EP van der Wolf. Data management was provided by A Blokstra, AWD van Kessel and PE Steinberger. The Doetinchem cohort study was financially supported by the National Institute for Public Health and the Environment and the Ministry of Health, Welfare and Sport of The Netherlands.

\section{References}

1. Wyatt SB, Winters KP, \& Dubbert PM (2006) Overweight and obesity: prevalence, consequences, and causes of a growing public health problem. Am J Med Sci 331(4):166-174.

2. Brug J, et al. (2012) Differences in weight status and energy-balance related behaviors among schoolchildren across Europe: the ENERGY-project. PLoS One 7(4):e34742.

3. Maclean PS, Bergouignan A, Cornier MA, \& Jackman MR (2011) Biology's response to dieting: the impetus for weight regain. Am J Physiol Regul Integr Comp Physiol 301(3):R581-600.

4. Wang P, et al. (2012) Circulating ACE is a predictor of weight loss maintenance not only in overweight and obese women, but also in men. International journal of obesity (2005).

5. Darimont C, Vassaux G, Ailhaud G, \& Negrel R (1994) Differentiation of preadipose cells: paracrine role of prostacyclin upon stimulation of adipose cells by angiotensin-II. Endocrinology 135(5):2030-2036.

6. Passaro A, et al. (2011) PPARgamma Pro12Ala and ACE ID polymorphisms are associated with BMI and fat distribution, but not metabolic syndrome. Cardiovasc Diabetol 10:112.

7. Frayling TM, et al. (2007) A common variant in the FTO gene is associated with body mass index and predisposes to childhood and adult obesity. Science 316(5826):889-894.

8. Scuteri A, et al. (2007) Genome-wide association scan shows genetic variants in the FTO gene are associated with obesity-related traits. PLoS Genet 3(7):e115.

9. den Hoed M, Westerterp-Plantenga MS, Bouwman FG, Mariman EC, \& Westerterp KR (2009) Postprandial responses in hunger and satiety are associated with the rs9939609 single nucleotide polymorphism in FTO. Am J Clin Nutr 90(5):1426-1432.

10. Smemo S, et al. (2014) Obesity-associated variants within FTO form long-range functional connections with IRX3. Nature 507(7492):371-375. 
11. Ragvin A, et al. (2010) Long-range gene regulation links genomic type 2 diabetes and obesity risk regions to HHEX, SOX4, and IRX3. Proceedings of the National Academy of Sciences of the United States of America 107(2):775-780.

12. Bouwman FG, et al. (2009) The physiologic effects of caloric restriction are reflected in the in vivo adipocyte-enriched proteome of overweight/obese subjects. Journal of proteome research 8(12):5532-5540.

13. Blouin K, et al. (2005) Expression and activity of steroid aldoketoreductases $1 \mathrm{C}$ in omental adipose tissue are positive correlates of adiposity in women. American journal of physiology 288(2):E398-404.

14. Wake DJ, et al. (2007) Intra-adipose sex steroid metabolism and body fat distribution in idiopathic human obesity. Clinical endocrinology 66(3):440-446.

15. Han DH, et al. (2008) Matrix Metallopeptidase 2 Gene Polymorphism is Associated with Obesity in Korean Population. Korean J Physiol Pharmacol 12(3):125-129.

16. Bouloumie A, Sengenes C, Portolan G, Galitzky J, \& Lafontan M (2001) Adipocyte produces matrix metalloproteinases 2 and 9: involvement in adipose differentiation. Diabetes 50(9):20802086.

17. Chavey C, et al. (2003) Matrix metalloproteinases are differentially expressed in adipose tissue during obesity and modulate adipocyte differentiation. J Biol Chem 278(14):11888-11896.

18. Lu Y, et al. (2008) Multiple genetic variants along candidate pathways influence plasma highdensity lipoprotein cholesterol concentrations. Journal of lipid research 49(12):2582-2589.

19. van den Berg SW, et al. (2009) Genetic variations in regulatory pathways of fatty acid and glucose metabolism are associated with obesity phenotypes: a population-based cohort study. International journal of obesity (2005) 33(10):1143-1152.

20. Verschuren WM, Blokstra A, Picavet HS, \& Smit HA (2008) Cohort profile: the Doetinchem Cohort Study. Int J Epidemiol 37(6):1236-1241.

21. Koh WP, et al. (2003) Angiotensin I-converting enzyme (ACE) gene polymorphism and breast cancer risk among Chinese women in Singapore. Cancer Res 63(3):573-578.

22. Johnson AD, et al. (2008) SNAP: a web-based tool for identification and annotation of proxy SNPs using HapMap. Bioinformatics 24(24):2938-2939.

23. Sole X, Guino E, Valls J, Iniesta R, \& Moreno V (2006) SNPStats: a web tool for the analysis of association studies. Bioinformatics 22(15):1928-1929.

24. Heidema AG, et al. (2007) Analysis of multiple SNPs in genetic association studies: comparison of three multi-locus methods to prioritize and select SNPs. Genet Epidemiol 31(8):910-921.

25. Arthur JW \& Reichardt JK (2010) Modeling single nucleotide polymorphisms in the human AKR1C1 and AKR1C2 genes: implications for functional and genotyping analyses. PLoS One 5(12):e15604.

26. Bradshaw PT, Monda KL, \& Stevens J (2013) Metabolic syndrome in healthy obese, overweight, and normal weight individuals: the Atherosclerosis Risk in Communities Study. Obesity (Silver Spring) 21(1):203-209.

27. Stevens J, Katz EG, \& Huxley RR (2010) Associations between gender, age and waist circumference. Eur J Clin Nutr 64(1):6-15.

28. Heidema AG, et al. (2010) Sex-specific effects of CNTF, IL6 and UCP2 polymorphisms on weight gain. Physiol Behav 99(1):1-7.

29. Veilleux A, et al. (2012) Glucocorticoid-induced androgen inactivation by aldo-keto reductase 1C2 (AKR1C2) promotes adipogenesis in human preadipocytes. American journal of physiology.

30. Blouin K, Veilleux A, Luu-The V, \& Tchernof A (2009) Androgen metabolism in adipose tissue: recent advances. Molecular and cellular endocrinology 301(1-2):97-103.

31. Blouin K, et al. (2009) Pathways of adipose tissue androgen metabolism in women: depot differences and modulation by adipogenesis. American journal of physiology 296(2):E244-255.

32. Takahashi RH, Grigliatti TA, Reid RE, \& Riggs KW (2009) The Effect of Allelic Variation in AldoKeto Reductase 1C2 on the In Vitro Metabolism of Dihydrotestosterone. The Journal of pharmacology and experimental therapeutics 329(3):1032-1039.

33. Mao S \& Huang S (2013) A meta-analysis of the association between angiotensin-converting enzyme insertion/ deletion gene polymorphism and the risk of overweight/obesity. $J$ Renin Angiotensin Aldosterone Syst.

34. Strazzullo P, et al. (2003) Genetic variation in the renin-angiotensin system and abdominal adiposity in men: the Olivetti Prospective Heart Study. Ann Intern Med 138(1):17-23. 
35. Bienertova-Vasku J, et al. (2009) Effect of ID ACE gene polymorphism on dietary composition and obesity-related anthropometric parameters in the Czech adult population. Genes Nutr 4(3):207-213.

36. Settin AA, Algasham A, Dowaidar M, \& Ismail H (2009) Methylene tetrahydrofolate reductase and angiotensin converting enzyme gene polymorphisms related to overweight/obesity among Saudi subjects from Qassim Region. Dis Markers 27(2):97-102.

37. Hamada T, et al. (2011) Genetic polymorphisms of the renin-angiotensin system and obesityrelated metabolic changes in response to low-energy diets in obese women. Nutrition 27(1):3439.

38. Rigat B, et al. (1990) An insertion/deletion polymorphism in the angiotensin l-converting enzyme gene accounting for half the variance of serum enzyme levels. $J$ Clin Invest 86(4):1343-1346.

39. Vimaleswaran KS, et al. (2012) Association Between FTO Variant and Change in Body Weight and Its Interaction With Dietary Factors: The DiOGenes Study. Obesity (Silver Spring).

40. Day FR \& Loos RJ (2011) Developments in obesity genetics in the era of genome-wide association studies. J Nutrigenet Nutrigenomics 4(4):222-238.

41. Andreasen $\mathrm{CH}$, et al. (2008) Low physical activity accentuates the effect of the FTO rs9939609 polymorphism on body fat accumulation. Diabetes 57(1):95-101.

42. Delahanty LM, et al. (2012) Genetic predictors of weight loss and weight regain after intensive lifestyle modification, metformin treatment, or standard care in the Diabetes Prevention Program. Diabetes care 35(2):363-366.

43. Woehning A, et al. (2013) The A-allele of the common FTO gene variant rs9939609 complicates weight maintenance in severe obese patients. International journal of obesity (2005) 37(1):135-139.

44. Speakman JR, Rance KA, \& Johnstone AM (2008) Polymorphisms of the FTO gene are associated with variation in energy intake, but not energy expenditure. Obesity (Silver Spring) 16(8):1961-1965.

45. Stratigopoulos G, et al. (2008) Regulation of Fto/Ftm gene expression in mice and humans. Am J Physiol Regul Integr Comp Physiol 294(4):R1185-1196.

46. Karra E, et al. (2013) A link between FTO, ghrelin, and impaired brain food-cue responsivity. $J$ Clin Invest 123(8):3539-3551.

47. Zaman AK, et al. (2001) Angiotensin-converting enzyme inhibition attenuates hypofibrinolysis and reduces cardiac perivascular fibrosis in genetically obese diabetic mice. Circulation 103(25):3123-3128.

48. Brown NJ, Agirbasli M, \& Vaughan DE (1999) Comparative effect of angiotensin-converting enzyme inhibition and angiotensin II type 1 receptor antagonism on plasma fibrinolytic balance in humans. Hypertension 34(2):285-290.

49. Brown NJ, Agirbasli MA, Williams GH, Litchfield WR, \& Vaughan DE (1998) Effect of activation and inhibition of the renin-angiotensin system on plasma PAl-1. Hypertension 32(6):965-971.

50. Crandall DL, et al. (2006) Modulation of adipose tissue development by pharmacological inhibition of PAI-1. Arterioscler Thromb Vasc Biol 26(10):2209-2215.

51. Kalupahana NS \& Moustaid-Moussa N (2012) The renin-angiotensin system: a link between obesity, inflammation and insulin resistance. Obes Rev 13(2):136-149.

52. Mariman EC (2012) Human biology of weight maintenance after weight loss. $J$ Nutrigenet Nutrigenomics 5(1):13-25.

53. Mariman EC (2011) An adipobiological model for weight regain after weight loss. Adipobiology 3:9-15.

54. Brown LM, et al. (1997) Role of the matrixin MMP-2 in multicellular organization of adipocytes cultured in basement membrane components. Am J Physiol 272(3 Pt 1):C937-949.

55. Dubois SG, et al. (2008) Potential role of increased matrix metalloproteinase-2 (MMP2) transcription in impaired adipogenesis in type 2 diabetes mellitus. Biochem Biophys Res Commun 367(4):725-728.

56. Marin-Castano ME, et al. (2003) Regulation of estrogen receptors and MMP-2 expression by estrogens in human retinal pigment epithelium. Invest Ophthalmol Vis Sci 44(1):50-59.

57. Wingrove CS, Garr E, Godsland IF, \& Stevenson JC (1998) 17beta-oestradiol enhances release of matrix metalloproteinase-2 from human vascular smooth muscle cells. Biochim Biophys Acta 1406(2):169-174.

58. Liu G, et al. (2010) FTO variant rs9939609 is associated with body mass index and waist circumference, but not with energy intake or physical activity in European- and AfricanAmerican youth. BMC medical genetics 11:57. 
59. Lappalainen T, et al. (2012) Association of the fat mass and obesity-associated (FTO) gene variant (rs9939609) with dietary intake in the Finnish Diabetes Prevention Study. The British journal of nutrition 108(10):1859-1865.

60. Corella D, et al. (2011) A high intake of saturated fatty acids strengthens the association between the fat mass and obesity-associated gene and BMI. The Journal of nutrition 141(12):2219-2225.

61. Ahmad T, et al. (2011) Lifestyle interaction with fat mass and obesity-associated (FTO) genotype and risk of obesity in apparently healthy U.S. women. Diabetes care 34(3):675-680. 
GENETIC BACKGROUND OF WEIGHT GAIN 


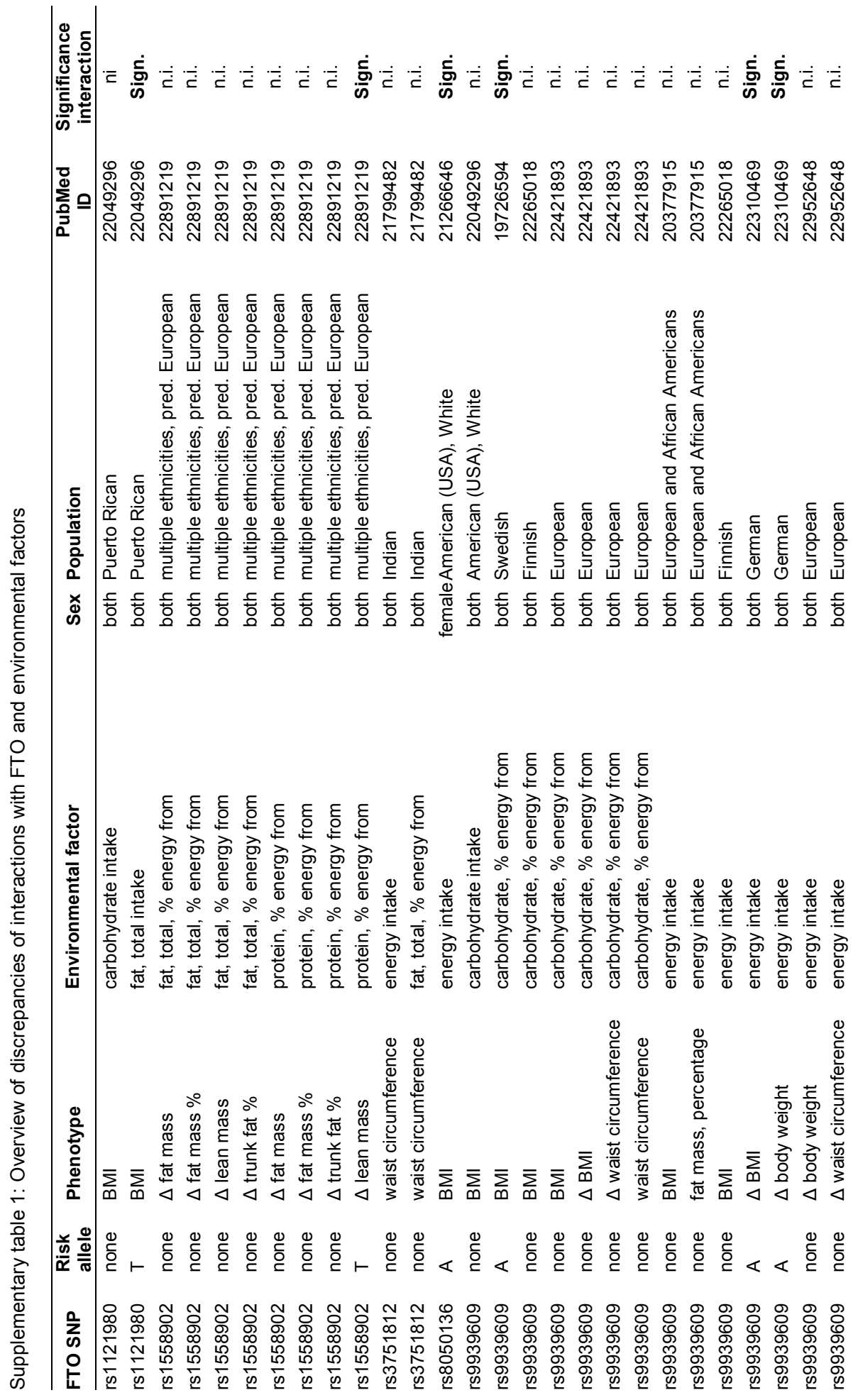




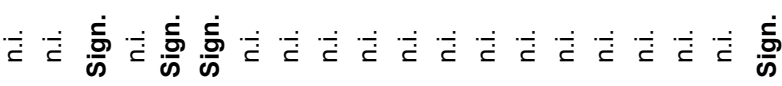

는 뉴 峁

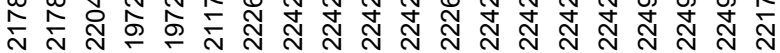

站

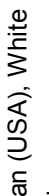

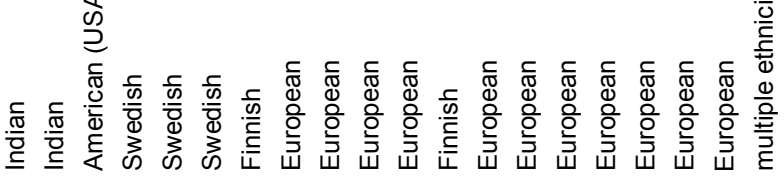

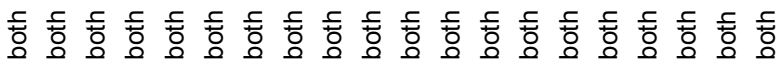

总骂兽

奇 蒿

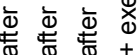

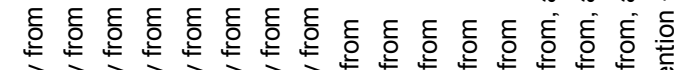

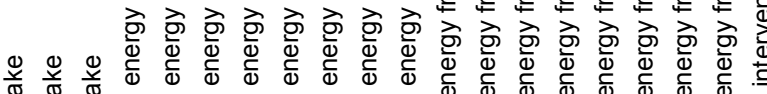

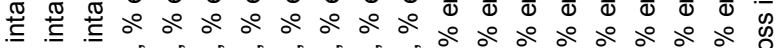

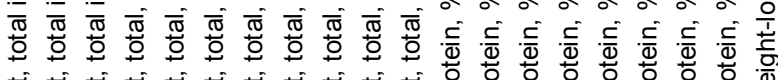

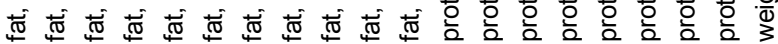

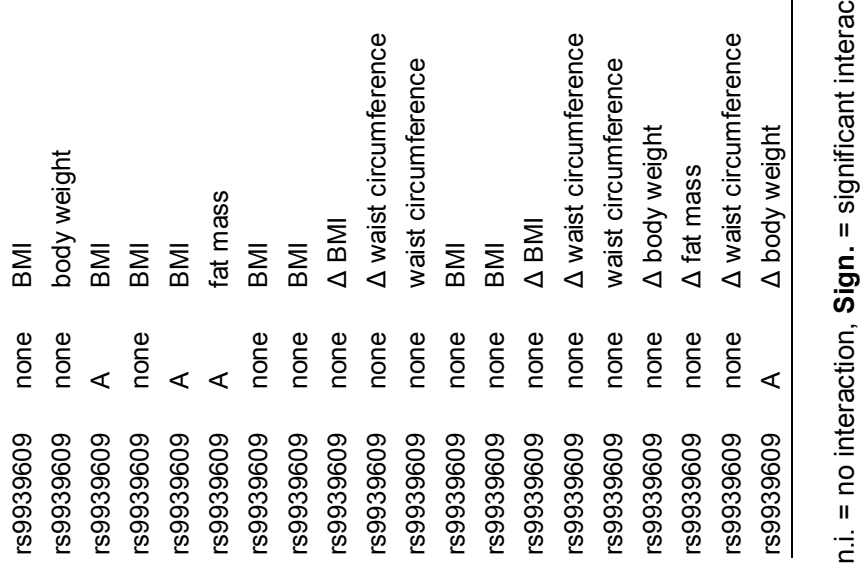




\section{Chapter 8}

General discussion 
Weight regulation is a complex process which is not well understood, but it is clear that when weight gain leads to obesity, this provides a health risk. The application of omics techniques is a promising approach to find biomarkers and identify cellular regulatory proteins with respect to body weight and obesity. These markers or marker panels can be used for the prediction of success of weight loss and weight maintenance after a diet.

\section{Proteomics in adipobiology}

Proteomics has developed enormously in the last decade [1]. It has been proven to be an effective method for finding biomarkers and exploring cellular pathways. Proteomics can be divided into two kinds of approaches, a targeted and non-targeted approach. Most targeted approaches are antibody-based. The use of antibodies can have a disadvantage, because only a fixed panel of proteins can be measured and isoforms are often not determined. Besides antibody-based approaches there are mass spectrometry-based methods like selected reaction monitoring, which are now rapidly emerging and more and more applied. Nevertheless, the targeted multiplex immunoassay is an effective method for identifying biomarkers and provides information on specific pathways [2]. Non-targeted approaches are 2 dimensional polyacrylamide gelelectrophoresis (2D-PAGE) combined with mass spectrometry or liquid chromatography combined with mass spectrometry (LCMS). An advantage of $2 \mathrm{D}$ electrophoresis is that it can visualize isoforms and protein modifications. However, 2D-PAGE is a relatively time-consuming and labour-intensive process. It has limitations concerning hydrophobic, alkaline/acidic and low/high molecular weight proteins [3]. Yet, since non-targeted methods do not depend on the availability of antibodies, they are able to cover a broad set of proteins in the search for biomarkers.

The first task when conducting a proteomics study is to select the right sample for investigation. Several aspects need to be taken into account: 1) the accessibility, 2) information content and 3) expected biological and technical variation, which has large impact on the required sample size. Body fluids and blood cells, such as plasma, serum, saliva, urine, PBMCs, and platelets, are easy to access in a minimally-invasive way, while biopsies like liver-biopsies require more invasive techniques and are sometimes difficult to obtain. However, biopsies give direct information about the status of a specific tissue. This thesis shows that of the minimally invasive samples, PBMCs appear to represent the best selection for biomarker discovery in human nutrigenomics [4] in regard to sensitivity to the diet and lowest between-subject variability. Another advantage of PBMCs is that they express RNA. This RNA expression could reflect the metabolic status of the subject. Notably, in that case it will not reflect the status of a particular tissue, but rather the status of the whole body. Of the minimally invasive samples, platelets have a relatively low between- 
subject variability, but show in our study no diet intervention effect. The substantial inter-individual variation has a large influence in omics studies regarding nutritional effects, which usually generate subtle gene expression differences [4]. Therefore, this variation may mask the true biological effect of the experiment on the proteome. As shown in chapter 2, figure 3 , it is possible to "fingerprint" the individual subjects by their proteomics profile. Increasing the sample size of the study may overcome this problem, but may also average out the effect with a chance of missing informative biomarkers. Alternatively, a stronger response may be generated by supplying pure isolated nutrients to the subjects or by better classifying the individuals at forehand and group them accordingly.

Most studies in this thesis were performed with adipose tissue. Proteomics is an effective tool to investigate molecular mechanisms in weight regulation in adipocytes. Two proteomic methods were developed by us to obtain more information from adipocytes in vitro and in vivo. We used a combination of stable isotope labelling and protein profiling to provide important information not only on the identity of proteins, but also on the turnover of proteins. This combination of protein profiling and isotopomer analysis revealed an active metabolism of the extracellular matrix of 3T3-L1 adipocytes. In general, this application, by adding stable isotope label as a third dimension, gives more detailed insight in the protein dynamics of specific tissues or cells and can thus be of great value. The limitation of the method is that it is difficult to obtain information on the turnover of long-lived proteins like some components of the cytoskeleton.

We also developed a subtraction method, which is a useful tool for new strategies, when there is a lack of pure biopsies [5], for example if the biopsies are contaminated with blood or other surrounding tissues.

By doing proteomics experiments we experienced that one needs to be careful with the interpretation of differentially expressed proteins, because some proteins seem to respond to almost every challenge irrespective of the tissue. Those proteins were reported by us as generally identified or detected proteins [6]. Using those proteins as biomarkers for cellular processes other than stress response should be done with caution. However these generally detected proteins may also have defined functions in specific pathways. Some differentially expressed proteins in response to weight loss/maintenance that are reported in this thesis seem to belong to the generally detected proteins. These proteins are: annexin A2, tubulin beta5, aldolases $A$ and $C$, and vimentin. In adipocytes, they have shown significant correlations with parameters of metabolism, indicating that they actually do play an important role in the adipocyte metabolism instead of only responding to any kind of challenge. Information from the scientific literature revealed that four of those generally 
detected proteins are active in regulation of glucose uptake by adipocytes. On the other hand, a change in expression of proteins involved in the glucose metabolism might be a general response to (minimal) stress. Therefore, our observation on those proteins may reflect either a specific functional change of adipocytes or a general response to experimental stress. Since we were able to correlate this process to fatty acid oxidation and handling in the adipocyte, it is most likely that we are dealing with a specific part of the metabolic changes of adipocytes during weight loss/maintenance. It shows that when generally detected proteins are identified as differential markers in proteomics studies, additional research should be done to verify whether these proteins fit in the complete metabolism of the target cells.

\section{Weight regulation on the molecular level of adipocytes}

An increase in adipocyte mass can be ascribed to preadipocyte differentiation, an increased number of adipocytes (hyperplasia), or overfilling of mature adipocytes (hypertrophy). Usually it is hypertrophy that leads to adult overweight, which can be treated by losing weight due to restricting the food intake and/or increasing energy expenditure. During caloric restriction, fatty acids are liberated from triacylglycerides (TAG) in the fat droplet by lipolysis [7]. Under those conditions, the responsible enzymes, ATGL, HSL and MGL will be activated/up-regulated. The liberated fatty acids are needed elsewhere in the body for energy. At the same time adipocytes switch from glucose to fatty acid as the source of energy by increasing mitochondrial beta-oxidation, which could be achieved by up-regulation of the enzyme HADH. The decrease of TAG will cause a reduction in the adipocyte size and may induce a risk for apoptosis, but a substantial increase in adipocyte death has not been observed to contribute to the weight loss [8]. When the energy balance is restored after caloric restriction, the lipases are expected to be deactivated/down-regulated [9]. In parallel, the energy supply for the adipocytes will switch back to glucose and beta-oxidation should be reduced as fat is being stored rather than burned. As described by MacLean [10], after recovery of the energy balance, some preadipocyte differentiation occurs but mainly there is refilling of the mature adipocytes. This refilling could even lead to overfilling of the adipocytes. This process explains weight regain and even can result in a higher body weight than before the diet. The repetition of this process is known as weight cycling.

In contrast to the expectation based on the above described process, we found that proteins ATGL and HADH were not increased directly after weight loss of obese subjects [11], but increased after return to an energy balanced state [12]. In principle, an increase of ATGL and HADH, when obese people lose weight, can be seen as a return to the more healthy pre-obese state because when lean people move on to develop overweight and obesity, levels of ATGL and 
activity of beta-oxidation decrease $[13,14]$. However, this does not explain the apparently delayed increase of the enzymes after return to energy balance. Our preliminary observations show that changes in protein abundances during weight loss/maintenance follow the relative abundance of a translation elongation factor. It suggests that during caloric restriction, energy-demanding protein translation is reduced for ATGL and HADH and upon return to energy balance, this process can be activated with the increased appearance of those enzymes. A combined explanation would be that during development of obesity, translation of ATGL and HADH mRNAs is (partly) blocked and that caloric restriction is a way to lift this blockade. More research is needed to find out what is actually going on, but this may lead to more mechanistic insight of obesity development and may provide intervention targets. However, it is surprising that 3 weeks after returning to an energy stable diet, the adipocytes remain an increased capacity to liberate and oxidize fatty acids. This is remarkable since glucose is their preferred fuel [15]. A delayed switching between fatty acid and glucose metabolism might be a safety precaution. It would be the perfect way to anticipate to a next sudden lack of food which has not been uncommon during evolution. As such, the adipocytes could have developed a kind of memory function in case of shortage of food or energy.

As mentioned above, weight loss/maintenance intervention not only showed changes of the lipid handling, but also alterations of the glucose metabolism in adipocytes. Our studies show that after starvation and 3 week maintenance aldolase $C$ is decreased. Aldolase is an enzyme of the glycolysis but also a structural component of the cytoskeleton and in particular under low cellular glucose concentration it binds to actin filaments. It also can bind to the glucose transporter GLUT4. Therefore it has been proposed that aldolase recruits GLUT4 vesicles from the microtubules and places them on the actin filaments directly under the cell membrane [16]. Then, annexin A2 supports the translocation of GLUT4 to the membrane [17]. When glucose is available and enters the cell, glycolysis starts and the substrate and reaction products of aldolase induce the detachment of aldolase from the actin filaments. Based on this theory, this process from a starved to a fed status is depicted in figure 1. 


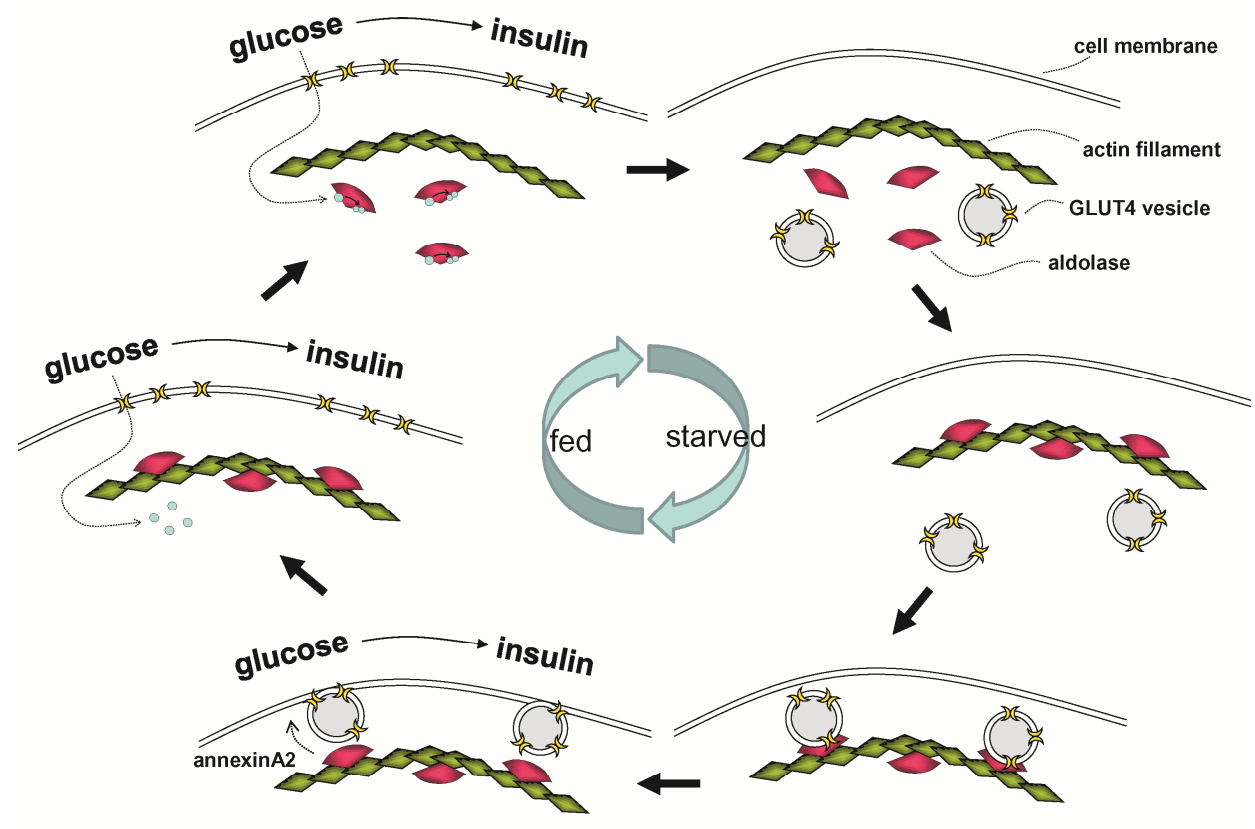

Figure 1: Aldolase and annexin A2 facilitated glucose uptake model in the starved and fed state.

According to this model, aldolase is supposed to be increased along with the enhanced glucose uptake capacity after weight loss. The decrease of aldolase $\mathrm{C}$ after weight loss and 3 weeks maintenance seems in contrast to this model. However, it is possible that due to our extraction procedure, only the free aldolase $\mathrm{C}$ is measured and therefore underestimated. A decrease could thus mean that more aldolase is efficiently bound to the cytoskeleton. In addition, adipocytes contain two isoforms of aldolase, $\mathrm{A}$ and $\mathrm{C}$, and it might be that the vesicles are actually recruited by aldolase $A$, which does not seem to change much in concentration over the intervention. In this respect, the decrease of aldolase $\mathrm{C}$ might more reflect a decrease in glycolysis capacity. Another explanation would be a modified model, that aldolase is actually anchoring the GLUT4 vesicles to the actin filaments and prevents their fusion to the membrane. As such, lowering the aldolase concentration would promote GLUT4 vesicle fusion and glucose import. At the moment we cannot decide what the true explanation is, and this has to await further research.

Although an increased lipolysis and beta-oxidation contribute to the health status after weight loss, what seems to be alarming is that shortly after return to energy balance adipocytes improve their capacity for lipid and glucose uptake. This increases the risk for weight regain after weight loss. 
In this thesis we only looked at the 3 week time point after caloric restriction. It would be of interest to investigate if after 3 or even 12 months in obese subjects the effect is still present. Verhoef et al. have recently shown that in obese subjects at 10 months after weight loss aldolase $C$ is still decreased and HADH and ATGL are still increased [11].

\section{Genetics and weight regulation}

The proteome is a reflection of the genome, not only because the DNA contains the code for protein synthesis, but also because genetic variation influences protein production and lifetime. Therefore, the outcome of proteomics research can provide attractive candidate genes or gene panels for genetic research in weight regulation and obesity. Our identification and genetic investigation of the AKRC1 protein/gene in chapters 3 and 7 of this thesis are a good example. It should be noted that in this way novel genetic variants with an impact on the phenotype can be discovered. On the other hand, the upcoming whole genome sequencing may give input for targeted proteomics research, for instance to assess the effect of genetic variation on the expression of allelic proteins. In the future, much more information can be expected to come from this proteogenetic integration of proteomics with genetics.

Protein biomarkers can be useful to evaluate the metabolic status of the body during interventions. Our research has provided several of those marker proteins with a function in the adipocytes. However, the use of those markers is hampered by the fact that their analysis requires invasive methods to obtain biopsies. Translation of protein markers to the level of genetic variation has the advantage that analysis can be done on DNA obtained from non-invasive methods like buccal swaps. In addition, analysis could be done before a change in the phenotype has occurred. It is therefore advised to be alert for such translational possibilities of proteomic and genetic research especially in the development of personalized nutrition, where in some cases protein markers, but in other cases genetic markers may be preferred. 


\section{Conclusions}

This thesis shows the application of proteomics techniques in weight regulation and obesity research. Proteomics gives more insight in the molecular metabolism of adipocytes during weight regulation. This insight can be used for better guidance in weight control. The major conclusions of this thesis are the following:

- PBMCs represent the best target sample to study nutritional intervention in a minimal invasive way.

- Mature adipocytes spend a lot of their energy on sustaining and renewing the extracellular matrix.

- Subtraction of 2D-PAGE proteome profiles can enrich the proteome of particular cells in tissue biopsies.

- Biomarker protein detection should be done with caution because some proteins show a general stress response to all kinds of treatments.

- Protein analysis of adipose tissue during weight loss/maintenance has revealed biomarkers of weight regulation: $\mathrm{HADH}$, Aldolase $\mathrm{C}$, Annexin A2 and tubulin $\beta 5$.

- After weight loss adipocytes increase their capacity for glucose and lipid uptake.

- Polymorphisms of FTO in men and MMP2 in women are associated with weight gain over a 10 year follow-up period.

- Proteomics experiments can provide candidates for genetic association studies.

\section{Suggestions for future research}

For obtaining crucial information about weight regulation during weight loss and maintenance, it would be of great interest to monitor all important metabolic pathways, which is quite a challenging task. However, key proteins or 'connection' proteins that function on the crossroads of different molecular pathways may be responsible for the flux through a particular pathway and through the whole metabolism [18]. Thus monitoring these key proteins can generate a complete metabolic profile. This selection of key proteins can be used to create a broadly applicable biomarker panel to get a signature for a certain metabolic status or disease.

Another issue is that not everyone reacts in a same way to an intervention. This implies that every person should be studied as an individual and not averaged out in a group. Averaging out in pre-defined groups does not take, for example, the genetic variation into account. Omics data nowadays can be used to 
quantify each individual first before doing any classification as suggested by Kaput and Morine [19]. This individual response or group classification is essential for the development of personalized nutrition or treatment. Emerging biobanks with the corresponding databases can be of use to classify these groups for more targeted and personalized research.

Also interaction or semantic networking can give more insight in the processes of the individuals. This should be done by looking beyond pathway analysis with the assistance of bioinformatics [20].

Besides studying static cell or tissue information, information on dynamic processes and fluxes need to be incorporated. Proteomics can be used to investigate the crosstalk between tissues, for example between brain and adipose tissue. This can generate more insight in the trafficking of signals and therefore help understanding health issues.

In this thesis protein turnover is measured in mouse cells, but doing such measurements in human biopsies is much more difficult. The challenge is to sufficiently label the (biopsy) proteins in humans to be detectable by the mass spectrometer.

Various intervention studies showed that, the weight loss process may become more difficult after several weeks in a negative energy balance. For many subjects it appears difficult to maintain the dietary strategy and sustain the weight loss. [21]. The question then is what causes this difficulty and what makes adipocytes sensitive or stressed after prolonged negative energy balance. Mature adipocytes spend a lot of energy on developing, renewing and maintaining the ECM [22]. Therefore, the role of the ECM in adipocyte biology with reflection on weight regulation should be studied in more detail. When adipocytes lose fat they may develop stress from mechanical tension between the ridged ECM and the shrinking cell [23]. It is supposed that the adipocytes then send off stress signals to other tissues like the brain in order to promote food intake. However, this creates a risk for weight regain [21]. Yet, these signals to the brain are very interesting and may be a key point in weight regulation if identified and understood. If we understand how the adipokines influence the brain, then we can give better guidance to subjects who want to lose weight in order to help them maintain the lost weight. Future research may therefore focus on the study of adipokine signalling to the brain regulating eating behaviour and on the adaptability of the ECM with ECM proteins as possible biomarkers or intervention targets.

Researchers now claim that the human proteome is mapped for $84-92 \%$ [ 24 , 25]. About 18.000 proteins are covered in published papers, which relates to 20.687 protein-coding genes [26]. However, this is probably just the tip of the iceberg, because every protein can have a large number of different 
posttranslational modifications leading to different treatment responses between individuals. This makes the understanding of the dynamic and complex human proteome very difficult. Fortunately, analytical techniques continue to develop. Whole genome sequencing is now emerging and can help to provide information on genetic variation to better explain individual proteome changes. Also the use of "supercharged or next generation" targeted proteomics like data independent acquisition (DIA or SWATH) methods are developing very fast and make it possible to quantify all detected proteins [27]. This may generate superior information leading to a better understanding of how weight in humans is regulated at the molecular level.

\section{References}

1. Mallick P \& Kuster B (2010) Proteomics: a pragmatic perspective. Nat Biotechnol 28(7):695709.

2. Wang $P$, et al. (2012) Blood profiling of proteins and steroids during weight maintenance with manipulation of dietary protein level and glycaemic index. The British journal of nutrition 107(1):106-119.

3. Boja E, et al. (2011) Evolution of clinical proteomics and its role in medicine. J Proteome Res 10(1):66-84.

4. Bouwman FG, et al. (2011) 2D-electrophoresis and multiplex immunoassay proteomic analysis of different body fluids and cellular components reveal known and novel markers for extended fasting. BMC Med Genomics 4:24.

5. Bouwman FG, et al. (2009) The physiologic effects of caloric restriction are reflected in the in vivo adipocyte-enriched proteome of overweight/obese subjects. J Proteome Res 8(12):55325540.

6. Wang P, Bouwman FG, \& Mariman EC (2009) Generally detected proteins in comparative proteomics--a matter of cellular stress response? Proteomics 9(11):2955-2966.

7. Langin D, et al. (2005) Adipocyte lipases and defect of lipolysis in human obesity. Diabetes 54(11):3190-3197.

8. Arner P \& Spalding KL (2010) Fat cell turnover in humans. Biochem Biophys Res Commun 396(1):101-104.

9. Ahmadian M, Wang Y, \& Sul HS (2010) Lipolysis in adipocytes. Int J Biochem Cell Biol 42(5):555-559.

10. Maclean PS, Bergouignan A, Cornier MA, \& Jackman MR (2011) Biology's response to dieting: the impetus for weight regain. Am J Physiol Regul Integr Comp Physiol 301(3):R581-600.

11. Verhoef SP, Camps SG, Bouwman FG, Mariman EC, \& Westerterp KR (2013) Physiological response of adipocytes to weight loss and maintenance. PloS one 8(3):e58011.

12. Bouwman FG, Wang $P$, van Baak M, Saris WH, \& Mariman EC (2014) Increased betaoxidation with improved glucose uptake capacity in adipose tissue from obese after weight loss and maintenance. Obesity (Silver Spring) 22(3):819-827.

13. Yang L, et al. (2014) Association of serum adipose triglyceride lipase levels with obesity and diabetes. Genetics and molecular research : GMR 13(3):6746-6751.

14. Astrup A (2011) The relevance of increased fat oxidation for body-weight management: metabolic inflexibility in the predisposition to weight gain. Obesity reviews : an official journal of the International Association for the Study of Obesity 12(10):859-865.

15. Frayn KN, Humphreys SM, \& Coppack SW (1995) Fuel selection in white adipose tissue. The Proceedings of the Nutrition Society 54(1):177-189.

16. Kao AW, Noda Y, Johnson JH, Pessin JE, \& Saltiel AR (1999) Aldolase mediates the association of F-actin with the insulin-responsive glucose transporter GLUT4. The Journal of biological chemistry 274(25):17742-17747. 
17. Huang J, Hsia SH, Imamura T, Usui I, \& Olefsky JM (2004) Annexin II is a thiazolidinedioneresponsive gene involved in insulin-induced glucose transporter isoform 4 translocation in 3T3L1 adipocytes. Endocrinology 145(4):1579-1586.

18. Bensimon A, Heck AJ, \& Aebersold R (2012) Mass spectrometry-based proteomics and network biology. Annual review of biochemistry 81:379-405.

19. Kaput J \& Morine M (2012) Discovery-based nutritional systems biology: developing N-of-1 nutrigenomic research. International journal for vitamin and nutrition research. Internationale Zeitschrift fur Vitamin- und Ernahrungsforschung. Journal international de vitaminologie et de nutrition 82(5):333-341.

20. Anderson C (2008) The end of theory: The data deluge makes the scientific method obsolete. Wired Magazine (16.07).

21. Mariman EC (2011) An adipobiological model for weight regain after weight loss. Adipobiology 3:9-15.

22. Bouwman F, Renes J, \& Mariman E (2004) A combination of protein profiling and isotopomer analysis using matrix-assisted laser desorption/ionization-time of flight mass spectrometry reveals an active metabolism of the extracellular matrix of 3T3-L1 adipocytes. Proteomics 4(12):3855-3863.

23. Eastman Q (2009) Very low calorie diet makes adipocytes "scream". J Proteome Res 8(12):5408.

24. Kim MS, et al. (2014) A draft map of the human proteome. Nature 509(7502):575-581.

25. Wilhelm M, et al. (2014) Mass-spectrometry-based draft of the human proteome. Nature 509(7502):582-587.

26. Consortium EP, et al. (2012) An integrated encyclopedia of DNA elements in the human genome. Nature 489(7414):57-74.

27. Liu Y, Huttenhain R, Collins B, \& Aebersold R (2013) Mass spectrometric protein maps for biomarker discovery and clinical research. Expert review of molecular diagnostics 13(8):811825. 


\section{Summary}


The purpose of this thesis was to value in general the application of proteomics in the field of nutrigenomics and more specifically, to apply proteomics to learn more about the complex regulation of human body weight and the role of the adipose tissue therein.

In Chapter 1 a general introduction to this thesis is presented. Part of planning a nutrigenomics experiment is the selection of the target tissue that is the most informative with regard to the applied omics technique.

Chapter 2 provides information on proteomics applied to various biological samples from an extended fasting study. PBMCs appear to represent the best material for biomarker discovery. Although the plasma proteome shows the highest within-subject variability, the PBMC proteome shows the lowest between-subject variability. Therefore, PBMCs are the preferred material for proteomics studies in nutrigenomics. In the field of nutrition research, betweensubject variation of omics applications is often bigger than the within-subject variation. As shown in chapter 2 , figure 3 , it even is possible to "fingerprint" the individual subjects based on the between-subject variation in proteomics data. This variation may therefore mask the true biological effect of the study on the proteome. Random Forests (RF) analysis performed on the entire dataset revealed that changes in the level of the RhoGDI2 protein of PBMC and plasma ApoA4 levels were the two most obvious biomarkers of an extended fasting. RF-analysis of multiplex immunoassay data revealed leptin and MMP-3 as biomarkers for extended fasting. It was concluded that an antibody based analysis is superior when plasma proteins are analyzed. However, in that case, proteins and their isoforms that are not represented in the antibody set could be missed.

In Chapter 3 we have applied our self-designed proteomics subtraction approach to search for protein changes in the in vivo adipocyte-enriched proteome of overweight/obese subjects, who underwent an intervention of 5 weeks of a very low calorie diet followed by 3 weeks of a normal diet. On average, the loss of $9.5 \mathrm{~kg}$ of the body weight was largely contributed by the loss of fat mass $(7.1 \mathrm{~kg})$. Various parameters of adiposity and lipid metabolism changed significantly. Proteomic analysis revealed 6 significantly changed proteins. Fructose-bisphosphate aldolase $C$ (two isoforms) and tubulin- $\beta 5$ changed in the same direction in all subjects. Therefore, these proteins are biomarkers for the weight loss-maintenance intervention. Further, identified proteins indicate a reduced intracellular scaffolding of GLUT4 (ALDOC, TUBB5, ANXA2) and an increased handling of fatty acids (FABP4). An improved inflammatory profile of the adipose tissue (ApoA1, AOP1) and a change in fat droplet organization (vimentin) were also found. The correlation between changes in the intensities of protein spots and parameters of adiposity or lipid metabolism points to a link between aldo-ketoreductase 1C2 (AKR1C2) and adiposity, which was followed-up in a genetic association study of long term weight gain (Chapter 7). Correlations were also detected between FABP4 and 
parameters of lipid metabolism, and between proteins for beta-oxidation (HADH, ACADS, ACAT1) and plasma free fatty acids levels. Altogether, our findings underscore the potential value of in vivo proteomics for human intervention studies. Moreover, they show that physiologic parameters are related to the molecular metabolism of adipose tissue.

In Chapter 4 we went deeper into the molecular pathways related to glucose and fatty acid handling to investigate more specifically what happens in the adipose tissue after caloric restriction and return to a balanced diet. The proteomic systems view of the cell molecular metabolism revealed that HADH, catalase, fatty acid translocase, fatty acid transporter protein 3 , adipose triglyceride lipase, FABP4, aldolase $C$, tubulin- $\beta 5$, and annexin $A 2$ changed significantly in relative abundance over the intervention. Perilipin $B$ showed the highest up-regulation $(10 \mathrm{x}, \mathrm{p}=0.058)$. It has been suggested that this protein associates with newly entered fatty acids at the cell membrane, after their conversion to triglycerides. An increased GLUT4 translocation was observed, which was mediated by phosphorylation of annexin A2 at tyrosine-24. Together, our findings suggest that after weight loss by calorie restriction and a short period of weight maintenance, adipocytes have increased their capacity for glucose and fatty acid uptake. "The adipocyes scream for fat after weight loss". This may generate a potential risk for weight regain after weight loss.

Differential gel electrophoresis followed by identification of proteins by mass spectrometry (MS) is a commonly used protein profiling method. However, observed changes in protein abundance can be explained in multiple ways, one of which is by the protein turnover rate. In order to easily and rapidly obtain information on both the identity and turnover of individual proteins, in Chapter 5 we applied a combination of protein labeling with L-(ring-2,3,4,5,6$\left.{ }^{2} \mathrm{H} 5\right)$ phenylalanine and MALDI-TOF MS. While the spectrum reveals the identity of a protein, mass isotopomer profile provides information about the rate of protein labeling as a measure of synthesis or turnover. Using this approach on mature 3T3-L1 adipocytes, cytoskeleton proteins appeared to be slowly metabolized, whereas components of the extracellular matrix (ECM), in particular collagen type I alpha 1 (COL1A1) and collagen type I alpha 2 (COL1A2), showed rapid accumulation of newly synthesized proteins. Both proteins appeared to be renewed in the same ratio as they are present in collagen fibers, i.e. 2:1 (COL1A1:COL1A2). In addition, functionally related proteins like collagen-processing enzymes, were also readily labeled. From those findings we concluded that 'resting' mature adipocytes spend much of their energy on the maintenance of the ECM.

It is crucial to have specific proteins identified by proteomics as biomarkers for defined conditions or as components of biological processes and pathways. In Chapter 6 we point out that one needs to be careful with assigning differential expression of proteins to specific experimental conditions, and regarding them as markers for those conditions. We critically reviewed 
differentially expressed proteins from comparative proteomic studies identified by 2-DE followed by MS, especially with MALDI technique. Based on 66 of those studies, a list of 44 proteins was presented as generally detected proteins regardless of species, in vivo or in vitro conditions, tissues and organs, and experimental objective. The enriched functions linked to these generally detected proteins reveal that there are some common biological features beyond technical limitations. Cellular stress response can be the universal reason as to why these proteins are generally expressed differentially. Using those proteins as biomarkers for cellular processes other than stress response should be done with caution. In future proteomic studies more profound approaches should be applied to look beyond these proteins to find specific biomarkers.

In Chapter 7 we studied the genetic background for long term weight gain over a 10-year period. In men the allelic distribution of FTO rs9939609, ACE rs4340 and AKR1C2 rs12249281 differed significantly between the weight stable and weight gainers group. Also an interaction between FTO rs9939609 and ACE rs4340 in men was observed. In women the allelic distribution of MMP2 rs1132896 differed between the weight stable and weight gainers group. The A allele of FTO was associated with a 1.99x higher risk of gaining weight in men, while in women the $C$ allele of MMP2 was associated with a 2.50x higher risk of weight gain,. This chapter also demonstrated that proteomics studies can be useful for the selection of candidates in genetic association analysis. AKR1C2, which was found differentially expressed in adipocytes during weight loss-maintenance (Chapter 3 ), has shown to be involved in the genetic background of long term weight gain.

Chapter 8 provides a general discussion based on the experimental studies presented in this thesis. The pros and cons of proteomics in nutritional studies are discussed and suggestions and guidelines are presented for further research.

The results of this thesis broaden the methodological applications of proteomics, including subtraction proteomics for the enrichment of cell typespecific proteome analysis, and protein isotopomer-labeling to obtain information on protein turnover by mass spectrometry. At the same time a warning is issued against misinterpretation of differentially expressed proteins. Using proteomics to study adipose tissue or adipocytes, a systems view was generated of the cell molecular metabolism, intervention biomarkers were detected, correlations were revealed between changes in cellular proteins and physiologic parameters, and candidate genes for genetic association studies were identified. In conclusion, the research of this thesis contributes to the methodological and cell metabolic knowledge for better understanding of the complex role of adipose tissue and adipocytes in the context of weight regulation. 
Samenvatting 
Dit proefschrift heeft als doel om de rol van het vetweefsel en de vetcellen te bestuderen in relatie tot gewichtsregulatie bij de mens. Daarbij is proteomics gebruikt als centrale analyse-strategie. In die zin heeft dit proefschrift ook als doel om het belang van proteomics binnen het gebied van de nutrigenomics aan te tonen.

Hoofdstuk 1 bevat de algemene inleiding tot dit proefschrift. Het laat onder meer zien, dat bij het opzetten van een nutrigenomics experiment de selectie van het te bestuderen weefsel van groot belang is. In principe moet het weefsel gekozen worden dat, in combinatie met de gebruikte omics techniek, de meeste informatie oplevert.

Hoofdstuk 2 geeft informatie over proteomics analyses van verschillende lichaamsmaterialen afkomstig van proefpersonen na langdurig hongeren. In het voedingsonderzoek wordt bij omics-toepassingen vaak een grote variatie tussen de proefpersonen waargenomen. Het is zelfs mogelijk om met de variatie in proteomics data een 'vingerafdruk' van proefpersonen te maken (figuur 3). Deze variatie kan het werkelijke biologische effect overschaduwen. Het plasma proteoom laat de meeste variatie tussen proefpersonen zien, terwijl het PBMC proteoom de laagste variatie tussen proefpersonen laat zien. Om die reden zijn PBMCs het meest te prefereren materiaal voor proteomics studies in nutrigenomics. Random Forests (RF) analyse uitgevoerd op de gehele dataset toont aan, dat veranderingen van de eiwitten RhoGDI2 in PBMCs en plasma concentraties van ApoA4 de meest duidelijke biomarkers zijn voor langdurig hongeren. RF analyse van multiplex immunoassay data wijst leptine en MMP-3 aan als biomarkers voor langdurig hongeren. Verder kwamen wij tot de conclusie, dat een analyse gebaseerd op antilichamen superieur is aan 2D-electroforese indien plasma eiwitten worden bestudeerd. Men moet zich wel realiseren, dat isovormen die niet worden herkend door de antilichamen, hierdoor kunnen worden gemist.

In hoofdstuk 3 hebben wij onze zelf-ontwikkelde proteomics substractie methode gebruikt in de zoektocht naar eiwit-veranderingen in het in vivo proteoom van proefpersonen met overgewicht of obesitas. Deze proefpersonen ondergingen gedurende 5 weken een zeer laag calorie dieet gevolgd door een 3 weken durend energie-neutraal dieet. Gemiddeld was het totale gewichtsverlies $9.5 \mathrm{~kg}$, waarvan het grootste gedeelte vetmassa $(7.1 \mathrm{~kg})$ was. Zoals te verwachten waren er voor en na het dieet significante verschillen waar te nemen in diverse parameters van vetzucht en het vetmetabolisme. Daarnaast laat proteomics analyse significante verschillen in zes eiwitten zien. De eiwitten fructose-difosfaat-aldolase $C$ (twee isovormen) en tubuline- $\beta 5$ veranderen voor alle proefpersonen in dezelfde richting, respectievelijk een verlaging en een verhoging. Om deze reden kunnen deze twee eiwitten worden beschouwd als biomarkers voor soortgelijke interventies. Verder suggereren andere geïdentificeerde eiwitten (ALDOA, TUBB5 en ANXA2) een verminderde verankering van GLUT4 in de cellen en een verhoogd transport van vetzuren 
(FABP4). Nog andere eiwit-veranderingen duiden op een vermindering van de inflammatoire conditie van het vetweefsel (ApoA1, AOP1) en op een verandering in de intracellulaire organisatie van de vetdruppel (vimentine). Correlatie analyse laat een verband zien tussen de verandering in aldoketoreductase 1C2 (AKR1C2) en parameters van vetzucht. Deze bevinding was aanleiding voor een genetische associatie studie met gewichtstoename over de lange termijn (Hoofdstuk 7). Er werden ook correlaties tussen FABP4 en parameters van het vetmetabolisme gevonden. De laatste correlaties bestaan tussen eiwitten van de $\beta$-oxidatie (HADH, ACADS, ACAT1) en de vrije vetzuren concentratie in plasma. Al deze bevindingen benadrukken de potentiële waarde van in vivo proteomics bij humane interventie studies. Daarnaast laten de resultaten zien dat fysiologische parameters zijn verbonden met het moleculaire metabolisme van het vetweefsel.

In hoofdstuk 4 wordt dieper ingegaan op de moleculaire pathways, die verband houden met het glucose- en vetzuur-metabolisme. Dit om meer specifiek te onderzoeken wat er gebeurt in het vetweefsel na een zeer laag calorie dieet, gevolgd door een gebalanceerd dieet. Proteomics analyse van het moleculaire metabolisme laat zien, dat de relatieve hoeveelheid van de eiwitten: HADH, CAT, FAT, FATP3, ATGL, FABP4, ALDOC, TUBB5 en ANXA2 significant verandert gedurende de interventie. Perilipine $B$ laat de grootste vermeerdering zien $(10 x, p=0.058)$. Er wordt verondersteld dat dit eiwit geassocieerd is met nieuw-opgenomen vetzuren, die bij het celmembraan worden omgezet in triglyceriden. $\mathrm{Er}$ werd ook een verhoogde GLUT4 translocatie naar het celmembraan waargenomen, gemedieerd door fosforylatie van annexine A2 op de tyrosine-24 positie.

Alles tezamen suggereren onze bevindingen, dat na gewichtsverlies door calorische restrictie en een korte periode van gewichtsbehoud, de vetcellen hun vermogen om glucose en vetzuren op te nemen verhogen. De vetcel 'schreeuwt als het ware' om vet na gewicht verlies. Dit lijkt een potentieel risico in te houden voor gewichtstoename na afvallen.

Differientiële gel elektroforese gevolgd door eiwit identificatie met behulp van massa spectrometrie (MS) is een veel gebruikte methode voor het in beeld brengen van eiwit-veranderingen in het proteoom. Maar de waargenomen eiwit-veranderingen kunnen op verschillende manieren worden verklaard, bijvoorbeeld door een verandering in de snelheid van aanmaak en afbraak van een eiwit. Om makkelijk en snel informatie over de eiwit identificatie en eiwit aanmaak te krijgen, hebben wij in hoofdstuk 5 een combinatie van eiwit labeling met L-(ring-2,3,4,5,6- $\left.{ }^{2} \mathrm{H} 5\right)$ fenylalanine en MALDI-TOF-MS toegepast. Terwijl het spectrum de identiteit van het eiwit onthult, geeft het isotopomeer-profiel na verschillende tijden informatie over de snelheid van eiwit labeling, wat een maat is voor de eiwit aanmaak. Door deze toepassing te gebruiken op 3T3L1 vetcellen vonden wij, dat in volwassen vetcellen het cytoskelet een lange levensduur heeft, terwijl componenten van de 
extracellulaire matrix (ECM) -vooral collageen type I a1 (COL1A1) en collageen type I a2 (COL1A2)- een snelle omzetting laten zien. Bovendien lijken beide eiwitten in dezelfde ratio van 2:1 (COL1A1:COL1A2) te worden aangemaakt als de ratio waarmee zij in collageen vezels voorkomen. Dit duidt op een gecoördineerde aanmaak. Ook functioneel gerelateerde eiwitten zoals collageen-processing eiwitten blijken een snelle omzetting te hebben. Hieruit valt te concluderen dat rustende, volwassen vetcellen veel energie besteden aan het onderhoud van hun ECM.

Het is van evident belang om met behulp van proteomics specifieke eiwitten te kunnen identificeren en als zodanig aan te wijzen als biomarkers voor specifieke condities of als onderdeel van biologische processen en pathways. In hoofdstuk 6 laten we zien dat men voorzichtig moet zijn met het toewijzen van differentieel geëxpresseerde eiwitten aan bepaalde experimentele condities, en om dergelijke eiwitten te benoemen tot markers voor die condities. Wij hebben van vergelijkbare proteomics studies de differentieel geëxpresseerde eiwitten verzameld die geïdentificeerd zijn met behulp van 2-DE gevolgd door MS, vooral de MALDI methode. Gebaseerd op 66 studies is er een lijst opgesteld van 44 eiwitten die in bijna alle studies gedetecteerd werden, ongeacht de soort, in vivo of in vitro conditie, type weefsel, orgaan, en studie doel. Functie-analyse van deze algemeen gedetecteerde eiwitten laat zien, dat ze gemeenschappelijke biologische functies hebben, los van de technische beperkingen. De cellulaire stress reactie kan een reden zijn, waarom deze eiwitten zo vaak geïdentificeerd worden. Het betekent, dat men uitermate voorzichtig moet zijn bij het toewijzen van deze eiwitten als biomarkers aan cellulaire processen anders dan de stress reactie. In toekomstige proteomics studies zal verder dan deze eiwitten moeten worden gezocht met meer specifieke benaderingen om betrouwbare biomarkers te vinden.

In hoofdstuk 7 bestuderen wij de genetische achtergrond op gewichtstoename gedurende een periode van 10 jaar. Bij mannen is de allelverdeling van FTO rs9939609, ACE rs4340 en AKR1C2 rs12249281 significant verschillend tussen de gewicht-stabiele groep en de groep met gewichtstoename. Ook werd er een interactie tussen FTO rs9939609 en ACE rs4340 bij mannen waargenomen. Bij vrouwen is de allel-verdeling van MMP2 rs1132896 significant verschillend tussen de gewicht-stabiele groep en de groep met gewichtstoename. Het A allel van FTO is geassocieerd met een 1.99x hoger risico op gewichtstoename bij mannen, terwijl bij vrouwen het $C$ allel van MMP2 geassocieerd is met een 2.50x hoger risico voor gewichtstoename. In dit hoofdstuk hebben we ook laten zien, dat proteomics studies kunnen worden gebruikt voor de selectie van kandidaat-genen voor genetische associatie analyses. Volgens de studie in dit hoofdstuk blijkt AKR1C2, dat differentieel geëxpresseerd is in vetcellen gedurende gewichtsverlies gevolgd door gewichtsbehoud (hoofdstuk 3), een bijdrage te 
leveren aan de genetische achtergrond van gewichtstoename over een langere periode.

Hoofdstuk 8 bevat een algemene discussie gebaseerd op de experimenten die in dit proefschrift zijn beschreven. De voor- en nadelen zijn benoemd, suggesties en richtlijnen zijn gegeven voor verder onderzoek.

De studies in dit proefschrift hebben bijgedragen aan de methodische toepassingen van proteomics, inclusief substractie-proteomics om tot een verrijking van het cel-specifieke proteoom te komen en eiwit isotopomeer labeling met massa spectrometrie voor het verkrijgen van informatie omtrent de snelheid van eiwit aanmaak. Tegelijkertijd hebben we gewaarschuwd voor het verkeerd interpreteren van algemene, differentieel geëxpresseerde eiwitten. Met het gebruik van proteomics om vetweefsel of vetcellen te bestuderen, is een systemisch overzicht gegenereerd van het moleculair cel-metabolisme, zijn interventie biomarkers gedetecteerd, zijn correlaties tussen veranderingen in cellulaire eiwitten en fysiologische parameters blootgelegd en zijn kandidaat genen voor genetische associatie studies geïdentificeerd. Geconcludeerd kan worden, dat het onderzoek van dit proefschrift een bijdrage heeft geleverd aan de methodologische en cel-metabolische kennis, waarmee de complexe rol van vetweefsel en vetcellen bij gewichtsregulatie beter kan worden begrepen. 


\section{The impact for society, Valorisation}


This thesis is focused on gaining fundamental knowledge about the adipose tissue cellular metabolism and candidate gene analysis in the context of weight gain, loss, regain and maintenance of overweight and obese humans.

\section{Obesity and society}

Weight gain resulting in overweight or obesity is becoming more and more a serious health problem. Nowadays almost 1 in 2 adults aged 20 years and over are affected by overweight including obesity. In 2014 globally and in the Netherlands roughly $36 \%$ of the adults is overweight (BMI>25) and $13 \%$ of the adults is obese (BMI>30) [1]. In the Netherlands overweight tends to be more common for men compared to women ( $41 \%$ men vs $29 \%$ women), while for obesity it is the opposite ( $15 \%$ women vs $12 \%$ men) [2]. The global prevalence of obesity has more than doubled between 1980 and 2014. An important factor for weight gain is not only the reduced physical activity, but the increased availability and intake of food. Weight regulation or weight reduction can have a huge impact on the quality of life. In 2013 obesity has been officially recognized as a disease by the American Medical Association. Weight reduction can get people out of their isolation and help them to become more socially accepted, more movable and it results in less health complications. On TV there is growing attention for the prevention of obesity, underlining its social impact and other problems regarding obesity. In fact, everybody can lose weight, but keeping off the lost weight is the hardest part.

\section{The value of obesity research}

Another important feature of weight loss is the reduction of health care costs. The total direct and indirect costs of overweight and obesity are estimated at 3 billion euros per year in the Netherlands. Of these 3 billion euros, 1.2 billion euros is directly linked to health care costs caused by overweight and obesity and 2 billion are linked to the lost productivity which is a result from the days taken off sick. Obesity itself can cause problems with joints, bones, and various organs. But there are also secondary effects like cardiovascular diseases, heart disease, hypertension or stroke, type 2 diabetes mellitus, and also some cancers are known complications.

All those complications together have a big effect on health care costs. This could in part be prevented by better guidance of weight regulation, which is relatively cheap. Combating obesity also results in other health benefits. For example, when combating obesity a $5 \%$ weight loss is associated with a $50 \%$ reduction in the development of type 2 diabetes [3]. 
Research into the etiology of obesity may provide novel or better means for treatment or prevention. However, obesity is more complex than originally thought and research might involve various disciplines ranging from genetics, proteomics and metabolomics to public health and social sciences. This thesis provides more insight on how molecular and genetic information may assist the regulation of weight.

\section{Scientific gain of this thesis}

In this thesis we have found that:

(1) We found that during weight loss, adipocytes increase their capacity for glucose uptake by reduced GLUT4 scavenging and increase their uptake of fatty acids. In other words, they are preparing themselves to get more energy in and store fat again, which will contribute to weight regain. When we can further prove this hypothesis, such knowledge will enlarge the awareness of people that after weight loss they need to take extra measures to prevent weight regain. "A very low calorie diet makes adipocytes scream for fat"

(2) We have shown that mature adipocytes spend a lot of their energy on sustaining and renewing the extracellular matrix (ECM). When adipocytes lose fat, mechanical stress builds up between the ECM and the cell. Refilling of the adipocytes removes adipocyte cellular stress. Studying the ECM during weight loss may lead to the identification of risk markers for weight regain after weight loss.

(3) Proteomics of adipocytes during weight loss has provided candidates for genetic association studies, which may lead to the identification of genetic risk factors for weight gain and regain.

(4) The investigated single nucleotide polymorphisms or so called SNPs in FTO in men and MMP2 in women are associated with weight gain over a 10 year follow-up period. A genetic risk profile could be generated to select people that are at high risk of weight gain, who can then be given better guidance of weight regulation. 


\section{Innovation}

The present thesis presents various novel findings and insight. We were able to use proteomics to show the great devotion of adipocytes to maintaining their extracellular matrix, which is in line with an active role of the ECM in the model that proposes adipocyte cellular stress as a driver of weight regain. Further we were able to use a systems proteomics approach to get an overview of the various lipid and glucose handling segments of the adipocyte cellular metabolism. This resulted in the detection of several biomarkers for weight lossmaintenance. Further, the importance of a molecular mechanism of glucose uptake-regulation in the regulation of adipocyte lipid turnover was revealed including the action of aldolase, annexinA2, and tubulinB5. Importantly, our observations showed that during weight loss, adipocytes prepare for uptake of glucose and fatty acids, which provides a risk condition for weight regain after weight loss. It is important that weight loss candidates are aware of this response of their fat tissue. Further, in this thesis we have shown that proteomics analysis can provide candidate proteins/genes for genetic risk assessment via cohort studies. Several genetic biomarkers were found in this thesis with risk alleles for long term weight gain in men and women. These polymorphisms and the found biomarkers could add to a genetic risk profile for weight regulation. A gender difference as observed here is not uncommon for research on weight regulation, but it underscores the importance for setting up sex-specific guidelines for weight loss and maintenance.

\section{Stakeholders in regard to knowledge application}

The most important target group is society itself. The scientific gain of this thesis will on the long term help to fight obesity by treating the overweight and obese subjects for weight loss. As such it will contribute to the reduction of the health burden for society. In fact, our knowledge can be incorporated with the current treatment and other new developments to offer a specific, personalized guideline to subjects who aim to lose weight. This will enhance the efficiency of the weight loss treatment and of weight maintenance. For example, subjects with a genetic profile predisposing to long-term weight gain should receive a more stringent and/or frequent guidance than those with a low number of genetic risk polymorphisms. To ultimately achieve this, high quality prediction models are a necessity, because the genetic predisposition of overweight and obesity is extremely complex with a great deal of individual genetic variation. Such models can be more easily worked out by collaborative actions between research groups and companies to explore large-scale genome data. 


\section{Dissemination}

Knowledge dissemination can be done by delivering prediction models and treatment guidelines to trained dieticians, specialists of hospital and obesity clinics such as Co-Eur (http://co-eur.com). Also it is possible to compose and monitor a complete overview of the health status and personalized guidelines for subjects, for instance in collaboration with companies such as Pre-Scan, a company specialized in preventive medical research (http://www.prescan.nl). Alternatively, the newly gained knowledge can be a starting point of a spin-off company of the university. The goal of such an undertaking would be personalized nutrition, a tailor made nutrition advice, which is based on the genetic, proteomics and metabolomics background of the subject. This tailor made advice can be of interest for health insurance companies. It could reduce the health care costs by combating the obesity epidemic. A good example of the possibilities of personalized nutrition is the use of plant sterol containing food products to lower the plasma cholesterol level [4].

It should be realized that using knowledge from the present thesis in setting up/supplying agencies for personalized advice on weight loss/maintenance that the use of genomic and genetic information is subject to ethical regulation, which may restrict the actual applications. One of the dangers is the chance of unexpected findings such as genetic predisposition to life-threatening conditions in the genetic data. On the other hand, it may be regarded a positive aspect of genetic analysis that such risk can be discovered before actual symptoms occur, but this is only beneficial if treatment is available. Those and other questions have still to be worked out for a complex trait as overweight and obesity. One example is 23andMe, a company giving personalized advice based on genome variation, which last year was severely restricted in their commercial activities because of privacy reasons.

\section{Summary and realization}

Valorization requires collaboration among research groups within and outside the university and with the industry, which can form the basis for spin-off companies and knowledge-transfer agencies, in which the social media will play an important role. This collaboration will provide more data and novel ideas, and leads to gain more, better and accurate insight in the health and risk condition of each individual. Our findings are a starting point in this respect, but further research is needed. Newer techniques like detailed proteome quantification and exome sequencing are getting better and cheaper. Nowadays it is possible to get a complete human genome sequenced for 1000 dollar and it will get even more cheaper in the future. Besides ethical consideration in the application of 
research findings, the data generated by modern techniques is enormous. Therefore, bioinformatics and biostatistics with a focus on modelling will play a huge role in the process of from data to application.

A reliable individual predictive profile for weight regulation can be available within the next 5 years for society. In the end, however, people should still worry about what they eat and keep sufficient physical activity, because you can't change your genes, but you can change your behavior.

\section{References}

1. WHO (2015) Obesity and overweight. (Fact sheet $\mathrm{N}^{\circ} 311$ ).

2. $\mathrm{Ng} \mathrm{M}$, et al. (2014) Global, regional, and national prevalence of overweight and obesity in children and adults during 1980-2013: a systematic analysis for the Global Burden of Disease Study 2013. Lancet 384(9945):766-781.

3. Visscher TL, et al. (2012) What is the value of obesity research? - Comment on Blundell JE, Hebebrand J, Oppert JM. What is the value of obesity research? Obes Facts 2010;3:279-282. Obesity facts 5(2):298-304.

4. De Smet E, Mensink RP, \& Plat J (2012) Effects of plant sterols and stanols on intestinal cholesterol metabolism: suggested mechanisms from past to present. Molecular nutrition \& food research 56(7):1058-1072. 


\section{Abbreviations:}

$\begin{array}{ll}\text { BMI } & \text { body mass index } \\ \text { BW } & \text { body weight } \\ \text { WAT } & \text { white adipose tissue } \\ \text { BAT } & \text { brown adipose tissue } \\ \text { VLCD } & \text { very low calorie diet } \\ \text { KRBH } & \text { Krebs Ringer bicarbonate buffer supplemented with HEPES } \\ \text { NFDM } & \text { nonfat dry milk power } \\ \text { FA } & \text { fatty acid } \\ \text { IEF } & \text { iso Isoelectric focusing } \\ \text { SDS-PAGE } & \text { sodium dodecyl sulfate polyacrylamide gel electrophoresis } \\ \text { 2DE } & \text { 2 dimensonal gel-electrophoresis } \\ \text { MALDI } & \text { matrix-assisted laser desorption ionization } \\ \text { TOF } & \text { time-of-flight } \\ \text { MS } & \text { mass spectrometry } \\ \text { MS/MS } & \text { Tandem mass spectrometry } \\ \text { FDR } & \text { false discovery rate } \\ \text { PBMC } & \text { peripheral blood mononuclear cell } \\ \text { RF } & \text { random forests } \\ \text { ECM } & \text { extracellular matrix } \\ \text { COL1A1 } & \text { collagen type I alpha 1 } \\ \text { COL1A2 } & \text { collagen type I alpha 2 } \\ \text { ALDH6A1 } & \text { methylmalonate semialdehyde dehydrogenase } \\ \text { TUBB5 } & \text { tubulin beta } 5 \\ \text { ApoA1 } & \text { apolipoprotein A1 } \\ \text { ALDOC } & \text { fructose-bisphosphate aldolase C } \\ \text { ANXA2 } & \text { annexin A2 } \\ \text { ACADS } & \text { short chain specific acyl-CoA dehydrogenase } \\ \text { HADH } & \text { short chain 3-hydroxyacyl-CoA dehydrogenase } \\ \text { ACAT1 } & \text { acetyl-CoA acetyltransferase } \\ \text { AOP1 } & \text { antioxidant protein 1 } \\ \text { GLUT4 } & \text { glucose transporter 4 } \\ \text { AKR1C2 } & \text { aldo-keto reductase family 1 member C2 } \\ \text { FABP4 } & \text { fatty acid binding protein 4 } \\ \text { FTO } & \text { fat mass and obesity-associated protein } \\ \text { ACE } & \text { angiotensin converting enzyme } \\ \text { MMP2 } & \text { matrix metalloproteinase } 2 \\ \text { LD } & \text { linkage disequilibrium } \\ \text { OR } & \text { odds ratio } \\ & \end{array}$




\section{Dankwoord}


Het is zover, mijn proefschrift is af! Ik wil graag iedereen bedanken die op welke wijze dan ook aan mijn proefschrift heeft bijgedragen. Promoveren is iets wat je niet alleen doet, het is een teamsport.

Allereerst wil ik mijn promotor Prof.dr. Edwin Mariman en copromotor Dr. Ping Wang bedanken. Edwin, dank je voor het vertrouwen dat je in mij hebt, voor je geduld en omdat je het beste in je mensen naar boven laat komen. Je mooie verhalen over rozenkransen zijn altijd indrukwekkend. Ping, thank you for the scientific discussions. It is always fun to discuss science with you and to see your passion for science. You are the master.

Ik wil graag de beoordelingscommisie bestaande uit Prof.dr.ir. Ellen Blaak, Prof.dr. Tilman Hakeng, Prof.dr. Peter Verhaert, Prof.dr.ir. Ronald Mensink en Prof.dr.ir Jaap Keijer bedanken voor hun kritische blik op dit proefschrift. Ronald, jij bent eigenlijk degene die me over de streep heeft getrokken om te gaan promoveren.

Jos "BBQ" Stegen, onze "godfather" van de vakgroep. Je stimuleert me elk jaar weer om deel te nemen aan de $\mathrm{ENCl}$ bergloop, met na afloop natuurlijk een Duveltje. Onze trip naar de kerstmarkt in Luik is onvergetelijk. En niet te vergeten de vrijdagmiddag integratie borrels, waar je je met hart en ziel voor inzet.

Antoine, wij hebben beide veel meegemaakt in de tijd van mijn promotie. Ik denk dat we veel steun aan elkaar hebben. Ondanks alles was er altijd tijd om plezier te maken. Zelfs onze dochters hebben dezelfde naam.

Wij drieën als "Die Gipfelfreunde" maken carnaval op de vakgroep altijd weer tot een succes. Het doet me dan ook goed dat jullie allebei achter me staan tijdens mijn promotie.

Science is a team effort, so I would like to thank all the co-authors: Mandy Claessens, Marleen van Baak, Wim Saris, Jean-Paul Noben, Baukje de Roos, Isabel Rubio-Aliaga, Katie Crosley, Susan Duthie, Claus Mayer, Graham Horgan, Abigael Polley, Carolin Heim, Susan Coort, Chris Evelo, Francis Mulholland, lan Johnson, Ruan Elliott, Hannelore Daniel, Martijn E.T. Dollé, Sandra Imholz, Monique Verschuren and Jolanda Boer.

Wim Engels en Bruce Wolfenbuttel bedankt dat ik een half jaar vrijwillig op jullie lab mocht werken. Dat was mijn eerste stap in de wetenschap. Carla van der Kallen, je was mijn eerste "baas". Al was Tjerk de Bruin de echte baas. Je hebt me een goede blik op onderzoek gegeven en de fijne kneepjes van celkweek geleerd. Ook Paul, Geertje, Mireille, Marleen, Vicky, Margee, Petra, Jan, Rob en Josefien, bedankt. En, Arjen Bakker, ergens geloof ik nog steeds in de adipogene potentiaal. 
Vervolgens was er een nieuwe leerstoel functionele genetica, FunGen, waar ik mijn proteomics carrière ben begonnen. Egbert Smit, bedankt voor de vele squash uren. Al heb ik in drie jaar tijd geloof ik maar één of twee keer gewonnen. Jonathan, jij hebt altijd een relaxte blik op zaken. Johan Renes, dank je voor het kritisch bekijken van de introductie en discussie. Dank aan alle AIO's binnen onze FunGen groep die mij zijn voorgegaan of nog bezig zijn: Anja, Geert, Nadia, Qing en Roel. Ik leer nog steeds van jullie.

Kaatje, Janneke en Anke bedankt voor de eer om jullie paranimf te mogen zijn, nu ik zelf promoveer ervaar ik pas echt wat jullie hebben doorstaan. Ronny "feest beest" Mohren, goed dat je nu weer bij ons werkt. Je gaat gezelligheid en hard werken niet uit de weg. Sanne van Otterdijk, bedankt voor de eerste hand die jij hebt gelegd aan hoofdstuk 7 . ledereen van de vakgroepen gemeenschap Humane Biologie en Bewegingswetenschappen wil ik bedanken. Zeker het OBP (Ontzettend Belangrijk Personeel): Joan "sterke verhalen" Senden, Annemie, Wendy, Hasibe, Esther, Martine, Maurice, Maud, Joy, Janneau, Nicole, Yvonne, Paul, Gert, Gabby en Loek.

Verder wil ik bedanken onze onmisbare "engeltjes of heksjes" van het secretariaat: Desiree, Claudia (jammer dat je niet meer bij ons werkt), Cleo en Jolanda.

Dennis Suylen samen met jou heb ik mijn eerste publicatie gemaakt. Leon Schurgers voor de verhelderende discussies in de trein. Marja van Dieijen, Will Wodzig en Douwe de Boer van klinische chemie. Jean-Paul Noben en Erik Royackers van de Universiteit Hasselt voor de hulp met eiwit identificaties op de LCMS. Ook de afdeling inkoop, de IDEE als ik weer iets stuk heb gemaakt (Simon, Eugene, Marc, Lau, Maurice en Paul), NUTRIM (Sef, Joanna, Yvonne en Marijke), het magazijn (Joke, Eddy, Noël), de spoelkeuken en DHV "Pierre wat deed ut weer", ook zonder jullie was dit proefschrift niet mogelijk. Ik hoop dat ik niemand vergeten ben. Mocht het toch zo zijn, bedankt voor de bijdrage.

Gedurende mijn promotietijd heb ik afscheid moeten nemen van een aantal dierbare mensen. Ineke van de Weerdt en Adelbert Anink. Harie Ruijters, "kleine opa" zoals Lieke en Veerle je noemen. Altijd als ik een zonnestraal voel, dan denk ik weer even aan je. Ik heb veel van je geleerd. Eric Reuling, je boodschap "Geneet van ut laeve" zal ik nooit vergeten.

Helen, er is veel gebeurd in de tijd van mijn promotie. Ik hoop dat wij beide vinden wat we zoeken. Thijs, Floris, Ben en Marie-Claire we zien elkaar niet meer zo vaak, maar ben benieuwd naar de ontwikkeling van de jongens.

Verder wil ik graag mijn vrienden bedanken voor de nodige ontspanning. De "Limbricht uitjes" groep, nooit gedacht dat ik op salsa dansles zou gaan. Mijn fiets maatjes: Jos vdL, Marco, Jos H, Gerard en Jos A. Met jullie heb ik mijn hoogste berg, de Mont Ventoux, beklommen. Een echte uitdaging. Mijn 
hardloop maatjes: Gerard, Henny, Jos A, Jos vdL, Luc, Mike en Rob, het is heerlijk om op zondagochtend een rondje te hardlopen en na afloop te kletsen met een bakje koffie.

Mijn vrienden en vriendinnen uit Oesjbik en omstreken wil ik zeker niet vergeten. Het zijn er teveel om op te noemen en ik ben bang daardoor iemand te vergeten. Maar de meeste zie ik bij Don Bosco, Zibbith, Har Rock Cafe, Jannie en de Schepenbank. Ik vind de band die er altijd is super en kom nog steeds graag terug naar de "Oetloat".

Bas, Marco, Dan, Kush, Hans, Sjra, Hum, Oeli, Maarten, Frank, Dio, Rob, Toine en Dennis, ik hoop dat wij nog lang van ons jaarlijkse bierkamp mogen genieten. Hans Alzer, ik geniet van onze alternatieve motor tour tijdens de motor zegening en Herk Rock. Bas en Marco, onze reis naar Peru is onvergetelijk. Onze vriendschap is hierdoor nog sterker geworden.

John Mevis, alias Nosh, dank je voor het enthousiast meedenken en ontwerpen van de kaft. Renske, dank je voor het doorlezen van de samenvatting. En dat er nog maar veel heerlijke gezellige etentjes mogen volgen. Chantal, dank je voor het meedenken aan de valorisatie paragraaf, maar ook voor het sparren en gezellig kletsen over van alles en nog wat.

Mieke, ook jij hebt een belangrijke rol gespeeld tijdens mijn promotie. Dank je voor de goede zorg voor Lieke en Veerle. Je bent een super oppas voor ze.

Mijn zusjes en broertje: Aniek, Hilly en Chris. Aniek jij bent me voorgegaan met promoveren en het is leuk om te zien dat ons onderzoek raakvlakken heeft. Ben benieuwd wanneer je van Mario nieuwe witte hakken schoenen krijgt. Aniek, Mario, Hilly en Martin, bedankt voor de heerlijke skivakantie in Sölden. Die week heeft mij echt goed gedaan. Hilly en Martin ik hoop dat jullie je droom om naar Indonesië te emigreren kunnen waar maken. Chris, hoeveel solexen heb je nu eigenlijk? Succes met het vinden van je droomhuis.

Pap en Mam jullie hebben me geleerd wat loyaliteit en doorzettingsvermogen is. Dank jullie voor alle steun en ruimte die jullie mij hebben gegeven. Ik ben trots op jullie als ouders. Ik kan me geen betere ouders wensen.

Lieke, mijn "Kruimeltje" en Veerle, mijn "Zonnetje", jullie vinden het maar gek dat mijn robot geen hand kan geven, niet kan lopen of praten. Ook zijn jullie benieuwd naar de nummerplaat van de mens, die wij de DNA code noemen. Ik ga nu nog meer tijd met jullie doorbrengen en van jullie genieten. Ik hou van jullie. 


\section{List of publications}




\section{As first auther}

2014 Freek G. Bouwman, Jolanda M.A. Boer, Sandra Imholz, Ping Wang, Monique Verschuren, Martijn E.T. Dollé, \& Edwin C.M. Mariman Gender-specific genetic associations of polymorphisms in ACE, AKR1C2, FTO and MMP2 with weight gain over a 10 year period Genes \& Nutrition 2014, 9 (6), 432

2013 Freek G. Bouwman, Ping Wang, Marleen van Baak, Wim H.M. Saris \& Edwin C.M. Mariman Increased $\beta$-oxidation with improved glucose uptake capacity in adipocytes from overweight/obese subjects after a weight loss/maintenance intervention.

Obesity 2014 2014, 22 (3), p. 819-827

2011 Freek G. Bouwman, Baukje de Roos, Isabel Rubio-Aliaga, L. Katie Crosley, Susan J. Duthie, Claus Mayer, Graham Horgan, Abigael C. Polley, Carolin Heim, Susan L.M. Coort, Chris T. Evelo, Francis Mulholland, Ian T. Johnson, Ruan M. Elliott, Hannelore Daniel \& Edwin C.M. Mariman

2D-electrophoresis and multiplex immunoassay proteomic analysis of different body fluids and cellular components reveal known and novel markers for extended fasting.

BMC Medical Genomics 2011, p. 4-24

2010 Freek G. Bouwman, Mireille M.E. van Ginneken, Johannes H. van der Kolk, Eric van Breda \& Edwin C.M. Mariman.

Novel markers for tying-up in horses by proteomics analysis of equine muscle biopsies.

Comp. Biochem. Physio. part D 2010 (5), p. 178-183

2010 F.G. Bouwman, Mireille M.E. van Ginneken, Jean-Paul Noben, Erik Royackers, Ellen de Graaf-Roelfsema, Inge D. Wijnberg, Johannes H. van der Kolk, Edwin C.M. Mariman \& Eric van Breda.

Differential expression of equine muscle proteins during normal training and intensified training in young standardbred horses using proteomics technology.

Comp. Biochem. Physio. part D 2010 (5), p. 55-64

2009 Freek G. Bouwman, Mandy Claessens, Wim H.M. Saris, Jean-Paul Noben, Marleen A. van Baak \& Edwin C.M. Mariman

The physiologic effects of calorie restriction are reflected in the in vivo adipocyte-enriched proteome of overweight/obese subjects J. Prot. Research 2009, 8 (12) p. 5532-5540

2005 Freek Bouwman, Dennis Suylen, Johan Renes \& Edwin Mariman Evaluation and improving the success rate of protein identification by peptide mass fingerprinting using matrix-assisted laser desorption/ionization time-of-flight mass spectrometry. 
Rapid Commun. Mass Spectrom. 2005, 19 (17), p. 2465-2468

2004 Freek Bouwman, Johan Renes \& Edwin Mariman.

A combination of protein profiling and isotopomer analysis using matrixassisted laser desorption/ionization-time of flight mass spectrometry reveals an active metabolism of the extracellular matrix of 3T3-L1 adipocytes.

Proteomics, 2004, Dec, 4 (12), p. 3855-3863

\section{As co-auther}

2015 Edwin C.M. Mariman, Freek G. Bouwman, Erik E.J.G. Aller, Marleen A. van Baak \& Ping Wang

Extreme obesity is associated with variation in genes related to the circadian rhythm of food intake and hypothalamic signaling

Physiol Genomics 2015, 24

2014 Elliott RM, de Roos B, Duthie SJ, Bouwman FG, Rubio-Aliaga I, Crosley LK, Mayer C, Polley AC, Heim C, Coort SL, Evelo CT, Mulholland F, Daniel H, Mariman EC \& Johnson IT

Transcriptome analysis of peripheral blood mononuclear cells in human subjects following a 36 hour fast provides evidence of effects on genes regulating inflammation, apoptosis and energy metabolism

Genes \& Nutrition 2014, 9 (6), 432

2014 R. Hursel, P.L.H.R. Janssens, F.G. Bouwman, E.C. Mariman \& M.S. Westerterp-Plantenga

The role of catechol-O-methyl transferase Val(108/158)Met polymorphism (RS4680) in the effect of green tea on energy expenditure and fat oxidation: a pilot study.

PlosOne 2014, Volume 9, Issue 9, e106220

2014 M Gielen, MS Westerterp-Plantenga, FG Bouwman, AMCP Joosen, R Vlietinck, C Derom, MP Zeegers, ECM Mariman \& KR Westerterp Heritability and genetic aetiology of habitual physical activity: a twin study with objective measures

Genes \& Nutrition 2014, 9 (4), 415

2014 Kristien Lemmens, Misha Vrolijk, Freek Bouwman, Wim van der Vijgh, Aalt Bast \& Guido Haenen

The Minor Structural Difference between the Antioxidants Quercetin and 4'O-Methylquercetin has a Major Impact on their Selective Thiol Toxicity Int. J. Mol. Sci. 2014, 15, p 7475-7484

2014 Edwin C.M. Mariman, Freek.G. Bouwman, Erik E.J.G. Aller, Marleen A. van Baak \& Ping Wang.

High Frequency of Rare Variants with a Moderate-to-high Predicted Biological Effect in Protocadherin Genes of Extremely Obese

Genes \& Nutrition 2014, 399 p 1-9 
2014 Martijn P. van Iersel, Milka Sokolovic, Kaatje Lenaerts, Freek G. Bouwman, Edwin C.M. Mariman \& Chris T. Evelo

Pathway visualization applied to a multi-omics study of starvation in mouse intestine Integrated visualization of a multi-omics study of starvation in mouse intestine Journal of Integrative Bioinformatics 2014, 11(1):235

2014 Sanne P.M. Verhoef, Stefan G.J.A. Camps, Freek G Bouwman, Edwin CM Mariman \& Klaas R. Westerterp

Genetic predisposition, dietary restraint and disinhibition in relation to weight loss and long-term weight loss.

Physiology \& Behavior 2014, 128, p. 247-251

2013 Anja Rosenow, Jean-Paul Noben, Freek G. Bouwman, Edwin C.M. Mariman \& Johan Renes

Hypoxia-mimetic effects in the secretome of human preadipocytes and adipocytes.

Biochimica et Biophysica Acta - Proteins and Proteomics 2013, Vol. 1834, Issue 12, p 2761-2771

2013 Ellen Dirkx, Freek G. Bouwman, Didier Vertommen, Edwin C. Mariman, Sakthivel Sadayappan, Jan F.C. Glatz, Joost J.F.P. Luiken \& Guillaume J.J.M. van Eys

Detection of cardiac myosin binding protein-C by a phospho-specific PKD antibody in contracting rat cardiomyocytes

J Adv. Biosci. Biotechnol. 2013, issue 4, p 1-6

2013 Sanne P.M. Verhoef, Stefan G.J.A. Camps, Freek G Bouwman, Edwin CM Mariman \& Klaas R. Westerterp

Physiological response of adipocytes to weight loss and maintenance.

PlosOne 2013, Volume 8, Issue 3, e58011

2013 Anke Van Summeren, Johan Renes, Daneida Lizarraga, Freek G. Bouwman, Jean-Paul Noben, Joost H. M. van Delft, Jos C. S. Kleinjans \& Edwin C. M. Mariman

Screening for drug-Induced hepatotoxicity in primary mouse hepatocytes using acetaminophen, amiodarone, and cyclosporin $A$ as model compounds: an Omics-guided approach.

Omics 2013, vol. 17, 2, p 71-83

2012 Anneke Jans, Ellen Konings, Gijs H. Goossens, Freek G. Bouwman, Chantalle C. Moors, Mark V. Boekschoten, Lydia A. Afman, Michael Müller, Edwin C. Mariman \& Ellen E. Blaak

Polyunsaturated fatty acids acutely affect triacylglycerol-derived skeletal muscle fatty acid uptake and increases postprandial insulin sensitivity Am. J. Clin. Nutr. 2012 ;95 (4) p. 825-36

2012 Ping Wang, Claus Holst, Arne Astrup, Freek G. Bouwman, Sanne van Otterdijk, Will K.W.H. Wodzig, Malene R. Andersen, Marleen A. van Baak, Lone G. Rasmussen, J. Alfredo Martinez, Susan A. Jebb, 
Andreas F. H. Pfeiffer, Anthony Kafatos, Teodora Handjieva-Darlenska, Petr Hlavaty, Wim H. M. Saris \& Edwin C. M. Mariman

Blood profiling of proteins and steroids during weight maintenance with manipulation of dietary protein level and glycaemic index

Brit. J Nutr. 2012, 107 p 106-119

2011 F. Rutters, A.G. Nieuwenhuizen, S.G. Lemmens, F. Bouwman, E. Mariman \& M.S. Westerterp-Plantenga

Associations between anthropometrical measurements, body composition, single-nucleotide polymorphisms of the hypothalamus/pituitary/adrenal (HPA) axis and HPA axis functioning.

Clin Endocrinol (Oxf) 2011, Jun 74 (6) p 679-686.

2011 Ine Kuipers, Scott W Aesif, Amy S Guala, Gonda Konings, Freek G Bouwman, Edwin C Mariman, Emiel FM Wouters, Yvonne MW Janssen-Heininger \& Niki L Reynaert

Cigarette smoke causes increases in protein S-glutathionylation and epithelial cell death by targeting glutaredoxin 1

Am.J.RCMB 2011, 45 (5) p.931-937

2011 F. Rutters, A.G. Nieuwenhuizen, F. Bouwman, E. Mariman \& M.S. Westerterp-Plantenga

Associations between a Single Nucleotide Polymorphism of the FTO Gene (rs9939609) and Obesity-Related Characteristics over Time during Puberty in a Dutch Children Cohort.

JCEM 2011, 96 (6) p.939-42

2011 Isabel Rubio-Aliaga, Baukje de Roos, Susan J. Duthie, L. Katie Crosley, Claus Mayer, Graham Horgan, Ian J. Colquhoun, Gwénaëlle Le Gall, Fritz Huber, Werner Kremer, Michael Rychlik, Suzan Wopereis, Ben van Ommen, Gabriele Schmidt, Carolin Heim, Freek G. Bouwman, Edwin C. Mariman, Francis Mulholland, Ian T. Johnson, Abigael C. Polley, Ruan M. Elliott \& Hannelore Daniel

Metabolomics of prolonged fasting in humans: from physiology to individual metabotypes.

Metabolomics 2011, 7 p. 375-387

2011 Ping Wang, Claus Holst, Freek Bouwman, Sanne van Otterdijk, Will Wodzig, Wim Saris \& Edwin Mariman

Blood proteins and steroid hormones predict successful weight maintenance after weight loss with gene-nutrient interaction in females PLOSOne 2011, Volume 6, Issue 2, e16773

2011 Anke Van Summeren, Johan Renes, Freek G. Bouwman, Jean-Paul Noben, Joost H. M. van Delft, Jos C. S. Kleinjans and Edwin C. M. Mariman

Proteomics investigations of drug induced hepatotoxicity in HepG2 cells.

Toxicological Sciences 2011, 120 (1), p 109-122 
2010 E. Konings, E. Corpeleijn, F.G. Bouwman, E.C. Mariman and E.E. Blaak

Expression of genes involved in lipid metabolism in impaired glucose tolerant men and the impact of weight loss.

J. Nutrigenetics and Nutrigenomics 2010 10,3 (1) p. 9-17

2010 Anja Rosenow, Tabiwang Arrey, Freek G. Bouwman, Jean-Paul Noben, Martin Wabitsch, Edwin C.M. Mariman \& Johan Renes

Identification of novel human adipocyte secreted proteins by using SGBS cells

J. Prot. Research 2010, 9 (10) p. 5389-5401

2010 Femke Rutters, Sofie G.T. Lemmens, Jurriaan M. Born, Freek Bouwman, Arie G. Nieuwenhuizen, Edwin Mariman \& Margriet S. Westerterp-Plantenga

Genetic associations with acute stress-related changes in eating in the absence of hunger

Patient Education and Counseling 2010, 79 (3) p. 367-371

2010 Geert Heidema, Ping Wang, Caroline TM van Rossum, Edith JM Feskens, Jolanda MA Boer, Freek G Bouwman, Pieter van 't Veer \& Edwin CM Mariman

Weight gain susceptibility: sex-specific leptin-independent effects of CNTF null G/A, IL6 -174 G/C and their interactions with UCP2 polymorphisms

Nutrition 2010, 99 p. 1-7

2009 Marcel den Hoed, Margriet S Westerterp-Plantenga, Freek Bouwman, Edwin CM Mariman \& Klaas R Westerterp

Postprandial responses in hunger and satiety are associated with the rs9939609 SNP in FTO

American Journal of Clinical Nutrition 2009 sep 30

2009 Katie Crosley, Susan J. Duthie, Abigael C. Polley, Freek G. Bouwman, Carolin Heim, Francis Mulholland, Graham Horgan, Ian T. Johnson, Edwin C. Mariman, Ruan M. Elliott, Hannelore Daniel \& Baukje de Roos Variation in protein levels obtained from human blood cells and biofluids for platelet, PBMC, plasma, urine and saliva proteomics

Genes Nutr. 20094 p. 95-102

2009 Ping Wang, Freek G. Bouwman \& Edwin C.M. Mariman

Common discovered proteins in proteomic analysis - A story of cellular stress response.

Proteomics 2009 9, p. 2955-2966

2009 AG Heidema, U Thissen, JMA Boer, FG Bouwman, EJM Feskens \& ECM Mariman

The association of 83 plasma proteins with CHD mortality, BMI, HDLand total-cholesterol in men: applying multivariate statistics to identify proteins with prognostic value and biological relevance. 
J Proteome Research 2009, Jun 5, 8 (6) p. 2640-2649

2009 Stijn Soenen, Edwin CM Mariman, Neeltje Vogels, Freek G Bouwman, Marcel den Hoed, Louise Brown and Margriet S Westerterp-Plantenga, Relationship between perilipin gene polymorphisms and body composition during weight loss and weight maintenanceweight maintenance after weight loss

Physiology \& Behavior 200996 p. 723-728

2008 Baccini M, Bachmaier EM, Biggeri A, Boekschoten MV, Bouwman FG, Brennan L, Caesar R, Cinti S, Coort SL, Crosley K, Daniel H, Drevon CA, Duthie S, Eijssen L, Elliott RM, van Erk M, Evelo C, Gibney M, Heim C, Horgan GW, Johnson IT, Kelder T, Kleemann R, Kooistra T, van lersel MP, Mariman EC, Mayer C, McLoughlin G, Müller M, Mulholland F, van Ommen B, Polley AC, Pujos-Guillot E, Rubio-Aliaga I, Roche HM, de Roos B, Sailer M, Tonini G, Williams LM and de Wit N NuGO proof of principle study package: a collaborative research effort of the European Nutrigenomics Organisation.

Genes Nutr. 2008 Dec 3(3-4), p. 147-151

2008 Marcel den Hoed, Astrid JPG Smeets, Margriet AB Veldhorst, Arie G Nieuwenhuizen, Freek Bouwman, A Geert Heidema, Edwin CM Mariman, Margriet S Westerterp-Plantenga \& Klaas R Westerterp

SNP analyses of postprandial responses in (an)orexigenic hormones and feelings of hunger reveal long-term physiological adaptations to facilitate homeostasis.

Int. J. of Obesity 2008, 32, p. 1790-1798

2008 Baukje de Roos, Susan Duthie, Abigael Polley, Francis Mulholland, Freek Bouwman, Carolin Heim, Garry Rucklidge, Ian Johnson, Edwin Mariman, Hannelore Daniel \& Ruan Elliott

Proteomic Methodological Recommendations for Studies Involving Human Plasma, Platelets, and Peripheral Blood Mononuclear Cells J Proteome Research 2008, Jun 7(6), p. 2280-2290

2008 Julie Staals, Judith A. P. Bons, Robert J. van Oostenbrugge, Iris Knottnerus, Marja P. van Dieijen-Visser, Freek G. Bouwman, Edwin C. Mariman, Joris R. Delanghe, Jan Lodder \& Will K.W.H. Wodzig

A SELDI-TOF-MS Study in Lacunar Stroke with Subsequent Haptoglobin Phenotyping

Current Neurovascular Research 2008, 5, p 93-98.

2008 Ellen C.M. Cranenburg, Cees Vermeer, Ralf Koos, Marie-Louise Boumans, Tilman M. Hackeng, Freek G. Bouwman, Martijn Kwaijtaal, Vincent M. Brandenburg, Markus Ketteler \& Leon J. Schurgers

The Circulating Inactive Form of Matrix Gla Protein (ucMGP) as a Biomarker for Cardiovascular Calcification

Journal of Vascular Research 2008, 45, p 427-436 
2008 F. Rutters, A.G. Nieuwenhuizen, N. Vogels, F. Bouwman, E. Mariman \& M.S. Westerterp-Plantenga

Leptin-adiposity relationship changes, plus behavioral and parental factors, are involved in the development of body weight in a Dutch children cohort

Physiology \& Behavior 2008, Mar 18, 93(4-5), p 967-974.

2008 Judith A.P. Bons, Désirée van der Heijde, Freek G. Bouwman, Edwin C. Mariman, Marja P. van Dieijen-Visser, Robert Landewé , Sjef van der Linden \& Will K.W.H. Wodzig

Searching for potential biomarkers which can be used as biomarkeres for diagnosing ankylosing spondylitis

Biomarkers of Medicine 2008, 2 p 23-30.

2008 Eva Corpeleijn, Maurice Pelsers, Stijn Soenen, Marco Mensink, Freek G. Bouwman, Wim HM Saris, Jan Glatz \& Ellen Blaak Insulin acutely upreggulates protein expression of the fatty acid transporter CD36 in human skeletal muscle in vivo.

J of Physiology and Pharmacology 2008, March, Vol. 59, 1, p. 77-83

2008 Judith A.P. Bons, Etienne C.H.J. Michielsen, Douwe de Boer, Freek G. Bouwman, Jaak Jaeken, Marja P. van Dieijen-Visser, M. Estela RubioGozalbo \& Will K.W.H. Wodzig

A specific immunoprecipitation method for isolating isoforms of insulinlike growth factor binding protein-3 from serumValidation IGFBP-3 Clinica Chimica Acta 2008, Jan 387(1-2), p. 59-65.

2007 M. Claessens, W. Saris, F. Bouwman, C. Evelo, G. Hul, E. Blaak \&

E. Mariman

Differential valine metabolism in adipose tissue of low and high fatoxidizing obese subjects

Proteomics Clinical Applications 2007 okt. 1 (10), p 1306-1315.

2007 Judith A. Bons, Marjolein Drent, Freek G. Bouwman, Edwin C. Mariman, Marja P. van Dieijen-Visser \& Will K. Wodzig

Potential biomarkers for diagnosis of sarcoidosis using proteomics in serum

Respiratory Medicin, 2007, Aug 101(8), p. 1687-1695.

2007 Ping Wang, Marleen M. J. van Greevenbroek, Freek G. Bouwman, Martijn C. G. J. Brouwers, Carla J. H. van der Kallen, Egbert Smit, Jaap Keijer \& Edwin C. M. Mariman

The circulating PBEF/NAMPT/visfatin level is associated with a beneficial blood lipid profile.

Eur J Physiol, 2007, Sep 454(6) p. 971-976.

2007 Kaatje Lenaerts, Freek G. Bouwman, Johan Renes \& Edwin C.M. Mariman

Comparative proteomic analysis of cell lines and scrapings of the human intestinal epithelium. 
BMC Genomics, 2007, Apr 3, 8(1), 91

2007 Kaatje Lenaerts, Johan Renes, Freek Bouwman, Jean-Paul Noben, Johan Robben, Egbert Smit \& Edwin Mariman

Arginine deficiency in preconfluent intestinal Caco-2 cells modulates expression of proteins involved in proliferation, apoptosis, and heat shock response.

Proteomics, 2007, Feb 7(4), p. 565-77

2007 Ping Wang, Johan Renes, Freek Bouwman, Annelies Bunschoten, Edwin Mariman, Jaap Keijer

Absence of an adipogenic effect of rosiglitazone on mature 3T3-L1 adipocytes: increase of lipid catabolism and reduction of adipokine expression.

Diabetologia, 2007, Mar 50 (3), p. 654-65.

2006 David .P.A. Cohen, Johan Renes, Freek Bouwman, Erwin G. Zoetendal, Edwin Mariman, Willem M. de Vos \& Elaine E. Vaughan

Proteomic analysis of log to stationary growth phase Lactobacillus plantarum cells and a two-dimensional electrophoresis database

Proteomics, 2006, Dec 6(24), p. 6485-93

2006 Neeltje Vogels, Edwin Mariman, Freek Bouwman \& Margriet S. Westerterp-Plantenga.

Determinants of Overweight and BMI Tracking in a Dutch Children Cohort

Am. J. Clin. Nutr. 2006, 84, p. 717-724.

2006 Ping Wang, Jaap Keijer, Freek Bouwman, Annelies Bunschoten, Johan Renes \& Edwin Mariman.

Insulin modulates the secretion of proteins from mature 3T3-L1 adipocytes: a role for transcriptional regulation of processing. Diabetologia, 2006, Oct 49 (10), p. 2453-62.

2006 Kaatje Lenaerts, Milka Sokolović, Freek Bouwman, Wout Lamers, Edwin Mariman Johan Renes

Starvation induces phase-specific changes in the proteome of mouse small intestine

J Proteome Research 2006, Sept. 1, 5 (9) p. 2113-2122.

2006 Johan Renes, Jonathan van Tilburg, Rachel van Haaften, Freek Bouwman, Andrea Kodde, Chris Evelo, Jean-Paul Noben, Johan Robben \& Edwin Mariman

Thiazolidinediones change the proteome of 3T3-L1 cells to enable increased triglyceride storage and fatty acid oxidation

Adipocyte 2006, vol. 2, No. 2, p 75-92

2006 Githa Breikers, Simone G.J. van Breda, Freek G. Bouwman, Marcel H.M. van Herwijnen, Johan W. Renes, Edwin C.M. Mariman, Jos C. Kleinjans \& Joost H.M. van Delft. 
Potential protein markers for nutritional health effects on colorectal cancer in the mouse as revealed by proteomics analysis.

Proteomics, 2006, May, 6 (9), p 2844-2852

2006 Kaatje Lenaerts, Edwin Mariman, Freek Bouwman \& Johan Renes

Glutamine regulates the expression of proteins with a potential healthpromoting effect in human intestinal Caco-2 cells.

Proteomics, 2006, April, 6 (8), p 2454-2464

2005 Neeltje Vogels, Edwin Mariman, Freek Bouwman \& Margriet S. Westerterp-Plantenga.

Relationship of weight maintenance and dietary restraint with PPAR $\gamma 2$, Glucocorticoid receptor and Ciliary neurotrophic factor polymorphisms.

Am. J. Clin. Nutr. 2005, 82, p. 740-746

2005 Kaatje Lenaerts, Edwin Mariman, Freek Bouwman \& Johan Renes

Differentiation stage-dependent preferred uptake of basolateral (systemic) glutamine into Caco-2 cells results in its accumulation in proteins with a role in cell-cell interaction.

FEBS journal, 2005, 272, p. 3350-3364

2005 Marjo M.P.C. Donners, Monique J. Verluyten, F.G. Bouwman, E. Mariman, Bart Devreese, Frank Vanrobaeys, Jozef van Beeumen, Luc H.J.M. van den Akker, Mat J.A.P. Daemen \& Sylvia Heeneman.

Differential expression of alpa-1 antitrypsin and vinexin-beta in human atherosclerotic plaque progression identified by proteomic analysis.

Journal of Pathology, 2005, 206, p. 39-45

2005 J. Renes, F. Bouwman, J.-P. Noben, J. Robben, C. Evelo \& E. Mariman.

Protein profiling of 3T3-L1 adipocyte differentiation and starvation teveals the importance of proteins involved in glycolysis, growth regulation and cytoskeletal rearrangements.

Cell. Mol. Life Sci., 2005, 62, p. 492-503

2004 Freek Bouwman, Johan Renes \& Edwin Mariman.

A combination of protein profiling and isotopomer analysis using matrixassisted laser desorption/ionization-time of flight mass spectrometry reveals an active metabolism of the extracellular matrix of 3T3-L1 adipocytes.

Proteomics, 2004, Dec, 4 (12), p. 3855-3863

2004 P. Wang, E. Mariman, J. Keijer, F. Bouwman, J-P Nobben, J. Robben \& J. Renes.

Profiling of the secreted proteins during 3T3-L1 adipocyte differentiation leads to the identification of novel adipokines.

Cell. Mol. Life Sci., 2004, 61, p. 2405-2417.

2002 J. Renes \& F.G. Bouwman.

Proteomics in nutrition research,

InFocus, 2002, issue 3, p. 6-7 
2002 C.J.H. van der Kallen, C. Voors-Pette F.G. Bouwman, H.A. Keizer, J.Y. Lu, R.W.J. van de Hulst, R. Bianchi, M-J.J. Janssen, E.T.P. Keulen, W.D. Boeckx J.I. Rotter \& T.W.A. de Bruin.

Evidence of Insulin resistant lipid metabolism in adipose tissue in Familial Combined Hyperlipidemia, but not in type 2 Diabetes Mellitus. Atherosclerosis, 2002 Oct. 164 (2), p. 337-346.

2000 C.J.H. van der Kallen, R.M. Cantor, M.M.J. van Greevenbroek, J.M.W. Geurts, F.G. Bouwman, B.E. Aouizerat, H. Allayee, W.A. Buurman, A.J. Lusis, J.I. Rotter \& T.W.A. de Bruin

Genome scan for adiposity in Dutch dyslipidemic families reveals novel quantitative trait loci for leptin, body mass index and soluble tumor necrosis factor receptor superfamily $1 \mathrm{~A}$,

Int. J. of Obesity. 2000 Nov. Vol. 24, Issue 11, p. 1381-1391. 


\section{Media program's}

2010 Jojo-effect, VARA Nieuwslicht

\section{Oral Presentations}

2013 Freek G. Bouwman, Jolanda M.A. Boer, Sandra Imholz, Ping Wang, Monique Verschuren, Martijn Dollé, \& Edwin C.M. Mariman

Gender-specific genetic associations of polymorphisms in ACE, AKR1C2, FTO and MMP2 with weight gain over a 10 year period ECO 12-15 mei 2013 te Liverpool, Engeland, Obesity Facts 2013; 6 (suppl 1) p42

2011 Freek G. Bouwman

Cellular metabolism in adipocytes after caloric restriction.

NWO voeding, 6-7 oktober 2011 te Deurne

2010 Freek G. Bouwman

Een nieuwe verklaring voor het jojo-effect.

13 e Voedings- en gezondheidscongres 19-20 november 2010 te Brussel, Belgie, Invited speaker

\section{Poster Presentations}

2012 Freek G. Bouwman \& Edwin C.M. Mariman

Physiological adaptations of adipocytes from obese subjects after caloric restriction. ECO 9-12 mei 2012 te Lyon, Frankrijk, Obesity Facts 2012; 5 (suppl 1) p162

2010 Freek G. Bouwman, Marleen A. van Baak \& Edwin C.M. Mariman

The in vivo coordinated response of energy metabolic processes in adipocytes to calorie restriction in humans. $11^{\text {th }}$ International Congres on Obesity (ICO), 11-15 July 2010, Stockholm, Sweden, Obes. Rev. 2010; 11 (suppl 1): p. 105 


\section{Curriculum Vitae}


Freek Bouwman was born on 14 November 1971 in Heerlen and raised in Oirsbeek, The Netherlands. He attended secondary school at the MAVO St. Fransiscus in Treebeek. In 1991 he graduated in chemistry at the ZuidLimburgse Laboratorium School (currently Leeuwenborgh) in Sittard. In 1995 he got his engineers (Ing.) degree at the Hogeschool Heerlen (currently Hogeschool Zuyd) in Sittard. In 1996 he started as a volunteer to work at the Maastricht University under the supervision of Dr. Wim Engels and Dr. Bruce Wolfenbuttel. From 1997 to 2001 he worked at the Molecular Metabolism and Endocrinology lab of Prof.dr. Tjerk de Bruin under the supervision of Dr. Carla van der Kallen. In 2001 he joined the Functional Genetics group of Prof.dr. Edwin Mariman as a research technician, which is a part of the Maastricht Proteomics Center.

Besides his work as a research technician, he started his PhD-project at the department of Human Biology of Maastricht University under the supervision of Prof.dr. Edwin Mariman in 2009. The results of this project are described in this thesis. 


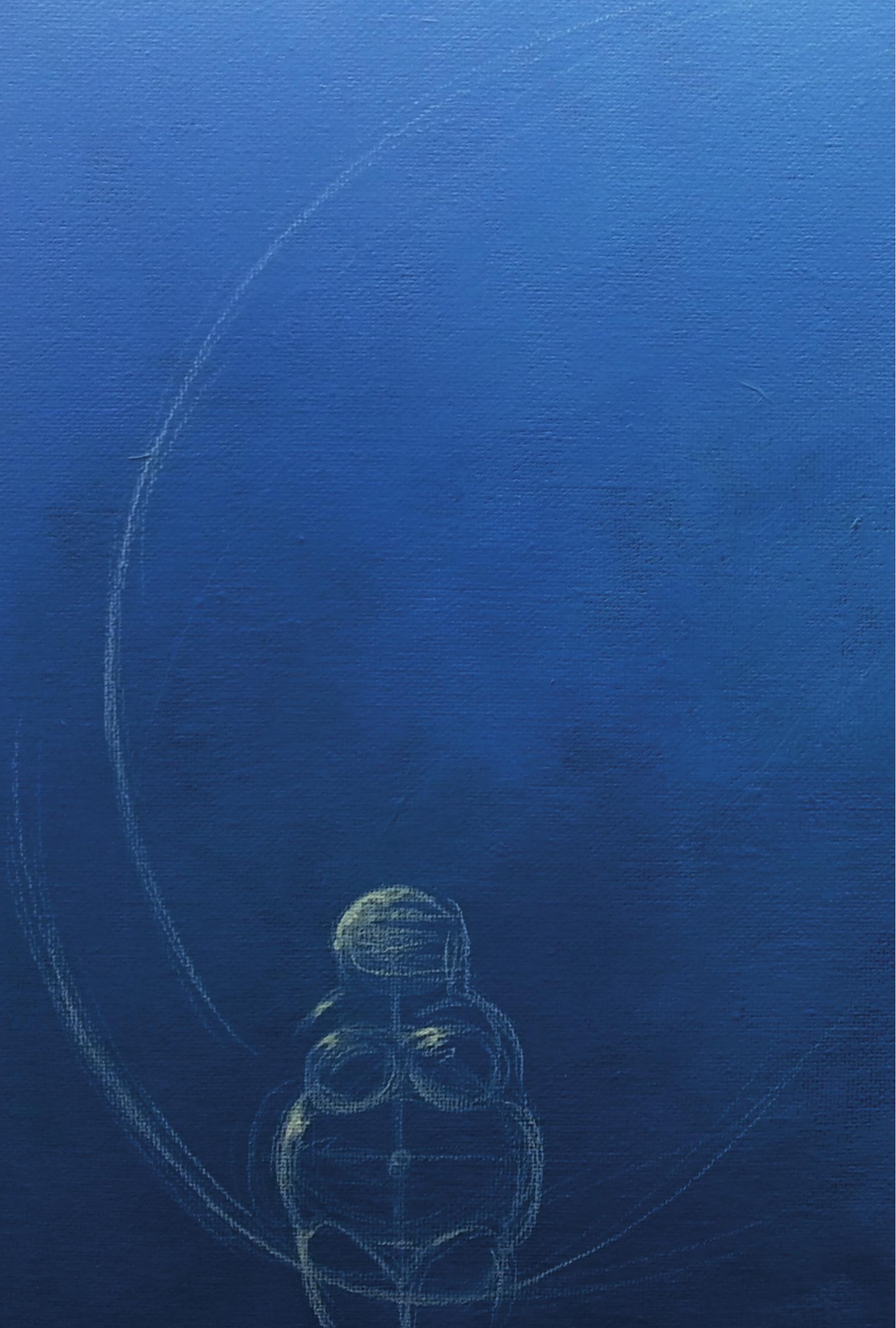

